\title{
Implementing the EU Directives on the selection of economic operators in public procurement procedures
}

\author{
SIGMA PAPER No. 56
}

Authorised for publication by Karen Hill, Head of the SIGMA Programme

2 Rue André Pascal 75775 Paris Cedex 16

France

mailto:sigmaweb@oecd.org

Tel: +33 (0) 145248200

www.sigmaweb.org
This document has been produced with the financial assistance of the European Union (EU). It should not be reported as representing the official views of the EU, the OECD or its member countries, or of partners participating in the SIGMA Programme. The opinions expressed and arguments employed are those of the authors.

This document, as well as any data and any map included herein, are without prejudice to the status of or sovereignty over any territory, to the delimitation of international frontiers and boundaries and to the name of any territory, city or area.

(C) OECD 2018 - The use of this material, whether digital or print, is governed by the Terms and Conditions to be found on the OECD website page http://www.oecd.org/termsandconditions. 


\section{Table of contents}

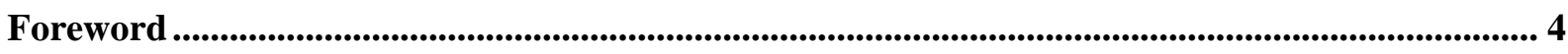

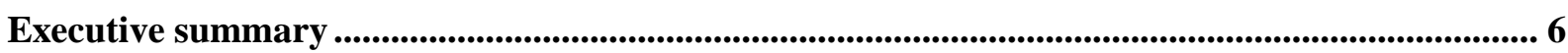

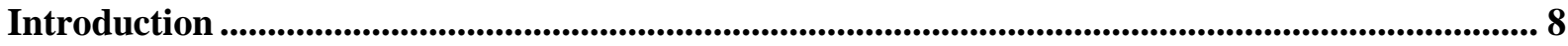

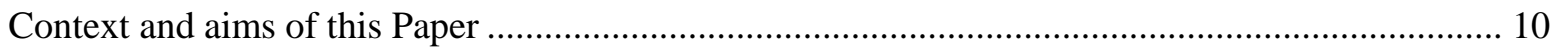

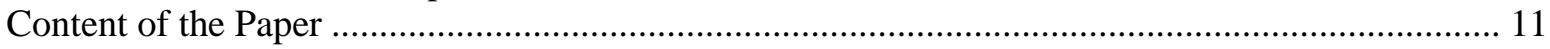

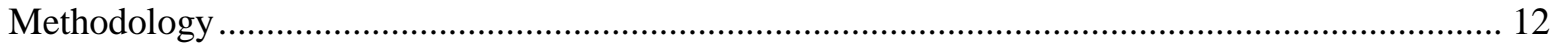

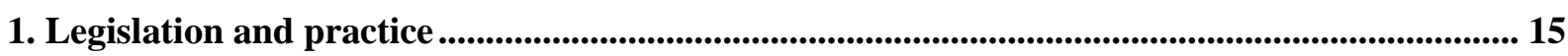

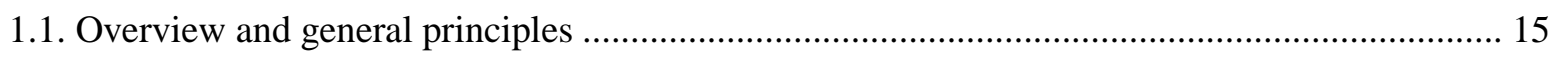

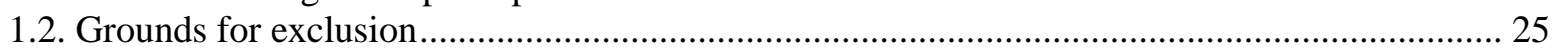

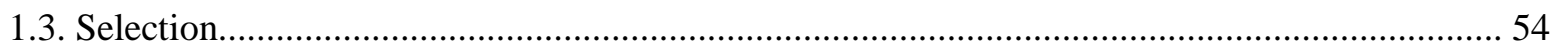

1.4. Reduction of the number of otherwise qualified candidates to be invited to participate ............ 58

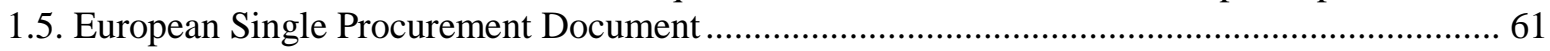

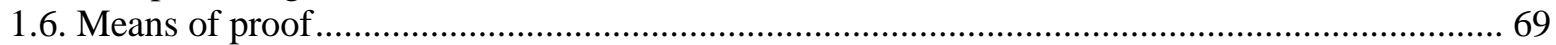

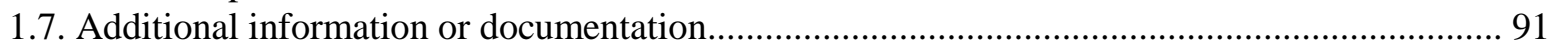

1.8. Open procedure - verification of information after examination of tenders.............................. 94

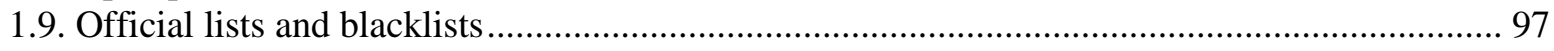

2. Key findings and success factors ............................................................................................. 104

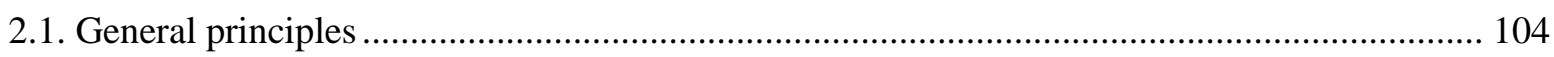

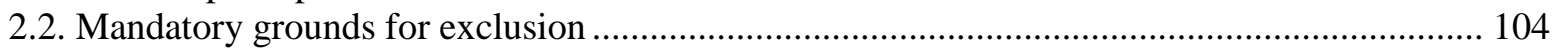

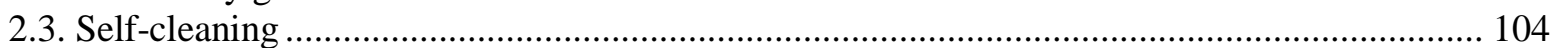

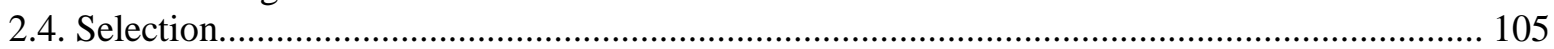

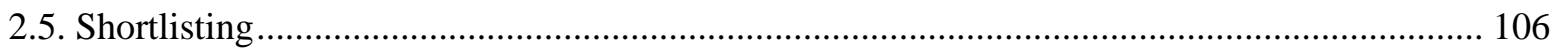

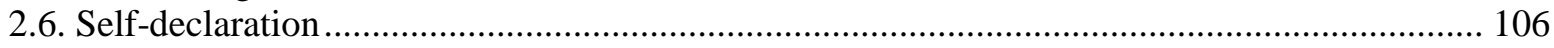

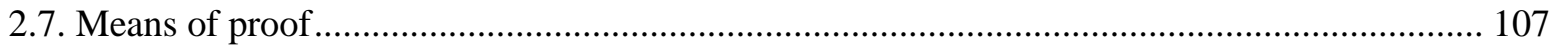

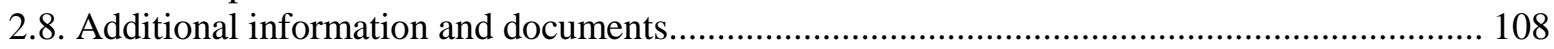

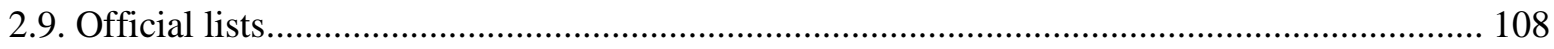

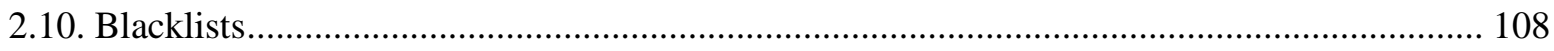

3. Country chapters ..................................................................................................................................... 110

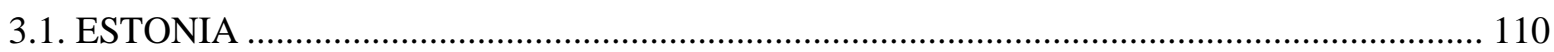

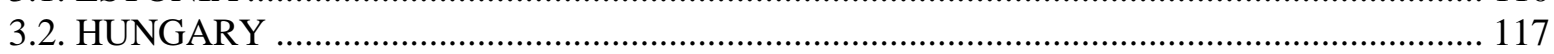

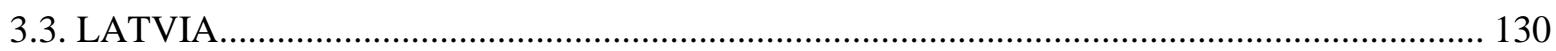

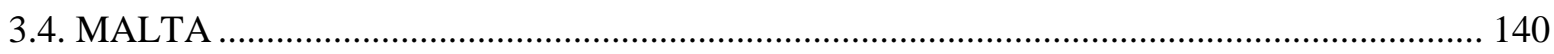

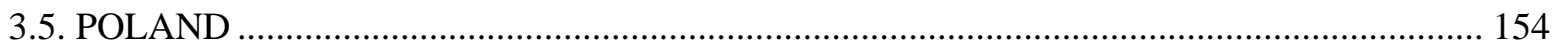

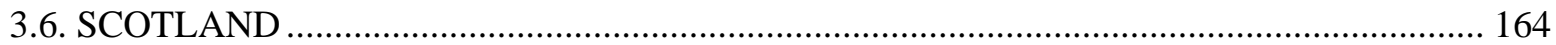

4. Case law of the Court of Justice of the European Union ............................................................. 174

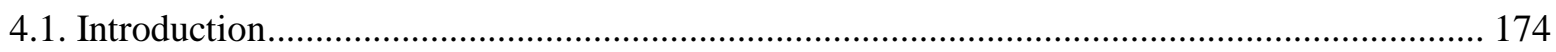




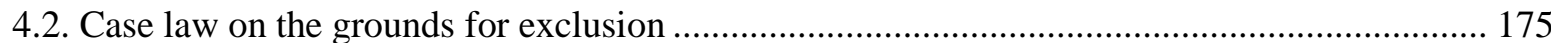

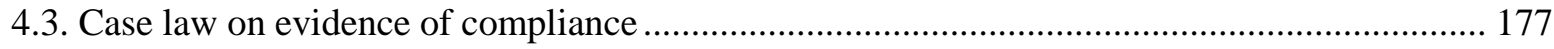

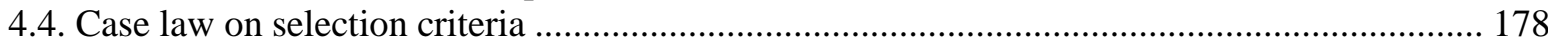

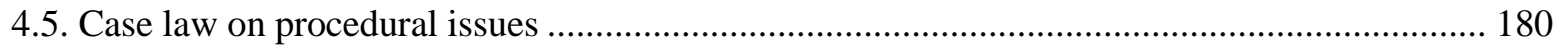

4.6. Case notes - Court of Justice of the European Union's cases in more detail .......................... 181

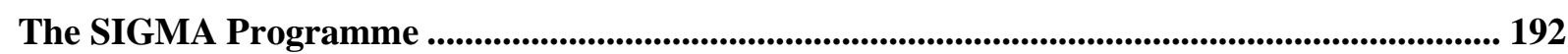




\section{Foreword}

SIGMA has regularly observed that its partner countries face difficulties related to the choice of participants in public procurement procedures. When choosing participants, it is assumed that consideration should be given to the tenders of economic operators that meet both the qualification and selection criteria, and to which none of the grounds for exclusion applies. All other tenders are to be rejected. In practice, however, qualification criteria, selection criteria and exclusion grounds are not always easy to determine and apply in a reasonable and consistent manner.

Complex requirements in national legislation and the sometimes formalistic approach of procurement officers often lead contracting authorities to take an over bureaucratic approach when they request and verify documents from economic operators for the purpose of assessing their suitability to participate in procurement procedures. For economic operators, especially small and medium-sized enterprises (SMEs), this often leads to inconvenience, uncertainty and unnecessarily high participation costs. It can also result in decreased competition, higher prices and lower quality, as well as a longer duration of award procedures and higher administrative costs for both contracting authorities and economic operators.

The objectives of the new legal framework for public procurement adopted by the European Union (EU) in 2014 are to reduce the administrative burden on economic operators seeking to participate in public procurement procedures, encourage the participation of SMEs, and allow contracting authorities greater flexibility in setting requirements. By meeting these objectives, the new legal framework should reduce overformalistic exclusion and unwarranted acceptance of tenderers and, as a result, increase competition and lower the costs of awarding public contracts. The transposition of the new provisions of the EU procurement Directives is underway in EU Member States and in many of SIGMA's partners.

The main objective of this Paper is to analyse and describe, for SIGMA's partners, the implementation in selected EU Member States of the new procurement tools related to the choice of participants. A detailed analysis of policies and rules, as well as practical examples, provide guidance on issues such as:

- how to reduce over-bureaucratic requirements and participation costs for economic operators;

- how contracting authorities can simplify and streamline the verification of information provided by economic operators;

- how other state authorities (tax offices, courts, etc.) can support contracting authorities;

- how to best operate official lists of economic operators;

- whether and how to use blacklists and under what conditions. 
The study gives a detailed overview of the provisions of the EU Directives on mandatory and discretionary grounds for exclusion, self-cleaning, selection of economic operators, self-certification, means of proof, official lists and blacklisting. It presents several practical examples of the transposition of those provisions into the national legislation of selected EU Member States and of the systems that have been put in place to support contracting authorities in their tasks.

The national procurement systems included in this Paper are those of Estonia, Hungary, Malta, Latvia, Poland and Scotland, described as of 30 June 2018. As the study will show, the implementation and practical application of the EU public procurement rules vary among these Member States. The study makes no attempt to evaluate the national systems presented, but rather to identify the most relevant factors that can successfully contribute to reducing the administrative burden and increasing the overall efficiency of public procurement systems. 


\section{Executive summary}

The 2014 EU Public Procurement Directive provides various tools that enable contracting authorities to exclude unsuitable economic operators and ensure that only those economic operators that possess adequate capacities are considered for the performance of public contracts. The EU legislative framework also enables Member States to use these tools to implement policies related to social and environmental considerations and to promote the participation of SMEs in public procurement. One of the objectives of the new Directive was to simplify the contract award process and make it more flexible, thus reducing the administrative burden both for contracting authorities and economic operators.

The Directive provides only a basic framework of rules for conducting procurement procedures and includes optional provisions and derogations that Member States may choose to transpose. Public contracts below financial thresholds are not regulated by the detailed provisions of the Directive but by the general principles of the EU Treaty and national regulations. Different Member States regulate procurement in different ways, with some opting for more detailed regulation than others.

This Paper analyses how the EU legal requirements regarding the choice of participants in public procurement procedures have been transposed into the national legislation of selected EU Member States, and how those provisions are implemented in practice. The main objective is to identify good practice that could inspire reforms among SIGMA's partners.

The exclusion of certain economic operators from public procurement procedures aims to protect the integrity of the process by preventing the participation of companies that are deemed to be undesirable partners of public administration. The grounds for exclusion extend to corruption and other areas of criminal activity, professional misconduct and other causes of a lack of reliability. The Directive lists the mandatory grounds for exclusion, but also allows Member States to establish additional grounds for exclusion. All six countries analysed in this study have established additional national grounds for exclusion, aimed at implementing legitimate policies, such as the protection of labour law and competition law.

The 2014 Directive introduced "self-cleaning" measures. Despite the existence of one or more relevant grounds for exclusion, self-cleaning measures allow economic operators to rehabilitate themselves on the basis of strict conditions and take part in procurement procedures. An interesting way of transposing this new mechanism has been chosen by Hungary, which opted for centralised management of self-cleaning decisions. A decision-making process that is carried out centrally enables the uniform application throughout the national procurement system, ensures legal protection and a higher level of legal certainty compared to decision making at the level of an individual contracting authority. 
In order to reduce the administrative burden and cost of participation in procurement procedures, the 2014 Directive introduced a new concept of "self-certification". At the stage of submission of tenders, instead of supplying a full set of supporting certificates and documents, all economic operators declare that the grounds for exclusion do not apply to them, using a special form called the European Single Procurement Document (ESPD). After the evaluation of tenders, only the tenderer to which the contracting authority has decided to award the contract is requested to produce all supporting documents and certificates. This approach can increase the competitiveness of procurement procedures by encouraging the participation of more economic operators.

While the ESPD is only a preliminary proof of eligibility, the certificates, statements and other means of proof confirming the absence of grounds for exclusion and the fulfilment of the selection criteria may be required from economic operators by the contracting authority. A balanced approach to the request for evidence from economic operators must be taken. On the one hand, it is necessary to verify the capacity of the tenderer. On the other hand, there is a risk of an over bureaucratic approach that could create a barrier for participation in public tenders, especially for SMEs. According to an EU-wide survey, $46 \%$ of SMEs consider the too onerous paperwork requirements as the main obstacle to applying for public contracts. Some EU countries (for example Estonia) have managed to eliminate the paperwork completely, by introducing electronic procurement systems that give the contracting authorities direct electronic access to databases (registers) kept by the responsible administrative or judicial bodies, thus removing the need to collect all the certificates by economic operators. The evaluation of past experience of companies can also be facilitated by the development of publicly accessible databases with information on concluded public contracts and their execution. Direct access to online databases is one of the most efficient means of solving the problem of bureaucracy in public procurement.

The Directive permits Member States to establish official lists of approved economic operators. However, in those Member States studied that have an official list, these lists are either not functioning in practice or the level of participation is extremely low. It seems that the benefits of the official lists have been eclipsed by other instruments facilitating the process of selecting the economic operators to participate in procurement (for example, the ESPD online databases).

The Directive does not deal directly with the possibility of maintaining a central list of economic operators excluded from public procurement procedures ("blacklist"). However, the new provisions of the 2014 Directive (especially on self-cleaning) mean that the establishment and use of blacklists is an area of uncertainty. The best option, until the issue is tested by the Court of Justice of the European Union (CJEU), is to avoid using such blacklists. The only safe exception is in the case of the blacklist of economic operators for which a final judgement specifies both the sanction of exclusion from public procurement procedures and the period during which the sanction will apply.

This Paper also provides a detailed description of relevant national provisions in the countries of this study (Estonia, Hungary, Latvia, Malta, Poland and Scotland) and a summary of related cases of the CJEU. 


\section{Introduction}

The system for the choice of participants in a public procurement procedure is generally guided by an ambition to provide access to public procurement markets only to suitable economic operators and to exclude unsuitable operators. The system also aims to ensure that only those economic operators that possess adequate capacities are chosen for the performance of public contracts. The existence of some sort of exclusion and selection regime is a common feature of all major procurement systems, and it is a requirement for public procurement systems in EU Member States.

The EU directives on public procurement have included, for many years, provisions on the choice of participants in procurement processes, covering grounds for exclusion, shortlisting and selection criteria, as well as the means of proof to demonstrate compliance with these requirements.

The EU drafting and review process leading up to the introduction of the new procurement directives in 2014 gave those involved the opportunity to build on lessons learned from day-to-day practice, respond to the concerns of stakeholders involved in the procurement process and incorporate some changes resulting from decisions of the CJEU. The process also led to reflection on EU-wide priorities related to social, environmental and labour law issues, and on ways of encouraging the involvement of SMEs in public procurement.

In the context of the choice of participants, a key problem identified in the process leading to the adoption of Directive 2014/24/EU' ("the Directive" or "the 2014 Directive", depending on the context) was the administrative burden and costs borne by economic operators wishing to participate in a public procurement procedure, particularly in relation to the means of proof required. This problem has been aggravated in some Member States where contracting authorities have adopted a rigid and formalistic approach to the assessment of the means of proof.

A number of Member States have nevertheless already taken steps to reduce and minimise this administrative burden. For example, they have permitted economic operators to clarify or complete exclusion-related evidence and to provide additional (pre-existing) documentation to contracting authorities, or they have accepted self-declarations related to all or some of the exclusion grounds. In addition, some Member States have developed systems that establish official lists of qualified economic operators and cover issues of exclusion as well as qualitative selection. Other examples include the simplification of verification requirements through the use of centralised registries that include information on the means of proof related to criminal activities, as well as information on taxes and social security contributions. Online electronic systems

\footnotetext{
${ }^{1}$ Directive 2014/24/EU of the European Parliament and of the Council of 26 February 2014 on public procurement, repealing Directive 2004/18/EC, O.J. L 94/65.
} 
have permitted contracting authorities to easily undertake verifications of qualifications without having to request documents from economic operators. Some of these approaches have been adopted in the Directive, with the aims of reducing the administrative burden on contracting authorities and economic operators, increasing flexibility in the conduct of procurement procedures, and accelerating the procurement process. Very significant developments have been the introduction of the concept of self-declaration by economic operators, using the ESPD, and the verification of the means of proof only in respect of the economic operator that has been proposed for the award of the contract.

The grounds for exclusion, self-declarations, the ESPD, means of proof, selection and other issues are discussed in more detail in Part 2 of this Paper.

Cases on public procurement considered by the CJEU have helped to identify legal issues concerning the choice of participants. The decisions of the CJEU in some of these cases influenced the drafting of the 2014 Directive. The CJEU has examined, for example, specific issues relating to the eligibility to participate ${ }^{2}$, automatic exclusion ${ }^{3}$, whether and which grounds for exclusion are exhaustive ${ }^{4}$, and registration requirements ${ }^{5}$. In relation to selection criteria, the CJEU has looked at, among other issues, the degree of freedom available to contracting authorities to require a minimum level of economic and financial standing $^{6}$ and when it is permitted to verify information received during the procurement process ${ }^{7}$.

The CJEU applies the Treaty principles and corresponding obligations of equal treatment, non-discrimination, transparency and proportionality. The influence of CJEU decisions on the 2014 Directive can be seen, for example, in relation to automatic exclusion, which is rarely permitted, and proportionality requirements when applying discretionary grounds for exclusion. Further discussion of relevant CJEU cases as they apply to specific topics is provided in Part 2 of this Paper. More details on several CJEU cases are found in Part V.

\footnotetext{
${ }^{2}$ C-357/06 Frigerio Luigi \& C, C-305/08 CoNISMa and C-203/14 Maresme.

${ }^{3} \mathrm{C}-213 / 07$ Michaniki.

${ }^{4}$ C-213/07 Michaniki, C-537/08 Assitur, C-376/08 Serrantoni and C-27/15 Pippo Pizzo.

${ }^{5} \mathrm{C}-74 / 09$ Bâtiments et Ponts and WISAG Produktionsservic and C-425/14 Impresa Edilux.

${ }^{6}$ C-218/11 Édukövízig and Hochtief Construction and C-324/14 Partner Apelski Dariusz

${ }^{7}$ C-599/10 SAG ELV Slovensko and Others and C-336/12 Manova.
} 


\section{Note on key elements in the choice of participant process}

The term choice of participants is used throughout this Paper to reflect collectively the following specific terms used in the Directive: grounds for exclusion, selection criteria, and reduction of the number of candidates, which is also referred to as shortlisting.

The exclusion of economic operators from public procurement procedures aims to protect the integrity of the process by preventing the participation of economic operators deemed to be undesirable partners of the public administration. The grounds for the exclusion of economic operators extend to corruption and other areas of criminal activity or professional misconduct, as well as to other causes for the lack of reliability. The rules on the exclusion of economic operators include substantive aspects of exclusion, providing mandatory and discretionary grounds for exclusion. Some rules offer the possibility of self-cleaning, and others focus on procedural aspects, such as requiring Member States to adopt explicit procedures and to regulate the maximum duration of periods of exclusion beyond the specific procurement procedure.

Besides excluding unsuitable economic operators, contracting authorities may require candidates and tenderers to meet selection criteria relating to their suitability to pursue the professional activity, their economic and financial standing, and technical and professional ability. Selection criteria are used in the process of deciding which economic operators, in order to meet the standards set by the contracting authority, demonstrate that they are able to perform the contract. Although contracting authorities are not required to establish selection criteria in a specific procurement procedure, in practice they generally prefer to check at least some elements of the financial and technical position of an economic operator before awarding it a contract.

Contracting authorities are also permitted, in a two stage procedure such as the restricted procedure, to reduce the number of otherwise qualified candidates in order to establish a shortlist. The aim of the process of reduction of the number of otherwise qualified candidates is to allow the contracting authority to select the candidates that are the best qualified to deliver the contract and to invite them to participate in the second stage of the procedure.

\section{Context and aims of this Paper}

The context for this Paper is the steadily growing interest that SIGMA has noticed among its partners in implementing rules on the choice of participants in public procurement procedures. The transposition of new elements of EU legislation into national legislation by them is in large part underway. An ongoing dialogue has revealed that in a number of areas some uncertainty remains concerning the rules and practices concerning the choice of participants. In general, a very formalistic approach has often been taken to the process of selecting participants.

It is common, for example, to see more attention being given to obtaining and checking documentary evidence, which often results in the automatic exclusion of tenderers or the rejection of tenders. At the same time, the substance of the requirements in the selection 
process is given less attention. In addition, many of SIGMA's partners hesitate to implement the instrument of requesting additional information and supplementary documents from economic operators. (See "Practical problems and observations" below for further details.)

Some of the practical issues and questions raised include:

- How can over bureaucratic requirements and the cost of participation for businesses be reduced with regard to the evidence demonstrating that the grounds for exclusion do not apply?

- How do contracting authorities verify the information provided by tenderers concerning the grounds for exclusion?

- How do state authorities (tax offices, courts, etc.) support contracting authorities?

- How can contracting authorities ensure that only adequate and proportionate selection criteria are determined?

- How can contracting authorities best administer official lists of economic operators?

- Is it permitted to use blacklists and under what conditions?

This Paper aims to provide further information and practical examples of the rules, policies and practices that apply during the stage of the choice of participants in procurement processes under the framework created by the Directive in selected EU Member States.

The implementation and practical application of the rules vary between Member States, as they may or may not exercise permitted derogations, and they have discretion as to whether or not to implement certain provisions. They may also decide to introduce additional national rules to complement the provisions of the Directive. Differences in legal and administrative traditions, of course, have an impact on implementation and practical application. The circumstances were similar under the Directive 2004/18/EC (2004 Directive).

\section{Content of the Paper}

Part 1 of the Paper introduces the study and describes the methodology used in preparing the Paper.

Part 2 looks at various aspects of the process for the choice of participants, namely: general principles, grounds for exclusion, selection, shortlisting, the ESPD, means of proof, and use of official lists and blacklists. Each chapter gives a short explanation of the relevant provisions of the Directive and relevant CJEU case law, an explanation of some of the practical problems or issues that arise, and examples of practice in the Member States studied for this Paper.

Part 3 reports on key findings and success factors. The Paper covers the systems for the choice of participants in Estonia, Hungary, Latvia, Malta, Poland and Scotland ${ }^{8}$. These

\footnotetext{
${ }^{8}$ Due to historical reasons as well as the devolved nature of government in the UK, Scotland has a separate legal system. The Directive has therefore been transposed separately into Scottish law and
} 
six countries all have a long experience with these issues and have established relevant policies and practices. The public administrations of these countries differ due to the way in which the public sector is structured and governed, and significant variations are found in administrative traditions and cultures. The approach of this study has been to include EU Member States that have transposed the Directive and/or have experience in using modern tools that aim to support this stage of the procurement process and to reduce the bureaucratic burden for economic operators. The transposition of the Directive is still recent at the time of writing. National practice in the application of the Directive and of national provisions is still developing. This Paper therefore provides an analysis of relevant legal provisions and, wherever possible, a commentary on the way in which those provisions are or will be applied in practice, whilst acknowledging that there will inevitably be further developments.

Part 4 contains country chapters that give an overview of the laws and regulations governing the choice of participants in each of the member countries studied.

Part 5 sets out information on some of the CJEU cases referred to elsewhere in the Paper.

The report has been structured to enable readers to select particular areas of interest, without necessarily having to read the Paper in its entirety, and to assist SIGMA's partners in their efforts to implement effective and efficient national systems for the choice of participants, in order reduce over bureaucratic requirements and the cost of participation for economic operators.

\section{Methodology}

The methodology used in this Paper was based on the following assumptions and approaches:

1. A selection of EU Member States willing to participate in the study and to provide the data and information requested; the participating countries should represent different public sector administrative systems and cultures. Each country should have already transposed the 2014 Directives or have a long experience and established practices and policies concerning the use of modern tools to support the stage of the procurement process involving the choice of participants and reducing administrative burdens for economic operators.

2. Local experts of the selected EU Member States to prepare the respective country chapters, providing a country-specific summary of the key issues in relation to the stage of the procurement process for the choice of participants, allowing for additions in order to describe particular local issues.

3. Interviews with policy makers, official bodies, contracting authorities and economic operators in each of the selected Member States, focusing on implementation and practical problems, and how they were dealt with and resolved.

The main narrative of the report was prepared by using a combination of various tools and instruments:

there is additional procurement legislation specific to Scotland which does not apply in England, Wales and Northern Ireland. 
1. Reviews of public procurement normative acts of the EU Member States studied concerning the stage of the procurement process involving the choice of participants (primary and secondary legislation).

2. Analysis of responses obtained from questionnaires completed by each Member State.

3. Information, opinions and suggestions gathered during interviews in to each Member State, during October 2016.

4. Analysis of key issues provided in country-specific chapters obtained from local experts, covered in more detail in the main body of the study (updated in January/February 2018).

5. Review and discussion of relevant CJEU cases.

This Paper covers the stage of the choice of participants in procurement procedures in the selected Member States that are both above and below the EU thresholds. The Paper focuses predominantly on issues covered by the Directive. The stage for the choice of participants covered by the 2014 Utilities Directive and the Defence Directive is only briefly mentioned.

The members of the SIGMA Project Team were Mr. Marian Lemke, SIGMA (Project Manager) and the external experts engaged to carry out the study: Ms. Małgorzata Stachowiak, Poland, Ms. Susie Smith, UK, and Ms. Teja Kolar, Croatia.

The following SIGMA staff supported the preparation of the study: Ms. Erika Bozzay, Mr. Daniel Ivarsson, Mr. Piotr-Nils Górecki and Ms. Ilana Demal.

SIGMA would like to warmly thank the management and staff of policy makers, official bodies, contracting authorities, economic operators and local experts in each of the selected EU Member States, in particular Ms. Tünde Tàtrai, Hungary; Mr. Tom Annikve, Estonia; Mr. Eriks Mezalis, Latvia; and Mr. Joseph Camilleri, Malta. 



\section{Legislation and practice}

This part of the Paper looks at specific issues or problems encountered in practice in the choice of participants in the public procurement process. It briefly comments on some of the drivers behind the 2014 Directive and their impact on the stage involving the choice of participants. It outlines applicable provisions in the Directive and, where relevant, comments on the interpretation of those provisions. In each case, the Paper then proceeds to look at the way in which the provisions have been transposed into national law. The information on transposition generally includes examples or illustrations of how the countries studied have transposed optional provisions. Where possible, notes are also provided on the extent to which national law has expanded upon the provisions in the Directive or introduced additional provisions. Where useful national data is available, that data is also included. At the end of each section, some key recommendations are given. The information on national rules and practice is shown in blue.

\subsection{Overview and general principles}

Public procurement is one of the market-based instruments to be used to deliver the Europe 2020 Strategy for Smart, Sustainable and Inclusive Growth by aiming to improve the conditions for business to innovate, encourage the wider use of green procurement, ensure the most efficient use of public funds, and keep procurement markets open EU-wide.

These aims are reflected in the changes incorporated into the 2014 Directive, which focus on ensuring transparency, increasing flexibility, and encouraging the involvement of SMEs in public procurement. Additional provisions deal specifically with green (environmental) issues. It is clearly recognised that e-procurement is a key factor in increasing efficiency and ensuring transparency, and greater emphasis is placed on the conduct of procurement processes using electronic means.

The changes reflected in the 2014 Directive have an impact on the entire procurement process, including the stage concerning the choice of participants. For example, the introduction of the concept of the self-declaration and the use of the ESPD should significantly reduce the administrative burden on economic operators seeking to participate in public procurement procedures and should also encourage the participation of SMEs. Increased flexibility has been given to contracting authorities in requesting economic operators to provide additional information or documentation concerning the grounds for exclusion and the selection criteria. This flexibility should assist in reducing over formalistic grounds for exclusion and rejection and, as a result, increase competition. In relation to the selection criteria, the limitation at the level of turnover that a contracting authority can require of an economic operator should also encourage the participation of SMEs. In addition, new grounds for exclusion specifically address the issue of compliance with environmental, social and labour laws. 


\subsubsection{Practical problems and observations based on SIGMA's assessment and monitoring reports}

One of the key problems that SIGMA has noted on several occasions is the bureaucratic and formalistic approach of contracting authorities to the request for documents from economic operators confirming their qualifications and legal and financial situation and to the verification of any possible grounds for exclusion.

This formalistic approach to documents requested from economic operators could be directly prescribed by the legislation - either a public procurement law and/or its implementing secondary legislation, standard forms or other legislation (administrative laws) that define in general the legal validity of documents to be submitted to public institutions. However, often it is also a result of an over bureaucratic interpretation applied by procurement officers - for example, the practice of applying all facultative grounds for exclusion and selection criteria in every procurement procedure, regardless of the nature of the contract.

The problem of an over bureaucratic interpretation of public procurement provisions may be compounded by very formalistic compliance audit by external auditors, who often tend to neglect the performance aspect. This results in:

- inconvenience and high costs of participation for economic operators: time and money spent to collect all of the documents and fulfil all of the formal requirements;

- a longer duration and higher cost of conducting procurement procedures, which require the effort of contracting authorities to verify all documents;

- decreased competition, as economic operators often mention the burden of collecting all of the documents as one of the main impediments to their participation in public tenders;

- the higher prices of public contracts, as economic operators include the cost of preparation of tenders in their bid prices;

- the frequent cancellation of contract award procedures, which increases the overall cost of running and participating in the public procurement system for all stakeholders;

- the rejection of good quality tenders for irrelevant or formalistic reasons.

The very formalistic approach to documents requested from economic operators could create a barrier, especially for SMEs, to participation in public procurement procedures. The results of the survey published in the report Evaluation of SMEs' Access to Public Procurement Markets in the $E U^{9}$ showed that SMEs had indicated as one of the most common problems with regard to their participation in procurement procedures, the too onerous paperwork requirements (46\% of the SMEs surveyed had experienced this problem regularly or often). In comparison, the technical and financial qualification requirements were seen less frequently as problematic (14\% for technical requirements and $19 \%$ for financial requirements).

\footnotetext{
9 "Evaluation of SMEs' Access to Public Procurement Markets in the EU", final report submitted by GHK and Technopolis within the framework of ENTR/04/093-Lot 1, 2014.
} 
Extreme (but not rare) instances of purely formalistic requirements, such as using a particular font size in relevant documents, resulting in the rejection of tenders of good quality and the selection of much more expensive tenders for artificially amplified formal reasons that are not related to the real quality of a tenderer and its tender, contribute to a great extent to the negative perception by the general public of public procurement practices as being inefficient and wasteful.

A typical example of a cost-multiplying factor is the requirement to submit all documents relating to the qualification of suppliers in originals or copies that have been officially certified by public notaries or municipalities or, in the case of foreign companies, by embassies or consular services. The cost of certifying a single document could be significant, but the total cost of participation is much higher because each economic operator must collect all of the documents several times in order to submit a full set of certified documents for each separate tender. Until recently, in most countries the procurement legislation required the submission of all documents at the beginning of the procurement process, from all candidates and not just from the successful candidate.

Another example of excessive requirements is the application by contracting authorities of all grounds for exclusion, even those defined by law as discretionary, for all contracts, including small-value contracts, regardless of the nature, scope and value of the contracts.

Problems also arise with the use of a very high financial threshold for participation (required annual turnover), which sometimes exceeds several times the value of a tendered contract, or other participation criteria that are unrelated to the subject matter of the procurement.

Provisions of procurement legislation that are vague and too general do not help - usually the procurement law provides for a general principle that the selection criteria should be proportionate to the value and nature of the contract, without providing, however, any detailed instructions on how to interpret the proportionality test in this context.

The procedure of verifying the legal and financial situation of economic operators is usually very strict and rigid - for example, there is no possibility of correcting documents that have already been submitted or submitting any missing documents. This rigidity leads to the necessity of excluding a tenderer or rejecting a tender if the submitted documentation is incomplete, even if objectively the grounds for exclusion do not exist. An example is the situation of an economic operator that has paid all local taxes regularly, but has omitted to submit all tax certificates or has submitted (even slightly) outdated documents.

Another negative tendency in some countries is the automatic exclusion of economic operators from all public procurement procedures for a specified period, for example up to five years, based on "negative references" or other "blacklists", whereas it could be argued that EU law requires a case-by-case analysis of every procurement procedure and offers the possibility of self-cleaning. 


\subsubsection{Main legal requirements in the Directive}

The main legal requirements relating to the selection of economic operators are set out in the following Articles of the Directive:

- Article 56 - General principles - sets out general principles, permits verification in open procedures to be undertaken after the examination of tenders (subject to the discretion for Member States to restrict this approach to specific types of procurement or specific circumstances). It also allows contracting authorities to request economic operators to submit, supplement, clarify or complete the relevant information or documentation.

- Article 57 - Exclusion grounds - sets out the grounds for mandatory and discretionary exclusion of economic operators. It also stipulates that an economic operator shall not be excluded from the procurement procedure where it provides evidence that it has taken measures that are sufficient to demonstrate its reliability, despite the existence of relevant grounds for exclusion (self-cleaning).

- Article 58 - Selection criteria - sets out the rules related to how contracting authorities may set requirements concerning an economic operator's suitability to pursue the professional activity, its economic and financial standing, and its technical and professional ability.

- Article 59 - European Single Procurement Document - sets out the rules on the ESPD as preliminary evidence to accompany requests to participate or tenders.

- Article 60 - Means of proof - sets out the rules concerning certificates, statements and other means of proof that may be required as evidence of the absence of grounds for exclusion and as the fulfilment of the selection criteria.

- Article 61 - Online repository of certificates - establishes the rules on the use of the online repository of certificates (e-Certis).

- Article 62 - Quality assurance and environment management standards - sets out the type of evidence of quality assurance standards and environmental management standards that contracting authorities must accept.

- Article 63 - Reliance on capacity of other entities - sets out the rules on the reliance on the capacities of other entities in order to fulfil the criteria relating to economic and financial standing and criteria relating to technical and professional ability.

- Article 64 - Official lists and certification - sets out the rules concerning the methods whereby EU Member States may establish and maintain official lists of approved economic operators or provide for certification by certification bodies, and on how economic operators may use their registration on official lists or certification to prove to contracting authorities their fulfilment of the relevant selection criteria.

- Article 65 - Reduction of the number of candidates - lays down the rules on the reduction of the number of otherwise qualified candidates to be invited to participate in restricted procedures, competitive procedures with negotiation, competitive dialogue, and innovation partnerships. 
- Annex XI lists the relevant professional and trade registers, and corresponding declarations and certificates for each Member State with regard to the provision of evidence of suitability to pursue the professional activity concerned.

- Annex XII, Part I sets out a non-exhaustive list of references that contracting authorities may require economic operators to submit to prove their economic and financial standing.

- Annex XII, Part II sets out an exhaustive list of the means that contracting authorities may require economic operators to use to prove their technical and professional ability.

The following Articles of the Directive are also relevant to the selection of economic operators:

- Article 2(10) - Definitions - defines the concept of "economic operator".

- Article 18 - Principles of procurement - sets out the general principles applying to all stages in the procurement process.

- Article 19 - Economic operators - sets out the provisions on whether economic operators (not in a group) and groups of economic operators may be required by contracting authorities to assume a specific legal form in order to participate in a procurement process.

- Article 55 - Informing candidates and tenderers - establishes, among other things, that contracting authorities must inform unsuccessful economic operators of the reasons for their rejection.

- Article 71 - Subcontracting - establishes that contracting authorities may require an economic operator to "disclose any share of the contract it may intend to subcontract to third parties" and to provide the details concerning any proposed subcontractors. It also allows contracting authorities to verify whether there are grounds for the exclusion of subcontractors.

The 2014 Directive introduced a number of changes and new provisions, when compared to the 2004 Directive $^{10}$. The key changes include the:

- addition of new mandatory grounds for exclusion, with particular reference to any breach of environmental, social and labour law provisions and, in certain cases, the failure to comply with tax and social security obligations;

- addition of new discretionary grounds for exclusion, including exclusion on the grounds of poor prior performance;

- introduction of the ESPD to support the concept of self-certification with regard to the grounds for exclusion and the selection criteria, with verification generally carried out in respect of the economic operator to which the contracting authority has decided to award the contract, prior to the contract award;

102004 Directive on the co-ordination of procedures for the award of public works contracts, public supply contracts and public service contracts, OJ L134/114. 
- introduction of the principle of self-cleaning, permitting economic operators to which the grounds for exclusion apply to submit information demonstrating their reliability;

- specific permission given to contracting authorities to ask economic operators to "submit, supplement, clarify or complete the relevant information or documentation";

- introduction of new provisions on selection criteria, relating in particular to economic and financial standing, where a specific reference is made to minimum turnover requirements and ratios.

The above changes are considered in further detail below under the relevant headings.

\subsubsection{Coverage of the Directive and freedom for Member States to decide on more detailed provisions}

It is important to bear in mind that the Directive provides only a basic framework of rules for the conduct of public procurement procedures. It is left to individual EU Member States and/or contracting authorities to decide on the detailed rules and implementation, subject to compliance with the general principles (see individual country chapters). Different Member States choose to regulate procurement in different ways, with some opting for more detailed regulation than others.

The Directive also includes optional provisions and derogations, which Member States may choose to transpose. For example, Article 57(3) of the Directive stipulates that Member States may provide for a derogation from mandatory exclusion on public interest grounds. Hungary, Latvia and Poland have not transposed this derogation, whereas Estonia, Malta and Scotland have done so, although Malta has introduced a condition on its use.

Some common issues arising in practice at the stage of the procurement process concerning the choice of participants are not covered at all by the Directives, such as whether documentary evidence submitted as means of proof needs to be submitted in the original form, in a copy or in a certified copy.

The widely varying legal systems and legal traditions as well as established country-specific practices are reflected in the different approaches to transposition taken by Member States. This variation can be seen, for example, by comparing the approach to transposition of the Directive in Scotland to the approach taken in Poland.

In Scotland, the approach adopted by the legislative drafters was to "copy-paste" the Directive as far as possible into the Public Contracts (Scotland) Regulations 2015 (PC(S)Rs), often using the same or very similar wording as in the Directive and following closely the structure of the Directive. Scotland does not have a tradition of detailed regulation of procurement procedures and only limited additions or expansion of the provisions in the Directive have been made. National legislation covers contracts above the EU thresholds, but it does not tend to focus on detailed procedural issues (see the country chapter for Scotland for further information). It is also the case that contracting authorities are often allowed to exercise a significant degree of discretion. For example, the Scottish Government has not made any of the discretionary grounds for exclusion listed in Article 57(4) of the Directive mandatory. Contracting authorities are therefore free to decide which discretionary grounds for exclusion to apply. Similarly, there is some statutory guidance that contracting authorities are required to follow, but the way in 
which contracting authorities conduct procurement on a day-to-day basis is lightly regulated at national level. A considerable amount of non-binding guidance and sample documents are available, however, on the Scottish Government website.

In contrast, Poland has a tradition of detailed regulation, and so significant additions and expansion of the provisions in the Directive have been made. For example, the discretionary grounds for exclusion in the Polish Public Procurement Law (PPL) are far more detailed than the provisions in the Directive with reference to national offences and decisions of administrative bodies in the fields of labour, environmental and social law. It is also the case that contracting authorities are given fewer choices. For example, the national legislators have decided to make a significant number of the discretionary grounds for exclusion listed in Article 57(4) of the Directive mandatory, as is permitted under that Article (see the chapter on Grounds for exclusion, Section 2.2, for more detail).

A further example from Poland is the provisions of the implementing regulations dealing with the evidence that may be required from economic operators, which, in relation to statements from banks documents, covers issues such as the time of issuance of a document. Another example is special requirements as to the content of documents used by those economic operators who wish to rely on the resources of other entities (see the chapter on Means of proof, Section 1.6, for more detail).

Contracts below the EU financial thresholds are not covered by the procedural requirements of the Directive. Such contracts comprise the vast majority of contracts awarded by contracting authorities and are therefore of great importance in all Member States. They represent significant expenditure by contracting authorities and major business opportunities for economic operators, not least for SMEs. As a result, contracting authorities award the majority of contracts by using national rules, policies and procedures.

It is common practice for Member States to distinguish between contracts above and below the EU thresholds and to treat them differently in terms of the procurement procedures that apply, including at the stage concerning the choice of participants. This report highlights some examples in the relevant sections of Part 2.

Even though the procedural requirements of the Directive do not apply, a number of important considerations should be borne in mind. Procurement processes for below-threshold contracts should be:

- efficient and effective, and therefore use processes, time scales and documents that reflect the needs and outcomes of the particular procurement;

- proportionate and avoid unnecessary bureaucracy;

- appropriately competitive;

- transparent;

- compliant with Treaty rules and principles and, where relevant to a particular contract of cross-border interest, compliant with basic standards developed by the CJEU;

- efficient in the use of public money, ensuring the optimal allocation of resources to achieve the intended outcomes. 
Reflecting their economic, social and administrative diversity, Member States may balance these and other issues when deciding how best to regulate the award of below-threshold contracts ${ }^{11}$.

The different approaches adopted are apparent when comparing Scotland with Hungary.

In Scotland, contracts below the (relatively high) national thresholds of GBP 50000 (EUR 58 689) for supplies and services and GBP 2 million (EUR 2.4 million) for works are unregulated by national law, although contracting authorities do have their own internal rules, which usually require a form of competitive process, except for very low-value contracts and the Scottish Government's "Procurement Journey - Route 1" website provides guidance and template documents for contracts below the national thresholds ${ }^{12}$. Scotland has an active e-marketplace, which many contracting authorities use, often for low-value purchases, with several thousand transactions processed each month $^{13}$. For contracts between the national thresholds and the EU thresholds some regulation occurs, including the requirement to apply the mandatory and discretionary grounds for exclusion, but in general, the legislation for these contracts is not as detailed or prescriptive as it is for contracts above the EU thresholds.

Hungary has several national thresholds. For example, for supplies and services contracts, there is a national minimum threshold of HUF 15 million (approximately EUR 48000 ) and a national intermediary threshold of HUF 25 million (approximately EUR 80 000). For works contracts, the national thresholds are higher and the situation is more complex, with additional intermediary thresholds. In the context of supplies and services contracts, various requirements for calls for competition apply to contracts below each of the national thresholds. The same provisions on exclusions are used for contracts above and below the EU thresholds, but some mandatory grounds for exclusion for contracts above the EU thresholds are not mandatory for those below the EU thresholds. The determination of minimum requirements of technical and professional suitability is obligatory for contracts above the EU thresholds but voluntary below the intermediary thresholds. Another difference is found in the means of proof. While for contracts above the EU thresholds the use of the ESPD is mandatory, for contracts above the national thresholds and below the EU thresholds there is no such obligation, and instead, a simple statement by the economic operator must be submitted ${ }^{14}$.

\subsubsection{General rules applying to all stages in the procurement process}

Article 18 of the Directive sets out the basic rules applying to all stages in the procurement process, including the exclusion, selection and shortlisting stages.

Contracting authorities must treat economic operators in accordance with the Treaty principles and the obligations derived from those principles, which are equal treatment, non-discrimination, transparency and proportionality. In the context of the process for the

11 See SIGMA Public Procurement Brief 15 on "Below Threshold Contracts" for further explanation and discussion of these issues.

12 www.procurementjourney.scot/route-1.

${ }^{13}$ In September 2016, for example, more than 8000 transactions were processed.

${ }^{14}$ See the country chapter on Hungary, Section 4.2, for more details. 
choice of participants, the CJEU has considered these principles and obligations and has confirmed the way in which they apply in practice.

Equal treatment: The CJEU has held that national law prohibiting participation in procurement procedures of a permanent consortium of economic operators while not prohibiting other forms of joint work did not constitute equal treatment ${ }^{15}$. The CJEU has also held that a national law excluding tenderers from participating in procurement procedures where there are particular relationships of control and affiliation does not constitute equal treatment ${ }^{16}$.

Non-discrimination: The CJEU has considered national legislation requiring contractors for specific public works to reserve a proportion of those works for sub-contractors that had their registered office in the Member State where the works were to be carried out. The CJEU held in that case that the national legislation discriminated against the firms established outside that Member State. It was not relevant that the national legislation also had the effect of discriminating against some firms established in the Member State concerned $^{17}$. Less direct measures, such as a requirement for firms to employ local labour as far as possible, have also been held to be discriminatory ${ }^{18}$.

Transparency: The CJEU has confirmed that the principle of transparency implies that all of the rules of the award procedure (including the selection criteria) must be clear, precise and unequivocal. This requirement is meant to ensure that (i) all reasonably informed tenderers understand the exact significance of the rules and interpret them in the same way, and (ii) the contracting authority is able to ascertain whether the tenders submitted satisfy the selection criteria ${ }^{19}$.

Proportionality: The CJEU has consistently ruled that whilst the grounds for exclusion listed in the directives are not exhaustive, any further exclusionary measure restricting access to the market should be proportionate to its objectives. For example, the CJEU has considered a national law prohibiting the award of public contracts to media undertakings or to certain companies or individuals linked to or working for media undertakings. The national law was aimed at preventing media undertakings from unlawfully influencing contract award decisions for a public contract. The effect of the national law was to automatically exclude certain types of economic operators from participating in tenders for public contracts. The CJEU ruled that the automatic and absolute nature of the prohibition was disproportionate and was not permitted under EU law ${ }^{20}$.

The 2014 Directive added a specific reference to the requirements for proportionality and the need to maintain competition as general principles of procurement. Both of these principles are important concepts that were not included in the 2004 Directive, but the CJEU has often referred to them when considering public procurement cases.

\footnotetext{
${ }^{15}$ C-376/08 Serrantoni.

${ }^{16} \mathrm{C}-537 / 08$ Assitur.

${ }^{17}$ C-360/89 Commission v Italy.

${ }^{18}$ C-243/89 Storebaelt.

${ }^{19}$ C-368/10 Commission v Netherlands.

${ }^{20}$ C-213/07 Michaniki.
} 
For a further explanation of these principles and obligations, see SIGMA Public Procurement Brief 1, Public Procurement in the EU: Legislative Framework, Basic Principles and Institutions ${ }^{21}$. See also Part 5, Case law of the CJEU, for a more detailed discussion of some of the cases mentioned above.

National legislation may include additional general principles or requirements applying to the exclusion, selection and shortlisting stages, or applying more generally.

For example, in Malta, contracting authorities must ensure the "clarity" of procurement documents, which include documents relating to exclusion, selection and shortlisting. Procurement documents "shall be written in clear and unambiguous terms so as to enable all interested parties to understand properly the terms and conditions of the process" (Regulation 38).

It is quite common in practice to see procurement documents that are unclear and uncertain. As a result of this lack of clarity, economic operators may request additional information or they will more than likely misunderstand the meaning of the documents or the requirements of the contracting authority and subsequently submit incomplete or incorrect tenders or expressions of interest. Furthermore, unclear or uncertain procurement documents often lead to problems in the evaluation stage carried out by contracting authorities that do not have a clear picture of what was required or meant by the documents. These problems may have the knock-on effect of reducing competition or increasing the likelihood of legal challenges.

The requirement of clarity should help to ensure that contracting authorities prepare and check procurement documents carefully in advance, before starting the procurement procedure. They should ask themselves whether the documents will be "clear and unambiguous" for the economic operators reading them. This clarity may also have the effect of reducing the number of legal challenges.

The EU has acknowledged that public procurement can be used as a tool to promote improvements in social, environmental and labour practices. Article 18 of the Directive requires Member States to "take appropriate measures to ensure that in the performance of public contracts economic operators comply with applicable obligations" in these fields. To ensure that public procurement will be a truly effective tool, these issues need to be considered by contracting authorities at an early stage.

Scotland has legislation that obliges contracting authorities to consider these issues at the procurement planning stage. The "Sustainable procurement duty" applies during both the pre-procurement planning stage and the procurement procedure for contracts over the national thresholds - Procurement Reform (Scotland) Act 2014 (PR(S)A), Section 9. In the context of the exclusion, selection and shortlisting stages, this legislation means that before carrying out a procurement procedure, the contracting authority has the duty to consider how it will be able, when conducting the procedure, to (1) improve the economic, social and environmental well-being of the authority's area, including the reduction of inequality; (2) facilitate the involvement of SMEs, third-sector bodies (organisations that exist wholly or mainly to provide benefits for society or the

21 See also SIGMA (2010), Public Procurement in EU Member States - The Regulation of Contracts Below the EU Thresholds and in Areas Not Covered by the Detailed Rules of the EU Directives, SIGMA Papers No. 45, OECD Publishing, Paris, www.oecd-ilibrary.org/ governance/public-procurement-in-eu-member-states_5km91p7s1mxv-en. 
environment), and supported businesses in the process; and (3) support innovation. The contracting authority must also carry out the procurement procedure with a view to securing improvements in the economic, social and environmental well-being of the authority's area, as identified in the planning stage. The contracting authority must only consider matters that are proportionate and relevant to the subject matter of the procurement.

Statutory guidance is available on how to implement sustainable procurement duty in Chapter 3 of the Guidance under the PR(S)A (the Guidance). It is interesting to note that the Guidance states in Chapter 3.4 that "compliance with the sustainable procurement duty may aid compliance with other legislation that places specific requirements on a contracting authority with respect to its procurement activities". In that context, it then refers to national legislation relating to equality and climate change. The Guidance also comments that a number of regulations in the PC(S)Rs (the Scottish Regulations) that implement the Directive are particularly relevant to sustainable procurement duty. The breach of the general principles of procurement or of environmental, social and labour laws constitutes grounds for exclusion (see the country chapter on Scotland, Section 4.6, for further references and links).

This type of provision encourages contracting authorities to adopt a structured, pre-planning stage that looks at more than just direct needs and budget issues. It forces contracting authorities to think carefully, at the pre-procurement planning stage, about how public procurement can be used to encourage engagement with SMEs as well as drive improvements in the areas of environmental, social and labour issues. This pre-procurement planning stage can include, for example, thinking about how to package the contract opportunity, draft the specifications, determine whether there are any special contract conditions, or decide at which level to set the minimum selection criteria. For more information, see the SIGMA Public Procurement Briefs on social and environmental issues in procurement ${ }^{22}$.

\subsection{Grounds for exclusion}

\subsubsection{Mandatory grounds for exclusion}

The exclusion of economic operators from public procurement procedures aims to protect the integrity of the process by preventing the participation of economic operators that are deemed to be undesirable partners of the public administration. The grounds for exclusion of economic operators extend to corruption and other areas of criminal activity, professional misconduct and other causes of a lack of reliability.

The Directive obliges and allows contracting authorities to exclude from a given procurement procedure those economic operators that are found to be in a specific situation. First, the Directive provides a list of circumstances where a contracting authority is obliged to exclude an economic operator. Such circumstances are known as

${ }^{22}$ OECD (2016), Incorporating Environmental Considerations into Procurement, SIGMA Public Procurement Brief No. 13, OECD Publishing, Paris, www.sigmaweb.org/ publications/Public-Procurement-Policy-Brief-13-200117.pdf; OECD (2016), Incorporating Social Considerations into Procurement, SIGMA Public Procurement Brief No. 14, OECD Publishing, Paris, www.sigmaweb.org/publications/Public-Procurement-Policy-Brief14-200117.pdf. 
mandatory grounds for exclusion because they must result in the exclusion of an economic operator. Second, a contracting authority may, but is not obliged to, exclude an economic operator in other circumstances. These grounds are referred to as discretionary grounds for exclusion.

In accordance with Article 57(1) of the Directive and in support of the EU's own policies, a contracting authority is obliged to exclude from participation in a contract award procedure, after it has verified or been made aware of the facts, an economic operator that has been convicted by final judgement for one or more of the following criminal activities:

- participation in a criminal organisation ${ }^{23}$;

- corruption $^{24}$;

- $\operatorname{fraud}^{25}$;

- terrorist offences or offences linked to terrorist activities ${ }^{26}$;

- money laundering or terrorist financing ${ }^{27}$;

- child labour and other forms of trafficking in human beings ${ }^{28}$.

In comparison to the 2004 Directive, the 2014 Directive added the following criminal activities as mandatory grounds for exclusion: terrorist offences or offences linked to terrorist activities, terrorist financing, child labour and other forms of trafficking in human beings.

The obligation to exclude from participation in a procurement procedure an economic operator that has been convicted by final judgement for a criminal activity was first introduced in the 2004 Directive as an example of the requirement by EU law for Member States to use their procurement power to support EU policy objectives extending beyond public procurement. According to the 2014 Directive, an economic operator

${ }^{23}$ As defined in Article 2 of Council Framework Decision 2008/841/JHA of 24 October 2008 on the fight against organised crime (OJ L 300, 11.11.2008, p. 42).

${ }^{24}$ As defined in Article 3 of the Convention on the fight against corruption involving officials of the European Communities or officials of Member States of the European Union (OJ C 195, 25.6.1997, p. 1) and Article 2(1) of Council Framework Decision 2003/568/JHA of 22 July 2003 on combating corruption in the private sector (OJ L 192, 31.7.2003, p. 54), as well as corruption as defined in the national law of the contracting authority or the economic operator.

25 Within the meaning of Article 1 of the Convention on the protection of the European Communities' financial interests (OJ C 316, 27.11.1995, p. 48).

${ }^{26}$ As defined in Articles 1 and 3 of Council Framework Decision 2002/475/JHA of 13 June 2002 on combating terrorism (OJ L 164, 22.6.2002, p. 3) or inciting, aiding, abetting, or attempting to commit an offence, as referred to in Article 4 of the same Framework Decision.

27 As defined in Article 1 of Directive 2005/60/EC of the European Parliament and of the Council of 26 October 2005 on the prevention of the use of the financial system for the purpose of money laundering and terrorist financing (OJ L 309, 25.11.2005, p. 15).

${ }^{28}$ As defined in Article 2 of Directive 2011/36/EU of the European Parliament and of the Council of 5 April 2011 on preventing and combating trafficking in human beings and protecting its victims, and replacing Council Framework Decision 2002/629/JHA (OJ L 101, 15.4.2011, p. 1). 
convicted for any of the above-mentioned crimes will be excluded from the procurement procedure, notwithstanding the subject matter of the contract and its relevance. It can be argued that in those cases the exclusion is automatic, although the 2014 Directive introduced self-cleaning measures as a defence against mandatory exclusion. To avoid exclusion, an economic operator must demonstrate that it has taken adequate measures to ensure that the conduct in question will not recur (see Section 3.3 on self-cleaning).

National legislators must transpose into national legislation all of the offences for which exclusion is required under the Directive. EU Member States have no discretion in this regard; they cannot decide to omit some or all of the offences described as mandatory grounds for exclusion. They may add to the list, but they may not remove any of the offences listed. Generally, most Member States include references to equivalent offences as defined in national legislation, which appears to be the best approach. It is in the interest of legal certainty that legislators translate the criminal offences as they are defined in the EU legal interest into equivalent national criminal offences provided in the criminal laws and other laws of the Member State concerned. A clear link to national criminal offences allows for the verification of the existence or non-existence of final judgements for specific crimes.

Article 57(1) of the Directive explicitly obliges Member States to introduce national provisions requiring contracting authorities to also exclude an economic operator in the event that the person convicted by final judgement for any of the criminal offences listed above is a member of the administrative, management or supervisory body of that economic operator or has powers of representation, decision making or control therein.

The detailed provisions of the Directive, including the mandatory grounds for exclusion, do not apply to contracts below the EU financial thresholds. The CJEU has developed a set of basic standards for the award of public contracts, which are not covered by the Directive but have a sufficient connection with the functioning of the Internal Market. The standards are derived directly from the rules and principles of the Treaty. The principles of equal treatment and non-discrimination on the grounds of nationality imply an obligation of transparency which, according to CJEU case law ${ }^{29}$, "consists in ensuring, for the benefit of any potential tenderer, a degree of advertising sufficient to enable the services market to be opened up to competition and the impartiality of the procedures to be reviewed" 30 .

Nevertheless, all of the selected EU member countries have decided to apply all or some of the mandatory grounds for exclusion to contracts below the EU thresholds as well, except for contracts of a modest value. This decision should be considered as desirable practice, as it prevents the public administration from awarding public contracts, no matter what their value may be, to unsuitable partners.

In all of the six member countries studied it is very rare to find an economic operator that has actually been excluded from a procurement procedure on the basis of mandatory grounds for exclusion. This does not mean that the rules on mandatory exclusion are ineffective, but suggests instead that unsuitable economic operators do not even attempt to participate in procurement procedures.

\footnotetext{
${ }^{29}$ Cases C-324/98 Telaustria, C-231/03 Coname and C-458/03 Parking Brixen.

${ }^{30}$ Cases C-324/98 Telaustria and C-458/03 Parking Brixen.
} 
In Scotland, Regulation 58(1)(a) to (k) of the PC(S)Rs lists the mandatory grounds for exclusion, which correspond to the mandatory grounds listed in Article 57(1) of the Directive. The list not only mirrors the provision of the Directive but also includes, where appropriate, references to related offences defined in national legislation.

For example, Article 57(1)(a) of the Directive refers to participation in a criminal organisation, as defined in Article 2 of Council Framework Decision 2008/841/JHA. Regulation 58(1)(a) of the PC(S)Rs refers to the same Council Framework Decision, but it also refers to an offence under Sections 28 or 30 of the Criminal Justice and Licensing (Scotland) Act 2010.

Similarly, Article 57(1)(c) of the Directive refers to fraud, according to the meaning of Article 1 of the Convention on the protection of the European Communities' financial interests, while Regulation 58(1)(e) of the PC(S)Rs also refers to Article 1 of the same Convention, but then elaborates by listing the following equivalent offences under national law:

- offence of cheating the Revenue;

- common law offence of fraud;

- common law offence of theft or fraud;

- fraudulent trading, according to the meaning of Section 458 of the Companies Act 1985 or Section 993 of the Companies Act 2006;

- fraudulent evasion, according to the meaning of Section 170 of the Customs and Excise Management Act 1979 or Section 72 of the Value Added Tax Act 1994;

- offence in connection with taxation in the EU, according to the meaning of Section 71 of the Criminal Justice Act 1993;

- common law offence of uttering ${ }^{31}$;

- common law offence of attempting to pervert the course of justice.

The exclusions also apply to an economic operator in the circumstances where the listed grounds for exclusion apply to a person who is a member of the administrative, management or supervisory body of the economic operator or who has powers of representation, decision or control in relation to that economic operator.

Sub-threshold ${ }^{32}$ contracts: The mandatory grounds for exclusion in relation to the conviction for offences listed in Regulation 8(1) of the Procurement (Scotland) Regulations 2016 (2016 Procurement Regulations) are essentially the same as the mandatory grounds listed in the PC(S)Rs, except that the 2016 Procurement Regulations do not include any reference to the use of the ESPD for verification of the grounds for exclusion. For contracts below the EU thresholds, it is not obligatory to use the ESPD.

Economic operators in Scotland are in fact rarely excluded from participation in tender processes on the basis of either mandatory or discretionary grounds for exclusion. The

\footnotetext{
31 The common law crime of uttering occurs when someone submits "as genuine" a forged document to the prejudice of another person.
}

32 In Sweden, the national financial thresholds are as follows: EUR 2 million for public works contracts and EUR 50000 for other public contracts. 
main focus of Scottish contracting authorities is on the stage of selection and shortlisting of economic operators.

It is also rare that excluded economic operators initiate legal proceedings in relation to the decisions of contracting authorities to exclude them on the basis of mandatory or discretionary grounds. Similarly, economic operators participating in a tender process rarely initiate legal proceedings in relation to the failure of a contracting authority to exclude another economic operator from a procurement procedure.

In Poland, Article 24.1(13) of the Act of 29 January 2004 PPL lists the mandatory grounds for exclusion, which correspond to the mandatory grounds listed in Article 57(1) of the Directive, using references to equivalent national criminal activities. The same mandatory grounds for exclusion apply to contracts below the EU financial thresholds but above the national financial thresholds ${ }^{33}$ (Article 4, paragraph 8 of the PPL).

The contracting authority must exclude from the public procurement procedure a contractor (economic operator) who is a natural person who has been validly sentenced for the following crime or offences:

- offence referred to in Article 165a, Articles 181-188, Article 189a, Articles 218-221, Articles 228-230a, Articles 250a, Article 258 or Articles 270-309 of the Penal Code ${ }^{34}$; or Article 46 or Article 48 of the Act on Sports $^{35}$;

- crime of terrorism, as referred to in Article 115, paragraph 20 of the Penal Code;

- offence against the Treasury (fiscal offence);

- crimes of human trafficking.

In Poland, entities other than natural persons cannot be sentenced for a crime or an offence. However, exclusion also applies to a contractor that has an executive member of the managing or supervisory body, a partner in a general/registered or (professional) partnership, a general partner in a limited partnership or limited joint-stock partnership or a commercial proxy who has been validly sentenced for an offence or crime listed above.

In Malta, Regulation 192(1) of the Public Procurement Regulations (PPRs) of 2016 (S.L.174.04 introduced by Legal Notice 352 of 2016) lists the mandatory grounds for

\footnotetext{
${ }^{33}$ In Poland, the national financial threshold is EUR 30000.
}

${ }^{34}$ Act of 6 June 1997, Journal of Laws, item 553. Amendments to the Act were published in the Journal of Laws of 1997, item 840; Journal of Laws of 1999, items 729 and 931; Journal of Laws of 2000, items 548, 1027 and 1216; Journal of Laws of 2001, item 1 071; Journal of Laws of 2003, items 1 061, 1 142, 1 750, 1935 and 2 255; Journal of Laws of 2004, items 219, 626, 889 and 2 426; Journal of Laws of 2005, items 732, 757, 1 109, 1 363, 1479 and 1 493; Journal of Laws of 2006, items 1 409, 1592 and 1 648; Journal of Laws of 2007, items 589, 850, 859 and 1 378; Journal of Laws of 2008, items 560, 782, 1 056, 1080 and 1 344; Journal of Laws of 2009, items 504, 533, 1 317, 1 323, 1 474, 1540 and 1 589; Journal of Laws of 2010, items 46, 227, 229, 625, 626, 842, 857, 1018, 1021, 1228, 1474 and 1602; Journal of Laws of 2011, items 78, 130, 202, 245, 381, 549, 678, 767, 964, 1 135, 1 280, 1381 and 1 431; Journal of Laws of 2012, item 611; Journal of Laws of 2013, items 849, 905, 1036 and 1 247; Journal of Laws of 2014, item 538; Journal of Laws of 2015, items 396, 541, 1 549, 1707 and 1 855; and Journal of Laws of 2016, items 189, 428, 437 and 862.

${ }^{35}$ Act of 25 June 2010, Journal of Laws of 2016, item 176. 
exclusion, which correspond to the grounds listed in Article 57(1) of the Directive. The same mandatory grounds apply to contracts below the EU financial thresholds but above the national financial thresholds ${ }^{36}$ (Regulation 9 of the PPR).

It is interesting to note that the provision practically repeats the wording in the Directive. However, at the end of all grounds for exclusion the following phrase is added: "... or an equivalent offence under Maltese law or as defined in the national law of the economic operator".

The exclusion of the economic operator also applies where the person convicted by final judgement is a member of the administrative, management or supervisory body of that economic operator or has powers of representation, decision or control therein [Regulation 192(2)].

Economic operators in Malta are very rarely excluded from participation in a tender process on the basis of either mandatory or discretionary grounds for exclusion.

With regard to legal challenges, economic operators participating in a tender process sometimes initiate legal proceedings as a consequence of the failure of a contracting authority to exclude another economic operator from a procurement procedure.

In Hungary, Act CXLIII of 2015 on Public Procurement (PPL), Article 62(1)(a), points aa) to ah), lists the mandatory grounds for exclusion, which correspond to the grounds listed in Article 57(1) of the Directive. The list includes references to crimes that are defined in national legislation. The list also includes a reference to "a criminal act similar to those listed, according to personal law of the economic operator". It is interesting to note that the Hungarian legislator has defined the term "similar criminal act", which is relevant in the case of tenderers established in another EU Member State and natural persons who are foreign nationals and subject to the criminal jurisdiction of another country. The term "similar criminal act" means a criminal act as defined in Article 57(1) of the Directive. For this purpose, Article 62(5) of the PPL repeats word for word the criminal activities as provided in the Directive.

The exclusions also apply to an economic operator that relies on the capacities of a tenderer, candidate, subcontractor or entity, where:

- "its executive officer or a member of its supervisory board, its manager or, in the case of a business organisation its sole member or a member of its similar management or supervisory body or a person vested with the same powers of decision is convicted by a final court judgement of a specified crime or

- a person who was convicted by a final court judgement of a specified crime was in the economic operator concerned at the time of committing the crime in question."

In Latvia, in the PPL of 15 December 2016, Article 42, point 1, lists the mandatory grounds for exclusion corresponding to Article 57(1) of the Directive.

The exclusion will apply to the economic operator if a candidate, tenderer or person who is a member of the candidate's or tenderer's management or supervisory board, a person

${ }^{36}$ A simpler procurement regime is applicable in Malta in the case of contracts with a value of below EUR 10 000, and an even more basic regime applies where the value is below EUR 5000 (Part III of the PPR). 
with representation rights, a proxy or a person entitled to represent the candidate or tenderer in the activities related to a branch has been found guilty of any of the criminal activities listed by the final judgement.

Economic operators in Latvia are in fact rarely excluded from participation in tender procedures on the basis of either mandatory or discretionary grounds for exclusion. In 2015 only $1.25 \%$ of economic operators were excluded from participation in a tender procedure ( 655 excluded tenderers out of 52568 bids received in a total of 3522 tender procedures).

The main grounds for mandatory exclusion that applied in 2015 were as follows:

- $6.44 \%$ of the grounds for exclusion related to the person indicated by the tenderer and on whose capacities it relied in order to prove the qualification requirements;

- $1.43 \%$ related to evasion in the payment of taxes and equivalent payments established by final judgement or decision;

- $1 \%$ concerned bribe taking, bribery, bribe misappropriation, intermediation in bribery, taking of prohibited benefit or commercial bribery;

- $1 \%$ related to fraud, misappropriation or money laundering.

With regard to legal challenges, excluded economic operators sometimes initiated legal proceedings against the decisions of contracting authorities to exclude them on the basis of mandatory or discretionary grounds. Similarly, economic operators participating in a tender procedure sometimes initiated legal proceedings in relation to the failure of a contracting authority to exclude another economic operator from that procedure.

\subsubsection{Additional mandatory grounds for exclusion}

EU Member States also have the freedom to establish additional grounds for exclusion, provided that those grounds are not based on criteria relating to the professional qualities of the candidate or tenderer and, more specifically, to professional honesty, solvency, and economic and financial capacity. These additional grounds can be either mandatory or discretionary. If they are made mandatory in the national legislation of a Member State, they become mandatory for the contracting authorities in that Member State. The Directive does not regulate additional grounds for exclusion.

The CJEU has clarified that the grounds listed in the directives ${ }^{37}$ are exhaustive only in relation to grounds for exclusion concerning professional qualities. Member States or contracting authorities are therefore entitled to use additional exclusionary measures while observing the principles of equal treatment and transparency. The principle of proportionality requires that such measures must not go beyond what is necessary and justified by the scope and nature of the contract.

For example, in C-213/07 Michaniki, the CJEU commented that Community law did not preclude the adoption of national measures aimed at avoiding the occurrence of practices that could jeopardise transparency or distort competition. The measures in C-213/07 Michaniki concerned the exclusion of tenderers involved in the media sector. Exclusion on those grounds was driven by concerns that there was a risk of interference by influential media organisations in contract award procedures. There were also concerns

\footnotetext{
${ }^{37}$ These directives are predecessors of the 2014 Directive.
} 
relating to fraud and corruption. As measures designed to ensure the observance of the principles of equal treatment and transparency, these types of measures could be considered permissible grounds for exclusion. However, additional measures are subject to the caveat that they must be proportionate to the situation and must not exceed what is necessary to achieve the objective. In C-213/07 Michaniki, the measures taken were considered to be disproportionate and therefore unlawful.

The CJEU has ruled in a number of other cases that additional grounds for exclusion applied by EU Member States were disproportionate, because they went beyond what was necessary to achieve the objective (C-538/07 Assitur and C-376/08 Serrantoni and Consorzio stabile edili). In C-465/11 Forposta and ABC Direct Contact, the CJEU concluded that a national law requiring the automatic exclusion of contractors for prior poor performance of public contracts was in breach of the proportionality principle.

The principles of transparency and equal treatment were confirmed in relation to exclusion on the grounds of failure to pay taxes and social security contributions. These grounds are among the optional grounds listed in Directive 92/50/EEC ${ }^{38}$ (see C-226/04 La Cascina and Others).

All the six member countries studied here have established additional national mandatory grounds for exclusion. It may be noted that although those additional grounds are diverse, they are nevertheless all aimed at implementing legitimate policies, such as the protection of labour law and competition law. In this regard, it is obvious that Member States tend to establish additional grounds for exclusion for the purpose of tackling particular domestic issues. For example, labour-related exclusions demonstrate that public procurement can be used as one of the instruments for curbing violations in the labour market, which should ultimately increase fair competition between economic operators.

In Scotland, Regulation 58(3)(b) of the PC(S)Rs lists additional grounds for mandatory exclusion. The same grounds apply to contracts below the EU financial thresholds [Regulation 9(1) of the 2016 Procurement Regulations], as follows:

"A contracting authority must exclude an economic operator from participation in a procurement procedure where it is aware that the economic operator has committed an act prohibited under the Employment Relations Act 1999 (Blacklist) Regulations 2010 (No. 493) and where either the economic operator has admitted that it has committed such an act, or it has been established by a judicial decision having a final and binding effect that the economic operator has committed such an act."

The Blacklist Regulations prohibit the compilation, use, sale or supply of blacklists containing detailed information on trade union members and activists, the purpose of which is to discriminate against workers on the grounds of trade union membership or trade union activities.

In Poland, Article 24.1, paragraphs 21-23 of the PPL list additional national grounds for mandatory exclusion. The same additional grounds apply to contracts below the EU financial thresholds but above the national financial threshold (Article 4, paragraph 8 of the PPL).

"The following shall also be excluded from the public procurement procedure:

${ }^{38}$ Article 45 of Directive 92/50/EEC of 18 June 1992, relating to the co-ordination of procedures for the award of public service contracts. 
- a contractor who is a collective entity and against whom a court has ruled the prohibition of applying for the award of public contracts on the basis of the Act on the responsibility of collective entities for acts prohibited under penalty ${ }^{39}$;

- a contractor against whom a preventive measure has been ruled, in the form of a public contract application ban;

- contractors who belong to the same group of companies, within the meaning of the Act on competition and consumer protection ${ }^{40}$, and who have submitted separate bids, partial offers or requests to participate in the proceedings, unless they demonstrate that the links existing between them do not lead to distortions of competition in the public procurement procedure."

With regard to the last exclusion indicated above, it is important to note that these grounds for exclusion are not covered by the ESPD. Economic operators do not indicate in the ESPD any information on possible links with other economic operators. This is because, at the time the ESPD is submitted to the contracting authority, it is too early for an economic operator to declare whether it belongs to the same capital group as other economic operators that have submitted tenders. At this stage of the procedure, economic operators do not have information concerning other tenderers. However, within three days of the date on which information on assessing the fulfilment of conditions for participation in the public procurement procedure has been sent to economic operators or in open procedure, economic operators must submit to the contracting authority a statement indicating whether they belong to the same capital group as other economic operators (Article 24.11 of the PPL).

In cases where the economic operator does belong to the same capital group as other tenderers, the economic operator may, with the statement, submit documents or information confirming that its existing relations with another economic operator will not lead to distortions of competition in the procurement procedure. In line with Article 24.1 of the PPL, there are other additional mandatory grounds for exclusion indicated in points 12 and $15-20$.

In Estonia, Article 38 (1) point 5 of the PPL provides for additional grounds for mandatory exclusion. A contracting authority shall not award a public contract to a person and shall exclude from a procurement procedure a tenderer or candidate "who has submitted a joint tender in the same public procurement (procedure) or concerning the same lot, having at the same time submitted the tender alone, several joint tenders with other different joint tenderers or given another tenderer the written consent to be named as a subcontractor in the performance of the public contract".

Hungary has also established additional mandatory grounds for exclusion in Article 62(1) of the PPL.

${ }^{39}$ Act of 28 October 2002 (Journal of Laws of 2015, items 1 212, 1844 and 1 855; and Journal of Laws of 2016, items 437 and 544).

${ }^{40}$ Act of 16 February 2007 (Journal of Laws of 2015, items 184, 1618 and 1 634). 
For example, economic operators that have been "prohibited from participating in procurement procedures by final decision ${ }^{41}$ of the Public Procurement Arbitration Board (the Board), until the end of the period established by the final decision or, in case of judicial review, by final court ruling" are to be excluded from procurement procedures. This example of exclusion concerns the issue of blacklisting in Hungary.

It is interesting to note that Hungary has also established grounds for exclusion in instances where an economic operator resides in another country. Such parties are not eligible to participate in procurement procedures. Hungary is the only EU Member State (of the six studied for this Paper) that has established such grounds for exclusion.

Economic operators that "have their fiscal domicile in a country outside the EU, the EEA, the OECD, the WTO/GPA or outside the overseas countries and territories specified in Article 198 of the Treaty on the Functioning of the European Union (TFEU) or in a country which has not signed any agreement with Hungary on avoiding double taxation or which has not signed a bilateral agreement with the EU concerning public procurement" cannot participate in public procurement procedures in Hungary.

This exclusion also applies to "companies (that) are not listed on any official stock exchange, (that) cannot identify their actual owner ${ }^{42}$ or economic operators in which any such companies own directly or indirectly a share exceeding $25 \%$ or have the right to vote".

In Hungary, for a contract below the EU financial thresholds but above the national financial thresholds according to Articles 114(1) and 117(4) of the PPL, the contracting authority is entitled to prescribe in the contract notice the application of one or more mandatory or discretionary grounds for exclusion, as set out in Articles 62 and 63 of the PPL.

Latvia has established two additional mandatory grounds for exclusion related to a breach of labour law, as established by judicial or administrative decision having final and binding effect, according to Article 42(1)(f) of the PPL. Thus, economic operators will also be excluded from the procurement procedure if they have been found guilty of the following breaches:

- employment of one or more non-EU citizens, if they reside illegally on EU territory;

- employment of a person without establishing a written employment contract.

In practice, the grounds for exclusion related to employment of a person without a written employment contract are applied quite frequently. In 2015, $11.44 \%$ of all excluded economic operators had been excluded on these grounds.

${ }^{41}$ In its decision, the Public Procurement Arbitration Board states that an infringement has. occurred and prohibits the tenderer, subcontractor or any other entity or person concerned from participating in the procurement procedure.

${ }^{42}$ Pursuant to Article 3(ra)-(rb) or (rc)-(rd) of Act CXXXVI of 2007 on the Prevention and Combating of Money Laundering and Terrorist Financing. 


\subsubsection{Exclusion on the grounds of non-payment of taxes and social security contributions}

The Directive provides for the exclusion of economic operators for the non-payment of taxes and social security contributions. The reason for including specific provisions on these matters is their particular importance for overall state policy. Here again, as seen above with the mandatory grounds for exclusion for criminal offences, the procurement power of EU Member States is used as a tool to enforce the compliance of economic operators with tax and social security obligations.

The exclusion of economic operators that are in breach of these obligations is automatic, unless the Member States have decided to derogate the exclusion in situations that are "clearly disproportionate", in particular cases where the amounts owed are insignificant or where there is no possibility of complying (see more on the subject of derogation from exclusion in Section 1.2.4).

Article 57 of the Directive distinguishes between mandatory and discretionary grounds for exclusion.

First, in the case where an administrative or judicial decision having final and binding effect $^{43}$ has established that a breach of obligations relating to the payment of taxes or social security contributions has occurred, a contracting authority is obliged to exclude the economic operator concerned from participation in a procurement procedure. Such a breach results in mandatory exclusion.

Second, even in the case where no final and binding decision exists, a contracting authority may exclude "or be required by Member States to exclude" an economic operator from participation in a procurement procedure if it can demonstrate by any appropriate means that the economic operator is in breach of its obligations relating to the payment of taxes or social security contributions. Such a breach results in discretionary exclusion "which Member States may render mandatory".

However, these exclusions are no longer applicable, i.e. the contracting authority shall not exclude the economic operator from participation in a procurement procedure, when the economic operator has fulfilled its obligations by paying or by entering into a binding arrangement with a view to paying the obligations due, including any interest accrued or fines, where applicable.

In Malta, Regulation 193(1) of the PPR refers to mandatory grounds for exclusion on the grounds of the non-payment of taxes or social security contributions, as follows:

"An economic operator shall likewise be excluded from participation in a procurement procedure where the authority responsible for the tendering process is aware that the economic operator is in breach of its obligations relating to the payment of taxes or social security contributions and where this has been established by a local or foreign judicial or administrative decision having final and binding effect."

Regulation 193(2) of the PPR refers to discretionary grounds for exclusion for the non-payment of taxes or social security contributions:

43 This provision of the Directive refers to an administrative or judicial decision that is in accordance with the legal provisions of the country in which the economic operator is established or with those of the Member State of the contracting authority. 
"The authorities responsible for the tendering process are also entitled to exclude an economic operator from participation in a procurement procedure if they can demonstrate by any appropriate means that the economic operator is in breach of its obligations relating to the payment of taxes or social security contributions, even in the absence of a local or foreign judicial or administrative decision."

It is interesting to note that Malta, in Regulation 193(3) of the PPR, has defined the term "appropriate means" referred to above as "any certificate, declaration or documentation issued by a competent entity which demonstrates that the economic operator is in breach of its obligations relating to the payment of taxes and/or social security contributions".

However, Regulation 193(4) of the PPR states that both exclusions no longer apply if the economic operator fulfils its obligations by paying, or by entering into a binding arrangement with a view to paying, the taxes or social security contributions due, including, where applicable, any interest accrued or fines [].

Both the mandatory and discretionary exclusions on the grounds of non-conformity with obligations to pay taxes and social security contributions, including the derogations discussed above, also apply to contracts below the EU financial thresholds but above the national financial thresholds (Regulation 9 of the PPR).

In Hungary, Article 62(1), point b), of the PPL refers to mandatory grounds for exclusion on the basis of the non-payment of taxes or social security contributions, as follows:

"The economic operators ${ }^{44}$ who have not fulfilled their tax, customs duty or social security contribution payment obligations for more than a year, are excluded from participating in the procedure."

It is interesting to note here that economic operators that are in breach of their payment obligations for less than a year will not be excluded from participating in the procurement procedure.

Exclusion does not apply if the economic operators "have paid the debt, including, where applicable, any interest accrued or fines by the time of the submission of the tender or the request to participate, or they were granted a permission for deferred payment of the debt".

With regard to these grounds for exclusion, the Hungarian legislator does not require the breach to be established by an administrative or judicial decision having final and binding effect. For more information on how the non-existence of these grounds for exclusion is verified in Hungary, see Section 2.6 on means of proof.

The PPL does not provide for discretionary grounds for exclusion for the non-payment of taxes or social security contributions. The reason for the absence of discretionary grounds is that the above-mentioned mandatory grounds provided in the PPL permit a contracting authority to exclude an economic operator where it can demonstrate by any appropriate means that the economic operator is in breach of its obligations related to the payment of taxes or social security contributions.

For contracts below the EU financial thresholds but above the national financial thresholds, according to Articles 114(1) and 117(4) of the PPL, the contracting authority

\footnotetext{
${ }^{44}$ In Hungary, the exclusion applies to a tenderer, candidate, subcontractor or entity on whose
} capacities the economic operator relies. 
is entitled to prescribe in the contract notice the application of one or more mandatory or discretionary grounds for exclusion that are set out in the PPL.

In Latvia, Article 42(1)1)f) of the PPL refers to mandatory exclusion on the grounds of the non-payment of taxes or social security contributions, as follows:

"The contracting authority shall exclude a candidate or tenderer from participation in a procurement procedure if a candidate, a tenderer or a person being a member of the candidate's or tenderer's management or supervisory board, a person with the representation rights, proxy or a person entitled to represent the candidate or tenderer in the activities related to a branch has been found guilty for evading payment of taxes and payments equivalent thereto by the final judgement."

It is interesting to note that in Latvia this exclusion is not based solely on the breach of the economic operator itself. The exclusion of the economic operator can also be based on the breach of a director or other persons associated with the economic operator.

Furthermore, Article 42(1)2) refers to mandatory exclusion on the grounds of the non-payment of taxes or social security contributions, as follows:

"The contracting authority shall exclude a candidate or tenderer from participation in a procurement procedure where a candidate or tenderer has tax debts in Latvia or a country where it is registered or permanently residing, including debts of mandatory State social insurance contributions in total exceeding 150 euro in each country."

It can be seen here that Latvia has decided to make the discretionary grounds for the non-payment of taxes and social security contributions mandatory for its contracting authorities.

These grounds for exclusion shall also apply to:

- the sub-contractor indicated by the tenderer, where the value of the works to be performed or the services to be provided is at least $10 \%$ of the total value of the public works or service contract;

- the person, as indicated by the tenderer, on whose capacities the tenderer relies in order to prove the qualification requirements laid down in the contract notice or procurement documents.

These grounds for exclusion are among the most frequently invoked: $41.2 \%$ of all excluded economic operators were excluded on these grounds.

\subsubsection{Derogation from the requirement of mandatory exclusion}

Article 57(3) of the Directive explicitly leaves it to EU Member States to provide for a derogation from the mandatory exclusion, on an exceptional basis, for overriding reasons related to the public interest, such as public health or protection of the environment. Recital 100 of the Directive elaborates on these derogations. Accordingly, derogations may be justified only in truly exceptional circumstances, for example where urgently needed vaccines or emergency equipment can only be purchased from an economic operator to which one of the mandatory grounds for exclusion would otherwise apply.

Article 57(3) of the Directive also allows Member States for a derogation from the mandatory exclusion of an economic operator that is in breach of its obligations related to the payment of taxes or social security contributions where the exclusion would be clearly disproportionate, in particular in one of the following cases: 
- where only an insignificant amount of taxes or social security contributions was left unpaid;

- where the economic operator was informed of the exact amount due, following the breach of its obligations, at a particular time when it did not have the possibility to pay, or to enter into a binding arrangement with a view to paying, prior to the expiration of the deadline for the submission of a tender (in an open procedure) or for the request to participate (in a two-stage procedure).

Here, the principle of proportionality, as an overarching principle of EU law, is expressly mentioned.

In Scotland, Regulation 58(6) of the $\mathrm{PC}(\mathrm{S}) \mathrm{Rs}$ provides for the derogation from mandatory exclusion on public interest grounds, as follows:

"A contracting authority may disregard any of the prohibitions imposed by paragraphs (1) to (3), on an exceptional basis, for overriding reasons relating to the public interest, such as public health or protection of the environment."

The Scottish Government explains this derogation on its "Procurement Journey" website ${ }^{45}$ :

"There is no definitive list of situations in which this derogation can be used and decisions should be made on a case by case basis. Organisations should be able to demonstrate that the actual or potential harm is so great, that the public interest in using the derogation outweighs the public interest in excluding a bidder. An example may be where urgently needed vaccines or emergency equipment can only be purchased from a bidder to whom one of the mandatory exclusion grounds otherwise applies.

Each situation must be judged on its merits, but the following situations are, on their own, unlikely to meet this test:

- where a bidder which should be excluded is offering a substantially better quality/more economical product or service;

- where there would otherwise be a lack of competition."

Regulation $58(7)$ of the $\mathrm{PC}(\mathrm{S}) \mathrm{Rs}$ also provides for the derogation from mandatory exclusion for the non-payment of taxes or social security contributions in cases where an exclusion would be clearly disproportionate, in particular:

- "where only minor amounts of taxes or social security contributions are unpaid; or

- where the economic operator was informed of the exact amount due following its breach of its obligations relating to the payment of taxes or social security contributions at such time that it did not have the possibility of fulfilling its obligations in a manner described in paragraph (5) before expiration of the deadline for requesting participation or, in open procedures, the deadline for submitting its tender."

\footnotetext{
${ }^{45}$ www.procurementjourney.scot/route-3/route-3-develop-documents-selection-award-andexclusion-criteria-exclusion-criteria.
} 
Describing this derogation, the Scottish Government explains: "An organisation must take a balanced view when deciding not to exclude on this basis. This could include consideration of the bidder's overall tax and social security obligations and the overall risk to the effective delivery of the contract. For example, there may be instances where an apparent 'minor amount' may significantly affect the liquidity of a bidder and its ability to perform the contract, or where the Organisation considers that sufficient time did exist for the outstanding amounts to be paid."

Regulation 8(3) of the 2016 Procurement Regulations also applies the first derogation on public interest grounds described above to contracts below the EU financial thresholds.

Since there is no mandatory exclusion for the non-payment of taxes or social security contributions for contracts below the EU financial thresholds, the second derogation described above is also not applicable to such contracts.

In Malta, the first derogation on public interest grounds is regulated in Regulation 197 of the PPR. It is interesting to note that contracting authorities may only use this derogation from mandatory exclusion with the prior approval of another body:

"On an exceptional basis only, the authority responsible for the tendering process may with the prior approval in writing of the Minister ${ }^{46}$ dispense from any exclusion mentioned under this Part for overriding reasons relating to the public interest."

Malta has not opted for the provision referred to in Article 57(3) of the Directive permitting EU Member States to allow for the possibility of not excluding an economic operator for the non-payment of taxes or social security contributions where such an exclusion would be clearly disproportionate.

Poland, Hungary and Latvia have not transposed the derogations permitted by the Directive.

In Latvia, however, exclusion on the grounds of the non-payment of taxes or social security contributions will not apply where the amount of overdue taxes and/or social security contributions does not exceed EUR 150.

In Estonia, this exclusion will not apply where the amount of overdue taxes as well as any interest charged does not exceed EUR 100, or where the tax arrears are being paid in instalments and such payments have been guaranteed in full.

\subsubsection{Discretionary grounds for exclusion}

In accordance with Article 57(4) of the Directive, contracting authorities may exclude from participation in a procurement procedure any economic operator to which one of the following situations applies:

a) $*^{47}$ where the contracting authority can demonstrate by any appropriate means a violation of applicable obligations referred to in Article 18(2), i.e. environmental, social and labour law established by Union law, national law, collective

\footnotetext{
46 The approval of the Minister responsible for Finance is required concerning a derogation on public interest grounds.

${ }^{47}$ The discretionary grounds for exclusion marked with an asterisk (*) were added in the 2014 Directive. Those not marked with an asterisk were also in the 2004 Directive.
} 
agreements or by the international environmental, social and labour law provisions;

b) where the economic operator is bankrupt or is the subject of insolvency or winding-up proceedings, where its assets are being administered by a liquidator or by the court, where it is in an arrangement with creditors, where its business activities are suspended or it is in any analogous situation arising from a similar procedure under national laws and regulations;

c) where the contracting authority can demonstrate by appropriate means that the economic operator is guilty of grave professional misconduct, which renders its integrity questionable;

d) *where the contracting authority has sufficiently plausible indications to conclude that the economic operator has entered into agreements with other economic operators aimed at distorting competition;

e) *where a conflict of interest within the meaning of Article $24^{48}$ cannot be effectively remedied by other less intrusive measures;

f) *where a distortion of competition from the prior involvement of the economic operators in the preparation of the procurement procedure, as referred to in Article $41^{49}$, cannot be remedied by other, less intrusive measures;

g) *where the economic operator has shown significant or persistent deficiencies in the performance of a substantive requirement under a prior public contract, a prior contract with a contracting entity or a prior concession contract which led to early termination of that prior contract, damages or other comparable sanctions;

h) where the economic operator has been guilty of serious misrepresentation in supplying the information required for the verification of the absence of grounds for exclusion or the fulfilment of the selection criteria, has withheld such information or is not able to submit the supporting documents required pursuant to Article 59; or

i) *where the economic operator has undertaken to unduly influence the decision-making process of the contracting authority, to obtain confidential information that may confer upon it undue advantages in the procurement procedure or to negligently provide misleading information that may have a material influence on decisions concerning exclusion, selection or award.

Given that this provision specifically addresses contracting authorities and not EU Member States, it clearly indicates that it is the contracting authorities that have the right to exclude based on the grounds specified above should they wish to do so, and that Member States cannot prohibit or otherwise limit this right.

On the other hand, it is important to note that the Directive allows Member States to implement the discretionary grounds (one or more listed above) as grounds for mandatory exclusion. Hungary, Latvia, Malta and Poland have opted for this possibility.

\footnotetext{
${ }^{48}$ Article 24 of the Directive regulates situations of conflict of interest.

${ }^{49}$ Article 41 of the Directive regulates the prior involvement of candidates or tenderers.
} 
The examples below indicate differences in the approach of national legislators. These may range from wording almost identical to that in the Directive (for example in the case of Scotland), to a much more detailed transposition of the discretionary grounds for exclusion (for example in the case of Poland). The examples also provide information on which discretionary grounds have been made mandatory in the national laws of the Member States studied. Lastly, the example of Hungary shows that this Member State has decided to provide for additional national discretionary grounds for exclusion related to the non-payment by contractors to their subcontractors.

In Scotland, Regulations 58(8)(a) to (j) of the PC(S)Rs list the discretionary grounds for exclusion, which virtually mirror the wording of discretionary grounds listed in the Directive. Regulation 9(5) of the 2016 Procurement Regulations allows that the same discretionary grounds for exclusion also apply to contracts below the EU financial thresholds. No discretionary grounds for exclusion listed in the Directive are mandatory in Scotland.

Apart from the mandatory grounds for exclusion that must be included in every procurement procedure, Scottish contracting authorities often include the discretionary grounds for exclusion in the procurement documents, namely the contract notice. For more information on how the grounds for exclusion are included in the contract notice, see the document "ESPD Standardised Statements" on the Procurement Journey website $^{50}$.

In Poland, Article 24.5 (1) to (8) of the PPL lists the discretionary grounds for exclusion. The same discretionary grounds apply to contracts below the EU financial thresholds but above the national financial thresholds (Article 4, paragraph 8 of the PPL).

Besides the discretionary exclusion on the grounds of the non-payment of taxes or social security contributions, the contracting authority may also exclude from the public procurement proceedings the following economic operators:

- "a contractor against whom a liquidation procedure has been initiated ${ }^{51}$, or the liquidation of its assets has been ordered by the court ${ }^{52}$, or a contractor whose bankruptcy has been declared;

- a contractor who culpably and materially violated its professional duties, which undermines its integrity, and particularly, if the contractor, as a result of deliberate action or gross negligence, failed to perform or improperly performed any contract, provided that the contracting authority is able to demonstrate the same by means of appropriate evidence;

- if the contractor, or persons referred to in Article 24.5, paragraph 1, point $14^{53}$, authorised to represent the contractor, is linked, in a manner specified in Article 17.1 points $2-4^{54}$, to:

\footnotetext{
${ }^{50}$ www.procurementjourney.scot/node/134/.

${ }^{51}$ The exclusion applies on condition that the composition agreement approved by the court in the restructuring proceedings provides for the satisfaction of creditors by the liquidation of the assets of the contractor.

${ }^{52}$ Pursuant to Article 332, section 1, of the Act of 15 May 2015 - Restructuring Law (Journal of Laws of 2015, items 978, 1 259, 1 513, 1830 and 1 844; and Journal of Laws of 2016, item 615).
} 
- the contracting authority,

- any person authorised to represent the contracting authority,

- any member of the tender committee,

- any person who has submitted the declaration referred to in Article 17.2a.

Unless it is possible to ensure the impartiality of the contracting authority in any way other than exclusion of a contractor from the proceedings;

- a contractor who, for reasons attributable to it, has not performed or improperly performed, to a significant extent, any earlier public procurement agreement or concession contract, which resulted in the termination of the agreement or award of compensation;

- $\quad{ }^{55}$ a contractor who is a natural person and who has been validly sentenced for an offence against employee rights or an offence against the environment, provided that the sentence involved detention, restriction of freedom or a fine of not less than PLN $3000^{56}$;

- *a contractor whose executive member of the management or supervisory body, partner of a general partnership or (professional) partnership, or general partner in a limited partnership or limited joint-stock partnership, or commercial proxy, has been validly sentenced for an offence referred to in the previous point;

- *a contractor against whom a final administrative decision has been issued with regard to the breach of obligations under the labour law, environmental law or social security legislation, provided that the sentence involved a fine of not less than PLN $3000^{57}$."

It is also important to note that the discretionary grounds for exclusion provided in Article 57(4), point $(a)^{58}$, of the Directive have been elaborated in much greater detail with regard to national crimes and offences in the fields of labour, environmental and social law and made partly mandatory and partly discretionary in the Polish PPL. The mandatory or discretionary character of the grounds depends on the degree of violation of obligations in the fields of environmental and labour law.

Article 24.1 (13a) of the PPL refers to crimes against environmental and labour law as mandatory grounds for exclusion. Thus a contracting authority must exclude an economic

53 This point in Article 24.5 of the PPL refers to an executive member of the managing or supervisory body, partner in a general/registered or (professional) partnership, or general partner in a limited partnership or limited joint-stock partnership, or commercial proxy.

${ }^{54}$ These points in Article 17.1 of the PPL refer to situations of potential conflict of interest.

${ }^{55}$ The three grounds for exclusion marked with an asterisk represent the specific discretionary grounds for exclusion for offences and violation of environmental and labour law.

${ }^{56}$ EUR 695.

${ }^{57}$ Ditto.

${ }^{58}$ The violation of applicable obligations is referred to in Article 18(2) of the Directive, i.e. environmental, social and labour law established by EU law, national law or collective agreements or by the international environmental, social and labour law provisions. 
operator if it has been validly sentenced for crimes against the rights of employees ${ }^{59}$ or for crimes against the environment ${ }^{60}$.

It is also important to note that according to Article 24.6 of the PPL, if the contracting authority provides for the discretionary exclusion of contractors, it must indicate the grounds for such exclusion in the contract notice, the terms of reference or the invitation to negotiate the contract.

Poland has also opted for the possibility of adding one or more discretionary grounds as grounds for mandatory exclusion in Article 24.1 (16) to (20) of the PPL. Those grounds for exclusion are related to the following:

- serious misrepresentation relating to the grounds for exclusion, selection or shortlisting;

- undue influence over the decision-making process, confidentiality, misleading information;

- distortion of competition due to prior involvement in the preparation of the procurement procedure;

- agreement to distort competition;

- violation of labour law, delegating work to foreigners unlawfully residing in the territory of Poland.

In Hungary, Article 63 of the PPL lists the discretionary grounds for exclusion. The same discretionary grounds may be applied to contracts below the EU financial thresholds but above the national financial thresholds, according to Articles 114(1) and 117(4) of the PPL. Three of the discretionary grounds for exclusion referred to in the Directive have remained discretionary in Hungary (failure to comply with environmental, social and labour obligations; grave professional misconduct; and poor prior performance), while other grounds have been made mandatory.

With regard to the grounds for exclusion related to grave professional misconduct, it is interesting to note that the PPL requires a final judicial or administrative decision that establishes such misconduct. The Directive, on the other hand, gives to the contracting authority the freedom to consider whether grave professional misconduct has occurred, before a final and binding decision has been rendered on the presence of mandatory exclusion grounds, where it can demonstrate, by any appropriate means, that the economic operator has violated its obligations, unless of course otherwise provided by national law.

One of the discretionary grounds for exclusion that has been made mandatory in Hungarian legislation requires the exclusion of an economic operator that:

"has committed an infringement of law established in a final and enforceable decision of the Hungarian Competition Authority or, in the event of a judicial review, by final court

\footnotetext{
${ }^{59}$ Articles 218-221 of the Act of 6 June 1997 - the Penal Code (Journal of Laws, item 553, as amended).

${ }^{60}$ Articles 181-188 of the Act of 6 June 1997 - the Penal Code (Journal of Laws, item 553, as amended).
} 
ruling $^{61}$, and was ordered to pay a fine; or if such infringement of law committed by the tenderer was established by another competition authority or court and at the same time the tenderer was ordered to pay a fine..."

These grounds for exclusion correspond to those provided in Article 57(4), point (d), of the Directive. However, unlike the provision of the Directive, which allows the exclusion to be applied "where the contracting authority has sufficiently plausible indications"; the Hungarian provision requires the infringement to be established by a final and enforceable administrative or judicial decision resulting in the imposition of a fine.

The CJEU dealt with this ground of exclusion in case C-470/13 Generali-Providencia Biztosító Zrt v. Közbeszerzési Hatóság Közbeszerzési Döntőbizottság. Although this case concerned the provision of Hungarian law transposing the 2004 Directive, the CJEU took the opportunity to refer to the new 2014 Directive, stating in paragraph 37:

"Furthermore, recital 101 in the preamble to Directive 2014/24, adopted after the material time, which states that contracting authorities should be able to exclude economic operators, inter alia, for serious professional misconduct, such as infringement of the competition rules, as such misconduct may render an economic operator's integrity questionable, shows that the cause for exclusion referred to in paragraph 35 above is considered justified in the light of EU law. Moreover, Article 57(4)(d) of that Directive makes clear and precise provision for that cause for exclusion."

The CJEU concluded that the principles of the freedom of establishment and the freedom to provide services did not preclude the application of national legislation that excluded the participation in a tendering procedure of an economic operator that had committed an infringement of competition law, as established by a judicial decision having the force of res judicata, for which a fine was imposed.

The Hungarian PPL also provides for additional national discretionary grounds for the exclusion of an economic operator that:

"in relation to a contract concluded as a result of an earlier procurement procedure or concession award procedure, failed to meet, towards their subcontractor, more than $10 \%$ of their payment obligation originating from a final or partial invoice and the breach of contract was established by final court ruling pronounced within the previous three years, although the party entering into the contract as contracting authority paid them in due time."

The contracting authority must identify in the contract notice the grounds for exclusion to be applied in accordance with the above provision.

In the case of contracts below the EU financial thresholds but above the national financial thresholds ${ }^{62}$, the contracting authority is entitled to prescribe in the contract notice the application of one or more mandatory or discretionary grounds for exclusion set out in Articles 114(1) and 117(4) of the PPL. No grounds other than those set out in the PPL may be prescribed. However, Article 62(1)g)-k),m) and q) of the PPL stipulates that

\footnotetext{
${ }^{61}$ This requirement is in accordance with Article 11 of the Competition Act (Act LVII of 1996 on the Prohibition of Unfair and Restrictive Market Practices) and with Article 101 of the Treaty on the Functioning of the European Union (TFEU).
}

${ }^{62}$ See the country chapter on Hungary, Section 4.2, for more information on the national financial thresholds. 
seven grounds for exclusion are mandatory in all procurement procedures below the EU thresholds but above the national thresholds.

In Latvia, Article 42(2)1 of the PPL provides for discretionary grounds for exclusion that are related only to poor prior performance ${ }^{63}$ :

"A contracting authority may exclude a candidate or tenderer from participation in a procurement procedure if a candidate or tenderer has not performed the procurement contract, framework agreement or concession contract concluded with the contracting authority and the contracting authority has used the right provided for in the public contract, framework agreement or concession contract to withdraw from the procurement contract, framework agreement or concession unilaterally."

It is important to note that not every instance of non-performance is considered as poor prior performance:

"A contracting authority shall take into account how essential is the infringement committed during the performance of the contract or framework agreement from which the contracting authority has withdrawn unilaterally, as well as the risk of non-performance of the procurement contract or framework agreement to be concluded."

It is interesting to note that this exclusion will no longer apply under certain conditions. The contracting authority may impose specific measures on the economic operator, such as:

- additional commitment performance security, for example a bank guarantee or insurance with regard to a specific sum of money;

- additional provisions in the contract that will make potential non-performance of essential terms of the contract or framework agreement economically unprofitable for the economic operator, for example a reduction of the intended advance payment, its postponement, or its revocation.

These discretionary grounds for exclusion, including the possibility of their derogation, may be applied only if they were indicated in the contract notice or in the procurement documents.

Latvia has also opted for the choice, referred to in Article 57(4) of the Directive, to implement one or more discretionary grounds as grounds for mandatory exclusion, in Article 42(1) of the PPL. Those grounds are related to the following:

- insolvency, bankruptcy, liquidation or suspension of an activity of the tenderer;

- infringement of competition rights;

- conflict of interest;

- prior involvement in the preparation of the procurement procedure;

- provision of false information to the contracting authority or failure to provide (requested) information.

\footnotetext{
${ }^{63}$ Grounds for exclusion related to poor prior performance are provided in Article 57(4), point (g), of the Directive.
} 
In practice, $27.04 \%$ of all economic operators excluded in 2015 were excluded based on serious misrepresentation in the provision of documents and 5.29\% were excluded on the basis of insolvency, bankruptcy, liquidation or suspension of an activity as a tenderer.

Provision of false information is, in practice, a ground for exclusion only where the false information is necessary to fulfil minimum requirements and where not taking it into account leads to non-compliance with the minimum requirements.

All of the grounds for exclusion are to be applied to the members of a group of candidates or tenderers, where applicable. Furthermore, all of the grounds for exclusion shall also apply to the following:

- the subcontractor, as indicated by the tenderer, where the value of the works to be performed or the services to be provided is at least $10 \%$ of the total value of the public works or services contract;

- the person, as indicated by the tenderer, on whose capacities the tenderer relies in order to prove the qualification requirements laid down in the contract notice or in the procurement documents.

However, in the latter case, the contracting authority shall request that the economic operator replace the subcontractor or the third person on whose capacities the economic operator relies. If the economic operator fails to propose a new subcontractor or a new third person within 10 business days following the request, the contracting authority shall exclude the economic operator from participation in the procurement procedure.

Concerning exclusion in practice, $2.72 \%$ of all exclusions of economic operators in 2015 were based on the existence of grounds for exclusion related to the subcontractor indicated by the tenderer.

The Latvian Procurement Monitoring Bureau $(\mathrm{PMB})^{64}$ has published a document entitled Information about the most common mistakes in procurement financed by EU funds ${ }^{65}$.

One of the issues discussed in the document concerns the application of grounds for exclusion related to prior involvement in the preparation of the procurement procedure. The PMB points out that procurement documents often contain the requirement that persons who themselves (or whose representatives) have participated in drawing up the procurement documents for a particular procurement procedure are prohibited from participating in that procedure, which therefore leads to the automatic exclusion of suppliers. The PMB emphasises that the supplier is not entitled to participate in the relevant procurement procedure only if its prior involvement would give it an advantage in that particular procedure, thus restricting competition. In addition, under the Article 11 (5) PPL, the contracting authority must allow such a supplier to prove, prior to its

64 The Procurement Monitoring Bureau (PMB) is a state administration institution that is supervised by the Ministry of Finance and is responsible for monitoring procurement compliance with legal requirements and conflicts of interest, preparing guidelines and instructions, and drafting standardised tender and contract documents. The PMB prepares annual reports to the Latvian Government on the monitoring and functioning of public procurement. The PMB also acts as a first-instance review body for complaints concerning public procurement. In addition, it carries out ex ante controls prior to the start of procurement procedures concerning projects co-financed by European Structural and Investment (ESI) funds.

${ }^{65}$ www.iub.gov.1v/sites/default/files/upload/Parkapumi_pirmsparbaudes_M_lapai_03_2016_0.pdf. 
possible exclusion, that there are no existing circumstances that would give it an advantage in the particular procurement procedure.

In the document, the PMB also tackles the issue of the automatic exclusion of economic operators that engage the same subcontractors or experts in the same procurement procedure. For the purpose of proper interpretation, the PMB draws attention to CJEU case law, in particular C-376/08 Serrantoni and C-538/07 Assitur. Taking into account the interpretations in these cases concerning conflict-of-interest issues, the PMB considers that the requirements, which are set by contracting authorities, do not conform to the CJEU's interpretations or to the principles of effective competition among suppliers. It concludes that relevant applicants could be excluded from a procurement procedure only if it has been established that the relationship between these applicants has influenced the prepared tenders, thus negatively affecting competition in the procedure, and the applicants have not been able to prove otherwise.

For more information on these and other issues, see the website of the $\mathrm{PMB}^{66}$.

\subsubsection{Derogation from the requirement of discretionary exclusion}

The Directive explicitly leaves it to EU Member States to require or to allow the possibility of a derogation from the discretionary exclusion of an economic operator that is bankrupt, insolvent, or in any other situation referred to in Article 57(4), point (b). The contracting authority has the option not to exclude an economic operator where it has been established that this economic operator would be able to perform the contract, taking into account the applicable national rules and measures on the continuation of business. Certain measures concerning bankruptcy, insolvency or similar proceedings enable a company to continue or to re-enter normal business activities. This situation means, for example, that the economic operator may still be able to participate and perform the contract in certain cases where the business in question is to be sold and continued as a going concern.

Poland has opted for this derogation in Article 24.5 (1) of the PPL: "An economic operator who, after the declaration of bankruptcy, entered into an arrangement approved under a valid court decision, if such arrangement does not provide for satisfaction of creditors by liquidation of the assets will not be excluded from procurement procedure."

Latvia has also opted for this derogation. However, Article 9(6) (1) of the PPL states that the derogation can be used only in national procurement procedures of an estimated value of between EUR 10000 and EUR 42000 for supply and service contracts, and between EUR 20000 and EUR 170000 for works contracts. Such an option is not applicable for procurement with an estimated value that is equal to or above the national thresholds indicated above.

Scotland, Hungary and Malta have not opted for this derogation.

\subsubsection{Moment of exclusion of economic operators from the procedure}

The mandatory and discretionary grounds for exclusion apply at all times during the procurement procedure.

\footnotetext{
${ }^{66}$ www.iub.gov.1v/lv/node/95.
} 
The rule is that before awarding a contract on the basis of the award criteria, the contracting authority must have verified that the tenderer is not subject to any of the grounds for exclusion and meets the required selection criteria. The exclusion must be applied at any point during the procurement procedure after such conduct occurs or when previous conduct becomes known.

In this respect, Article 57(5) of the Directive requires contracting authorities to exclude an economic operator at any time during the procedure in the case where the economic operator, in view of acts committed or omitted, either before or during the procedure, falls into one of the situations that constitute mandatory grounds for exclusion.

In the case of discretionary grounds for exclusion, contracting authorities may exclude, or may be required by Member States to exclude, an economic operator at any time during the procedure where the economic operator, in view of acts committed or omitted either before or during the procedure, is in one of the situations that constitute discretionary grounds for exclusion.

In Scotland, Regulation 58(9) of the PC(S)Rs requires a contracting authority to exclude an economic operator if the authority becomes aware, at any time during the procedure, that the economic operator is, in view of acts committed or omitted either before or during the procedure, in one of the situations leading to mandatory exclusion. Regulation 58(10) allows a contracting authority to exclude an economic operator where it becomes aware at any time in the procedure that the grounds for discretionary exclusion apply because of acts committed or omitted by the economic operator either before or during the procedure. This provision also applies to discretionary exclusion on the grounds of the non-payment of taxes or social security contributions, referred to in Regulation 58(4).

In Poland, Article 24.12 of the PPL allows a contracting authority to exclude an economic operator at any stage of the public procurement procedure. This permission applies to both mandatory and discretionary grounds for exclusion.

In Malta, Regulation 196 of the PPR requires the authority responsible for the tendering process to exclude an economic operator at any time during the procedure leading to the award of the contract when it transpires that the actions committed or omitted by the economic operator, either before or during the procedure, constitute mandatory or discretionary grounds for exclusion (Regulations $192^{67}, 193^{68}$ and $194^{69}$ ).

In Estonia, Article 38(1), point (2) of the PPL requires the authority responsible for the tendering process to exclude an economic operator at any time during the procedure leading to the award of the contract, when it transpires that the actions committed or omitted by the economic operator, either before or during the procedure, constitute mandatory or discretionary grounds for exclusion. Article 38(1), point (4) requires that in the case of taxes or social security contributions, the economic operator will be excluded if it has arrears on the date of commencement of the procurement procedure. In addition, after declaring a tender successful, but before awarding the public contract, the contracting authority will verify the absence of tax arrears of the winning tenderer only as from the date indicated by the contracting authority. It is important to mention that an

\footnotetext{
${ }^{67}$ Exclusion on the grounds of a conviction.

${ }^{68}$ Exclusion for failure to abide by obligations concerning taxes or social contributions.

${ }^{69}$ Other grounds for exclusion.
} 
economic operator does not have to submit any documentary evidence. It is the contracting authority that verifies this information on the basis of public data available in a tax database.

In Hungary, the contracting authority shall exclude an economic operator if it transpires that the economic operator is subject to any of the grounds for exclusion to be applied in the procedure.

\subsubsection{Self-cleaning}

The 2014 Directive introduced "self-cleaning" measures. Despite the existence of one or more relevant grounds for exclusion, either mandatory or discretionary, self-cleaning measures allow economic operators to rehabilitate themselves on the basis of strict conditions set forth in Article 57(6) of the Directive, and to take part in procurement procedures.

Recital 102 of the Directive states that "allowance should be made for the possibility that economic operators can adopt compliance measures aimed at remedying the consequences of any criminal offences or misconduct and at effectively preventing further occurrences of the misbehaviour".

Accordingly, any economic operator that is in one of the situations constituting mandatory grounds for exclusion, Article 57(1), or discretionary grounds for exclusion, Article 57(4), may provide evidence to the effect that the measures it has taken are sufficient to demonstrate its reliability despite the existence of relevant grounds for exclusion.

The following self-cleaning measures can generally be regarded as effective, if the economic operator has proved that it has:

- paid or undertaken to pay compensation in respect of any damage caused by the criminal offence or misconduct;

- clarified the facts and circumstances in a comprehensive manner by actively collaborating with the investigating authorities;

- taken concrete technical, organisational and personnel measures that are appropriate to prevent further criminal offences or misconduct.

Recital 102 gives further guidance on the details regarding technical, organisational and personnel self-cleaning measures: "...the severance of all links with persons or organisations involved in the misbehaviour, appropriate staff reorganisation measures, the implementation of reporting and control systems, the creation of an internal audit structure to monitor compliance and the adoption of internal liability and compensation rules."

An economic operator must provide all of the relevant evidence in order to prove that it has taken sufficient self-cleaning steps. The measures taken by the economic operator shall then be evaluated, taking into account the gravity and particular circumstances of the criminal offence or misconduct.

If such evidence is considered to be sufficient, the economic operator concerned shall not be excluded from the procurement procedure on those grounds alone. However, the contracting authority can deny the request for participation in the procedure if it considers that the measures are insufficient. In that event, the economic operator must be provided with a statement giving the reasons for that decision. 
In implementing requirements on self-cleaning measures, Member States have the discretion to determine the exact procedural and substantive conditions that will be applicable. In particular, they are free to decide whether to allow the individual contracting authority to carry out the relevant assessment or to entrust another authority, on a central level (see the example of Hungary, Section 4.2) or a decentralised level, with this task.

Self-cleaning is not available to economic operators that have been excluded from participating in procurement or concessions award procedures by way of a final judgement ${ }^{70}$ during the period of exclusion resulting from that judgement. This restriction applies, however, only in the Member States where the judgement is effective. In other Member States, on the other hand, such economic operators can use self-cleaning measures.

In Scotland, Regulations 58 (13) to (17) of the $\mathrm{PC}(\mathrm{S}) \mathrm{Rs}$ provide for self-cleaning measures. These measures also apply to contracts below the EU financial thresholds (Regulations 8 and 9 of the 2016 Procurement Regulations):

"Any economic operator that is in one of the situations referred to in paragraph $(1)^{71}$, (3)(b) ${ }^{72}$ or $(8)^{73}$ may provide evidence to the effect that measures taken by the economic operator are sufficient to demonstrate its reliability despite the existence of a relevant ground for exclusion."

The remainder of the provision virtually repeats the wording of Article 57(6) of the Directive. In Scotland, it is the contracting authority's responsibility to evaluate the measures taken by an economic operator and to make a decision as to whether the economic operator has or has not been self-cleaned:

"If the contracting authority is satisfied that the evidence proves that the measures are sufficient, the authority must not exclude the economic operator from the procurement procedure.

Where the contracting authority considers that the measures are insufficient, the authority must give to the economic operator a statement of the reasons for that decision."

General comment: The exclusion of economic operators has not been a common practice in Scotland, and it rarely occurs. A self-declaration in relation to the grounds for exclusion was standard practice prior to the transposition of the Directive. On the rare occasion that an economic operator has declared that grounds for exclusion apply, the individual contracting authority has sometimes adopted a self-cleaning approach, considering the nature and gravity of the grounds for exclusion and then making the decision whether to exclude the economic operator based on the information that it has available. This process was not regulated by legislation prior to the transposition of the Directive as described above.

${ }^{70}$ In some jurisdictions, exclusion from participation in a procurement procedure can be an additional sanction in criminal court decisions.

${ }^{71}$ Grounds for mandatory exclusion for one or more criminal offences.

${ }^{72}$ Blacklist Regulations exclusion.

${ }^{73}$ Discretionary grounds for exclusion. 
In Hungary ${ }^{74}$, the model introduced on 1 November 2015 by the new PPL does not give freedom to contracting authorities, but instead delegates the decision on self-cleaning to the Public Procurement Authority (PPA) in a centralised manner. The legal practice of self-cleaning is evolving gradually.

In the interest of legal certainty, the decision was made to transfer, through the PPL, the powers related to self-cleaning to the PPA. Thus the PPL does not entrust contracting authorities with decision making related to the evaluation of the reliability of the economic operator concerned. The PPA or the court, in the event of a judicial review, may declare that the measures taken by the economic operator meet the conditions prescribed by law and accordingly serve as verification of the economic operator's reliability. If the economic operator has been self-cleaned, it cannot be excluded from a procurement procedure in the future, even if grounds for exclusion exist. The contracting authority has no opportunity of expressing a different viewpoint, since it must accept the decision of the PPA.

According to the legislator, the decisions of the PPA may provide guidance to bidders in the evaluation of future self-cleaning measures. Indirectly, therefore, self-cleaning managed centrally by the PPA is an element that facilitates improvement. In this way, practice will evolve in a uniform manner, and the various interpretations of the law by individual contracting authorities will be replaced by one governing interpretation of the law. The PPA publishes on its website ${ }^{75}$ the list of successful self-cleaning processes, and the number of such processes is increasing constantly. The PPA does not publish any information on unsuccessful processes and initiatives.

Article 64 of the PPL allows economic operators to carry out self-cleaning in the event of any mandatory or discretionary grounds for exclusion other than those mentioned in Article $62(1)(b)^{76}$ and (f) ${ }^{77}$. Self-cleaning is available to a tenderer, candidate, subcontractor or other entity on whose capacities the economic operator relies.

The economic operator wishing to participate in a procurement procedure submits, together with the ESPD, the final decision of the PPA or, in the case of a review thereof, the final judicial decision establishing that the economic operator subject to the given grounds for exclusion is reliable. The contracting authority shall accept such a decision, as it has no discretion in this regard.

Under the detailed rules of the procedure stipulated in Article 188 of the PPL, an economic operator may submit an application to the PPA to verify that the measures that it has taken sufficiently demonstrate its reliability, despite the existence of grounds for exclusion. The evidence of the measures taken is submitted, together with the application.

\footnotetext{
${ }^{74}$ Extracts taken from Tatrai, T. (2017), Self-cleaning - Hungarian Case.

${ }^{75}$ http://kozbeszerzes.hu/tevekenysegek/megbizhatosagot-megallapito-hatarozatok/.

${ }^{76}$ Exclusion on the grounds of non-conformity with obligations to pay taxes and social security contributions.

${ }^{77}$ Restriction of the activity of a tenderer during the period of prohibition by final court ruling under Article 5(2)(b) or (c) or (g), as appropriate in the given procurement procedure, of the Act CIV of 2001 on Measures Applicable to Legal Entities in Criminal Law, or by final court ruling for a similar reason and in a similar manner by another court.
} 
The types of measures for self-cleaning are regulated in the same Article 188 of the PPL, and they replicate the measures provided in Article 57(6) of the Directive.

The extent of severity of the breach of the law has an impact on the decision of the PPA. As the decision making of the PPA covers a broad range of criminal acts, conflicts of interest and provision of false data, a decision is possible only after weighing the individual circumstances. The PPA needs to be aware of the unique circumstances of the individual case in order to arrive at a decision. This decision-making process is regulated in paragraph 3 of Article 188:

"The measures referred to in paragraph 2 shall be evaluated by the Authority taking into account the gravity and particular circumstances of the criminal offence, misconduct or other infringement."

The PPA decides within a very short time - 15 days from the receipt of the application whether the measures taken by the economic operator are appropriate. In duly justified cases, this time limit may be extended once, but by no more than 15 business days. The PPA may invite the applicant to make a further statement or attach further evidence or documents, allowing an appropriate period of time for such clarification.

The decision needs to be unambiguous, that is, it must not contain any conditions or requirements for the economic operator to take additional measures.

If the economic operator disagrees with the PPA's decision, it has two possible courses of action. It may initiate a new process of self-cleaning if it intends to demonstrate its reliability by reference to any measures taken subsequent to the rejection of its previous application. It may also turn to the court within 15 days following the receipt of the PPA's decision. The court must take its decision no later than 60 days after the submission of the economic operator's request to reverse the decision of the PPA.

The time limits are very short, and therefore the PPA and the court have little time to review the cases. Together with a court review, the case can be closed in about three months.

Article 188 of the PPL also deals with conflicts of interest. That is, a person whose right or legitimate interest is directly affected by the case, or who cannot be expected to assess the case objectively, may not be involved in the examination of the application.

\section{Practical experiences in applying self-cleaning}

Economic operators began to use the opportunity of self-cleaning relatively soon after 1 November 2015, which resulted in a number of interesting and instructive cases. The practice of self-cleaning is still evolving. The PPA puts emphasis primarily on certificates and the appropriate arguments. One of the fundamental pillars of reliability based on the available data is that the applicant should demonstrate its reliability with the appropriate documents, ideas and activities.

The two cases concerning self-cleaning, i.e. STRABAG Property and Facility Services and Recom Park Kft., presented in the country chapter on Hungary, illustrate the approach taken by the Hungarian PPA in this context.

The practice of centralised management of self-cleaning by economic operators established in Hungary could be endorsed and considered as a way forward in the establishment of national practices in other Member States. Centralised management ensures the avoidance of arbitrary decision-making on self-cleaning by individual contracting authorities and goes beyond specific procurement procedures. It enables the 
uniform application of adopted decisions throughout the entire national procurement system, covering all contracting authorities and all procedures. The decision-making process carried out centrally by professionals, with legal protection against unfavourable decisions, ensures a higher level of legal certainty than decision making at the level of the individual contracting authority. In this way, the reliability and integrity of the national procurement system in Hungary can be ensured. Taking into consideration the existing institutional framework, namely the network of fully functioning public procurement offices/agencies, various options are provided for establishing similar practices without having to set up new institutions to carry out the task of managing the self-cleaning processes of economic operators.

\subsubsection{Conditions for the implementation of the grounds for exclusion}

Article 57(7) of the Directive explicitly requires EU Member States to specify, by national law, any regulation or administrative provision, taking into account EU law, the conditions for the implementation of the provisions on the mandatory and discretionary grounds for exclusion. This requirement is intended to ensure a transparent system for the selection of economic operators. The points considered below are only some of the implementing conditions that are likely to be addressed by Member States.

Article 57(7) provides that the maximum periods of exclusion during which the mandatory grounds for exclusion will be relevant are to be determined by the Member States. That period must not exceed five years, calculated as of the date of the conviction by final judgement (Member States may provide for a shorter period).

Article 57(7) of the Directive also provides that the Member States are to determine the maximum periods of exclusion during which the discretionary grounds for exclusion listed above will be relevant. The period shall not exceed three years, calculated as of the date of the relevant event (Member States may provide for a shorter period).

An exception to these maximum periods applies to cases where the period of exclusion has been set by final judgement. In such cases, the limitation of five years for mandatory grounds or three years for discretionary grounds may be exceeded.

The maximum period of exclusion only applies if the economic operator has not taken self-cleaning measures to demonstrate its reliability, despite the existence of mandatory or discretionary grounds for exclusion.

Most of the Member States studied here have decided to set a maximum period of mandatory exclusion of five years, calculated as of the date of conviction by final judgement for relevant criminal offences. Latvia has provided for a shorter period of three years. In Estonia, the exclusion applies for as long as the data concerning the conviction has not been deleted from the criminal records database.

Similarly, for discretionary exclusion, most of the Member States have decided to set a maximum period of exclusion of three years from the relevant event. In Malta, this period is two years.

The Directive does not set a maximum period of time for the application of the grounds for exclusion established under Article 57(2), which concern a breach of obligations to pay taxes and social security contributions. Therefore, an economic operator must be or may be excluded, unless it has paid the obligations due or entered into an arrangement regarding their payment. Nevertheless, Poland and Latvia have set a maximum period of three years of exclusion in these circumstances as well. 


\subsection{Selection}

The Directive makes it explicit that, in addition to excluding unsuitable economic operators by applying mandatory and discretionary grounds for exclusion, contracting authorities may require candidates and tenderers to meet selection criteria related to their suitability to pursue a professional activity, economic and financial standing, and technical and professional ability.

Selection criteria are used in the process of deciding which economic operators meet the standards set by the contracting authority and demonstrate that they are able to perform the contract.

Although contracting authorities are not required to establish selection criteria in a specific procurement procedure, in practice, authorities often wish to check at least some elements of the financial and technical position of companies before awarding them a contract. This verification is necessary because it is important for a contracting authority to ensure that it will be entering into a contract with an economic operator that has the ability to perform and complete the contract. A contracting authority may want to check, for example, that an economic operator has sufficient financial resources, relevant experience, skills and technical resources.

In some cases, however, a contracting authority may choose to not use any selection criteria, for example when awarding a contract in a field that is heavily regulated by law or where the contract is for a low-value, low-risk purchase. What the contracting authority does and does not ask is determined by both the nature of the contract itself and by the authority's knowledge of the market. Where the contracting authority applies selection criteria, it will then exclude from the procurement process those economic operators that do not satisfy the requirements.

A common problem encountered in practice is the use of inappropriate selection criteria, such as criteria that are disproportionate, discriminatory or unrelated to the subject matter of the contract. The use of inappropriate selection criteria can have a negative effect on competition, reducing the number of economic operators whose tenders are considered or that can be invited to tender. A similar problem arises when the minimum requirements set by the contracting authority are too high. It is quite common, for example, for contracting authorities to set financial requirements that have the effect of excluding SMEs or new start-ups, which reduces competition and may mean that the contracting authority does not obtain the best value for money.

Article 58 of the Directive covers the selection stage of the procurement process. In compliance with the principle of transparency, a contracting authority must indicate in the contract notice the selection stage criteria to be applied, the minimum requirements for participation, and any relevant information to be provided by the economic operator. Under no circumstances may the selection criteria that have already been set be changed or waived. At this stage, the selection criteria must be applied as they stand. The criteria used to select economic operators must be limited to those that are appropriate to ensure that an economic operator has the capacities or abilities to perform the contract to be awarded. These criteria must be related and proportionate to the subject matter of the contract.

In general, the Directive lets contracting authorities decide whether they require economic operators that satisfy the minimum capacity levels and what those levels are. Where a contracting authority decides to set minimum capacity levels, these levels must 
be related and proportionate to the subject matter of the contract, and they must be set out in the contract notice.

Suitability to pursue the professional activity: Article 58(1)(a) and (2) of the Directive provide that a contracting authority may verify whether economic operators are generally suitable and fit to carry out the professional activity by asking them to prove that they are enrolled on trade or professional registers in their Member State of establishment. The registers and corresponding declarations or certificates of each Member State are listed in Annex XI of the Directive. See the chapter on Means of proof, Section 2.6, for a detailed discussion of this issue.

Economic and financial standing: The Directive provides in Article 58(1)(b) and (3) that a contracting authority may consider the economic and financial standing of economic operators. The economic and financial standing criteria are used to assess whether economic operators have the necessary economic and financial capacity to perform the contract.

The requirement of a certain minimum yearly turnover is one of the areas that the 2014 Directive regulates in more detail than the previous directives. Article 58(3) permits contracting authorities to require that economic operators have a specific minimum yearly turnover, including a minimum turnover in the subject matter of the contract. As a general rule, the Directive prohibits contracting authorities from demanding a minimum yearly turnover higher than twice the estimated contract value. A contracting authority may require a larger turnover, but only in justified cases, such as circumstances related to the special risks involved due to the nature of the works, services or supplies concerned. The main reasons for such a requirement should also be indicated in either the procurement documents or the individual report on the procurement procedure.

The provisions on minimum turnover are new and were not included in the 2004 Directive. According to Recital 84 of the 2014 Directive, "overly demanding requirements concerning economic and financial capacity frequently constitute an unjustified obstacle to the involvement of SMEs in public procurement". Minimum turnover requirements that are disproportionate have been identified as one of these obstacles. Article 58(3) of the 2014 Directive aims to remove this obstacle, where appropriate.

Article 58(3) also provides that contracting authorities may require economic operators to submit information on their annual accounts, showing the ratios between assets and liabilities, for instance. This requirement can be met where the contracting authority specifies the methods and criteria for such verification in the procurement documents. The methods and criteria must be transparent, objective and non-discriminatory.

The provisions on ratios are also new and were not included in the 2004 Directive. Recital 84 of the 2014 Directive states that "a positive ratio showing higher levels of assets than of liabilities could provide additional evidence that the financial capacity of economic operators is sufficient".

Contracting authorities need to understand the impact of the criteria and minimum levels that they choose to apply to a particular contract. An analysis of the relevant marketplace and of the economic operators in the marketplace is required to ensure that the criteria do not have the effect of limiting competition. For example, in some markets, such as new technologies, economic operators may be new start-ups or may find themselves in a heavy investment stage in their business cycle. The required asset/liability ratios therefore need to be considered carefully. Similarly, minimum turnover may not be the best way of 
assessing an economic operator's suitability in a market where many SME economic operators are active. Contracting authorities need to ensure that they have the competency to both set appropriate selection criteria and assess the means of proof submitted by economic operators against those criteria.

Contracting authorities may also require an appropriate level of professional risk indemnity insurance. What the appropriate level may be will differ depending on the subject matter of the contract. In some cases, professional risk indemnity insurance may not be necessary. Contracting authorities should consider this requirement on a case-by-case basis.

The means of proof of economic and financial standing are listed in the Directive in Part 1 of Annex XII. The CJEU considered the means of proof of economic and financial standing under the 2004 Directive and confirmed that it was not an exhaustive list and that Member States had discretion to set additional requirements in that regard ${ }^{78}$. The CJEU has also stated that it was not the purpose of the rules on economic and financial standing to constrain Member States as to the level or manner in which they fixed requirements ${ }^{79}$.

The 2014 Directive reflects the standpoint of the CJEU that the list of means of proof of economic and financial standing is not exhaustive. See the chapter on Means of proof, Section 2.6, for detailed discussion of this issue.

Technical and professional ability: Article 58(1)(c) and (4) provides that a contracting authority may also consider the technical and professional ability of economic operators. The technical and professional ability criteria aim to ensure that economic operators possess the necessary human and technical resources and experience to perform the contract according to an appropriate standard of quality.

The CJEU considered the means of proof of technical and professional ability under the 2004 Directive and confirmed that it was an exhaustive list. The 2014 Directive reflects the standpoint of the CJEU that the list of the means of proof of technical ability is exhaustive.

Article 60(4) deals with the proof of an economic operator's technical ability. It states that one or more of the means listed in Annex XII, Part II, of the 2014 Directive may provide this proof. The list in that annex is similar to the list provided in the 2004 Directive. The 2014 Directive adds a new reference to supply chain management and tracking systems. The assessment of educational and professional qualifications is subject to the condition that these matters are not evaluated as award criteria. This condition reflects the new provisions in the 2014 Directive permitting the use of award criteria concerning educational and professional qualifications only in specified cases.

In relation to quality assurance standards and environmental management standards, the Directive states in Article 60 that contracting authorities may not require means of proof other than those referred to in Articles 60 and 62.

See the chapter on Means of proof, Section 2.6, for a detailed discussion of this issue.

\footnotetext{
${ }^{78}$ C-218/11 Édukövízig and Hochtief Construction.

${ }^{79}$ C-76/81 Transporoute v Ministère des travaux publics, C-29/86 Bellini, and C-31/87 Beentjes v State of Netherlands.
} 
Contracting authorities must consider carefully the criteria for technical and professional ability that they choose to apply and ensure that these criteria are relevant and proportionate to the subject matter of the contract. As is the case with the criteria for economic and financial standing, it is also important to ensure that the criteria and means of proof required are necessary and do not adversely affect competition. To use the example of a contract involving new technologies, economic operators may, in general, have completed only a very limited number of contracts of the same type. In that event, the assessment of an economic operator's suitability based simply on the number of contracts it has completed may disadvantage newer entrants into the market and may not result in the best outcome in terms of quality.

As mentioned above, the Directive does not oblige contracting authorities to use all of the selection criteria. National practices vary, as can be seen below.

In Scotland, contracting authorities have discretion as to whether and which selection criteria to use. In some cases they may decide to not use the economic and financial criteria but to base their selection solely on technical and/or professional ability. This approach should help to promote competition by setting fewer limitations on which economic operators are allowed to participate in the procurement procedure. The Scottish Government Guidance under the Procurement Reform (Scotland) Act 2015 at section 5.5.3 confirms that:

"A contracting authority should take a rounded, commercial approach to considering what is a relevant criterion in respect of economic and financial standing. For some contracts, an assessment of an economic operator's economic or financial standing may not be required, for example where the contract is low value, low risk or payment does not occur until delivery of the contract is complete. $"{ }^{\prime 80}$

In Hungary, it is not mandatory to use the economic and financial standing criteria for contracts above the intermediary national threshold, including contracts above the EU thresholds. For contracts above the intermediary national thresholds it is mandatory to use technical criteria.

In Latvia, the PPL stipulates only framework rules for the use of selection criteria. However, the rulings of the review body, as well as guidelines and explanatory documents, have established some more detailed rules that must be respected by contracting authorities. These rules assist in providing clarity and certainty for both contracting authorities and economic operators in terms of setting the selection criteria and the means of proof for the selection stage.

Some important examples of detailed rules established in this way follow. For example, whereas the PPL requires three-year reference periods for turnover and experience requirements, the ruling of the review body confirmed that:

- economic operators established within the past three years were entitled to rely on turnover accumulated during their period of activity. The level of turnover should not exceed twice the contracting value, unless objective justification could be provided;

${ }^{80}$ www.gov.scot/Publications/2016/03/8410. 
- experience in terms of years could never be used as a selection criterion. Instead, contracting authorities had to refer to projects carried out by a tenderer during the previous three years. To ensure the principle of proportionality, contracting authorities were not allowed to demand projects with higher parameters (financial value, scope, etc.) than the subject matter of the contract and, as a general rule, contracting authorities should not refer to more than three such projects;

- in the context of economic and financial standing, if a price/equity ratio was used as a qualification criterion, it should not, as a general rule, be higher than one.

In Malta, contracting authorities have the freedom to decide whether to use selection criteria and which criteria to apply. In practice, economic and financial standing are generally assessed on the basis of yearly turnover, and yearly accounts of the preceding years are requested of economic operators. In terms of technical and professional ability, contracting authorities tend to request evidence of both a minimum number of contracts and a minimum total value of contracts completed. Such selection criteria are applicable for above national thresholds.

In Estonia, contracting authorities are required to use a minimum of one selection criterion for economic and financial standing and one selection criterion for technical and professional ability. Contracting authorities are required to use selection criteria listed in PPL Article 40 (economic and financial standing) and PPL Article 41 (technical and professional ability). Contracting authorities have the freedom to decide which of the listed selection criteria to use and also to use more than one of the listed selection criteria.

In conclusion, it is important to note that contracting authorities are not obliged to use selection criteria if it is inappropriate and irrelevant to do so. They can also choose which selection criteria to use, as there is no obligation to use all of the criteria. Where contracting authorities do use selection criteria, those criteria should be aimed at selecting the most qualified economic operators, and they should not have the effect of inappropriately limiting competition. Minimum requirements need to be set to encourage participation by economic operators rather than acting as a disincentive. In each case, the decision as to when and which selection criteria to use and at what level to set minimum requirements needs to be based on a thorough understanding on the part of the contracting authority of the particular market and the impact of the criteria on competition. When selection criteria and minimum requirements are specified, they must be clear so that economic operators understand the conditions that they need to meet.

\subsection{Reduction of the number of otherwise qualified candidates to be invited to participate}

Article 65 of the Directive lays down the rules on the reduction of the number of otherwise qualified candidates to be invited to participate in two-stage procedures: the restricted procedure, competitive procedure with negotiation, competitive dialogue, and innovation partnerships.

When conducting these two-stage procedures, a contracting authority may limit the number of candidates that it will invite to tender or with which it will conduct negotiations, dialogue or discussions (as appropriate, depending on the particular procedure). The rules on the reduction of the number of otherwise qualified candidates are essentially the same as those provided under the 2004 Directive, Article 44 (3) and (4). 
The aim of the process of reduction of the number of otherwise qualified candidates is to allow the contracting authority to select the candidates that are the best qualified to deliver the contract and to invite them to participate in the second stage of the procedure.

Inviting a limited number of qualified candidates to participate in the second stage of the procedure can result in keener competition between economic operators with regard to both price and quality elements in the tender/bid submission. For more complex projects, the bidding process can be costly and time consuming for both economic operators and contracting authorities. This situation may result in some economic operators dropping out if they consider that they have a very limited chance of success, for example if there is a large number of bidders. Reducing the number of economic operators participating in the process can help to maximise competition by reducing bid costs and/or retaining a smaller number of economic operators that are fully engaged in the procurement procedure.

Where a contracting authority wishes to reduce the number of otherwise qualified candidates, it must indicate in the contract notice or in the invitation to confirm interest "the objective and non-discriminatory criteria or rules" and also "the minimum number of candidates they intend to invite and, where appropriate, the maximum number".

The minimum number must be no fewer (but can be more) than five in a restricted procedure, and no fewer (but can be more) than three in a competitive procedure with negotiation, a competitive dialogue or an innovation partnership. In any event, the number of candidates invited must be sufficient to ensure genuine competition.

Where the number of qualified candidates is lower than the minimum number specified in the contract notice or invitation to confirm interest, the contracting authority does not have to cancel the procedure. It may continue the procedure by inviting the candidates that are participating in the procedure and that have the required capabilities.

An ongoing debate is focusing on whether (1) the criteria used for shortlisting ("shortlisting criteria") must overlap with the selection criteria used to establish the qualification of candidates; or (2) different criteria may be used. The first option means that when selecting candidates, a contracting authority must take into account their relative financial or technical capacity, assuming that those selection criteria were used. For the second option, the shortlisting criteria do not need to be the same as those used to establish whether the candidates are qualified. Alternative and/or additional criteria can also be used.

The case law of the CJEU ${ }^{81}$ decided in the early 1990s supported the first option and confirmed that the criteria or rules used to limit the number of candidates must be based on information related to the personal position of the contractor and the minimum economic and technical standards. This decision meant that when selecting candidates, a contracting authority had to take into account their relative financial or technical capacity. This analysis would result in a relative ranking of the qualified candidates, thus enabling the contracting authority to identify the candidates that were the best qualified to perform the contract to be awarded.

The prevailing interpretation, however, is that according to the wording of Article 65 of the Directive, the shortlisting criteria do not need to be the same as the selection criteria.

${ }^{81}$ C-360/89, Commission v Italy (1992) E.C.R. I-3401 (see in particular Paragraph 18). 
Alternative and/or additional criteria (chosen from among the admissible selection criteria listed by the Directive) can also be used. These additional criteria are to be aimed at identifying the candidates that are the best qualified to perform the contract. Therefore, it is argued, the criteria must relate to the contract to be awarded ${ }^{82}$.

In order to identify the relative ranking of the qualified economic operators and to determine which economic operators to invite to participate from among the qualified candidates, a contracting authority may also develop methodologies based on a weighting/scoring system.

It is sometimes argued that random selection, for example by drawing lots, is a permitted method for shortlisting candidates, subject to adequate monitoring and verification. Random selection may be an "objective" process, but it does raise concerns about transparency and equal treatment. In addition, it does not ensure that the most qualified candidates are shortlisted and is not a recommended approach.

It has been common practice in Scotland for contracting authorities to use two-stage procedures, in particular the restricted procedure. The publication of the objective and non-discriminatory criteria or rules that the contracting authority intends to apply in order to reduce the number of otherwise qualified candidates to be invited to participate (shortlisting) is therefore a live issue. In interviews conducted as part of this study, contracting authorities and economic operators confirmed that a standard approach used for shortlisting is to use the relative ranking approach, applying the selection criteria and selecting the most qualified (highest-scoring) candidates for the shortlist. Little evidence was given during the interviews of the use of additional or different criteria in the shortlisting stage.

In Hungary, it is common to use procedures that include two phases, in particular the negotiated procedure. The contracting authority is to provide objective criteria, which are in line with the basic principles laid down in PPL and on the basis of which the tenders are ranked. The contracting authority may indicate which certificates are to be submitted by the economic operators regarding their compliance with those objective criteria, in support of the self-declaration included in the ESPD. In practice, it is common to base the objective criteria for shortlisting on the selection criteria. For example, if the requirement for selection is to possess a minimum of one reference, then the objective criterion for shortlisting will be based on the number of references provided. The more references an economic operator provides, the higher it will be ranked. This approach means that economic operators must include as many references as possible in anticipation of the shortlisting process.

In Latvia, the provisions on the reduction of otherwise qualified candidates are set out in point 29 of the regulations of the Cabinet of Ministers "The process of procurement procedures and design contest" (28 February 2017: No. 107). These provisions stipulate that contracting authorities should use only objective and non-discriminatory criteria, which need to be set in advance in the tender documentation. The tender documents must clearly indicate the minimum (selection) requirements and the criteria for shortlisting. In practice, the option of reducing the number of candidates is not used very often in Latvia. When contracting authorities choose to use it, however, they usually refer to extensive

\footnotetext{
${ }^{82}$ For further discussion of these alternative interpretations presented by Steen Treumer, see Burgi, M., M. Trybus and S. Treumer, eds. (2016), Qualification, Selection and Exclusion in EU Procurement, DJØF Publishing, Chapter 1, pp. 29-32.
} 
experience that exceeds the minimum requirements set out in the tender documents for the purpose of shortlisting candidates. For example, in order to comply with the selection requirements, an economic operator must refer to at least two projects with particular characteristics that it has previously undertaken. An economic operator would be given additional points in the shortlisting process if it referred to more than two projects (i.e. relevant experience in addition to the two mandatory projects) in its request to participate in the procurement procedure.

In conclusion, when a contracting authority undertakes a shortlisting process, it is very important for it to bear in mind the purpose of shortlisting when deciding on the "objective and non-discriminatory criteria or rules" to be used. The purpose of the shortlisting process is to allow the contracting authority to select the candidates that are the most qualified to deliver the contract. All of the criteria and rules used for shortlisting must therefore be appropriate, in terms of obtaining the outcome of selecting the most qualified candidates, as well as relevant to the contract. These criteria and rules should not be subjective. The use of inappropriate or irrelevant criteria or rules may result in a shortlist of candidates that are not the most qualified to participate. Inappropriate shortlisting includes the use of random selection, which is unlikely to achieve the aim of selecting the most qualified candidates. The use of inappropriate or irrelevant criteria or rules may limit competition and reduce the likelihood of an outcome resulting in the greatest value for money. Transparency is also important, so that economic operators understand the way in which the shortlisting process will be conducted, which criteria will be used (including the kind of methodology or scoring system that will be used and how it will be applied), and the proposed minimum number of economic operators to be shortlisted.

\subsection{European Single Procurement Document}

\subsubsection{Self-certification - overview}

Many economic operators find that a major obstacle to their participation in procurement procedures is the necessity of presenting a substantial number of certificates or other documents related to exclusion and to the selection criteria. One objective of the 2014 Directive is to decrease the administrative burdens of contracting authorities and economic operators in public procurement procedures. The most important step in that direction is introducing self-certification during the submission of tenders or requests to participate in the public procurement procedure. Rather than submit a set of required certificates or documents, the new Directive provides for self-certification by economic operators, confirming that the grounds for exclusion do not apply to them. Self-certification uses a form known as the ESPD.

After the evaluation of tenders, only the tenderer to which the contracting authority has decided to award the contract needs (at the request of the contracting authority) to submit up-to-date, supporting certificates and documents. The time for the request to submit documents is set up before the contract is awarded. Nevertheless, the contracting authority may ask tenderers and candidates at any point in the procedure to submit all or some of the supporting documents, if they deem it necessary to ensure the proper conduct of the procedure. The Directive regulates the scope and types of certificates and documents, while the detailed rules (e.g. concerning the form of the documents or their validity) remain within the competence of Member States. 
The acceptance of the implemented solution of the self-declaration is revolutionary for countries with "traditional" administrative procedure regulations. The self-declaration can potentially reduce the cost of participation in the procedure for bidders and improve the efficiency and economy of the procedure for the contracting authority. This solution does not particularly determine the length of the procedure. The successful tenderer needs time to prepare and submit requested statements and certificates in the last stage of the procedure, but this problem can be resolved at least partially by the instruments enabling direct access to official databases by contracting authorities (for more information, see the chapters on Means of proof and Official lists and blacklists, Sections 2.6 and 1.9).

The ESPD is a tool designed to limit administrative requirements and simplify the public procurement process. Instead of documents issued by public authorities or other entities, economic operators submit a completed ESPD. According to Article 59 of the Directive, the ESPD constitutes preliminary evidence in the form of a self-declaration of the economic operator, attesting to its fulfilment of the following conditions:

- It is not in one of the situations stipulated in the Law as providing grounds for the economic operator to be excluded.

- It meets the relevant selection criteria set by the contracting authority.

- It fulfils, where applicable, the rules and criteria set by the contracting authority for shortlisting.

The ESPD is to be used in procedures where, depending on the characteristics of the procedure, the participation of more than one economic operator is foreseen ${ }^{83}$.

\subsubsection{Contents}

In accordance with Article 59(2) of the Directive, the Commission adopted Commission Implementing Regulation (EU) 2016/7 of 5 January 2016 establishing the standard form for the ESPD ${ }^{84}$. The standard form consists of a few tables with questions and answers.

\footnotetext{
${ }^{83}$ Negotiated procedures with one economic operator (single-source procedures) do not require the submission of an ESPD. In Annex 1, Instructions to the Commission Implementing Regulation 2016/7, footnote 5 stipulates: "The situation is more complex in respect of negotiated procedures without prior publication, provided for under Article 32 of Directive 2014/24/EU and Article 50 of Directive 2014/25/EU, as these provisions apply to very different realities. Requesting an ESPD would constitute an unnecessary administrative burden or be otherwise inappropriate 1) where only one, predetermined participant is possible, for the two Directives, respectively Article 32, paragraph 2(b), paragraph 3(b), paragraph 3(d) and paragraph 5 of Directive 2014/24/EU and Article 50, letters (c), (e), (f) and (i) of Directive 2014/25/EU; and 2) because of the urgency involved, as stipulated in respectively Article 32(2)(c) of Directive 2014/24/EU and Article 50, letters (d) and (h) of Directive 2014/25/EU, or because of the particular characteristics of the transaction for supplies quoted and purchased on a commodity market, as stipulated in Article 32(3)(c) of Directive 2014/24/EU and Article 50, letter (g) of Directive 2014/25/EU. On the other hand, the ESPD would play its role in full and should be requested in the remaining cases, which are characterised by the possible participation of more than one participant and the absence of urgency or particular characteristics linked to the transaction; such is the case in respect of Article 32, paragraph 2(a), paragraph 3(a) and paragraph 4 of Directive 2014/24/EU and Article 50, letters (a), (b) and (j) of Directive 2014/25/EU."
}

${ }^{84}$ Official Journal of the European Union (OJEU), L 3, 6 January 2016, p. 16. 
The economic operator must answer yes/no questions or provide the required information.

The standard form includes the following parts and sections:

\section{Part I. Information concerning the procurement procedure and the contracting authority or contracting entity}

In this part, the contracting authority provides basic information on the procurement procedure: date and number of publication of a notice in the Official Journal, identity of the contracting authority, and short description of the procurement.

\section{Part II. Information concerning the economic operator}

In this part, the basic information concerning the economic operator should be provided, including information on the representatives, if any, empowered to represent it for the purposes of the procurement.

In the event that the economic operator is registered on an official list of approved economic operators, it is not obliged to complete Part III, Exclusion criteria, or Part IV, Selection criteria, in the sections referring to the criteria covered by the official registration list (for more information, see the chapter on Official lists and blacklists, Section 2.9).

The economic operator must state if it is participating in the procedure together with other economic operators (group of economic operators). In that event, the names of all of the members of the group should be provided. The other opportunity provided by law is for economic operators to rely on the capacity of other entities, which should also be declared in the ESPD.

The contracting authority may also request information concerning any subcontractors with capacity on which the economic operator relies. The ESPD form enables the provision of such information.

\section{Part III. Exclusion criteria}

Part III is divided into four sections. Section A contains statements concerning the grounds for exclusion related to criminal convictions, the application of which is mandatory pursuant to Article 57(1) of the Directive. Section B refers to the grounds for exclusion related to the payment of taxes or social security contributions (the application of these grounds is mandatory pursuant to Article 57(2) of the Directive in the case of a final and binding decision). Section $\mathrm{C}$ includes statements connected with the grounds related to insolvency, conflicts of interest, or professional misconduct. Section D refers to other grounds for exclusion that may be foreseen in the national legislation of the contracting authority's Member State (for more information, see the chapter on Grounds for exclusion, Section 1.2).

Economic operators declare whether the relevant grounds for exclusion do or do not apply. If the economic operator is in a situation resulting in its exclusion, it is obliged to provide details (e.g. in the event that the economic operator does not meet all of its obligations related to the taxes in the country in which it is established or in the Member State of the contracting authority) it must present data on the amount concerned, the way in which the breach has been established (judicial or administrative decision or other means), date of the decision, length of the period of exclusion if it is established directly in a decision, etc. All this data should enable the contracting authority to make its decision on exclusion. In cases where self-cleaning could be applied, the economic 
operator describes the self-cleaning measures it has taken (for more information, see the chapter on Self-cleaning, Section 1.2.8).

When the information on the grounds for exclusion can be verified based on certificates or other supporting documents that are available electronically, the economic operator provides the name of the issuing body, its web address and references to the documentation available.

\section{Part IV. Selection criteria}

In this part, the contracting authority can choose between two possible means of declaration by the economic operator that it meets the selection criteria described in a notice and in tender documentation. The first is a global indication for all of the selection criteria in Section $\alpha$. The other way requires the completion of Sections A to D, where the economic operator provides detailed information concerning the selection criteria concerned (which have been required by the contracting authority in the relevant notice or tender documentation).

Section A refers to suitability to pursue the professional activity. Section B contains statements relating to economic and financial standing. Section $\mathrm{C}$ refers to technical and professional ability, while Section $\mathrm{D}$ concerns quality assurance schemes and environmental management standards.

\section{Part V. Reduction of the number of otherwise qualified candidates to be invited to tender}

In procedures with pre-qualification, contracting authorities may select participants on the basis of objective and non-discriminatory rules and criteria. The information required for the reduction of the number of otherwise qualified candidates invited to participate should be provided in Part V of the ESPD (for more information, see the chapter on Reduction of the number of otherwise qualified candidates to be invited to tender, Section 1.4).

\section{Part VI. Concluding statements}

In the last part of the ESPD form, the economic operator is required to confirm the following:

- The information stated in the ESPD is accurate and correct.

- It is able, upon the request of the contracting authority, to provide the certificates and other forms of documentary evidence in reference.

- It formally consents to give access to the contracting authority to documents supporting the information provided in the ESPD for the purposes of the procurement procedure.

As mentioned above, the economic operator is not obliged to submit the supporting documents with the ESPD. With some exceptions, only the economic operator to which the contract is to be awarded will be asked to provide these documents. Where the contracting authority can obtain the supporting documents directly by accessing a database that is available free of charge, the ESPD shall contain the information required for this purpose, such as the Internet address or other identification data. The incorporation of special sections into the ESPD form is envisaged for that purpose.

\subsubsection{Forms of participation in a procurement procedure}

The ESPD must be submitted together with a tender or a request to participate by: 
- the economic operator when it participates on its own;

- the members forming a group of economic operators participating in the procedure (including temporary associations), each submitting a separate ESPD setting out the information required in Part II, Information about the economic operator; Part III, Grounds for exclusion; Part IV, Selection criteria, and Part V, Reduction of the number of qualified candidates;

- the economic operator and the entities with the capacity on which the economic operator relies, each submitting a separate ESPD setting out the information required; the other entities should consider in particular Part III, Grounds for exclusion, and relevant points in Part IV, Selection criteria.

\subsubsection{The form of the European Single Procurement Document}

As of 18 October 2018, the ESPD will be provided exclusively in electronic form. In the transition period, some EU Member States have decided to allow the use of a paper-based ESPD. In that case, the economic operator must submit an ESPD that has been signed by a representative person.

The European Commission (EC) provides a free Internet service for buyers, bidders and other parties interested in filling in the ESPD electronically ${ }^{85}$ ("e-ESPD"). The online form can be completed, printed, and then sent to the buyer together with the rest of the bid. If the procedure is carried out electronically, the e-ESPD can be exported, stored and submitted electronically. An e-ESPD provided in a previous public procurement procedure can be reused, as long as the information contained in the e-ESPD remains correct.

The ESPD Internet service enables contracting authorities to create an ESPD template (or to reuse a template created for a previous procedure) adjusted to the procedure, e.g. in the parts relating to selection criteria and discretionary grounds for exclusion. The e-ESPD will then be made electronically available, together with the other tender documents. The economic operator can import this template, fill in the necessary data (or have the data pre-filled via the respective e-procurement tool in use), download, print if needed and submit the e-ESPD with the tender or the request to participate. The electronic form of the ESPD can be used in different procedures (with only minor adjustments), representing a distinct savings for economic operators in the cost and time needed to prepare for participation in a public procurement procedure.

\subsubsection{Transposition to national legislation}

All EU Member States are obliged to transpose the concept of initial self-declaration (in the form of the ESPD) to national legislation. As the 2014 Directive and the Commission Implementing Regulation concerning the ESPD are strict and detailed, little room is allowed for individual interpretation. Nevertheless, the administrative bodies responsible for public procurement in the countries studied were striving to ensure that the transition would be smooth and easily comprehensible for contracting authorities and economic operators. Transposition activities were adjusted to the level of development of the public procurement system (including the use of electronic communication) and to the customs of the stakeholders. Some of these activities are described below.

\footnotetext{
${ }^{85}$ https://ec.europa.eu/tools/espd.
} 
In May 2017, the EC published a report on "the review of the practical application of the European Single Procurement Document (ESPD)" ${ }^{\prime 86}$. The main conclusions were that, as of 31 December 2016, use of the ESPD was broadly limited to paper versions and the EC's e-ESPD service. The EC's e-ESPD service reported frequent usage. The report noted that few Member States had developed a national solution for the ESPD, although several planned to do so in the medium term. The majority of Member States did not intend to use the ESPD for below EU threshold procedures or for concession contracts.

The report noted that there was insufficient practical experience to assess the need for amending the ESPD, partly due to late transposition of the 2014 Directives in a number of Member States. By 31 December 2016, 22 Member States had started to use the ESPD. Table 3 in the Annex to the report does, however, list the benefits and disadvantages reported by Member States in the use of the ESPD. The report noted that a thorough assessment should be undertaken in 2019 to provide a comprehensive review of the situation, based on several years of application of the ESPD. The EC confirmed in the report that it would continue to support use of the ESPD in Member States and, in particular, support its integration with national e-procurement systems and registers/databases of certificates/evidences. It is planned that the EC's e-ESPD service will be discontinued after April 2019, by which time Member States should have fully implemented e-procurement and the ESPD into their national systems.

In Hungary, the contracting authority will make available electronically, together with the procurement documents, the $\mathrm{ESPD}^{87}$ related to the procedure, which will contain:

- the data required in Part I of the standard ESPD form enabling the identification of the procedure or, in the case of the publication of a notice, the notice number published in the Official Journal of the European Union (OJEU);

- the grounds for exclusion to be applied in the procedure;

- the suitability criteria established in the procedure, except when the contracting authority accepts a simple declaration made by the economic operator.

The contracting authority is allowed to use the Internet service established by the EC. Consequently, in a given procurement procedure, an economic operator obtains, together with other tender documents, the ESPD form adjusted to the needs of the procedure (e.g. without sections that are irrelevant) such as selection criteria that are not defined or discretionary grounds for exclusion that do not apply. This service makes the process more efficient for both contracting authorities and economic operators. The electronic form also facilitates the use of the ESPD by the economic operator, as well as the evaluation of the ESPD by the contracting authority. Hungary has adopted a phased approach to transposition of the ESPD. On 15 April 2018, the procedure described above changed, when the ESPD became part of the Hungarian Electronic Public Procurement System. From 15 April 2018, contracting authorities make the ESPD available electronically, using the Electronic Public Procurement System, to publish the ESPD in Hungarian and English. Where a contracting authority completes the ESPD in a language

\footnotetext{
${ }^{86}$ http://eur-lex.europa.eu/legal-content/en/ALL/?uri=CELEX:52017DC0242.

${ }^{87}$ Chapter II of Government Decree 321/2015 (30 October) (GD) on the means of certifying suitability and the non-existence of the grounds for exclusion, as well as the definition of public procurement technical specifications in contract award procedures.
} 
other than Hungarian or English, it will not be able to use the Electronic Public Procurement System. It will therefore need to use another means, such as the e-ESPD Internet service established by the EC.

The Scottish Government issued a special national ESPD (Scotland) for use by all contracting authorities for contracts above the EU financial thresholds as of 18 April $2016^{88}$.

A template version in Microsoft Word of the ESPD (Scotland) can be downloaded from the Procurement Journey website. For contracting authorities using the Public Contracts Scotland tender portal, an online version of the ESPD is available. Contracting authorities are not permitted to amend the ESPD (Scotland) or to add new questions.

The ESPD (Scotland) differs slightly from the ESPD provided by the European Commission Implementing Regulation. Two types of changes were introduced. First, changes were made to reflect the language and terms that are more commonly used in Scotland. For example, the ESPD (Scotland) refers to "supported businesses" rather than "sheltered workshops". The ESPD also includes instructions with definitions and detailed guidelines, with sections that may be applied in a given procurement procedure. The second type of change concerned special developments in Scotland. For example, a sub-question in the ESPD (Scotland) asks specifically whether the bidder has breached the Employment Relations Act 1999 (Blacklist) Regulations 2010, as such a breach constitutes mandatory grounds for exclusion in Scotland.

The Polish solution concerning the ESPD is different from the Scottish one. The form of the ESPD introduced by the Commission Implementing Regulation must be used without any changes. The contracting authority is obliged to set in a contract notice or in tender documentation the specific requirements to be met by economic operators. The contracting authority may demand that an economic operator present the facts, which are limited to the applied grounds for exclusion, selection criteria, and criteria for shortlisting. The means of stipulating which parts of the ESPD should be completed remains within the competences of the contracting authority. This means it may list sections or prepare instructions using the ESPD form. In practice, economic operators are often unable to determine which parts of the ESPD should be completed and how the information should be presented.

As the ESPD is a new instrument for all Member States, the administrative bodies responsible for public procurement have been striving to explain the ESPD and to establish good practice in its use.

In Hungary, the legal provisions provide instructions for contracting authorities on how to prepare the ESPD and for economic operators on how to complete it ${ }^{89}$.

The Scottish form of the ESPD Scotland is accompanied by:

- ESPD Standardised Statements Document: standardised statements have been developed to assist procurement officers in setting selection criteria and minimum standards in a consistent way, and to provide a clear link between the selection

${ }^{88}$ In Scotland, Article 60 of the Public Contracts (Scotland) Regulations 2015 sets out the provisions concerning the ESPD.

${ }^{89}$ The Hungarian instructions are found in Articles 4-7 of Decree 321/2015. 
criteria set out in the contract notice and the questions that bidders will be required to answer in the ESPD (Scotland);

- ESPD Frequently Asked Questions, including the most common questions concerning the preparation and submission of the ESPD (Scotland). ${ }^{90}$

In Poland, the Public Procurement Office (PPO) has published guidelines on its website explaining the ESPD and how to prepare for the procurement procedure ${ }^{91}$. The main concern raised by the ESPD form, as published in the OJEU, is that the terminology used in the form mirrors the terminology used in the Directive, which to some extent is different from the wording applied in the national law. In its guidelines, the PPO attempts to clarify the interpretation of certain terms.

The recent entry into force of the new provisions on the ESPD did not allow for an in-depth assessment of practice in this study. However, it is possible to comment on problems concerning the previous practices in each country.

In Scotland, the ESPD has replaced the standard Pre-Qualification Questionnaire (sPQQ) previously used by Scottish contracting authorities. The sPQQ included self-declarations by economic operators on the grounds for mandatory and discretionary exclusion, and this concept is therefore not new for contracting authorities in Scotland. The SPQQ also included standard selection-stage questions, which permitted contracting authorities to request a considerable amount of information related to technical and professional capacity, and to ask a number of optional, additional questions. The main problem that has been observed is related to the change of the well-established practice with the SPQQ, where detailed questions on selection criteria were allowed (for example, referring to defined financial ratios). The ESPD is not structured to permit this level of detail in relation to selection criteria. With the introduction of the ESPD, contracting authorities are obliged to describe the selection criteria in the contract notice instead of in the SPQQ, a requirement that offers less flexibility. In published documents, the Scottish Government has emphasised the importance of the information provided in the contract notice advertising the opportunity.

In Poland, mandatory use of the ESPD in electronic form is required as of April 2018. The contracting authorities have a positive view of the use of the online ESPD service provided by the EC. This service makes it possible to limit the ESPD form to questions that are relevant to the particular procedure. The sections referring to discretionary grounds for exclusion or selection criteria that are not applied in the particular procedure do not appear in the ESPD form prepared by the contracting authority for the given procurement. From April 2018, contracting authorities submit the ESPD in electronic form.

${ }^{90}$ ESPD documents (Scotland), ESPD Standardised Statements Document, ESPD Frequently Asked Questions, www.procurementjourney.scot/route-3/route-3-develop-documents-espdscotland.

${ }^{91}$ www.uzp.gov.pl/baza-wiedzy/jednolity-europejski-dokument-zamowienia. 


\subsection{Means of proof}

\subsubsection{Introduction}

While the ESPD is only a preliminary proof of eligibility to execute a public procurement contract, the certificates, statements and other means of proof confirming the absence of grounds for exclusion and the fulfilment of the selection criteria may be required by the contracting authority in the course of the process.

The general concept of the Directive assumes that the tenderer to which the contracting authority has decided to award the contract shall, at the request of the contracting authority, submit up-to-date supporting documents. The timing of the request for submitting documents is stipulated as being before the award of the contract, as stipulated in Article 59(4)(2) of the Directive. In spite of this provision, the contracting authority may ask the tenderer at any point during the procedure to submit all or part of the supporting documents, if the contracting authority considers this necessary in order to ensure the proper conduct of the procedure, as stipulated in Article 59(4) of the Directive. In particular, such a request might be made in two-stage procedures - restricted procedures, competitive procedures with negotiation, competitive dialogues, and innovation partnerships - in which contracting authorities may invite only qualified candidates to the next stage in the procedure. The same situation applies to the use of electronic auctions. Requiring the submission of supporting documents just as candidates are selected avoids the problematic situation in which contracting authorities invite candidates that, at the award stage, prove to be unable to submit the supporting documents, thus depriving other qualified candidates from participating.

The approach to the request for evidence (certificates, documents and statements of various kinds) must be balanced. On the one hand, it is necessary to verify the capacity of the tenderer, with the aim of ensuring the proper execution of the contract. On the other hand, adopting too bureaucratic an approach carries its own risks. A highly formalistic approach to requesting proof can create a barrier, especially for SMEs, to participating in public procurement procedures. The results of a survey published in the report Evaluation of SMEs' Access to Public Procurement Markets in the EU $U^{92}$ show that SMEs consider onerous paperwork requirements as one of their most common problems (46\% of companies experienced this problem regularly or often). By comparison, the technical and financial qualification requirements were less frequently seen as problematic (14\% and $19 \%$ respectively).

Article 60(1) of the Directive restricts the ability of contracting authorities to request certificates, statements, etc., to documents serving as a means of proof, as referred to in paragraphs 2, 3, and 4 of Article 60(1) and in Annex XII.

The provisions of the Directive refer directly to the contracting authority (and not to a member country), which is responsible for setting out the means of proof required in advance - in a contract notice and in tender documentation. Annex V of the Directive, Part $\mathrm{C}$, Information to be included in contract notices, stipulates that the contract notice must include "a list and brief description of criteria regarding the personal situation of economic operators that may lead to their exclusion and of selection criteria; minimum

92 Evaluation of SMEs' Access to Public Procurement Markets in the EU, final report submitted by GHK and Technopolis within the framework of ENTR/04/093-Lot 1, 2014. 
level(s) of standards possibly required; indication of required information (self-declarations, documentation)". The contracting authority is bound by the published contract notice or tender documentation. It cannot change, waive or add new requirements for the means of proof.

The CJEU has made it clear that it is the responsibility of the contracting authority to comply strictly with the conditions relating to the conduct of the procurement procedure, which it has itself laid down in advance ${ }^{93}$. An interesting decision in the context of the selection of economic operators is C-336/12 Manova. In this case, the contracting authority required candidates to submit specific information with their requests to participate. This information included copies of the candidates' balance sheets. Two of the nine candidates did not submit copies of their balance sheets by the set deadline. The contracting authority subsequently asked these two candidates to submit the missing documents. Both candidates did so, were appointed to the framework agreement and were awarded contracts. One of the unsuccessful economic operators participating in the process challenged the award decisions. The referring court asked the CJEU "whether the principle of equal treatment meant that, after the deadline for applications to take part in a tendering procedure, a contracting authority may not ask a candidate to forward a copy of its most recent balance sheet if the candidate did not provide such documents with its application".

The CJEU considered the question in the light of the equal treatment and transparency principles. The CJEU referred to the general principles and rules that it had laid down in C-599/10 SAG ELV Slovensko and Others, where it had considered the issue of permitted clarification in the context of award criteria. It also confirmed the general rule that a tender could not be amended after it has been submitted. It applied this reasoning in C-599/10 to the selection stage and concluded that a contracting authority could request the correction or amplification of the details of an application, but only on a limited and specific basis. This request is permitted as long as it relates to details or information that are objectively shown to pre-date the deadline for submission of applications. The CJEU also emphasised an overriding condition: the request for missing information must not unduly favour or disadvantage the candidate concerned. The CJEU looked at the facts in C-336/12. It confirmed that the balance sheets already existed and were published prior to the deadline for applications. It concluded that by accepting copies of the balance sheets after the closing date for applications, the contracting authority was not in breach of the principle of equal treatment. The CJEU explained that this would not be the case, however, if the contract documents stated that applications would be rejected if the specific documents were not provided with the application.

The CJEU looked at a similar issue in C-42/13 Cartiera dell'Adda. In this case, the contracting authority set out in the procurement documents a series of grounds on which an economic operator might be excluded from participation in the procurement process. One of the grounds for exclusion related to documents or statements that the economic operator had submitted to demonstrate compliance with general and special requirements. Where the documents or statements were incomplete or irregular, the economic operator could be excluded, unless the irregularity was of a purely formal nature. One of the economic operators was excluded because it failed to submit a statement certifying that its technical director had no relevant criminal proceedings pending against him and had

${ }^{93}$ Case C-496/99 P Commission v CAS Succhi di Frutta (2004), ECR I-3 801, paragraph 115. 
not been convicted of specific offences. This economic operator subsequently submitted the required statement, but only after it had been excluded from the tender procedure. It was also subsequently established that there was no need for the economic operator to submit a statement in respect of the technical director concerned because he had been incorrectly identified in the tender.

The CJEU applied the principles of equal treatment and the obligation of transparency. It confirmed that the exclusion was permitted. The decision to exclude was in accordance with the conditions for participation set out in the procurement documents. The CJEU confirmed, based on the facts of the case, that "in so far as the contracting authority takes the view that the omission is not a purely formal irregularity, it cannot allow the economic operator subsequently to remedy the omission in any way after the expiry of the deadline for submitting bids".

The judgements of the CJEU refer to the previous Directive, adopted in 2004. The change of attitude regarding the timing of the submission of documents and the limitation to one or specified economic operators do not influence this general rule. If the contracting authority stipulates the grounds for exclusion or the selection criteria and related means of proof, it is bound by the provisions of the contract notice or tender/procurement documentation, and it cannot refrain from requesting suitable certificates or documents.

The change of approach introduced by Directive 2014 generally consists of the change of timing for the submission of the means of proof (after evaluation of the tenders, but before the award of the contract) and the obligatory scope of requests limited to the one tenderer that submitted the most advantageous tender. The implementation of the Directive's provisions on the means of proof remains within the competences of countries. However, the Directive promotes the system that limits the obligations of economic operators (e.g. wherever possible). Information on the current situation of an economic operator must be obtained from official databases. The contracting authority shall not ask for still up-to-date documents or statements that it already possesses from previous procedures (Recital 85 of the 2014 Directive).

\subsubsection{Grounds for exclusion}

The rules for confirming that there are no grounds for exclusion are described in Article 60(2) of the Directive.

As for the mandatory grounds for exclusion listed in Article 57(1) of the Directive, where the economic operator or members of the administrative, management or supervisory body have been convicted by final judgement for certain reasons, the contracting authority shall accept an extract from the relevant register, such as judicial records, or, failing that, any equivalent document issued by a competent judicial or administrative authority in the country where the economic operator is established.

For confirmation of the absence of grounds for exclusion - breach of obligations related to the payment of taxes or social security contributions (described in Article 57(2) of the Directive), bankruptcy, insolvency or winding-up procedure, suspension of business activities or any analogous situations arising from a similar procedure, as described in Article 57(2)(b) of the Directive - the contracting authority should accept a certificate issued by the competent authority in the country concerned.

In cases where no documents or certificates are issued in the country concerned, or where the documents or certificates do not cover all of the cases specified by law, these means of proof may be replaced by a declaration on oath or, in countries without any provision 
for a declaration on oath, by a solemn declaration of the person concerned before a competent judicial or administrative authority, notary or competent trade or professional body.

For evidence of the absence of grounds for exclusion, other than those mentioned above, the general rule applies that the economic operator may rely on any appropriate means of proof.

As the provisions of the Directive are rather detailed and clear, the transposition to national legislation does not leave room for discretion as far as the types of certificates or documents are concerned. The national legislation refers to administrative systems established in each country to gather data concerning the following:

- bankruptcy, liquidation, or similar processes in progress

- tax arrears

- social contribution payments

- criminal record of a member of the administrative, management or supervisory body of the economic operator, or of a person with powers of representation.

In some countries, other databases gather information that is convenient for the evaluation of the specific grounds for exclusion.

In Hungary, for example, the contracting authority can consult the following:

- the database available on the homepage of the Public Procurement Authority (PPA) concerning a prohibition from participating in procedures imposed by the Public Procurement Arbitration Board;

- the register kept by the Labour Inspectorate enabling the verification of grounds for exclusion specified in Article 62(1)(1) of the PPL (Public Procurement Act, see above);

- the database available on the website of the Hungarian Competition Authority regarding its decisions and final court rulings on the infringements of competition law;

- the register of National Tax and Customs Administration;

- the company register of the Ministry of Justice.

Nowadays, all databases are run electronically, and they can be used to improve the process of verifying the absence of grounds for exclusion.

In this respect, the most efficient method, of all the countries studied, is that of Estonia. The model, based on electronic access to databases maintained by administrative or judicial bodies, eliminates any activity on the part of the economic operator ${ }^{94}$. The use of

94 According to Article 38(2)2) of the PPA, the contracting authority may exclude from the procurement procedure a tenderer or candidate that has not submitted the data or documents requested by the contracting authority about the absence of grounds for exclusion of the tenderer or candidate from the procurement procedure. This exclusion applies unless the data or documents are available to the contracting authority, without incurring any major expenses, on the basis of public information kept in a database. 
existing databases maintained by administrative or judicial bodies responsible in the field ensures that the information gathered is up-to-date and reliable.

All procurement procedures are conducted electronically on the e-procurement platform ${ }^{95}$. The platform gives contracting authorities, directly and free-of-charge, access to the following databases:

- Central Commercial Register - an online service based on the central database of Estonian registration departments of the courts ${ }^{96}$; the gathered data provides, with other information, reference to the status of the economic operator, including any liquidation, bankruptcy or winding-up procedures, the person empowered to represent the entity, and annual financial reports;

- Criminal Records Database - a state database of data on persons convicted of crimes and the penalties they incurred; information on persons convicted in a final judgement who are members of a management or supervisory body of the economic operator;

- Tax Register - a database gathering information on taxpayers ${ }^{97}$; in the service, data is available on state taxes, local taxes are not included; the dedicated database for local taxes is available electronically, merged with the e-procurement platform for Tallinn City;

- Register of Business Activities - an online service with data on licences and notifications for specific business activities ${ }^{98}$.

In the Central Commercial Register, the contracting authority can also verify the selection criteria on economic standing using financial reports, while in the Register on Business Activities, the data on special permits for conducting the activity can be verified.

Procurement officers conducting a procedure log into the e-procurement platform using an e-signature. Then they issue a request to one of the above-mentioned registers to retrieve information on an economic operator that has submitted a tender or a request to participate in the procedure. The information is available immediately, in the form of an extract from the relevant register in .pdf format.

\footnotetext{
${ }^{95}$ https://riigihanked.riik.ee.

${ }^{96} \mathrm{https}$ ://ariregister.rik.ee.

${ }^{97} \mathrm{https}: / / a p p s . e m t a . e e / e-s e r v i c e$.

${ }^{98}$ https://mtr.mkm.ee/?m=1.
} 


\section{Figure 1. E-procurement platform in Estonia}

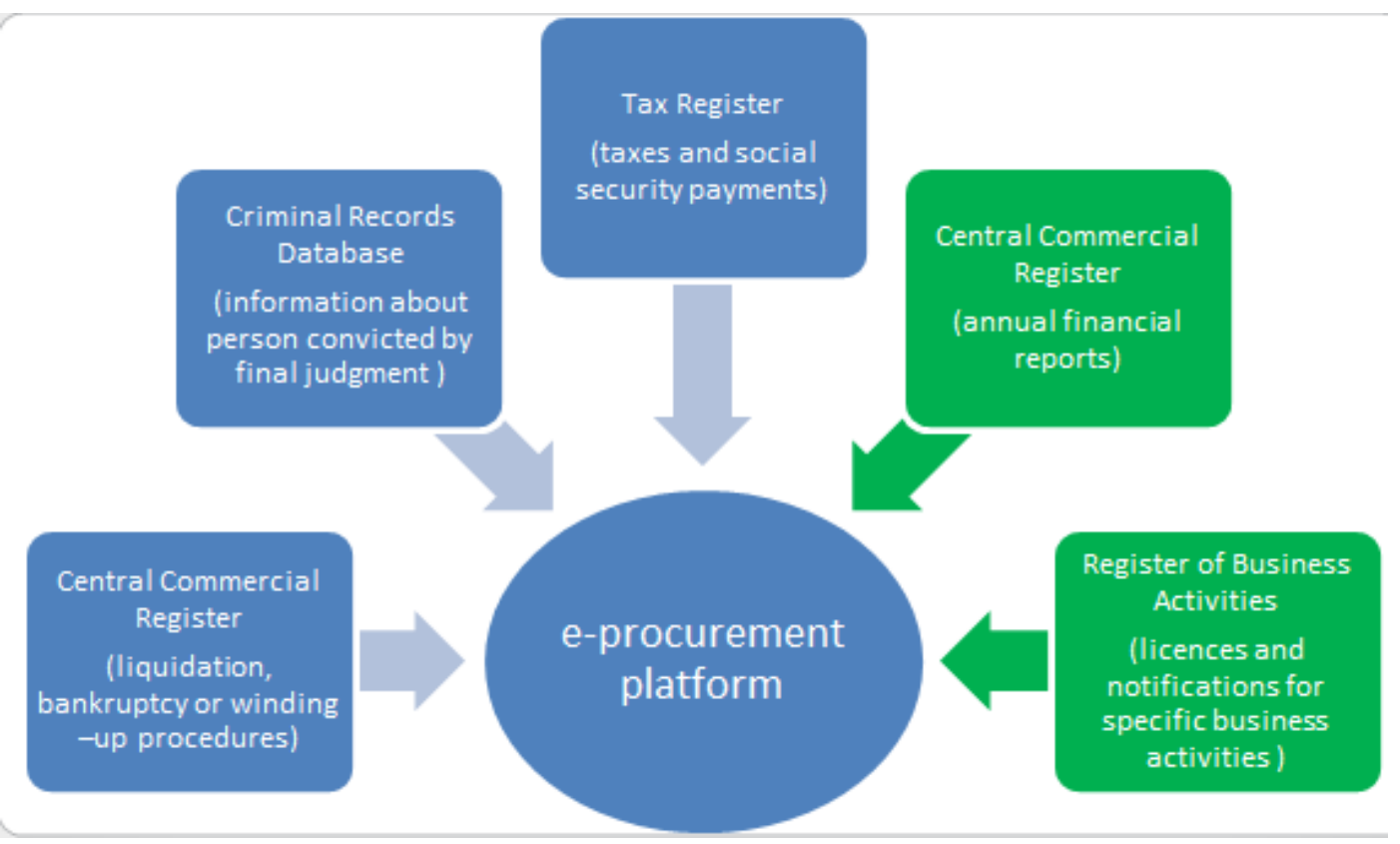

It should be noted, however, that foreign economic operators are obliged to present relevant certificates or documents, since information on their situation is not available in the electronic databases.

The simplification of the verification process is directly related to the development of e-procurement platform functionalities. The e-platform does not consist of databases, but instead facilitates the access to existing databases run by the relevant administration or judicial bodies. The e-platform was included in an e-Estonia project based on the X-road exchange data layer ${ }^{99}$. As a result, economic operators registered in Estonia do not have to present certificates from the various administrative agencies, saving time, effort and money.

The system of verification is fast and easy, and it creates no costs for economic operators and contracting authorities. At the same time, the data is reliable and up-to-date. The results of verifications are stored on the e-procurement platform for each procurement

${ }^{99}$ One of the key elements of e-Estonia is that its databases are decentralised, which means that:

- $\quad$ there is no single owner or controller;

- $\quad$ every government agency or business can choose the product that is suitable for them;

- $\quad$ services can be added one at a time, as they are ready.

$\mathrm{X}$-Road is the all-important connection between these databases, the tool that allows them to work together for maximum impact. All Estonian e-solutions serving multiple databases use X-Road. All outgoing data from X-Road is digitally signed and encrypted. All incoming data is authenticated and logged. Originally, X-Road was a system used for making queries to the various databases. It has now developed into a tool that can also link up with multiple databases, transmit large data sets and perform searches across several databases, www.e-estonia.com/component/x-road/. 
procedure. The control institution can check whether the contracting authority performed all of the activities according to the legal provisions.

In Latvia, a similar system has been implemented, but the scope of the information available is not as great. Contracting authority officials also have to wait longer than in Estonia for responses from the relevant databases.

Contracting authorities verify the non-existence of grounds for exclusion by using the e-procurement platform, Electronic Procurement System (EPS), administered by the State Regional Development Agency. The registered authority can obtain information from relevant official registries on economic operators that have submitted tenders or requests to participate. The following information is available:

- State Revenue Registry: payment of taxes and social security contributions

- Information Centre of Criminal Records: convictions by final judgement

- Register of Enterprises: bankruptcy or liquidation procedures

According to Article 41(4) of the PPL, if the contracting authority obtains the necessary information regarding the tenderer directly from the competent authority, databases or other sources, including the EPS, the relevant candidate or tenderer is entitled to submit a statement or other document regarding the relevant fact if the information acquired by the contracting authority does not conform to the actual situation.

In countries where there is no single point of access (such as the e-platform for public procurement), such as Hungary or Poland, the legislation obliges the contracting authority to verify the absence of grounds for exclusion through online services, where they are directly accessible.

In Hungary, the contracting authority has direct access to online databases, as follows:

- a database of taxpayers without public debts ${ }^{100}$;

- company registers available through the Company Information Service, which gather among other data, data on liquidation, bankruptcy and prohibition from participating in procurement procedures;

- a database, available on the homepage of the PPA, on those prohibited from participating in procedures, as imposed by the Public Procurement Arbitration Board;

- a register maintained by the Labour Inspectorate, enabling the verification of grounds for exclusion specified in Article 62(1)(1) of the PPL;

- a register maintained by the Labour Inspectorate, enabling the verification of grounds for exclusion specified in Article 63(1)(a);

${ }^{100}$ Since not all economic operators are included in the database of taxpayers, the regulations provide for the opportunity to submit a certificate of the competent tax and customs authority. If the document certifies that an economic operator has no public debts owing for more than one year, that operator shall be accepted by the contracting authority, even if the document was issued for a purpose other than a public procurement procedure or if the issuing authority determined less than one year of validity for the document, which has already expired. 
- a database available on the website of the Hungarian Competition Authority on its decisions and final court rulings on infringements of competition law;

- a register maintained by the Immigration and Asylum Office, enabling the verification of grounds for exclusion specified in Article 62(1)(1).

These solutions are not as convenient for contracting authorities as an e-platform with access to several databases, but nevertheless do not require the submission of documents by economic operators.

In Poland, the only database to which the contracting authority has direct online access is the Commercial Register, which gathers, among other things, information on liquidation and bankruptcy. Otherwise, the system is very traditional and requires economic operators to obtain and submit relevant documents or certificates. The contracting authority may request from the economic operators the following information and certificates issued by competent authorities:

- information from the National Criminal Register, within the scope specified by the PPL;

- a certificate of the head of the competent tax office, confirming that the contractor is not in arrears with the payment of any taxes;

- a certificate of the competent local organisational unit of the Social Insurance Institution or the Agricultural Social Insurance Fund.

The traditional system requires the economic operator to undertake activity. It must first make a request to a specific administrative body to issue a document. The economic operator then has to deliver the document obtained to the contracting authority. The system is inefficient and costly. The other disadvantage of the traditional system is that it does not prevent exclusion that is based merely on formal issues.

To dispel doubts on the validity of documents, secondary legislation ${ }^{101}$ regulates this issue. In the case of information obtained from the National Criminal Register, the validity is six months prior to the deadline for the receipt of tenders or requests to participate in a procurement procedure. In the case of other documents, the validity is three months prior to the deadline for the receipt of tenders or requests to participate in the procedure. It is worth noting that in Poland, taxes and social security contributions are paid on a monthly basis. For the purposes of public procurement procedures, documents issued in a given period (longer than one month) are sufficient to confirm the lack of tax or social security contribution arrears.

The period of validity of documents refers to the deadline for the receipt of tenders or requests to participate. This arrangement enables economic operators to gather all of the documents in advance. In spite of this arrangement, if there are reasonable grounds to believe that the statements or documents submitted previously are no longer valid, the contracting authority has the right to request up-to-date documents.

Certificates are issued by the competent authorities in writing in the original or as a copy certified by the economic operator. The contracting authority cannot request notary

${ }^{101}$ Regulation of the Minister of Economic Development of 26 July 2016 on the type of documents that may be required by the contracting authority from the contractor in the procedure for the award of the contract. 
endorsement or endorsement by any other authorities, which enables economic operators to submit documents that have been obtained without additional effort and cost.

\subsubsection{Selection criteria}

The contracting authority is empowered to require the adequate documents to satisfy the selection criteria. Article 60 of the Directive provides for certificates, documents and other means of proof that may be required.

The means of proof related to selection criteria on suitability to pursue a professional activity are listed in Article 58(1) of the Directive. Economic and financial standing may be proved as a general rule by the documents listed in Annex XII, Part I, of the Directive, while technical and professional abilities of economic operators may be proved by the means listed in Annex XII, Part II, of the Directive.

The CJEU has considered the means of proof of economic and financial standing as well as the means of proof concerning technical and professional ability under the 2004 Directive. The lists of documents provided in the 2004 Directive are similar to the lists in the 2014 Directive.

The CJEU has confirmed that as far as the means of proof for economic and financial standing is concerned, the list is not exhaustive. The CJEU stated that it was not the purpose of the rules on economic and financial standing to constrain Member States with regard to the level or manner in which they fixed requirements (C-76/81 Transporoute $v$ Ministère des travaux publics, C-29/86 Bellini, and C-31/87 Beentjes v State of Netherlands). In the case C-218/11 Édukövizig and Hochtief Construction, the ECJ confirmed the non-exhaustive nature of the list of information or evidence to demonstrate economic and financial standing. It also confirmed that Member States had discretion to set additional requirements in that context.

The Directive reflects the approach of the CJEU, that is, that the list of the means of proof of economic and financial standing is not exhaustive.

Article 60(3) of the Directive deals with the proof provided by economic operators in order to attest to their economic and financial standing. It states that the proof may "as a general rule" be provided by one or more of the references listed in Annex XII, Part I. However, where for any valid reason the economic operator is unable to provide the references requested, it may prove its economic and financial standing by "any other documents which the contracting authority considers appropriate".

Article 60(4) deals with the proof submitted by economic operators of their technical and professional ability. It states that this proof may be provided by one or more of the means listed in Annex XII, Part II, "in accordance with the nature, quantity or importance, and use of any works, supplies or services". There is no provision permitting the use of alternative means of proof of technical ability.

\section{Suitability to pursue a professional activity}

As for the selection criteria on suitability to pursue a professional activity, Article 58(1) of the Directive specifies that the contracting authority may require economic operators to be enrolled in one of the professional or trade registers maintained in their Member State of establishment, as described in Annex XI. In procurement for services, if the national law requires the economic operator to have a particular authorisation or to be a member 
of a particular organisation in order to be able to perform in the country of origin the services concerned, the contracting authority may require adequate evidence.

The regulation of economic activity remains at the discretion of Member States, as limited by Treaty provisions, especially Article 56 of the Treaty on the Functioning of the European Union (TFEU) (for more information, see the chapter on Selection, Section 1.3).

If the national law restricts economic activity only to entities with licences, special authorisations, or membership in a particular organisation, the contracting authority has the right to require adequate evidence. The obligation to obtain permission arises from regulations other than the PPL.

When special requirements have been established in Estonian legislation for an activity to be carried out under a public contract, the contracting authority must specify in the contract notice which special requirements, registrations or activity licences are required in order to qualify the tenderer. The fulfilment of requirements is verified by means of the evidence submitted, which attests to the fact that the economic operator holds the relevant activity licence or permission. In the case of Estonian economic operators, the contracting authority, instead of requesting the submission of documents, is obliged to verify the requirements using the e-procurement platform, which is linked to the Register of Business Activities ${ }^{102}$. The Register holds data on activities controlled by the administration. The search functions available allow contracting authorities to obtain the relevant data rapidly.

In Latvia, according to the provisions of Article 44 of the PPL, the contracting authority may request evidence that the relevant supplier is registered, licensed or certified in accordance with the requirements of the laws and regulations of the relevant country. In the case of a services contract, insofar as suppliers must be specially authorised or be members of a specific organisation to provide the particular service in the relevant country, the contracting authority may request evidence regarding such authorisation or membership. The PPL stipulates that the contracting authority shall not determine the requirements governing the minimum time since the registration, licensing or authorisation of a supplier, or since he/she became a member of any special organisation.

In Poland, Article 22b of the PPL reflects the provisions of Article 58(1) of the Directive. The register indicated in Annex XI is the National Court Register, in which all legal persons and organisational units without legal personality that are running a business activity have to be registered. The contracting authority cannot ask the economic operator to submit an extract from the Register; the contracting authority is obliged to access the database online.

Licencing or permissions control some fields of activity. The contracting authority is allowed to request the submission of a concession, permit, licence or any other document confirming that the contractor has been entered into one of the professional or trade registers that are maintained in the EU Member State in which the contractor has its domicile (registered office) or residence ${ }^{103}$. The documents may be submitted in the

102 https://mtr.mkm.ee.

${ }^{103}$ Based on paragraph 2(1) of the Regulation of the Minister of Economic Development of 26 July 2016, on the type of documents that may be required by the contracting authority from the contractor in the procedure for the award of the contract. 
original or via a copy certified by an economic operator. The requirement to submit the documents proving the possession of rights granted to undertake the activity must be included in the contract notice and in the tender documentation.

According to established practice, based on judgements of the National Chamber of Appeal $(\mathrm{NCoA})^{104}$, the contracting authority shall accept the licences or permits even if their period of validity is shorter than the period of contract execution. The economic operator must provide evidence, during the evaluation stage, of the right to carry on a restricted activity at the time of submission of the tender or the request to participate. In such a case, however, the contracting authority has the right to request the extension of licences or permits during the execution of the contract.

In the case of a consortium, the established practice is that the licences or permits must be granted to that member of a consortium, which will be responsible for the execution of the part of the contract concerned with regulated activity.

\section{Economic and financial standing}

Economic and financial standing may be proved as a general rule by the documents listed in Part I of Annex XII of the Directive:

- appropriate statements from banks or, where appropriate, evidence of relevant professional risk indemnity insurance;

- financial statements or extracts from financial statements, where the publication of financial statements is required under the law of the country in which the economic operator is established;

- statement of the undertaking's overall turnover and, where appropriate, of turnover in the area covered by the contract for a maximum of the last three financial years available, depending on the date on which the undertaking was set up or the economic operator started practising, as far as the information on these turnovers is available.

The contracting authority can ask for a document from financial institutions to prove the financial status of the economic operator. The operation of banks is regulated by legal provisions that subject banks to certain requirements, restrictions and guidelines, which are designed, among other aims, to create market transparency between the banking institutions and the corporations and individuals with whom they conduct business. The contracting authority can request documents that are issued by banks in order to obtain information on the funds available to an economic operator or to verify its creditworthiness. The contracting authority assumes that the professional institution can assess the financial ability necessary to perform the contract in question.

The fundamental purpose of insurance regulatory law is to protect the public as insurance consumers and policyholders. Insurance companies are also subject to requirements and restrictions aimed at ensuring trust and transparency. The contracting authority can request the submission of insurance certificates that prove the economic ability of an economic operator to execute a contract and provide evidence of its reliability.

${ }^{104}$ The National Chamber of Appeal is the procurement review body responsible for examination and issuing of a judgement in an appeal procedure (first-instance review). 
To assess the financial and economic capacity to perform a contract, the contracting authority can require the presentation of financial statements or relevant extracts of such statements. The financial statement is a formal record of the financial activities and position of an entity. Relevant financial information is presented in a structured manner, as required by law. Although national requirements may differ, a financial statement typically includes the following:

- a balance sheet, which is also referred to as a statement of financial position, and reports on a company's assets, liabilities, and owners' equity at a given point in time;

- a statement of revenue and expenditure (profit and loss report), and reports on a company's income, expenses, and profits over a specific period of time;

- additional information, such as an equity statement and a cash-flow statement.

Based on the financial statement or its relevant section, the contracting authority can verify if the requirements, at the minimum level of economic indicators, are fulfilled.

Overall turnover or turnover in the area covered by the contract is one of the most popular indicators of the economic performance of an entity. The indicator is also easy to establish and verify. The contracting authority that is establishing selection criteria can refer to the indicator, which will be evaluated based on the statements of the economic operator.

In Estonia, Hungary, Latvia, Malta, Poland and Scotland, the provisions of the Directive stated in Article 60(3) have been transposed into national law, listing substantially the same means of proof.

\section{Statements from banks and evidence of relevant professional risk indemnity insurance}

In Poland, the provisions of secondary legislation give a more detailed description of documents than the provisions of the Directive. The time of issuance of a document and special requirements related to the content of documents are regulated. The contracting authority may request the following ${ }^{105}$ :

- Information from a bank or a savings and credit society confirming the amount of funds held by an economic operator or its creditworthiness; the information shall be issued not earlier than one month before the deadline for the receipt of tenders or requests to participate in the procurement procedure. The document is regarded as appropriate when it confirms the amount of money or creditworthiness in relation to an amount specified in the tender documentation. The contracting authority may not impose any specific wording or form of the information.

- Documents confirming that the economic operator is insured (that is, has an insurance policy) against civil liability in the area of the activity performed associated with the contract, for the insured sum specified by the contracting authority; the contracting authority can request that the economic operator be

${ }^{105}$ Paragraph 2(1)2) of the Regulation of the Minister of Economic Development of 26 July 2016 on the type of documents that may be required by the contracting authority from the contractor in the procedure for the award of the contract. 
insured for the specified sum (normally not higher than the value of the contract). The contracting authority shall accept any kind of document confirming the insurance issued by the insurance company, such as an insurance policy, agreement or insurance certificate.

In Hungary, the contracting authority shall accept statements issued by a financial institution. The statement shall refer to the two years preceding the publication of the contract notice concerned ${ }^{106}$. Certificates attesting to the existence of professional risk indemnity insurance, as prescribed in the contract notice, may also be required ${ }^{107}$. The Hungarian Chamber of Commerce and Industry maintains the list of economic operators. An economic operator can submit only the clarification identifying the relevant requirements and the means of access to the available document certifying compliance ${ }^{108}$ (for more information, see the chapter on Official lists and blacklists, Section 1.9).

In Estonia, the contracting authority may request a professional liability insurance certificate or any other relevant document indicating that the tenderer possesses the funds required for the compensation of loss that may be caused by a possible violation of the public procurement contract, or that the tenderer has the possibility of obtaining such funds.

\section{Financial statements}

The list in Annex XII of the Directive mentions only financial statements, and does not specify the period for which the financial statements are to be required. Neither do the provisions of the Directive stipulate how to deal with economic operators that are not obliged to present financial statements. The countries studied have attempted to resolve the question of potentially different interpretations of such cases by adopting more detailed regulations. For example, in Hungary and Poland, special provisions specify a substitute document that would be submitted by the economic operators that are not obliged by law to present financial statements or to have them endorsed.

In Hungary, economic operators may be asked to prove their economic standing by submitting financial reports or specified parts of these reports. In the case of companies that are obliged to submit annual reports to the company register available through the Company Information Service, the contracting authority must verify the related information online, and the financial reports do not have to be submitted ${ }^{109}$. If the economic operator began its operations after the beginning of the period stipulated by the contracting authority, and as a result the required financial statements are not at its disposal for the entire period of the contract, the economic operator is entitled to submit a declaration regarding its revenue with respect to the subject matter of the procurement. The tenderers that do not present financial reports, due to the legal form of operation, may certify their capability by submitting other declarations or documents that the contracting authority considers to be suitable.

\footnotetext{
${ }^{106}$ Article 19(1)(a) of GD 321/2015.

${ }^{107}$ Article 19(1)(d) of GD 321/2015.

${ }^{108}$ This possibility applies only to works procurement.

${ }^{109}$ Article 19(1)(b) of GD 321/2015.
} 
In Estonia, contracting authorities have the option of evaluating the economic standing of an economic operator based on financial reports available electronically in the Central Commercial Register, an online service based on the central database of the Estonian registration departments of the courts ${ }^{110}$. The contracting authority submits a direct request to the database, using the e-procurement platform.

In Poland, a contracting authority may, in practice, specify that a specific part of a financial report should be submitted, such as a balance sheet or a profit and loss account for a given period (one, two or three completed financial years). The contracting authority is allowed to check the economic situation for the years for which the financial statements were prepared, according to special provisions on accountancy that have been approved and signed by relevant bodies (management board or supervisory board). The contracting authority is not allowed to ask for financial statements for a completed year before the end of the legally specified period for the preparation and approval of financial statements. For example, according to the accountancy provisions, a six-month period is allowed for the preparation and adoption of reports. Thus, in March 2016, an economic operator was permitted to submit the 2012, 2013 and 2014 reports, but was not obliged to present the 2015 documents, because the standard six-month period for the preparation and adoption of the reports had not yet come to an end. In the case of an economic operator that is not obliged to prepare financial statements, any other documents specifying, for example, turnover, assets and liabilities may be presented ${ }^{111}$.

\section{Proof by other means}

The Directive states that when the economic operator is unable to provide the documents requested by the contracting authority, it may prove its financial or economic standing by any other document that the contracting authority considers to be appropriate. The wording of the Directive is that this applies to evidence that the authority "thinks" is appropriate, but the implication appears to be that the authority's decision whether to accept the evidence offered must be reasonable.

All of the countries studied transposed Article 60(3) of the Directive. If, for valid reasons, the economic operator is unable to provide the documents listed in the relevant provisions, it may prove its financial standing by presenting other documents.

In Estonia, according to paragraph 40 of the PPL, if the economic operator is unable, for good reason, to submit the documents prescribed in the contract notice, it may furnish its financial and economic standing by using documents that are accepted by the contracting authority. However, this possibility applies only on the condition that this determination does not give the economic operator a competitive edge over other tenderers.

The economic and financial standing of an economic operator is one of the crucial factors used to assess its capacity to perform the contract. The means of proof used for the evaluation of selection criteria in this field are the certificates and documents issued by entities other than administrative bodies but regulated by special provisions. It is important that the certificates and documents used to evaluate whether the selection

${ }^{110}$ https://ariregister.rik.ee.

${ }^{111}$ Paragraph 2(1)2) of the Regulation of the Minister of Economic Development of 26 July 2016 on the type of documents that may be required by the contracting authority from the contractor in the procedure for the award of the contract. 
criteria have been satisfied are also used in normal business activities. Financial statements are prepared for accounting reasons. Companies co-operate with banks and insurance companies independently of their participation in public procurement procedures.

To accelerate the process of submitting documents, it is recommended that copies that have not been certified by authorities and electronic versions of documents be admitted. It is useful to gather financial statements from electronic databases, such as a commercial register, because this gives contracting authorities direct access to them.

\section{Technical and professional abilities}

Technical abilities of the economic operator may be proved by the means listed in Annex XII, Part II, of the Directive. The provision of the Directive stipulates that the appropriate means should be provided in accordance with the nature, quantity, importance and use of the works, supplies or services.

The means providing evidence of the economic operator's technical abilities, as referred to in Article 58 of the Directive, are:

a) The following lists:

i. A list of the works carried out over at most the past five years, accompanied by certificates of satisfactory execution and outcome for the most important works; where necessary in order to ensure an adequate level of competition, contracting authorities may indicate that evidence of relevant works carried out more than five years before will be taken into account.

ii. A list of the principal deliveries effected or the main services provided over at the most the past three years, with the sums, dates and recipients, whether public or private, involved. Where necessary, in order to ensure an adequate level of competition, contracting authorities may indicate that evidence of relevant supplies or services delivered or performed more than three years before will be taken into account.

b) An indication of the technicians or technical bodies involved, whether or not they are part of the economic operator's undertaking, especially those responsible for quality control and, in the case of public works contracts, those upon whom the contractor can call in order to carry out the work;

c) A description of the technical facilities and measures used by the economic operator for ensuring quality and the undertaking's study and research facilities;

d) An indication of the supply chain management and tracking systems that the economic operator will be able to apply when performing the contract;

e) Where the products or services to be supplied are complex or, exceptionally, are required for a special purpose, carried out by the contracting authorities or on their behalf by a competent official body of the country in which the supplier or service provider is established, subject to that body's agreement, verification of the production capacity of the supplier or the technical capacity of the service provider and, where necessary, of the means of study and research that are available to it and the quality control measures it will operate; 
f) The educational and professional qualifications of the service provider or contractor or those of the undertaking's managerial staff, provided that they are not evaluated as an award criterion;

g) An indication of the environmental management measures that the economic operator will be able to apply when performing the contract;

h) A statement of the average annual manpower of the service provider or contractor and the number of managerial staff for the last three years;

i) A statement of the tools, plant or technical equipment available to the service provider or contractor for carrying out the contract;

j) An indication of the proportion of the contract that the economic operator plans to subcontract.

The documents required by a contracting authority are to be specified in the contract notice or the tender documentation.

The requirements must be related and proportionate to the subject matter of the contract. The requirement that technical capabilities relate to the contract means that the contracting authority cannot lay down conditions relating to the conduct of the economic operator's business as a whole, but only conditions referring to the ability of that operator to perform the particular contract being awarded ${ }^{112}$ (for more information, see the chapter on Selection, Section 1.3).

The means of proof required by the contracting authority must be adjusted to the selection criteria defined in a contract notice or in tender documentation. Contracting authorities have the freedom of choice between the various means of proof from the Directive's list. Different contract conditions require different kinds of capacity, which entail different means of proof for evaluation.

From a formal point of view, the economic operator prepares most of the documents required for the purposes of the procedure. Its statements are to include information on its specific technical or professional abilities.

EU Member States have incorporated the list of documents into national legislation. In some cases, the description of documents required is regulated with additional details.

Documents presented in regard to the experience of the economic operator

In practice, the most common requirement of contracting authorities is concerned with selection criteria based on the experience of the economic operator. Contracting authorities may make use of the opportunity to establish a minimum level of required experience and may request that the economic operator prove compliance with this minimum requirement by providing various kinds of evidence, which can be classified into two types. The first type is the list of executed contracts with their specific characteristics, and the second type is the reference letter from a customer for which the works, supplies or services were performed. The practice in Member States differs with regard to detailed provisions.

112 Arrowsmith, S. (2010), EU Public Procurement Law (PPL): An Introduction, University of Nottingham, Nottingham, UK, p. 143. 
The provisions of the Directive establish a period of three years in the case of services and supplies and five years for works procurement, over which time the experience of the economic operator should be evaluated. Contracting authorities may indicate that evidence of relevant works carried out over a period of more than five years and of relevant supplies or services delivered or performed for more than three years will be taken into account.

In the countries studied, the national provisions establish in different ways the period of three years' experience for supplies and services or five years for works. In Poland, the period of three years or five years is counted back from the date of submission of the tender or request to participate in a procedure ${ }^{113}$. In addition, in the case of works, supplies or services that started earlier than three or five years prior to the date of submission of a tender or request to participate but were completed within the three- or five-year period, the established practice is to accept the experience as conforming with the requirement ${ }^{114}$. In Hungary, the period is counted back from the publication of the contract notice launching the procurement procedure ${ }^{115}$. In Latvia, the relevant provisions of the PPL" ${ }^{116}$ establish the period for "works carried out during not more than the five preceding years" and for "supplies or services provided in the previous three-year period". No precise provision specifies how the five or three previous years should be understood, but the practice, based on judgements of the Procurement Monitoring Bureau $(\mathrm{PMB})^{117}$, is that the years should be understood as the last three or five calendar years. For example, for the submission of bids for a services procurement procedure that took place in October 2018, the contracting authority should have taken into account the experience of an economic operator in 2015, 2016, 2017 and 2018 - up until the deadline for the submission of tenders.

The Directive allows contracting authorities to indicate that evidence of relevant works, supplies or services carried out during a period that is longer than five years or three years will be taken into account.

According to Hungarian legislation, the contracting authority may consider the extension of the period for which experience will be taken into account to six years for supplies and services and to eight years for works ${ }^{118}$. In Poland, it is allowable to consider experience for longer than three years for services and supplies and five years for works, without any

\footnotetext{
${ }^{113}$ Paragraph 2(4), 1) and 2), of the Regulation of the Minister of Economic Development (26 July 2016) on the type of documents that may be required by the contracting authority from the contractor in the procedure for the award of the contract.

${ }^{114}$ Exceptions to the general rule are made, for example when the contracting authority buys services or supplies that are regular by nature and when the requirement is to provide services or supplies of a certain value.

115 Article 21.1(a), 2(a) and 3(a) of GD 321/2015.

${ }^{116}$ Article 46(3)1) of the PPL for works and Article 46(3)2) of the PPL for supplies and services.

${ }^{117}$ The PMB is the procurement review body in Latvia responsible for handling appeals.

${ }^{118}$ Articles 21.1(a), 2(a) and 3(a) of GD 321/2015.
} 
limitations. Contracting authorities shall establish the period according to the type of procurement and the market situation, to ensure an adequate level of competition ${ }^{119}$.

In national legislation, regulations provide for details that should be included in the list of executed contracts.

In Latvia, the economic operator shall prepare information detailing the amount of the relevant works, structure types, time periods of implementation, and location, and it shall consider whether all of the work has been dutifully completed and performed in conformity with the relevant regulations. In the case of supplies or services, the information regarding the most significant supplies provided or services performed shall indicate amounts, time of execution, and recipients (public or private persons) ${ }^{120}$. Similar provisions are included in the Polish regulations. The list of executed works shall contain information regarding the kind, value, date and place of performance of the works, and on the entities on behalf of which such works have been performed. The list of performed services or supplies provided shall include information on the value and object as well as on the dates and recipients of such supplies or services ${ }^{121}$.

It is worth remembering that the ESPD is used as preliminary evidence for the verification of technical and professional abilities according to the new legislation. The sections of the ESPD regarding past experience allow the presentation of details about contracts performed. These details are similar to the details that an economic operator must provide in a list, which is mentioned in Annex XI of the Directive.

In Poland, if the contracting authority recognises that the content of the information provided by the economic operator in the ESPD corresponds to the scope of information that the authority requires, it may refrain from requesting such documents from the economic operator. In this case, the proof of meeting the selection criteria, including the criteria referring to experience, shall be the relevant information provided by the economic operator in the ESPD. This solution allows for savings of time and effort in presenting the necessary documents.

National legislation allows contracting authorities to request the submission of documents accompanying the list of performed contracts, such as certificates of satisfactory execution.

In Poland, the economic operator shall submit evidence that the works have been performed properly. The regulations stipulate that this evidence shall be letters of reference or other documents issued by the entity on behalf of which such works have been performed. If the contractor, for valid, objective reasons, is unable to obtain these documents, other documents will be taken into consideration. In the case of services or supplies, accompanied evidence of proper performance shall be the letters of reference or other documents issued by the entity to which such supplies or services have been provided. If the tenderer, for valid, objective reasons, is unable to obtain these documents,

${ }^{119}$ Paragraph 2.5 of the Regulation of the Minister of Economic Development (26 July 2016) on the type of documents that may be required by the contracting authority from the contractor in the procedure for the award of the contract.

${ }^{120}$ Article 46(3)1) of the PPL for works and Article 46(3)2) of the PPL for supplies and services.

${ }^{121}$ Paragraphs 2.4 1) and 2) of the Minister of Economic Development (26 July 2016) on the type of documents that may be required by the contracting authority from the contractor in the procedure for the award of the contract. 
a statement by the economic operator is required. According to the judgements of the NCoA, the contracting authority cannot limit the evidence to documents issued only by entities in the public sector and not by those in the private sector. The judgements of the $\mathrm{NCoA}$ also state that the contracting authority cannot require special contents in the reference letters, such as the value of the contract or details concerning the technical solutions applied. The documents shall be accepted if the contract performed is described in a manner that allows for its identification and contains the confirmation of proper performance. The economic operator cannot be forced to obtain a separate document for each procedure in which it wants to take part. As far as the form of the reference letter is concerned, copies certified by the economic operator shall be accepted.

In Hungary, the contracting authority shall request the submission of certificates attesting to proper performance. When the supplies or services were performed for a contracting authority established in the EU and covered by Article 5(1)(a)-(c) and (e) of the PPL, the economic operator shall present a certificate issued or signed by that contracting authority. For contracts concluded outside the EU, the certificate issued by the contracting authority or the declaration of the tenderer shall be accepted. In the case of works, the certificate(s) issued by the contracting authority (authorities) shall be provided. The legal provisions specify the content of such certificates.

Hungarian legislation provides an interesting solution that enables economic operators to obtain the necessary certificates. If the performance of the contract was in compliance with its regulations, the Hungarian contracting authority that was party to the executed contract is obliged to issue a certificate free of charge within two business days of the receipt of the request by the economic operator, but no later than 15 days after the performance of the contract.

In Estonia, the request for a certificate on proper performance is not an obligation for the contracting authority, but it is permissible. If the other party to the completed contract was a contracting authority, the economic operator shall present a certificate issued by that authority. In other cases, a confirmation by the other party to the contract or a written statement of the tenderer shall be accepted. In practice, contracting authorities request a list of performed contracts, together with the contact details of the previous authority (authorities) in order to have the possibility of confirming the proper execution of the contract(s) ${ }^{122}$.

According to Latvian legislation, for services and supplies, the information on proper performance shall be attached to the list of performed contracts. According to the interpretation given by the PMB, the contracting authority is not allowed to establish any period of validity for the certificates. The contracting authority is also not allowed to ask the economic operator to submit the originals of certificates. Only in the event of reasonable doubt regarding the authenticity of the document may the contracting authority ask the tenderer to present an original or an attested copy of the document in question.

The Directive does not set out the manner of evaluating the experience of the economic operator that was gained during the performance of a contract together with other entities (in a consortium).

\footnotetext{
${ }^{122}$ Paragraph 41(4) of the Public Procurement Act.
} 
In Hungary, legislation deals with the situation where an economic operator wishes to rely on a certificate or declaration of works for services or works performed or delivered jointly by a number of economic operators, and where the nature of the performance or delivery of the services or works means that the certificate or declaration of works is not divisible. In such cases, the certificate or declaration of works relates to the entirety of the services or works delivered by all of the economic operators, not to the particular service or work performed by the economic operator seeking to rely on the certificate or declaration of works. The contracting authority accepts the certificate or declaration of works relating to the entirety of the services or works delivered by all of the economic operators but uses the percentage remuneration received by the economic operator concerned as the measure of evidence of performance by that economic operator.

Poland has no particular provisions on the issue. According to the judgements of the $\mathrm{NCoA}$, the contracting authority shall accept the evidence issued on contracts executed jointly. According to the judgements of the NCoA, the contracting authority shall accept the evidence issued with regard to contracts executed jointly. In judgements issued in 2017, the NCoA stated that the verification of actual participation of the contractor in contract execution shall be carried out. In circumstances where a contract was managed by all of the consortium members and crucial decisions were taken jointly by all of the consortium members, an economic operator is permitted to refer to the whole of the scope of that contract. The NCoA explained that the consortium, according to the PPL, is jointly and severally responsible for the execution of a contract. In any other situation, the consortium member can refer to the scope of the contract executed directly by that consortium member.

None of the countries studied have established a comprehensive system enabling contracting authorities to verify an economic operator's experience in performing contracts in the public sector. Contracting authorities nevertheless have the opportunity to check whether the contract was concluded and with which entity, using the procurement services for the publication of notices, such as Tenders Electronics Daily ${ }^{123}$. In all countries, contracting authorities are obliged to publish contract award notices that include details concerning the economic operator chosen. Those notices can be used as an additional method of verification of the reliability of data. These sources of information cannot be used for contracts executed in the private sector.

Some countries are striving to improve the access to data on contracts concluded in the public sector. In the Czech Republic, a special law on the publication of the whole text of public contracts was adopted in $2015^{124}$. According to paragraph 2 of the Czech Act on the Contract Register (Act No. 340/2015), entities are obliged to disclose the contents of their contracts with the following: the state, territorial self-governed units, state-funded organisations, state funds, public universities and research institutions, state-owned enterprises including national enterprises, municipally owned enterprises, public-benefit organisations, health insurance companies, Czech Television, Czech Radio and other legal entities that are governed or owned by the state or a territorial self-governed unit,

123 www.ted.europa.eu/.

${ }^{124}$ Bouda, P., M. Fadrný and M. Chatrná; Contributing Authors: B. Kwiatkowski and M. Žuffová (2016), Shedding Light on Public Contracts: The Register of Contracts in Public Spending Oversight, Brno, Czech Republic, www.rekonstrukcestatu.cz/shedding-lighton-public-contracts--the-register-of-contracts-in-public-spending-oversight.pdf. 
including those entities in which the state or a municipality has a majority stake. The Contract Register does not include data on the execution of contracts, but online access to the register enables the verification of the conclusion of the contract, its scope and its value.

The inclusion on state-governed databases of information on concluded contracts and their execution constitutes a tool that replaces the letters of reference issued by contracting authorities.

In Romania, after the execution of each contract, a contracting authority issues a certificate ("ascertaining document") on contract performance within a prescribed period. The contracting authority is obliged to issue an ascertaining document containing information regarding the fulfilment or, as the case may be, the non-fulfilment, of the contracting obligations by the economic operator concerned. The ascertaining document may be subject to an appeal, in accordance with the Law on Administrative Appeals.

The contracting authority publishes the ascertaining document on the Electronic System for Public Procurement. Other contracting authorities have direct access to information on contract execution ${ }^{125}$.

\section{Qualifications and experience of staff}

Contracting authorities may make use of the option to verify ability to perform a contract with respect to human resources. In the list set out in Annex XII, Part II, of the Directive, two items indicate the evaluation of the staff of the economic operator:

- "... an indication of the technicians or technical bodies involved, whether or not belonging directly to the economic operator's undertaking, especially those responsible for quality control and, in the case of public works contracts, those upon whom the contractor can call in order to carry out the work;

- the educational and professional qualifications of the service provider or contractor or those of the undertaking's managerial staff, provided that they are not evaluated as an award criterion ..."

The contracting authority describes the selection criteria concerning the team of specialists needed to perform the contract, which include the educational requirements and professional qualifications that are understood as authorisation to perform activities (if there are special rules in this regard) as well as experience.

When specialists are required to perform activities in areas that are regulated by national administrative law, the general rule on the recognition of qualifications must be applied. In Latvia, the PMB has emphasised that the requirement for experts to possess the necessary certificates at the moment of submission of tenders results in the unequal treatment of foreign companies. The economic operator shall be allowed to prove expert qualifications by other means, and their inscription in a relevant register can take place after the award of the contract. The list of documents certifying the qualifications of personnel is not strictly specified, but the contracting authority may ask only for documents that are relevant to the subject matter of the procurement and cannot impose unnecessary obligations. Contracting authorities are obliged to stipulate in the tender

${ }^{125}$ Article 166, Government Decision No. 395/2016. 
documentation the requirements concerning the scope of information on persons designated to perform a contract.

In Estonia, contracting authorities can check whether proposed experts are incorporated in obligatory registers using the electronic platform of the Register of Business Activities, which is accessible through the e-procurement platform.

In Poland, the contracting authority may require a list of persons designated by the economic operator to perform the contract, and in particular those responsible for the provision of services, quality control or managing construction works, together with information on their professional qualifications and licences, experience and education necessary to perform the public contract. It may also require information on the scope of work to be carried out by such persons, as well as on their availability. According to the judgements of the NCoA, the contracting authority is not allowed to ask for copies of diplomas, permissions, etc. that have been issued to the persons listed by the economic operator. The evaluation shall be conducted on the basis of information included in the list prepared by the economic operator.

\subsubsection{Procurement of contracts below the EU thresholds}

The system of means of proof regulated in the Directive and the examples of its implementation refer to procedures that have a value equal to or above the EU thresholds. Below the thresholds, each EU Member State has the freedom to regulate the preparation and conduction of a public procurement procedure as long as it is in line with the principles of the Treaty.

With the alignment of national legislation with the provisions of the Directive, some countries have also modernised the procedures for small-value procurement. The main aim of this modernisation was to avoid maintaining two totally different concepts for the proof of an economic operator's ability to perform a contract. One type of proof relies on a self-declaration and the requirement for submission of documents only by the economic operator to whom the contract has been awarded. The second type of proof maintains the former concept of verification of all tenderers taking part in the procedure.

In general, the countries studied permit contracting authorities to accept the statements of economic operators, in preference to certificates or documents issued by relevant authorities.

In Poland, the system of initial self-declaration for procurement below the EU thresholds was introduced, and the final verification was carried out concerning the winner only. The form of the self-declaration is not specified by the PPL or any secondary legislation. Contracting authorities may prepare drafts of forms to be completed by participants of tender procedures and include them in the tender documentation, but economic operators are not obliged to use the forms. Contracting authorities must accept statements drafted by an economic operator on its own if the documents include a required declaration on the grounds for exclusion and the selection criteria. The PPO has prepared and published on the website the examples of statements that may be used for low-value procurement.

The contracting authority is permitted but is not obliged to verify the winner's proof of qualifications based on relevant certificates and statements. A general rule has been adopted that the contracting authority may rely on the statements of an economic operator instead of documents and certificates. If the contracting authority decides to require such 
documents, the requirement must be limited to documents listed in the Regulation of the Minister of Development ${ }^{126}$.

In Hungary, the tenderer shall submit a simple declaration, in its tender or request to participate, that it is not subject to the grounds for exclusion stated in the contract notice. In the case of small-value procurement, contracting authorities may accept a declaration of the tenderer or the means proving economic and financial standing as required for procurement of a value above the EU thresholds. Instead of certificates of proper performance for works and services contracts, the declaration of the tenderer shall also be taken into account.

In Scotland, for contracts below the EU thresholds, the ESPD (Scotland) states that it is best practice to use the ESPD for all nationally regulated procurement below the EU thresholds, but contracting authorities are not obliged to do so. Scotland has regulated to a limited extent the means of proof for both types of contracts - those above the national thresholds and below the EU thresholds.

\subsection{Additional information or documentation}

An important practical issue is the manner in which contracting authorities respond to a candidate or tenderer that has not complied with the requirements for the submission of information or documents relating to the stage of the choice of participants.

In some of the countries studied, the process for the choice of participant is carried out in a highly formalistic manner. As a result, economic operators may for example be excluded from participation in a procurement process due to a simple administrative mistake, such as the failure to include a page from their publicly available accounts. The main purpose of the stage of the choice of participants is to ensure that economic operators are suitable and capable of delivering the contract, whilst maintaining as much competition as possible. The exclusion or rejection of economic operators on formalistic grounds that are unrelated to their suitability and capability does not help achieve this purpose. The Directive tackles this problem directly, and explicitly allows for a flexible approach.

Article 56(3) of the Directive refers to situations where "information or documentation submitted by economic operators is or appears to be incomplete or erroneous or where specific documents are missing". In these cases; contracting authorities may, unless otherwise provided by national law implementing the Directive, "request the economic operators concerned to submit, supplement, clarify or complete the relevant information or documentation". The contracting authority must set an appropriate time limit for the submission of additional information and documentation. Article 56(3) concludes with the statement that the request by the contracting authority must be made in full compliance with the principles of equal treatment and transparency.

Under the 2004 Directive; a contracting authority was permitted to invite economic operators to "supplement or clarify the certificates or documents" submitted in the

\footnotetext{
${ }^{126}$ The provisions of the Regulation of the Minister of Economic Development of 26 July 2016 on the type of documents that may be required by the contracting authority from the contractor in the procedure for the award of the contract apply to all procedures independently, of their value. The only difference is that in the case of small-value procurement, the contracting authority may disregard certificates and documents and consider self-statements to be sufficient.
} 
context of proof relating to grounds for exclusion, selection and shortlisting. This provision was quite narrowly drawn, limiting the process to supplementing or clarifying certain types of documents in specified situations. It could be argued that the provision did not allow for the submission of new documents. Article 56(3) of the 2014 Directive is much more generous, reflecting the need to prevent unnecessary formalistic reasons being invoked to justify the exclusion or rejection of economic operators at the stage of the choice of participants.

Article 56(3) is a permissive provision, as it provides for contracting authorities to request information, subject to national provisions. Some of the limitations applied in national law are illustrated below. The provision does not cover, however, the issue of whether there could be any situation where a contracting authority would be obliged to ask for clarification. There is room for debate on this point, with some commentators arguing that there is a duty in exceptional cases, such as where there is an obvious need for clarification and where the correct information is also obvious but it is not disproportionate to ask for clarification ${ }^{127}$. For example, it could be argued that a contracting authority should seek clarification where one page is missing from published accounts submitted by an economic operator.

Article 56(3) covers all information or documentation submitted by economic operators. It is not limited to supplementing or clarifying certificates or documents, as was the case under the 2004 Directive. It specifically provides the possibility of submitting additional information or documentation. It is an important practical provision for contracting authorities and economic operators because (subject to national provisions), it can for example prevent a situation where economic operators are excluded from a procurement procedure due to their failure to provide part of the information or documentation required in relation to the exclusion, selection or shortlisting stages.

Subject to national provisions, this approach can be used, for example, where an economic operator fails to complete fully all sections of the ESPD. In this case, Article 56(3) would permit the contracting authority to ask the economic operator concerned to re-submit the sections of the ESPD that it had failed to complete initially. To comply with the principles of equal treatment and transparency, all of the economic operators must have the same opportunity to re-submit missing ESPD information, where relevant. The contracting authority must also undertake this process in a transparent manner. It should, ideally, make it clear in the procurement documents that it reserves the right to ask economic operators to submit, supplement, clarify or complete the information required in the ESPD, and it should describe the process that will be used to do so.

It is useful to look at examples of countries where it was common, even before the transposition of the Directive, for contracting authorities to seek clarification or further information. For example, in Hungary, a well-established practice allows economic operators to submit missing information relating to the grounds for exclusion and the selection criteria. Article 71 of the Hungarian PPL contains detailed provisions on this issue, outlining a clear course of action for contracting authorities.

${ }^{127}$ Burgi, M., M. Trybus and S. Treumer, eds. (2016), Qualification, Selection and Exclusion in EU Procurement, DJØF Publishing, pp. 23-30. 
According to Article 71(1) to (3) and (5) of the PPL, which applies to the ESPD as well as to information provided in other formats:

"1. The contracting authority shall ensure the possibility of supplying missing information under the same conditions for all tenderers and candidates and it shall request information from the tenderer or candidate for the purpose of clarifying the content of any ambiguous statement, declaration, certificate included in the tender or request to participate.

2. The request for supply of missing information or provision of information shall be sent by the contracting authority directly to the tenderer or candidate, informing about this fact at the same time all the other tenderers or candidates and setting the time limit and, in the case of request for the supply of missing information, specifying the information to be supplied.

3. The supply of missing information shall be restricted to align the tender or the request to participate with the requirements set out in the procurement documents or the relevant legislation. In the course of the supply of missing information the documents, including the documents to be submitted according to Article 69(4)-(5) (grounds for exclusion, suitability criteria and where appropriate criteria/rules applying to shortlisting), included in the tender or the request to participate may also be modified or complemented.

$[\ldots]$

5. Throughout the whole time available - specified in the request or notification according to paragraph 2 - for any tenderer or candidate in order to supply missing information, the tenderer or candidate has the right to supply any missing information in relation to which he has not been requested by the contracting authority to supply missing information ...."

The above Article assists contracting authorities by setting out a process to follow. It is also clear in restricting the purpose of the request. In addition, Article 71(5) establishes the right of the economic operator to supply missing information, which goes beyond the provisions of the Directive but should further assist in promoting competition. It is also possible that these provisions could result in an increase in legal challenges based on a contracting authority's alleged failure to seek clarification or further information, in breach of these provisions.

Other Articles in the Hungarian PPL deal with the provision of additional information in the context of a reliance on the capacity of third parties, restrictions on additional information in relation to economic operators that were not originally included in the procurement procedure, and the replacement of professionals and the late supply of missing information. In the context of the tender itself, a provision requires a contracting authority to correct an error in calculating a price or value in a specified manner.

This approach is used for the ESPD, allowing economic operators to amend and resubmit the ESPD where responses or information are missing. In practice, economic operators are not permitted to merely re-submit the amended section of the ESPD; they must re-submit the entire ESPD.

In Latvia, Article 41(6) of the PPL requires that if the information submitted by an economic operator about its qualifications is inaccurate or incomplete, the contracting authority must ask the economic operator to provide an explanation or to submit additional information. As is the case in Hungary, this situation places an obligation on the contracting authority to make the request. 
According to the PPL, the contracting authority shall determine the deadline for submission of the necessary information, leaving sufficient time for the preparation and submission of such information. If the economic operator does not comply with the contracting authority's request for an explanation or further information, the contracting authority is not obliged to repeat the request.

The Directive refers to the possibility of national laws modifying or restricting the provisions set out in Article 56(3). As has already been noted, the PPL in Hungary specifies the coverage of this permission. In Latvia, Article 41(6) of the PPL is limited to the qualification of economic operators and cannot be used in the case of missing information in the technical bid or financial proposal. Malta and Scotland do not modify or restrict this principle.

The provisions in Article 56(3) of the Directive are a positive development, introducing flexibility into the process for the choice of participants by reducing the likelihood of over-formalistic reasons for exclusion or rejection and by increasing competition.

The process of requesting additional information or documentation must be conducted in a transparent manner, ensuring compliance with the principle of equal treatment. It is advisable to include clear provisions that set out reasonable timescales applying to the requests for the provision of additional information or documents. The provision of additional information or documents should not permit an economic operator to change its situation or to change the tender document ${ }^{128}$ that it has submitted.

\subsection{Open procedure - verification of information after examination of tenders}

As explained in Part 1, several new provisions of the Directive concerning the choice of participants were introduced with the aim of reducing the administrative burden on both contracting authorities and economic operators and thus of speeding up the procurement process. Another aim was to increase flexibility in the choice and conduct of procurement procedures.

One of the main burdens under the 2004 Directive (and preceding Directives) was the requirement for contracting authorities to verify the proof of the grounds for exclusion and the compliance with selection criteria at the stage for the choice of participants, with all economic operators submitting tenders or expressions of interest. These issues are outlined in more detail in Part 1, and the application of the new practices is explored further in Sections 1.5 and 1.6 on the ESPD and means of proof.

Article 56(2) of the 2014 Directive introduces an approach that potentially reduces the burden of verification to a significant degree. It is also an example of the Directive's introduction of more flexibility.

Article 56(2) permits a contracting authority using an open procedure to examine tenders before verifying the absence of grounds for exclusion and the fulfilment of the selection criteria. This provision is new, as no equivalent rule was included in the 2004 Directive.

\footnotetext{
${ }^{128}$ In this context, the "tender document" refers to the (contract-specific) information provided by the economic operator as to how it will deliver the contract and at what cost/price. See Section 2.8 on open procedure - verification of information after the examination of tenders, for a further explanation of the concept and contents of the tender document.
} 
It gives contracting authorities the flexibility of adopting a new approach to the way in which they conduct the open procedure.

\section{Explanatory note}

In this context, it is important to understand that the Directive makes a clear distinction between two stages of evaluation: (1) choice of participants (sometimes referred to as "selection"); and (2) tender evaluation. The two stages each have a different purpose and different documents are considered at each stage.

In the stage for the choice of participants, the contracting authority evaluates the documents that it has requested from the economic operator related to grounds for exclusion, selection criteria and shortlisting, in order to exclude economic operators that are unsuitable and select those that are suitable. These documents essentially mean the ESPD and, where necessary for the proper conduct of the process, other means of proof. The documents provided at this stage do not constitute the "tender" document (according to the Directive).

In the tender evaluation stage, the contracting authority evaluates the tender, containing specific information provided by the economic operator as to how it will deliver the contract and at what cost/price. The information in the tender document is used to evaluate the extent to which the proposal of the economic operator satisfies the technical specifications, contract award criteria and other conditions.

In the open procedure, an economic operator submits at the same time both the ESPD/documents relating to the choice of participants and the tender document. However, the distinction between the two stages still applies. Contracting authorities need to understand the different purposes and the different documents that are required at each stage, and to conduct the open procedure accordingly, recording the two types of evaluation separately in clearly identified, distinct stages.

Before the new approach was introduced in the Directive, the evaluation process in an open procedure would normally start with an assessment of the documents related to the choice of participants submitted by all tenderers. Then an assessment of the "tender" of those suitable tenderers would follow.

Article 56(2) requires that in the situation where a contracting authority makes use of this "tenders-first approach", it must ensure that the verification process is carried out in an impartial and transparent manner. The contracting authority must ensure that no contract is awarded to a tenderer that should have been excluded or that fails to meet the selection criteria.

EU Member States have the option of excluding or restricting the use of this tenders-first approach to specific types of procurement or specific circumstances. In the countries studied, the tenders-first approach in the open procedure is not restricted to particular types of procurement. 
The new tenders-first approach introduced in the 2014 Directive can reduce the administrative burden of verification, because the contracting authority only undertakes verification of the economic operator that appears to be successful. This entails no waste of administrative resources, in contrast to the case where the contracting authority undertakes the verification of all tenders, including those of economic operators whose tenders subsequently turn out to be unacceptable or non-compliant.

In Poland, the tenders-first approach is permitted provided that the contracting authority announces in the tender notice or the tender documentation that it will adopt this approach. This provision is helpful because it promotes transparency and ensures that economic operators are informed from the start of the time when verification will be undertaken. In practice, the use of the tenders-first approach is mixed and depends on the historic practices of a particular contracting authority and its level of activity. It is worth noting that the overall change in the verification process, consisting of self-certification and obligatory verification of certificates and documents submitted only by the winner, has overshadowed the advantages of the tenders-first approach.

In Scotland, the Procurement Journey website provides some guidance on the tendersfirst approach. It explains that where the contracting authority is using an open procedure, then "it may be desirable to assess the tenders (award stage) prior to checking minimum criteria are met when only a small number of bids have been received. Where this is done you must still ensure that you verify the absence of grounds for exclusion and of fulfilment of the selection criteria. This needs to be carried out in an impartial and transparent manner so that no contract is awarded to a bidder that should have been excluded or does not meet the selection criteria"129. In practice, whilst contracting authorities are aware of the tenders-first approach, the authors of this study found little evidence of its being used. This observation may well be due to the relatively limited use of the open procedure in Scotland, where the restricted procedure is often the chosen procedure for more complex purchases and where framework arrangements are commonly used.

The tenders-first approach makes sense where a tender evaluation process, carried out for all compliant tenders, can be undertaken in a time-efficient and cost-effective manner. It may therefore be suitable where the award criteria can be evaluated routinely - for example, where the most economically advantageous tender is determined on the basis of price alone (or when adopting a cost-effectiveness approach that can be evaluated by using a simple spreadsheet).

The advantages are fewer where the tender evaluation is more complex and thus more time-consuming and costly to undertake. Indeed, it is possible that the overall administrative burden is greater, as the contracting authority may find itself evaluating tenders of economic operators that do not satisfy the exclusion or selection requirements. Where verification is carried out before the assessment of tenders, it is possible to reduce the number of tenders to be evaluated.

There is also room for debate as to whether this new provision represents a significant advantage in terms of reduction of the overall administrative burden, in the light of the introduction of the ESPD. The ESPD reduces the burden of verification to a significant

\footnotetext{
${ }^{129}$ www.procurementjourney.scot/route-3/route-3-develop-documents-selection-award-andexclusion-criteria-exclusion-criteria.
} 
extent, due to the use of self-declaration and the general principle of verification only in respect of the economic operator (the successful tenderer) to which the contracting authority proposes to award the contract. (see Sections 1.5 and 1.6 on ESPD and means of proof).

Some potential risks are associated with the tenders-first approach. There is a greater possibility that a contracting authority may treat the successful tenderer more favourably when verifying the grounds for exclusion and the selection criteria, because it is aware that the tender is the most economically advantageous. The stakes are also higher for a successful tenderer that knows it has submitted the most economically advantageous tender and then finds itself excluded. It is possible that this situation could result in more legal challenges. In addition, where the evaluation of tenders is based, for example, on a relative pricing model - with prices scored in relation to the lowest price tender - the whole outcome of a tender evaluation could be different if the lowest price tenders were rejected because the successful tenderer had subsequently been excluded from the tender process $^{130}$.

\subsection{Official lists and blacklists}

\subsubsection{Official lists of approved economic operators and certification by bodies established under public or private law}

Article 64 of the Directive permits Member States to establish or maintain official lists of approved economic operators that have submitted acceptable evidence of their suitability to deliver public contracts. Member States may also provide for a certification by certification bodies confirming that the economic operator complies with specified European certification standards ${ }^{131}$. The provisions in the 2004 Directive were substantially the same as those in Article 64 of the 2014 Directive.

The main purpose of using official lists is to streamline the procurement process by reducing administrative burdens on both economic operators and contracting authorities.

An official list system allows economic operators to apply for registration at any time by supplying evidence to the public authority responsible for administering the list. The evidence to be submitted by economic operators is the same evidence required, in accordance with the Directive and with the Member State's implementing legislation, to demonstrate their suitability for selection ${ }^{132}$. This evidence should demonstrate the following:

- Grounds for mandatory exclusion do not apply to the economic operator.

- Grounds for discretionary exclusion do not apply to the economic operator.

- The economic operator meets the requirements related to economic and financial standing and to technical and professional ability.

\footnotetext{
${ }^{130}$ Further practical discussion on these and other issues is aired in an article by Anne-Marie Curran, www.algoodbody.com/media/WWL_GovContracts_ALGoodbody1.pdf.

${ }^{131}$ These certification standards are provided in Annex VII of the Directive.

${ }^{132}$ Member States' implementing legislation must ensure that applications for registration by economic operators belonging to a group include the establishment of proof that the relevant resources in the group will continue to be available for the period of validity of the certificate.
} 
- The economic operator has the necessary certification of quality assurance and environmental management standards.

An economic operator that is registered on an official list may submit as means of proof to the contracting authority, in the context of a specific procurement procedure, a certificate of registration issued by the competent body administering the official list.

The certificate constitutes a presumption of suitability for the requirements for qualitative selection embodied in the official list or certificate, and deals with the issues in question. The contracting authority can rely on that certificate as evidence of suitability in relation to the grounds specified. Indeed, the contracting authority shall not call into question without justification the information that can be deduced from an economic operator's registration on an official list.

\section{Example: A Member State operates an official list of waste management contractors}

As part of the process for registration on that official list, a waste management contractor must provide evidence that it has not been convicted of criminal offences relating to breaches of environmental and waste management legislation.

The official list does not cover convictions for offences relating to breaches of labour law. Waste management contractors applying for registration on the official list therefore do not provide evidence relating to labour law, because that is outside the scope of the official list.

In this case, the contracting authority must assume that an economic operator that is enrolled on the register and provides a certificate of registration has not been convicted of offences relating to breaches of environmental and waste management legislation. A certificate of registration on the official list is sufficient evidence of suitability with respect to the grounds for exclusion relating to breaches of environmental and waste management legislation. The contracting authority may not request any further evidence from the economic operator on this matter.

The contracting authority may, however, request evidence demonstrating that the economic operator to which it wishes to award the contract has not been convicted of relevant labour law offences. This request is allowed because the official list does not cover convictions for offences relating to breaches of labour law. A certificate of registration on the official list does not provide evidence of suitability in relation to the grounds for exclusion concerning labour law offences. The contracting authority is entitled to ask for evidence from the economic operator on this matter.

With regard to the payment of social security contributions and taxes, an additional certificate may be required of a registered economic operator whenever a contract is to be awarded.

In the context of the use of the ESPD, an economic operator will self-certify that it has the necessary registration. The official list certificate will be the means of proof that the 
contracting authority may request from the economic operator to which it proposes to award the contract.

Contracting authorities must not make registration on an official list of approved economic operators a condition for participation in the tender procedure or in the award of the contract. Contracting authorities must accept other equivalent means of proof of suitability for participation in a procurement procedure. Registration on official lists of other Member States must be accepted.

Economic operators registered on an official list or possessing a certificate are not to be treated more favourably than those that are not registered on such a list, and the registration system must allow economic operators to request registration or certification at any time.

Member States that have official lists or certification bodies are obliged to inform the EC and other Member States of the address of the body to which applications for registration should be sent. Member States must also make available to other Member States any information relating to the documents that must be produced as evidence that an economic operator fulfils the requirements for registration on the official list.

It is not entirely clear what evidence contracting authorities are permitted to request in the context of matters that are subject to change. This issue concerns, for example, an official list that is only updated periodically, for example every six or 12 months, so that information on that list may not be up-to-date and accurate. As mentioned above, the Directive specifically mentions the possibility of requesting an additional (updated) certificate concerning the payment of social security contributions and taxes. It is sensible to apply a similar approach to other certificates that are time-critical.

In Estonia, under the 2007 PPL, which implemented the 2004 Directives, a voluntary list of recognised construction companies has been set up by Government regulation (RT I, 26 June 2012, 26). Little use is made of this voluntary list, and the issue will be reviewed after the adoption of the new PPL. Provisions in the new PPL concern the setting up of official lists of approved economic operators. The creation, maintenance and renewal of the lists for various fields of activity will be reviewed and procedures established by the Government. The official keeper of each list is the ministry responsible for the relevant area. These new official lists are not yet operational.

Hungary has legal provisions in place permitting the establishment and operation of official lists of approved economic operators by the PPL and the Chamber of Commerce and Industry, as well as by other professional chambers. The lists are voluntary and economic operators are not obliged to be included in the lists. The lists relate to information on compliance with minimum requirements, including annual accounts, financial situation, profession risk indemnity insurance and references.

The PPA is required to manage, update and publish on its homepage the official list of approved economic operators. The official list operated by the PPA provides the certification of compliance with some, but not all, of the mandatory and discretionary grounds for exclusion, as well as with suitability criteria. A key advantage of the official list is the reduction of administrative effort and bureaucracy, and in particular notarising the self-declaration by the successful economic operator is not needed. At the time of this study, participation in the official list operated by the PPA was very limited, with only 26 economic operators listed. It appeared, from the interviews carried out for this study, that economic operators perceived the official list to be of limited use because it did not provide certification for all the grounds for exclusion. Economic operators still have to 
provide separate means of proof on the grounds for exclusion not covered by the official list.

The Chamber of Commerce and Industry and other professional chambers are also permitted to set up official lists. The PPA is responsible for assessing the adequacy of the conditions for inclusion as an approved tenderer on the lists drawn up by the Chamber of Commerce and Industry and other professional chambers and for registration on those lists. The official lists operated by these organisations are limited to certification of the suitability criteria applicable to the activities of the chamber's members. These lists inform the contracting authority concerning the qualification and licence of the member, and they are used if official eligibility to practice the profession is needed. In theory, these lists should appear on the PPA's website. Most of the chambers publish their lists of members on their websites ${ }^{133}$.

In Malta, the new PPL provides that the minister responsible for Finance shall have the authority to establish regulations for drawing up official lists of approved economic operators and for certification by bodies established under public or private law. No such regulations have as yet been issued.

It is interesting to note that in the countries studied that do have official lists, either these lists are not functioning in practice or the levels of participation of economic operators are low. It is not entirely clear what the reason for this situation is in each case. A number of changes introduced by the 2014 Directive may mean that the practical importance of official lists has diminished. The introduction of the principle of self-declaration, combined with the assessment of the means of proof for the winner only, reduces the administrative burden for economic operators to a significant degree. Economic operators that may have benefited previously from reduced administration as a result of being included on an official list may now find that the benefits are less pronounced in the light of self-declaration and "winner-only" assessment of the means of proof. The introduction of automated means of proof on national databases and online certificates that must be checked by the contracting authority also shifts the administrative burden away from the economic operator and thus may also reduce the appeal of official lists.

\subsubsection{Blacklists}

The Directive does not deal with the specific issue of the possibility of maintaining a central list of economic operators resulting in automatic exclusion ("blacklists" or debarment lists, as they are sometimes called). The permissibility, use and operation of blacklists therefore need to be considered in the light of the provisions in the Directive on the grounds for exclusion and self-cleaning, the Treaty and general EU law principles. The case law of the CJEU is also relevant. Although there is currently no CJEU case law on the use of blacklists under the 2014 Directive, the CJEU has often considered the way in which grounds for exclusion have been applied in Member States. The CJEU has consistently emphasised the importance of the principle of proportionality in the context of decisions to exclude economic operators. In one of these cases, concerning exclusion on the grounds of grave professional misconduct, the CJEU held that the decision to exclude had to be made on a case-by-case basis, as will be discussed later in this section.

${ }^{133}$ Hungarian Chamber of Engineers, www.mmk.hu/kereses/tagok. 
The recent introduction of new and amended grounds for exclusion in the 2014 Directive, together with additional national grounds for exclusion, still to be tested in the CJEU, and the new and important right granted to economic operators to demonstrate "self-cleaning" measures, leaves the establishment and use of blacklists in some doubt. Commentators have expressed different opinions on what is, and is not, permissible or advisable, and national practices vary ${ }^{134}$.

The new provisions on self-cleaning are an important factor to take into account in a discussion on the permissibility of blacklists. Article 57(6) of the Directive gives an economic operator the right to provide evidence of its reliability, despite the existence of mandatory or discretionary grounds for exclusion applying to that economic operator. Where the evidence provided by the economic operator is sufficient to demonstrate its reliability, the economic operator "shall not be excluded from the procurement procedure".

The Directive provides only one exception to the right to self-cleaning: where the economic operator "has been excluded by final judgement from participating in procurement ... procedures" and where that final judgement specifically stipulates the period of time for which the exclusion from procurement procedures applies ${ }^{135}$. The right to self-cleaning can therefore only be taken away from an economic operator if a final judgement specifies both the sanction of exclusion from procurement procedures and the period during which that sanction applies. Where the final judgement does not cover both of these issues, automatic exclusion is not permitted and the right to self-cleaning is available to the economic operator concerned. When the existence of grounds for exclusion has been confirmed by final judgement, but the court has not ordered a sanction of exclusion from participation in procurement procedures within a period that is specified in the final judgement, the economic operator cannot be automatically excluded. The economic operator in that situation has the right to demonstrate self-cleaning. It follows that a blacklist of automatically excluded economic operators can only include economic operators that have been excluded from public procurement procedures by final judgement for a specified period.

Good arguments support the position that the nature and seriousness of the alleged wrongful conduct and the impact of exclusion should always be assessed on a case-by-case basis, except for the exemption referred to above. This approach seems to be in line with the interpretation of the CJEU in case C-465/11 Forposta, concerning the exclusion of economic operators on the grounds of "grave professional misconduct" under the 2004 Directive (similar grounds are found in the 2014 Directive). The CJEU interpreted the 2004 Directive as precluding national legislation that would oblige a contracting authority to automatically exclude in a new procedure an economic operator found guilty of grave professional misconduct, without granting to that contracting authority the power to assess, on a case-by-case basis, the gravity of the allegedly wrongful conduct of that operator in the performance of the previous contract. This requirement to consider the question of exclusion on a case-by-case basis eliminates the

\footnotetext{
${ }^{134}$ Examples are given in the country chapters for Hungary and Malta, Sections 4.2 and 4.4.

135 This exception to the right to self-cleaning applies only in the Member State where the judgement is effective. In other Member States, where the judgement is not effective, the economic operator can use self-cleaning measures.
} 
possibility of including an economic operator on a central, automatic blacklist on the grounds of grave professional misconduct.

Proportionality is another important factor when considering the permissibility of blacklists, and it is one of the basic safeguards (it is also discussed in Section 1.9.2). In C-21/03 Fabricom, the CJEU ruled that national legislation in Belgium that prohibited (that is, excluded) from tendering for a contract all persons who had been involved in preparatory work for that contract, even when those persons could demonstrate that competition would not be affected, was not a proportionate measure. The CJEU considered that the national legislation extended beyond what was necessary to achieve the objective of ensuring equal treatment. This objective could be achieved and competition safeguarded by a less restrictive measure. It could be achieved by giving economic operators the opportunity to demonstrate that their participation represented no risk to competition and by prohibiting only those operators that were unable to prove that their participation was not a risk.

The CJEU has also applied the proportionality principle and ruled that national legislation that has the effect of automatically excluding particular types of providers - such as those with media connections (C-213/07 Michaniki), with specific relationships of control or affiliation (C-538/07 Assitur), consortia and their members in certain cases (C-376/08 Serrantoni) - goes beyond what is necessary to achieve the objective and is in breach of the proportionality principle. National grounds for exclusion have been introduced in addition to the grounds set out in the 2014 Directive. The national grounds for exclusion differ between the Member States studied in this paper, which is likely to increase the uncertainty on the issue of use of central automatic blacklists. The proportionality principle and other general principles will apply to the use of these national grounds (see Part 5, Section 5.6, for more information on these CJEU cases).

Basic safeguards: Any process that may potentially lead to the exclusion of an economic operator must be open and fair. It must comply with basic safeguards ensuring non-discrimination, transparency and proportionality, both in the conduct of the process and in decision making. The process must be:

- Proportionate: The effect of the exclusion must be reasonable and proportionate to the nature and seriousness of the grounds for exclusion, as discussed above.

- Non-discriminatory: This requirement means that the process must operate in a manner that ensures that an economic operator from one EU Member State is not treated in a different manner - either less favourably or more favourably - than an economic operator from another Member State. All economic operators must be treated equally.

- Transparent: This requirement means that the process must be determined with absolute certainty and made public, so that economic operators understand how and in what circumstances they may be excluded or removed from the exclusion list.

- Fair and equitable: The process must operate in a manner that ensures fair and equal treatment. The process must be applied and the decisions must be made consistently, in a manner that treats all economic operators equally and does not favour a particular economic operator. 
- Respectful of due process and right of review: Due process must be applied to the exclusion process, which includes ensuring that timescales are fair and that economic operators understand the process and have an effective right of appeal.

In conclusion, in view of the uncertainty concerning the permissibility and use of central automatic blacklists, the safest approach is to avoid using such blacklists except in the case of a blacklist of economic operators for which a final judgement has specified both the sanction of exclusion from public procurement procedures and the period during which that sanction will apply. 


\section{Key findings and success factors}

\subsection{General principles}

- A structured pre-planning stage that focuses on more than simply direct needs and budget issues assists contracting authorities with driving improvements and creating a relevant and streamlined procurement procedure and procedure outcome.

Structured pre-planning encourages contracting authorities to think carefully about how public procurement can be used to encourage engagement with SMEs and to drive improvements with regard to environmental, social and labour issues. Structured pre-planning also informs decisions where the contracting authority determines which discretionary grounds for exclusion, selection criteria and shortlisting rules are both appropriate and relevant to the particular contract and procurement procedure.

\subsection{Mandatory grounds for exclusion}

- A clear explanation of the link between the grounds for exclusion based on criminal offences listed in the Directive and the equivalent national criminal offences assists contracting authorities with verifying the existence or non-existence of final judgements for specific crimes.

In each of the six Member States studied, it is very rare for an economic operator to actually be excluded from a procurement procedure on the basis of mandatory grounds for exclusion

All six Member States have established additional national mandatory grounds for exclusion. It is significant that those additional grounds are diverse, although they all aim to implement legitimate policies, such as the protection of labour and competition law. In that regard, it is obvious that Member States tend to create additional grounds for exclusion in order to tackle particular domestic issues. For example, labour-related exclusions show that public procurement can be used as one of the instruments in the fight against violations in the labour market, which should ultimately increase fair competition between economic operators.

\subsection{Self-cleaning}

- Centralised management of self-cleaning by economic operators is a positive way of ensuring the uniform application of decisions on self-cleaning measures, developing a centre of expertise in the assessment of self-cleaning measures, and establishing a higher level of legal certainty.

The concept of self-cleaning means that, in most cases, an economic operator to which grounds for exclusion apply has the right to submit evidence of measures that it has taken to demonstrate its suitability to perform a contract, despite those grounds for exclusion. 
The contracting authority must take that evidence into account when deciding whether or not to exclude the economic operator concerned.

In five of the six countries studied, contracting authorities must themselves determine, on a case-by-case basis, whether the self-cleaning measures are acceptable. When making a decision as to whether or not to exclude an economic operator, the contracting authority must take into account basic principles, such as equal treatment, transparency and competition. It must also take corruption risks into account, and this task places quite a burden on the contracting authority.

Centralised management of self-cleaning by economic operators, as established in Hungary, appears to have had a positive influence on the establishment of national practices elsewhere. Centralised management prevents arbitrary decision making on self-cleaning by individual contracting authorities that goes beyond a specific procurement procedure. It enables the uniform application of adopted decisions throughout the national procurement system, covering all contracting authorities and procedures. A decision-making process that is carried out centrally by professionals ensures legal protection against unfavourable decisions and a higher level of legal certainty compared to decision making at the level of an individual contracting authority. This can ensure an overall higher level of reliability and integrity in the national procurement system. Taking into consideration the existing institutional framework, namely the fully functioning public procurement offices/agencies, various options are available to establish similar practices without setting up new institutions to carry out this task.

\subsection{Selection}

- Using selection criteria and minimum requirements which are appropriate, relevant and transparent assists contracting authorities with selecting the most qualified economic operator and does not inappropriately limit competition.

Contracting authorities do not have to use selection criteria if they are inappropriate or irrelevant. They can also choose which selection criteria to apply, and they are not obliged to apply all of the criteria. Where contracting authorities do use selection criteria, those criteria should aim to select the most qualified economic operators and should, in accordance with the Directive, not have the effect of inappropriately limiting competition. Minimum requirements which are set to encourage the participation of economic operators, rather than acting as a disincentive, help to create more competition. Clear wording of selection criteria and minimum requirements assists economic operators to understand which criteria and requirements they need to meet.

In each case, the decision as to which selection criteria are to be used and when, and as to the level at which minimum requirements are to be set, needs to be based on a thorough understanding on the part of the contracting authority of the particular market and of the impact that the criteria and requirements will have on competition.

It is also worth noting that both assessment of the necessary human and technical resources and experience in performing a contract are permitted criteria for the selection stage. It is possible to use the organisation, qualification and experience of staff assigned to the performance of the contract as award criteria, in cases where the quality of staff assigned can have a significant impact on the level of performance of the contract. In certain cases, it may be preferable to focus on the assessment of human resources at the 
tender evaluation stage rather than the selection stage, where, for example, overrestrictive selection criteria would limit competition.

\subsection{Shortlisting}

- Using criteria and rules for shortlisting which are relevant to the contract, transparent and appropriate, assists contracting authorities with selecting the best qualified candidates.

The purpose of a shortlisting process is to allow the contracting authority to select the candidates that are the most qualified to deliver the contract. When the contracting authority fully understands this purpose and ensures that the criteria and rules used for shortlisting are both relevant to the contract and objective and appropriate, this is likely to achieve the outcome of selecting the most qualified candidates. The use of inappropriate or irrelevant criteria or rules may result in a shortlist of candidates that are not the most qualified to participate in the procurement procedure. Random selection, for example, is unlikely to achieve the aim of selecting the most qualified candidates. The use of inappropriate or irrelevant criteria or rules may limit competition and reduce the likelihood of achieving the best value for money. Transparency is also important, so that economic operators understand the way in which the shortlisting process will be conducted, what criteria will be used (including what and how a methodology or scoring system will be applied), and the proposed minimum number of economic operators to be shortlisted.

\subsection{Self-declaration}

- The concept of self-declaration is a welcome and positive development, and it has significant potential for reducing administrative burdens and increasing efficiency and competition.

The general concept of self-declaration by economic operators in EU Member States with the introduction of the ESPD is a positive development that can significantly help reduce administrative burdens and the costs of participation in procurement, as well as in streamlining the procurement process in general.

The self-declaration reduces the burden on economic operators applying to participate in a public procurement procedure, since their only requirement is to provide a statement. The obligation to present means of proof of eligibility generally applies only to the tenderer to which the contracting authority has decided to award the contract. Limiting this obligation to the "winning" tenderer significantly reduces the administrative burden and can also enhance competition by encouraging economic operators to participate.

- A simple, adjustable, user-friendly form of self-declaration helps to streamline procurement.

The form of the self-declaration can be regulated in national legislation, taking into account local practices and environment. Unnecessarily complex or lengthy self-declaration may be a disincentive for participation by economic operators and add to the administrative burden of contracting authorities. A form of self-declaration which leaves room for adjustment by the contracting authority to the given procedure, helps to streamline procurement, by providing the opportunity to avoid requests for information that are not material to the task at hand. 


\subsection{Means of proof}

- A clear list of certificates and documents that may be requested from economic operators assists in promoting transparency and effectiveness of the procurement process.

A defined list of documents that can be requested from contracting authorities makes the process more transparent. In this way, economic operators are informed in advance of the documents they may be asked to submit in any public procurement procedure.

Some flexibility, to allow for the diversity of the documents that may be relevant to a particular procurement procedure is a helpful approach in ensuring the effectiveness of the procurement process. Avoiding over detailed descriptions of, or artificial constraints on, the documents to be provided by economic operators may also assist in reducing the administrative burden on both contracting authorities and economic operators.

- Official e-databases for documents issued by the public administration, such as tax certificates and criminal records, have significant advantages.

It is most efficacious to use existing systems where administrative bodies already have the technology in place, and where the legal conditions are already established for sharing information on economic operators on electronic platforms.

Besides the obvious saving of time and costs for economic operators, contracting authorities have access to reliable and up-to-date information. This solution prevents the exclusion of economic operators based only on formal issues, such as the submission of a certificate in an inacceptable form, which can occur in more traditional systems. A properly designed e-procurement platform gives the contracting authority direct and cost-free access to the data necessary to verify the absence of grounds for exclusion.

- Developing publicly accessible online databases gathering information on concluded contracts and their execution will also streamline the task.

The evaluation of past experience in the execution of contracts of comparable type and value is the most common selection criterion in public procurement procedures. When the experience presented by economic operators involves their performance of public contracts, it also provides an opportunity to use gathered data for public procurement.

The development of publicly accessible online databases in which information on concluded contracts and their execution will be gathered and published can assist in this process.

A related and crucial issue is the need for pro-active contract management by contracting authorities, to ensure that the information gathered on concluded contracts and their execution is accurate and reliable.

- Direct access to available online databases is one of the most efficient means of solving the problem of bureaucracy in public procurement.

Nevertheless, in areas where more traditional systems are still in place, other means of accelerating the verification process may be adopted.

- To avoid excluding economic operators on purely formal grounds and to increase the transparency of the system, it may be helpful to regulate grey areas, such as: 
- Period of validity of documents: a reasonably long period of validity may reduce economic operators' need to obtain the same types of documents repeatedly;

- Form of document: ensuring that there is no requirement for a special form of document, such as an original, a copy certified by a notary or relevant administrative body, or a sworn translation, may reduce the administrative burden on economic operators.

\subsection{Additional information and documents}

- A flexible approach permitting contracting authorities to request additional information or documentation from economic operators associated with the stage for the choice of participants is a positive way of encouraging competition.

The exclusion or rejection of economic operators on formalistic grounds unrelated to their suitability and capability discourages competition. The Directive tackles this problem directly. It allows contracting authorities to take a flexible approach by accepting additional information or documentation from economic operators associated with the stage for the choice of participants.

The process of requesting additional information or documentation must, in accordance with the Directive, be conducted in a transparent manner, ensuring compliance with the principle of equal treatment. Clear provisions that set out reasonable timescales applying to the requests for the provision of additional information or documentation add transparency and clarity to the process and assist in ensuring equal treatment.

\subsection{Official lists}

\section{- The operation of official lists appear to be limited.}

In the Member States studied that do have official lists, these lists are either not functioning in practice or the levels of participation by economic operators are very low. In each country, the reason for this situation is not clear.

A number of changes introduced by the 2014 Directive may have decreased the practical importance of official lists. The introduction of the principle of self-declaration, combined with the assessment of the means of proof for the "winner-only", have significantly reduced the administrative burden for economic operators. Those that benefitted from reduced administration because they were included on an official list might now find that those benefits less pronounced after the introduction of the self-declaration and the "winner-only" assessment of the means of proof. The introduction of automated means of proof on national databases, as well as online certificates that must be checked by the contracting authority, have shifted the administrative burden away from the economic operators.

\subsection{Blacklists}

\section{- The permissibility of central automatic blacklists is uncertain.}

The permissibility and use of central automatic blacklists, is uncertain and the safest approach to adopt is to avoid using such blacklists. A clear exception is in the case of the 
blacklist of economic operators for which a final judgement specifies both the sanction of exclusion from public procurement procedures and the period during which the sanction will apply because, in this case, no self-cleaning measures can be used as a defence against exclusion. 


\section{Country chapters}

\subsection{ESTONIA}

\subsubsection{Overview}

\section{Public procurement legislation}

\section{Key legislation}

The key public procurement legislation covering the exclusion, selection and shortlisting stage of public procurement processes undertaken by contracting authorities is provided in the Public Procurement Act of 14 June 2017.

The Parliament (Riigikogu) issues the primary public procurement legislation, and the Government of the Estonian Republic ("the Government") and the relevant ministries (mainly the Minister of Public Administration) issue the secondary legislation (regulations).

\section{Primary legislation}

- Public Procurement Act of 14 June 2017 (RT I, 1 July 2017, 1) ("Public Procurement Act" or "PPL"), replacing the Public Procurement Act of 2007 (2007 PPL), in force as of 1 September 2017.

- Placing orders for Works of Art Act (RT I 2010, 43, 257).

\section{Secondary legislation}

- Requirements for electronic communication devices - Minister of Public Administration Regulation (RT I 15.08.2017,3).

- Statute of the State Public Procurement Register - Government Regulation (RT I, 01.09.2017, 13).

- Statute of the Public Procurement Appeal Committee - Minister of Public Administration Regulation (RT I, 20.07.2017, 1).

- Regulations for centralised procurements conducted by the Central Purchasing Authority - Government Regulation (RT III, 05.07.2016, 10; RT III, 05.07.2016, 11; RT III, 14.10.2017, 7; RT III, 14.10.2017, 8 ).

- Rules for handling and forwarding information through the Ministry of Finance to the European Commission (RT I, 15.08.2017, 4).

Brief description of the key legislation

The Statute of the State Public Procurement Register is established by the Government pursuant to Article 181.6 of the PPL for the adoption of the Register's statutes. 
The Statute of the Public Procurement Appeal Committee, approved by the Minister of Public Administration, is established pursuant to Article 187.13 of the Public Procurement Act for the review proceedings carried out by the members of the Review Committee.

\section{Transposition issues according to Directive 2014/24/EU}

The new PPL was adopted by the Parliament on 14 June 2017 and announced by the President on 22 June 2017.

The PPL applies to contracts above and below the EU financial thresholds and the national financial thresholds for supplies, services and works.

The PPL establishes the national legislative framework for sustainable public procurement, and it also contains provisions on remedies that are adapted to align with the national legal system, in accordance with Remedies Directives 89/665/EC, 92/13/EC and 2007/66/EU.

The regulation on exclusion covers mandatory and discretionary grounds for exclusion, including national grounds for exclusion.

National financial thresholds

The national financial thresholds, according to the PPL, are the following:

- EUR 150000 (EUR 250000 in the 2007 PPL) for public works;

- EUR 60000 (EUR 40000 in the 2007 PPL) for other public contracts.

\section{Regulation of contracts above the EU financial thresholds}

The PPL regulates contracts above the EU thresholds.

\section{Regulation of contracts above the national thresholds and below the EU financial thresholds}

The PPL regulates contracts between the national financial thresholds and the EU financial thresholds.

\section{Regulation of contracts below the national financial thresholds}

The PPL regulates contracts below the national thresholds.

According to the PPL, the financial thresholds for simplified procedures below the national financial thresholds are the following:

- EUR 60000 (EUR 30000 in the 2007 PPL) for public works;

- EUR 30000 (EUR 10000 in the 2007 PPL) for other public contracts.

Guidance, policy and other information

The following guidance, policy and other information are also relevant.

The e-procurement environment was launched on 2 February 2011, to provide an innovative workspace for contracting authorities to organise public procurement procedures and for tenderers to participate in those procedures. 
The environment consists of a procurement register where contracting authorities can publish procurement procedures and tenderers can participate ${ }^{136}$.

The Estonian procurement website is part of the website of the Ministry of Finance and provides additional resources, including links to public procurement legislation, guidance (on how to use the legislation and information that is useful to know), manuals, procurement policy, news, FAQ, training, procurement search, statistics, appeal search, thresholds and timelines, as well as contact information concerning important institutions in the public procurement field ${ }^{137}$.

The first electronic Procurement Register was launched on 1 April 2001. In 2011, the possibility to submit e-tenders was added. Estonian citizens can $\log$ in using modern electronic identification tools, an ID card or a mobile-ID solution. Cross-border tenderers are also welcome to login, with a username and password or with an e-residency for foreign persons, Dig-ID. The Ministry of Finance has launched a project to update the Procurement Register. This project will enable the register to accommodate new standard forms, flexible procurement procedure mechanisms and innovative e-procurement tools, as provided for in the $2014 \mathrm{EU}$ public procurement Directives. The updated register (Public Procurement e-Register) will also have a new technical platform and an updated interface with interactive capability. The results of the project will reach the end-users during the period 2016-2019.

\section{Advertising}

All contracts below the national thresholds (simplified procedures), as well as those above the national thresholds and the EU thresholds, must be advertised on https://riigihanked.riik.ee/register.

\subsubsection{Choice of participants: exclusion, selection and shortlisting - further information}

\section{General principles}

Article 18 of the Directive sets out the general principles of procurement, namely equal treatment, non-discrimination, transparency and proportionality. Article 18 also requires that procurement not be designed with the intention of excluding it from the scope of the Directive or of artificially narrowing competition. Article 3 of the PPL sets out these general principles.

Article 56(1) of the Directive sets out the general principles applying to the choice of participants and the award of contracts.

Article 56(2) of the Directive permits contracting authorities to examine tenders submitted in an open procedure prior to verifying the absence of grounds for exclusion and the fulfilment of the selection criteria. Member States have the option to exclude or restrict the use of this approach for specific types of procurement or in specific circumstances. Article 52.3 of the PPL contains this provision. The provision applies to all types of procurement and in all circumstances.

\footnotetext{
${ }^{136} \mathrm{https} / / /$ riigihanked.riik.ee/register/

${ }^{137}$ https://riigihanked.riik.ee.
} 
Article 56(3) of the Directive allows contracting authorities to ask economic operators to "submit, supplement, clarify or complete the relevant information or documentation" where information or documentation submitted by those economic operators is, or appears to be, incomplete or erroneous or where specific documents are missing. This provision applies "unless otherwise provided by national law". Article 46.4 of the PPL contains a provision allowing the economic operators to clarify documents and information presented. New information and new documents cannot be submitted.

\section{Mandatory grounds for exclusion}

\section{Mandatory grounds for exclusion - conviction by final judgement:}

Article 57(1) of the Directive lists mandatory grounds for exclusion for specified offences. Article 95 of the PPL lists mandatory grounds for exclusion:

Exclusion for the non-payment of taxes or social security contributions - judicial or administrative decision: Article 57(2) of the Directive refers to mandatory exclusion on the grounds of non-payment of taxes or social security contributions, as established by a judicial or administrative decision having final and binding effect. Article 95.1.4 of the PPL refers to these mandatory grounds for exclusion.

Exclusion for the non-payment of taxes or social security contributions - other means of proof: Article 57(2) of the Directive permits contracting authorities to exclude an economic operator where they can demonstrate by any appropriate means that it in breach of its obligations relating to the payment of taxes or social security contributions. Member States may make exclusion on these grounds mandatory.

Article 95.1.4 of the PPL refers to these mandatory grounds for exclusion. According to Article 95.4.1 of the PPL, the contracting authority may exclude economic operators on the grounds of non-payment of local (municipal) taxes.

\section{Derogations from mandatory exclusion}

Article 57(3) of the Directive permits Member States to provide for a derogation from mandatory exclusion on grounds of public interest. This derogation is included in Article 95.3 of the PPL.

Article 57(3) of the Directive permits Member States to provide for derogation from mandatory exclusion for non-payment of taxes or social security contributions where exclusion would be clearly disproportionate. This derogation is included in Articles 95.1.4, 95.3 and 95.6 of the PPL.

Additional national mandatory grounds for exclusion

According to Article 95.1 of the PPL, the contracting authority is not allowed to enter into a contract and should exclude from the procurement procedure any tenderer or applicant whose administrative, management or supervisory body member or other legal or relevant procurement-related, contractual representative has been:

- punished by the Court for enabling the employment of an alien who is residing in the country without legal grounds;

- the subject of international sanctions in accordance with the International Sanctions Act. 


\section{Discretionary grounds for exclusion}

Article 57(4)(a)-(i) of the Directive provides the discretionary grounds for exclusion. Member States have the option to make some or all of these grounds for exclusion mandatory.

No discretionary grounds for exclusion are mandatory. All discretionary grounds are listed in Article 95.4 of the PPL. The same principle applied to the 2007 PPL, where the grounds for exclusion were more limited than in the new PPL.

\section{Additional national discretionary grounds for exclusion}

In Article 95.4 of the PPL, all of the national discretionary grounds for exclusion are provided. The contracting authority may exclude from the procurement procedure a tenderer or applicant that:

- has local tax arrears (local or municipal taxes) concerning the location of a contracting authority, in accordance with the meaning provided in the Tax Administration Act;

- has been punished, or whose administrative, management or supervisory body members or other legal representatives have been punished, for offences in the area of taxation;

- lacks the legal right to submit an application or a tender.

Option to not exclude an economic operator in the case of bankruptcy or the equivalent: Article 57(4) of the Directive permits Member States to provide for the possibility to not exclude an economic operator on the grounds of bankruptcy or in equivalent situations where national rules and measures apply concerning the continuation of business. This option is included in Article 95.4.2 of the PPL.

Exclusion at any time in the procedure: Article 57(5) of the Directive permits a contracting authority to exclude an economic operator where it becomes aware at any time in the procedure that the grounds for mandatory or discretionary exclusion apply, because of acts committed or omitted by the economic operator either before or during the procedure. Member States have the option to make exclusion in these circumstances mandatory. This option is included in Article 104.7 of the PPL.

Maximum periods of exclusion: The maximum periods of exclusion are as follows:

- Mandatory grounds for exclusion, listed in Article 95.1 of the PPL, entail five years of exclusion, as from the date of conviction by the final judgement.

- Discretionary grounds for exclusion, listed in Article 95.4 of the PPL, entail three years of exclusion, as from the date of the relevant event.

\section{Self-cleaning}

Article 57(6) of the Directive permits an economic operator to provide evidence of measures it has taken to demonstrate its reliability despite the existence of relevant grounds for exclusion. If such evidence is considered to be sufficient, the economic operator concerned shall not be excluded from the procurement procedure. Article 97 of the PPL sets out the provisions related to self-cleaning. 


\section{Selection}

Article 58 of the Directive provides that selection criteria may relate to: (a) suitability to pursue the professional activity; (b) economic and financial standing; and (c) technical and professional ability. These requirements must be appropriate, related and proportionate to the subject matter of the contract.

The provisions on selection are set out in Articles 98, 99, 100 and 101 of the PPL. Suitability to pursue professional activity is stipulated in more detail and in a separate Article (Article 99) of the PPL. In the 2007 PPL, the contracting authority was obliged to check the economic and financial standing of the economic operator (a minimum one requirement on the list) and its technical and professional ability (also a minimum one requirement on the list). The most common selection criteria have been the requirement for a specified turnover and the requirement for a number of contracts of a specified value (both of which reflect the value of the object of the procurement).

\section{Reduction in the number of otherwise qualified candidates to be invited to participate}

Article 65 of the Directive lays down the rules on the reduction of the number of otherwise qualified candidates to be invited to participate in restricted procedures, competitive procedures with negotiation, competitive dialogue, and innovation partnerships.

The provisions on the reduction of otherwise qualified candidates are set out in Article 54.3 of the PPL for restricted procedures; in Article 68.3 of the PPL for competitive procedures with negotiation; in Article 64.3 of the PPL for competitive dialogues; and in Article 58.3 of the PPL for innovation partnerships. Due to the relatively low number of exceptional procedures utilised, the results of this approach on reducing the number of candidates have been limited.

\section{European Single Procurement Document}

Article 59 of the Directive requires contracting authorities to accept the ESPD as preliminary evidence in the replacement of certificates issued by public authorities or third parties confirming that the relevant economic operator fulfils conditions relating to the grounds for exclusion, the selection criteria and, where applicable, the objective rules and criteria for reduction of the number of otherwise qualified candidates to be invited to participate. The provisions of the ESPD are set out in Article 104 of the PPL.

According to Articles 104.11 of the PPL, the economic operator is not obliged to submit the required data or documents if this information/documentation is available on public electronic databases. In that case, the contracting authority can easily check in a few seconds through the e-Procurement Register application, which interfaces with other databases through the public X-Road e-Cloud application, linking to the following databases: Business Register, Activities Register, Tax Register and Criminal Register. The fields for these checks are as follows: company status, representatives, annual reports, fields of activity, tax report on selected data, Tallinn City local tax arrears query and punishment data. The menu "communications - queries to other registries" of the e-Procurement Register should be used to apply the above-mentioned data. 
Means of proof

Article 60 of the Directive sets out the provisions for the means of proof serving as evidence for the grounds for exclusion and the fulfilment of the selection criteria. The provisions on the means of proof are set out in Articles 96.2, 96.3, 98.4, 99.2, 100 and 101 of the PPL.

\section{Reliance on the capacity of other entities}

Article 63 of the Directive provides that, where appropriate and with regard to a specific contract, an economic operator may rely on the capacity of other entities to satisfy the criteria set by the contracting authority in relation to economic and financial standing. This provision is subject to the fulfilment of specified conditions. The provisions on the reliance on the capacity of other entities are set out in Article 103 of the PPL.

Lists

Official lists of approved economic operators

Article 64 of the Directive permits Member States to establish or maintain official lists of approved economic operators that have submitted acceptable evidence of their suitability to deliver public contracts.

The provisions for setting up official lists of approved economic operators are set out in Articles 105 and 106 of the PPL. According to these provisions, the designation of recognised companies and the maintenance and renewal of a list of various fields of activities are to be reviewed and procedures are to be established by the Government (Article 106.4). The official keeper of the list is the ministry responsible for the relevant area (Article 106.5).

The list of recognised construction companies was established by a regulation of the Government of Estonia (RT I, 26 June 2012, 26). The usage of the list of recognised construction companies by contracting authorities was voluntary and in recent times, the list was rarely used in accordance with the provisions of Articles 38-42 of the 2007 PPL.

\section{Blacklists}

No specific provisions in the Directive permit or prohibit the use of blacklists of economic operators that are subject to the grounds for mandatory or discretionary exclusion.

No authorised or centralised blacklisting exists in Estonia. 


\subsection{HUNGARY}

\subsubsection{Overview}

\section{Public procurement legislation}

\section{Key legislation}

The key public procurement legislation is in the form of primary and secondary legislation.

The legislation covering the exclusion, selection and shortlisting stage of public procurement processes undertaken by contracting authorities is contained in the following:

\section{Primary legislation}

- Act CXLIII of 2015 on PPL.

\section{Secondary legislation}

- Government Decree 321/2015 (30 October 2015) on the way of certifying suitability and the non-existence of the grounds for exclusion as well as the definition of public procurement technical specifications in contract award procedures (GD).

All public procurement legislation can be downloaded from the official website of the PPA: www.kozbeszerzes.hu (partly in English).

\section{Brief description of the key legislation}

The PPL and several Government Directives (PPRs) transpose Directives 2014/23/EU (award of concession contracts), 2014/24/EU (public procurement) and 2014/25/EU (entities operating in the water, energy, transport and postal service sectors). The PPL also contains provisions on remedies, adapted to align with the national legal system, in accordance with the Remedies Directive 89/665/EC. The PPRs are in the form of secondary legislation (GD) and subsidiary legislation (Ministerial Decrees).

The PPRs apply to all contracting authorities and utilities above the EU financial threshold (Part 2) and above the national threshold (Part 3).

The PPL took effect on 1 November 2015 and covers all of the public procurement procedures and contracts of contracting authorities. The system for procurements below the EU threshold is quite complex.

The Government has taken advantage of the delay allowed in the transposition of provisions applicable to electronic communication, which came into force on 18 April 2017 for central purchasing bodies and which came into force on 15 April 2018 for all contracting authorities. The legislation also includes requirements concerning the electronic format of the ESPD and e-Certis. All procedures must be conducted according to the new rules, including the use of the ESPD, but unfortunately, most contracting authorities continue to use the word form of the ESPD. The PPRs on exclusions include mainly mandatory and some discretionary grounds for exclusion, including several national grounds for exclusion. 
National financial thresholds

The national financial thresholds have been revised and, from 1 January 2018, are the following:

\section{Contracting authorities}

National (minimum) thresholds:

- HUF 15 million (EUR 48 000) for goods and services;

- HUF 25 million (EUR 80 000) for works;

- HUF 30 million (EUR 96 000) for services concessions;

- HUF 100 million (EUR 324 527) for works concessions.

Intermediary threshold 1 :

- HUF 300 million (EUR 962 000) for works.

Intermediary threshold 2:

- HUF 700 million (EUR 2244 000) for works.

\section{Utilities}

National (minimum) thresholds:

- HUF 50 million (EUR 162 263) for goods and services;

- HUF 100 million (EUR 324 527) for works;

- HUF 100 million (EUR 324 527) for services concessions ;

- HUF 200 million (EUR 649 054) for works concessions.

Intermediary threshold 1 :

- HUF 700 million (EUR 2244 000) for works.

\section{Regulation of contracts above the EU financial thresholds}

The PPL and several GDs and Ministerial Decrees regulate contracts above the EU thresholds. The same provisions on exclusions apply to contracts below the EU thresholds. The differences between the provisions are found in the means of proof.

While for contracts above the EU thresholds the use of the ESPD is mandatory, for contracts above the national thresholds and below the EU thresholds no such obligations apply; instead, simple statements from the economic operator must be submitted (Article 114 (2) of the PPL).

Regulation of contracts above the national thresholds and below the EU financial thresholds

The PPL regulates contracts between the national thresholds and the EU financial thresholds, and it includes provisions on the exclusion of economic operators. The 
regulation concerning the national threshold is divided into three sub-regimes, which over-complicates the procedural rules ${ }^{138}$.

National (minimum) thresholds:

- HUF 15 million (EUR 48 000) for goods and services;

- HUF 25 million (EUR 80 000) for works.

Intermediary (maximum) threshold 1 :

- HUF 300 million (EUR 962 000) for works.

According to Article 115(1) of the PPL, if the estimated value of public works is below HUF 300 million, the contracting authority may proceed to conduct either open procedure or negotiated procedure without prior publication of a contract notice under the rules of national treatment, except if the contract is related to a project financed by EU funds. The contracting authority may use the procedure under this Section if it is aware that an appropriate number of suitable economic operators is available to guarantee fair competition. Contracting authorities shall ensure competition and, instead of publishing a call for competition, shall invite, simultaneously and in writing, at least five economic operators to submit a tender. According to Article 115 (2) of the PPL, contracting authorities are not required to stipulate eligibility criteria for such procedures.

Intermediary threshold 2:

- Below HUF 700 million (EUR 2244 000) for works.

According to Article 113(1) of the PPL, the open, restricted and negotiated procedures below the threshold do not require publication of a notice. The contracting authority sends a summary of the information concerning the procedure to be initiated to the PPA, at least five business days before the starting date of the procedure but within a maximum of 12 months, and the summary is published by the PPA on its homepage. In this case, in accordance with Article 113(2) of the PPL, the contracting authority sends the notice initiating the procedure to at least three economic operators and to all those economic operators who expressed their interest in the procedure.

- Above HUF 700 million (EUR 2244 000) for works.

According to Article 113 (6) of the PPL, it shall suffice to have the notice of change relating to the time limit for the submission of tenders or the time limit for participation, the notice published for setting the procedure in motion or the tender documents dispatched before the initial time limits, without having to publish them. However, the economic operators having expressed their interest for the procedure (notably if they obtained the procurement documents or requested additional information), shall be informed, simultaneously and in writing, of the intent to make changes and on the dispatch of the notice of change, before the initial time limit for the submission of tenders or the time limit for participation expires.

138 The national thresholds were revised with effect from 1 January 2017, creating new and additional intermediary thresholds and some new requirements concerning advertising and the conduct of the tender process, and also introducing greater regulation of contracts above HUF 1 million. 
Furthermore, the procedure mentioned above shall be applied if the estimated value of the services under Annex 3 reaches or exceeds the EU threshold or where the contracting authority used a prior information notice, periodic indicative notice or prequalification notice as a means of calling for competition.

The differences between national sub-regimes are based on the characteristics of the publication of notices, summaries and the direct invitation of economic operators. The determination of minimum requirements regarding technical and professional suitability is obligatory above the EU threshold and above the intermediary threshold 2, it is voluntary below the intermediary threshold 1, based on the PPL, Article 115(2), but it is not applicable for the electronic bidding procedure below the EU threshold (based on the PPL, Article 116(2)).

\section{Regulation of contracts below the national financial thresholds}

GD 459/2016 regulates contracts of a value of between HUF 1 million (EUR 3200 ) and the national minimum thresholds of HUF 15 million (EUR 48000 ) for goods, services and: HUF 25 million (EUR 80 000) for works. GD 459/2016 specifies in detail the contracting authorities to which it applies.

Other contracting authorities not subject to GD 459/2016 have their own internal rules concerning the award of contracts under the national thresholds. It is common practice for contracting authorities to use a form of competitive process for the award of contracts below these thresholds.

\section{Guidance, policy and other information}

The PPA issues guidelines, briefings and notices on various important topics for the procurement community, publishing them on its official website (www.kozbeszerzes.hu). The publication of guidance, policy and other information is obligatory for the Authority, in accordance with the PPL.

The PPA publishes guidelines which include the following issues:

- the methods for calculating the estimated value and the criteria to be taken into account when selecting the method to be applied;

- the evaluation of tenders;

- the methods for the calculation of life-cycle costs and, where appropriate, it shall indicate that a common method for the calculation of life-cycle costs has been made mandatory by a legislative act of the EU;

- international agreements related to public procurements and concerning countries that have an agreement on the avoidance of double taxation with Hungary, as stipulated in PPL, Article 187(2).

The PPA publishes the most important guidelines and presidential briefings on its home page in Hungarian and also in English (http://www.kozbeszerzes.hu/cikkek/authoritysguidelines, and http://www.kozbeszerzes.hu/cikkek/presidents-briefings).

\section{Advertising}

All contracts above the national thresholds, including those above the EU thresholds, must be advertised on the portal of the PPA. From 15 April 2018, all contracts above the national threshold, including in-house contracts, are published on the Electronic Public 
Procurement System as well as the portal of the PPA. All notices are published in the Hungarian Public Procurement Bulletin. Contracts above the EU thresholds must be advertised in the OJEU at www.ted.europa.eu. Summary information should be advertised above the intermediary threshold 1 and below the intermediary thresholds 2 for works and below the EU thresholds for goods and services. Above the intermediary threshold 2, all of the notices must be advertised in the Public Procurement Bulletin.

\subsubsection{Choice of participants: exclusion, selection and shortlisting - further information}

\section{General principles}

Article 18 of the Directive on public procurement sets out the general principles of procurement, namely equal treatment, non-discrimination, transparency and proportionality. Article 18 also requires that procurement not be designed with the intention of excluding it from the scope of the Directive or artificially narrowing competition. Article 2 of the PPL sets out the above general principles.

Article 56(1) of the Directive sets out the general principles applying to the choice of participants and the award of contracts. Article 69 of the PPL sets out these general principles.

Article 56(2) of the Directive permits contracting authorities to examine tenders submitted in an open procedure prior to verifying the absence of grounds for exclusion and the fulfilment of the selection criteria. Member States have the option to exclude or restrict the use of this approach for specific types of procurement or in specific circumstances. Article 81 (5) contains this provision and Articles 69(2)-(9) of the PPL apply to all types of procurement and in all circumstances.

Article 56(3) of the Directive allows contracting authorities to ask economic operators to "submit, supplement, clarify or complete the relevant information or documentation" where the information or documentation submitted by economic operators is, or appears to be, incomplete or erroneous or where specific documents are missing. This provision applies "unless otherwise provided by national law". Article 71 of the PPL sets out this provision in a detailed manner.

\section{Mandatory grounds for exclusion}

Mandatory grounds for exclusion - conviction by final judgement: Article 57(1) of the Directive lists mandatory grounds for exclusion for specified offences. Articles 62(1)a) aa)-af), partially ah) and 62(2) of the PPL list those mandatory grounds for exclusion.

Exclusion for the non-payment of taxes or social security contributions - judicial or administrative decision: Article 57(2) of the Directive refers to mandatory exclusion on the grounds of non-payment of taxes or social security contributions established by a judicial or administrative decision having final and binding effect. Article 62(1) b) of the PPL refers to these mandatory grounds for exclusion.

Exclusion for the non-payment of taxes or social security contributions - other means of proof: Article 57(2) of the Directive permits contracting authorities to exclude an economic operator where it can be demonstrated by any appropriate means that it is in breach of its obligations relating to the payment of taxes or social security contributions. 
Member States may make exclusion on these grounds mandatory. Article 62(1) b) of the PPL provides that exclusion on these grounds is mandatory.

\section{Derogations from mandatory exclusion}

Article 57(3) of the Directive permits Member States to provide for a derogation from mandatory exclusion on grounds of public interest. This derogation is not included in the PPL.

Article 57(3) of the Directive permits Member States to provide for a derogation from mandatory exclusion for non-payment of taxes or social security contributions where an exclusion would be clearly disproportionate. This derogation is not included in the PPL.

Additional national mandatory grounds for exclusion

Most of the discretionary grounds for exclusion in the Directive are national mandatory grounds, whereas some of the Directive's discretionary grounds are also national discretionary grounds (see table below).

\begin{tabular}{lll}
\hline $\begin{array}{l}\text { Directive 2014/24/EU discretionary } \\
\text { exclusions }\end{array}$ & $\begin{array}{l}\text { Hungarian PPL } \\
\text { exclusions }\end{array}$ & $\begin{array}{l}\text { Mandatory/discretionary characteristic in the } \\
\text { Hungarian PPL }\end{array}$ \\
\hline Article 57(4) a) & Article 63(1) a) & Discretionary \\
Article $57(4)$ b) & Article 62(1) c), d) & Mandatory \\
Article $57(4)$ c) & Article 63(1) b) & Discretionary \\
Article 57(4) d) & Article 62(1) n), o) & Mandatory \\
Article 57(4) e) & Article 62(1) m) & Mandatory \\
Article 57(4) f) & Article 62(1) m) & Mandatory \\
Article 57(4) g) & Article 63(1) c) & Discretionary \\
Article 57(4) h) & Article 62(1) h), i) & Mandatory \\
Article 57(4) i) & Article 62(1) j) & Mandatory \\
\hline
\end{tabular}

The national mandatory grounds for exclusion that are not covered by the Directive are the following: PPL, Article 62(1) a) ag), partially ah), e)-g), k)-l), p) and q).

\section{Discretionary grounds for exclusion}

Article 57(4)(a) to (i) of the Directive lists the discretionary grounds for exclusion. Member States have the option to make some or all of these grounds for exclusion mandatory.

Some of the discretionary grounds for exclusion in the Directive are national mandatory grounds. The Articles of the PPL concerning these grounds are listed in the above table (see preceding section on additional national mandatory grounds for exclusion).

\section{Additional national discretionary grounds for exclusion}

Article 63(1)(d) of the PPL provides for an additional national ground for exclusion that is not covered by the Directive: the contracting authority may exclude an economic operator who failed to fulfil his payment obligations (more than 10 per cent) towards subcontractors in previous public procurement contracts. This option has to be announced in advance in the procurement notice.

Option to not exclude an economic operator in the case of bankruptcy or the equivalent: Article 57(4) of the Directive permits Member States to provide for the possibility to not exclude an economic operator on the grounds of bankruptcy or in 
equivalent situations where there are national rules and measures on the continuation of business. This option is not included in the Hungarian PPRs.

Exclusion at any time in the procedure: Article 57(5) of the Directive permits a contracting authority to exclude an economic operator where it becomes aware at any time in the procedure that the grounds for mandatory or discretionary exclusion apply because of acts committed or omitted by the economic operator either before or during the procedure. Member States have the option to make exclusion in these circumstances mandatory. This option is included in Article 63(3) of the PPL.

Maximum periods of exclusion: The maximum periods of exclusion are as follows:

- Mandatory grounds for exclusion, stipulated in Article 62(1)a) of the PPL: five years from the date of conviction by final judgement;

- Mandatory grounds for exclusion, stipulated in Article 62(1) e), h), j), n) and p) and discretionary grounds stipulated in Article 63(1)a), b), c) and d) of the PPL: three years from the date of the relevant event;

- Mandatory grounds for exclusion, stipulated in Article 62 (1) q): not earlier than 90 days from the final and binding decision of the Board or the court.

\section{Self-cleaning}

Article 57(6) of the Directive permits an economic operator to provide evidence of measures it has taken to demonstrate its reliability despite the existence of relevant grounds for exclusion. If such evidence is considered to be sufficient, the economic operator concerned shall not be excluded from the procurement procedure.

With the entry into force of the new public procurement guidelines in Hungary on 1 November 2015, self-cleaning became part of the regulations. The Hungarian model does not give freedom to contracting authorities, but instead delegates the decision on self-cleaning in a centralised manner to the PPA (http://www.kozbeszerzes.hu/cikkek/onti sztazas).

According to Article 64 of the PPL the decision confirming self-cleaning is taken by the Public Procurement Authority and can be challenged before the court.

A number of cases, presented in summary in the Information Note at the end of this chapter, illustrate the approach taken by the PPA when it makes decisions concerning the acceptability of self-cleaning measures taken by economic operators.

\section{Selection}

Article 58 of the Directive provides that selection criteria may relate to: (a) suitability to pursue the professional activity; (b) economic and financial standing; and (c) technical and professional ability. These requirements must be appropriate, related and proportionate to the subject matter of the contract. The provisions on selection are set out in Article 65(1) and (3) of the PPL.

\section{Reduction in the number of otherwise qualified candidates to be invited to participate}

Article 65 of the Directive lays down the rules on the reduction of the number of otherwise qualified candidates to be invited to participate in restricted procedures, competitive procedures with negotiation, competitive dialogue, and innovation 
partnerships. The provisions on the reduction of otherwise qualified candidates are set out in the PPL as follows:

- Article 82(4) and (5): restricted procedures;

- Article 86(3): negotiated procedures;

- Article 90(4): competitive dialogue;

- Article 97(2): innovation partnerships.

It is common to use procedures that include two phases, in particular the negotiated procedure. The contracting authority shall provide the objective criteria, which are in line with the basic principles laid down in the PPL, on the basis of which the tenders are ranked. The contracting authority may indicate which certificates are to be submitted by the economic operators, in accordance with Article 69 of the PPL, regarding compliance with those objective criteria, in order to support the self-declaration included in the ESPD.

\section{European Single Procurement Document}

Article 59 of the Directive requires contracting authorities to accept the ESPD as preliminary evidence in replacement of certificates issued by public authorities or third parties confirming that the relevant economic operator fulfils the conditions relating to grounds for exclusion, selection criteria and, where applicable, the objective rules and criteria for the reduction of the number of otherwise qualified candidates to be invited to participate. The provisions concerning the ESPD, set out in Article 69(2) and (5) of the PPL and in Articles 2-7 of the GD, are obligatory above the EU thresholds.

\section{Means of proof}

Article 60 of the Directive sets out the provisions on the means of proof as evidence for grounds for exclusion and fulfilment of the selection criteria. The provisions on the means of proof are set out in Article 69 of the PPL and in several Articles of the GD, as follows:

- Articles 8-18 of the GD on certification of the non-existence of grounds for exclusion;

- Articles 19-20 on certification of economic and financial standing;

- Articles 21-25 on certification of technical and professional suitability;

- Article 26 on certification of suitability for the pursuit of a professional activity.

The PPRs differentiate between tenderers or candidates established in Hungary and those that are not established in Hungary, which makes the burden of proof difficult for foreign tenderers and candidates.

A common problem is the method of certification stipulated by Article 57(1) of the Directive:

"The obligation to exclude an economic operator shall also apply where the person convicted by final judgement is a member of the administrative, management or supervisory body of that economic operator or has powers of representation, decision or control therein." 
The contracting authority needs to have the evidence mentioned above, which is either provided by the economic operator or accessed directly by the contracting authority through a free database. There are three ways of obtaining the evidence that is required:

- direct access by contracting authorities to the relevant criminal records;

- a certificate attesting to the lack of a criminal record;

- self-declaration by the natural person as part of the economic operator's ESPD.

According to the GD, the self-declaration of tenderers established in Hungary suffices, whereas additional documentary evidence is required from tenderers that are not established in Hungary.

\section{Reliance on the capacity of other entities}

Article 63 of the Directive provides that, where appropriate and with regard to a specific contract, an economic operator may rely on the capacity of other entities to satisfy the criteria set by the contracting authority in relation to economic and financial standing. This provision is subject to the fulfilment of specified conditions. The provisions concerning the reliance on the capacity of other entities are set out in Article 65(7) of the PPL.

Lists

\section{Official lists of approved economic operators}

Article 64 of the Directive permits Member States to establish or maintain official lists of approved economic operators that have submitted acceptable evidence of their suitability to deliver public contracts.

The provisions for the official list on approved tenderers held by the PPA and for the list of approved tenderers held by the relevant economic and professional Chamber are set out in the GD, Articles 27-44. These official lists cover the non-existence of grounds for exclusion and the fulfilment of the suitability criteria, in accordance with the internal guidelines of the Chamber and the Authority.

According to Article 27 of the GD (and Article 187 (2) of the PPL), the official list of approved tenderers is maintained by the Authority. The official list prepared by the Authority may also cover the non-existence of the grounds for exclusion and the fulfilment of the suitability criteria.

The list of approved tenderers created by an economic and professional chamber on the basis of Article 69(12) of the PPL is registered by the Authority according to Article 36 of the GD. According to Article 27 (2) of the GD, the list of the chamber may only cover the certification of suitability criteria applicable within the scope of activity of the chamber's members.

\section{Blacklists}

The Directive has no specific provisions permitting or prohibiting the use of blacklists of economic operators to whom the grounds for mandatory or discretionary exclusion apply.

The Hungarian public procurement legislation includes provisions concerning the publication of official blacklists. The blacklists concern economic operators that are either excluded from participation in a procurement procedure as a result of a decision by 
the procurement appeal body or of a final court ruling relating to a breach of contract or admission by the economic operator of a breach of contract. The PPA is required, according to Article 187(2) of the PPL, to manage, update and publish on its homepage the lists of economic operators excluded from procurement procedures. The list contains information about: the duration of the exclusion, the substantial elements of the breach of the contract, including information about the compensation or claim for compensation or other sanctions and a reference to the decision of contracting authority or the final ruling of the court.

The decision to include the economic operator into the list of excluded companies is made by the Public Procurement Arbitration Board (Board). The decision of the Board can be appealed challenged before the court. When a decision made by the Board results in the blacklisting of an economic operator, the nature and period of blacklisting will be decided by the Board or, in the case or a review of that decision, by a final court ruling. The period of blacklisting decided by the Board can range between six months and three years. No economic operator is currently on this blacklist (http://www.kozbeszerzes.hu/cikkek/eltiltott-ajanlattevok). All of the decisions of the Board are available on the official website of the PPA (www.kozbeszerzes.hu).

When an economic operator is blacklisted on the grounds of a serious breach of contractual obligations (more fully described in Article 63(1)(c) of the PPL), that economic operator is automatically excluded from participating in procurement procedures for a period of three years as from the date of the judicial decision or the breach of contract. There are two economic operators currently on that blacklist (http://www.kozbeszerzes.hu/cikkek/szerzodesszegesek).

According to Article 187 (2) a) ac), the Authority shall publish on its homepage without considering the gravity of the infringement, the number and date of all decisions of the Arbitration Board or, in case of a review thereof, final and binding judicial decisions justifying the exclusion under Article 62(1)(q) (who seriously infringed the provisions of the PPL concerning the fulfilment of the contract concluded as a result of the procurement procedure or concession award procedure and such infringement was established by the final and binding decision of the Public Procurement Arbitration Board). There are three economic operators currently on that blacklist (http://www.kozbeszerzes.hu/cikkek/kbt-62-1-bekezdes-q-pont).

\subsubsection{Information note - practical experiences in applying self-cleaning in Hungary $^{139}$}

Economic operators began to take advantage of the possibility of self-cleaning relatively soon after the entry into force of the public procurement guidelines on 1 November 2015, which resulted in a number of interesting and instructive cases. The practice of self-cleaning is still evolving. The PPA puts emphasis primarily on certificates and the appropriate arguments. One of the fundamental pillars of reliability based on the available data is that the applicant should demonstrate its reliability with the appropriate documents, ideas and activities.

\footnotetext{
${ }^{139}$ Extracts taken from Tatrai, T. (2017), Self-cleaning - Hungarian Case.
} 
The following cases, presented in summary, illustrate the approach taken by the PPA in this context.

\section{Case 1: STRABAG Property and Facility Services}

\section{Grounds for exclusion}

An employee of the applicant suffered an accident during electric maintenance activities on the employer's premises on 7 May 2015. The applicant investigated the reasons that gave rise to the accident, in accordance with the legal regulations. The Labour Inspectorate conducted an on-site review in order to clarify the facts of the case, as a result of which it imposed a labour safety fine. To determine the amount of the fine, the Labour Inspectorate assessed the behaviour of the applicant assisting in the exploration of the facts of the case and the behaviour of the employee, who by violating the rules had also played a part in the accident. These circumstances reduced the amount of the fine.

Accordingly, the applicant was subject to the following optional grounds for exclusion: "A final judicial decision, a final administrative decision or, in the case of a review of the latter, a final judicial decision delivered within the previous three years established that he had failed to comply with the obligations in the fields of environmental, social and labour law."

\section{Demonstration of reliability}

The applicant demonstrated its reliability as follows:

\section{a) Training}

With a view to the safe performance of work that does not endanger health, the applicant has set a detailed Labour Safety Rule, which devotes a special chapter to personal protective equipment, to be provided to employees in accordance with their activities and with the rules of performing electrical work. The employees are familiar with the requirements set out in the Labour Safety Rule, and the applicant furnished evidence of holding annual labour safety training. Furthermore, following the accident in reference, the employees concerned participated in extraordinary training.

\section{b) Organisational measures}

The applicant's property management activities are organised in four separate business lines. The applicant introduced immediate and stringent measures for work organisation during the transitory period, until the conditions of the safe performance of work were guaranteed in the organisational unit concerned. An agreement was concluded between the individual business lines so that the employees of one of the business lines having the necessary electrical training and instruments would carry out the electrical plant activity concerned.

\section{c) Procurement of instruments}

Following the exploration of the reasons that gave rise to the accident, the applicant took measures immediately and on a comprehensive basis to procure the transmission of documentation and to require the use of the protective equipment and work tools necessary and suitable for the electrical work.

\section{d) Other circumstances}


In the course of the check by the labour safety authority, the applicant assisted in the exploration of all of the circumstances of the case. In its application, the applicant declared that it had not committed, either since or prior to the work accident constituting the subject matter of the decision, such a violation of the law and that no such procedure had been conducted against it. The applicant's commitment to labour safety was evidenced by the fact that it took regular and major efforts to make both its managers and employees aware of labour safety requirements while at work. It also placed particular emphasis on the regular labour safety training of its employees, the further training of its managers, and the improvement of its labour safety organisation.

\section{Procedure and decision of the Public Procurement Authority}

The PPA assessed the case and established that the measures taken by the applicant were suitable for demonstrating reliability. The justification of the decision of the Labour Inspectorate revealed that the applicant had failed to meet the requirements related to health and safety at work and had thereby gravely and directly jeopardised the health and physical safety of the employee concerned. The applicant actively co-operated with the competent authorities to comprehensively clarify the facts of the case and already began taking the necessary measures during the investigation and prior to the decision of the Labour Inspectorate. The PPA established that the measures taken by the applicant sufficiently demonstrated its reliability despite the grounds for exclusion and that it would therefore "self-clean" the applicant.

\section{Case 2: Recom Park Kft.}

\section{Grounds for exclusion}

The Environment Protection and Nature Conservation Inspectorate fined the applicant for burning waste in an open space and thereby violating the air protection requirements. The applicant stated that an employee had thrown an electrode used for welding into the garbage bin at its bitumen storage premises in Hódmezővásárhely, which had set the bin on fire.

Accordingly, the applicant was subject to the following optional grounds for exclusion: "A final judicial decision, a final administrative decision or, in the case of a review of the latter, a final judicial decision delivered within the previous three years established that he had failed to comply with the obligations in the fields of environmental, social and labour law".

\section{Demonstration of reliability}

No damage was sustained in relation to breaching the legal requirements, no claim for damages was made, and the applicant paid the fine.

In its report addressed to the Environment Protection Inspectorate, the applicant acknowledged the fact that it had breached the legal regulation and undertook to pay particular attention to waste management in the future.

Following the above case, the applicant did not breach any obligation related to the protection of the environment. Its co-operation with the authorities in exploring the facts of the case was appropriate. The documents it submitted addressed every issue in detail, from making use of environmental consulting through giving a warning to the employees to the decision by the environmental authority. 
Procedure and decision of the Public Procurement Authority

In the course of the investigation, no information or document contrary to the statement of the applicant was made available to the PPA. The Authority took into account that the applicant had begun to take the necessary measures even prior to the adoption of the decision.

Based on the above elements, the applicant demonstrated its reliability, that is, it cleaned itself. 


\subsection{LATVIA}

\subsubsection{Overview}

\section{Public procurement legislation}

\section{Key legislation}

The key public procurement legislation covering the exclusion, selection and shortlisting stage of public procurement processes undertaken by contracting authorities is contained in the PPL of 15 December 2016. No regulations in secondary legislation are related to the exclusion, selection and shortlisting stages.

Public procurement legislation can be downloaded from the official website of the Latvian PMB at www.iub.gov.lv/lv/node/29.

\section{Brief description of the key legislation}

Three primary laws regulate public procurement in Latvia:

- PPL of 15 December 2016 (for "classical sector" procurement);

- Law on Procurement for Utilities Service Providers of 2 February 2017 (for the utilities sector);

- Law on Defence Procurement of 13 October 2011 (for defence-related procurement).

In addition, the Law on Public and Private Partnerships of 18 June 2009 regulates issues related to public-private partnership (PPP) contracts, including their co-ordination, procedures for the award of concessions, and requirements for PPPs.

Secondary legislation in the public procurement area covers the duration of public procurement procedures as well as technical issues, such as financial threshold values, and sectoral issues, such as centralised procurement and demands related to environmental protection for specific categories of procurement. Secondary decrees directly attributable to exclusion, selection and shortlisting are:

1. Regulations of Cabinet of Ministers No. 107 of 28 February 2017 "The process of procurement procedures and design contest". These regulations describe, with references to the PPL, the conduct of all stages of procurement procedures, including the exclusion and selection stage;

2. Regulations on "electronic references in public procurement". These regulations provide a legal description of the electronic system for obtaining references regarding grounds for exclusion, the amount of information to be used in the system and the aims and limitations thereof, as well as the organisation of co-operation with other related electronic information systems.

EU Directives 2014/23/EU (award of concession contracts), 2014/24/EU (public procurement) and 2014/25/EU (entities operating in the water, energy, transport and postal services sector) are fully transposed in the Latvian legislation.

The approach of the PPL to contracting authorities mirrors that of the Directive: all public sector entities are covered, as well as bodies governed by private law, subject to the fulfilment of specified conditions. The Law on Procurement for Utilities Service 
Providers covers public utility companies and private utility companies operating on the basis of special or exclusive rights.

The PPL regulates the award of works, services and supply contracts that are both above and below the EU financial thresholds. In addition, the PPL contains a chapter on public procurement review, defining the bodies that are responsible for first- and secondinstance review, as well as the requirements for the review process.

No significant derogations or additions to the provisions of the Directive have been established in relation to exclusion, selection and shortlisting.

\section{National financial thresholds ${ }^{140}$}

The PPL establishes two tiers of national thresholds:

- EUR 10000 to EUR 42000 for supply and service contracts and EUR 20000 to EUR 170000 for works contracts;

- EUR 42000 up to the EU thresholds for supply and service contracts and EUR 170000 up to the EU thresholds for works contracts.

No formal public procurement rules apply if the estimated value of a supply or service contract is lower than EUR 10 000, or if the estimated value of a works contract is lower than EUR 20000 . However, in those cases, the contracting authorities are asked to ensure the implementation of the principle of value for money.

The requirements for the conduct of public procurement procedures for exclusion, selection and shortlisting are similar for:

- procurement contracts above the EU thresholds;

- supply and service contracts with an estimated value between EUR 42000 and the EU thresholds for supply and service contracts and works contracts with an estimated value between EUR 170000 and the EU thresholds for works contracts. For these contracts, contracting authorities may, however, decide on shorter deadlines for bid submission and to publish contract notices at the national level only.

When the estimated value of the supply or service contract falls in the range between EUR 10000 and EUR 42000 , or if the estimated value of the works contract ranges between EUR 20000 and EUR 170 000, the provisions related to exclusion, selection and shortlisting are different, according to Article 9 of the PPL:

- Only four grounds for exclusion are available: insolvency or bankruptcy, outstanding tax debts of the tenderer, conflict of interest and off-shore registration. In addition, the tenderer must be excluded if the representative of contracting authority is connected with the tenderer or is interested in its selection, and there are no more proportionate means for remedying the situation.

- Qualification and technical requirements have to be designed fully according to the PPL (i.e. no "lighter regime" is provided in this respect).

${ }^{140}$ A new PPL, adopted on 15 December 2016, entered into force on 1 March 12017 (Latvijas Vēstnesis: 254 (5826), 29 December 2016). 
- No shortlisting is possible, as the procurement in question is essentially a single-stage procedure.

- The use of the ESPD or an analogous self-declaration is envisaged, according to Article 49 of the PPL.

- Lowest price or cost or best price/quality ratio may be used as a tender award criterion, according to the decision of the contracting authority.

- After conclusion, the procurement contract and any amendments thereto must be made publicly available on the website of the contracting authority.

Guidance, policy and other information

The PMB issues guidelines, recommendations and other explanatory documents, but they are not binding. They are nevertheless used in practice, in particular in the process of monitoring procurement procedures that are fully or partially financed by EU funds or other financial instruments. Guidelines and other documents can be found on the website of the Procurement Monitoring Bureau, under the topic "Procurement Guidelines" www.iub.gov.lv/lv/node/95.

\section{Advertising}

All contracting opportunities, including those related to contracts above the EU thresholds, must be advertised on the website of the PMB. According to the PPL, the PMB must ensure publication of the notice within three working days of its electronic submission (no paper notices are permitted). Contracts above the EU thresholds must be advertised in the OJEU.

All notices must contain a hyperlink to the website of the contracting authority, where tender documentation must be available electronically and free of charge.

\subsubsection{Choice of participants: exclusion, selection and shortlisting - further information}

\section{General principles}

Article 18 of the Directive sets out the general principles of procurement, namely equal treatment, non-discrimination, transparency and proportionality. Article 18 also requires that procurement not be designed with the intention of excluding it from the scope of the Directive or artificially narrowing competition.

The general principles of procurement are set out in Article 2 of the PPL. Rules regarding the establishment of an estimated value of the object of procurement, including the prohibition of intentionally splitting the object of procurement, are provided in Article 9 of the PPL.

Article 56(1) of the Directive sets out general principles applying to the choice of participants and the award of contracts.

The general principles set out in Article 2 and 9 apply to all stages of procurement procedures, including exclusion, selection and shortlisting. In addition, point 29 of the Regulations of Cabinet of Ministers, "The process of procurement procedures and design contest" (28 February 17; No. 107), provides that if shortlisting is applied, the number of shortlisted candidates must be sufficient to ensure effective competition. Points 16, 35 
and 54 of those Regulations provide that in open and restricted procedures, the tenders must be evaluated according to the requirements set forth in the tender documentation. Although it is not explicitly stated in the PPL, the same approach must be taken for other procurement procedures as well, in accordance with the principle of equal treatment.

Article 56(2) of the Directive permits contracting authorities to examine tenders submitted in an open procedure prior to verifying the absence of grounds for exclusion and the fulfilment of the selection criteria. Member States have the option to exclude or restrict the use of this approach for specific types of procurement or in specific circumstances.

Point 16 and point 17 of the Regulations of Cabinet of Ministers, "The process of procurement procedures and design contest" (28 February 2017; No. 107), provides that in an open tender procedure, the absence of grounds for exclusion and the fulfilment of the selection criteria must be verified only for tenderers that potentially have the right to be awarded a contract.

Article 56(3) of the Directive allows contracting authorities to ask economic operators to "submit, supplement, clarify or complete the relevant information or documentation" where the information or documentation submitted by economic operators is, or appears to be, incomplete or erroneous or where specific documents are missing. This provision applies "unless otherwise provided by national law".

Article 41(6) of the PPL states that if the information that a tenderer has submitted in relation to its qualification is inaccurate or non-exhaustive, contracting authorities are obliged to give the tenderer an opportunity to submit additional information. It is important to note that this provision relates only to documents submitted regarding the selection criteria and cannot be applied in the case of missing information in a technical bid or financial proposal.

\section{Mandatory grounds for exclusion}

Mandatory grounds for exclusion - conviction by final judgement: Article 57(1) of the Directive provides the mandatory grounds for exclusion for specified offences.

The PPL provides the corresponding grounds for exclusion in Article 42(1) ${ }^{1}$.

Exclusion for the non-payment of taxes or social security contributions - judicial or administrative decision: Article 57(2) of the Directive refers to mandatory exclusion on the grounds of non-payment of taxes or social security contributions, as established by a judicial or administrative decision having final and binding effect.

The PPL provides the corresponding grounds for exclusion in Article 42(1)f) ${ }^{1}$.

Exclusion for the non-payment of taxes or social security contributions - other means of proof: Article 57(2) of the Directive permits contracting authorities to exclude an economic operator where they can demonstrate by any appropriate means that it is in breach of its obligations relating to the payment of taxes or social security contributions. Member States may make exclusion on these grounds mandatory.

The PPL provides the corresponding grounds for exclusion in Article 42(1)2) ${ }^{1}$. However, with regard to tenderers registered in Latvia, contracting authorities are only entitled to use, as a means of proof, the information available in the information system established in accordance with the Regulations of Cabinet of Ministers No. 1516 of 17 December 2013, "Regulations on electronic references in public procurement". Tenderers registered 
outside Latvia must submit the relevant references from competent authorities in their respective countries.

\section{Derogations from mandatory exclusion}

Article 57(3) of the Directive permits Member States to provide for a derogation from mandatory exclusion on grounds of public interest.

No corresponding provision is contained in the PPL.

Article 57(3) of the Directive permits Member States to provide for a derogation from mandatory exclusion for the non-payment of taxes or social security contributions where an exclusion would be clearly disproportionate.

No corresponding provision is contained in the PPL.

Additional national mandatory grounds for exclusion

The following additional national exclusion grounds are provided in Article 42(1)7) ${ }^{1}$ of the PPL:

- employment of a person without a work permit or unlawfully present in the EU;

- employment of a person without a written employment contract.

Such circumstances must be established by a judicial or administrative decision having final and binding effect.

\section{Discretionary grounds for exclusion}

Articles 57(4)(a) to (i) of the Directive provides the discretionary grounds for exclusion. Member States have the option to make some or all of these grounds for exclusion mandatory.

The discretionary grounds for exclusion mentioned in Article 57(4)(a), (c) and (i) of the Directive have not been transposed.

Discretionary grounds for exclusion mentioned in Article 57(4)(b), (d), (e), (f) and (h) have been transposed in Article $39(1)^{1}$ of the PPL as mandatory exclusion grounds. The following situations are covered:

- insolvency, bankruptcy, liquidation or suspension of an action of the tenderer;

- entry into a horizontal cartel agreement, in accordance with the Competition Law. Such circumstances must be established by a judicial or administrative decision having final and binding effect. The exclusion must not be applied if a competent competition authority has annulled or decreased the penalty for the tenderer concerned in the framework of a tolerance programme;

- connection of the person in charge of the preparation of tender documents, a member of the tender commission, an expert connected with the tenderer according to the provisions of the PPL, or a person interested in awarding the contract to a particular tenderer, where the situation cannot be rectified by more proportionate means;

- involvement of the tenderer in the preparation of the procurement procedure, thereby being in a favourable position in comparison with the other tenderers. In 
addition, such a situation distorts competition and cannot be rectified by more proportionate means, and the tenderer is not in a position to prove the contrary;

- provision by the tenderer of false information to the contracting authority or failure to provide (requested) information at all.

The discretionary grounds for exclusion provided in Article 57(4)(g) of the Directive have been transposed in Article 41(2) of the PPL as discretionary exclusion grounds.

\section{Additional national discretionary grounds for exclusion}

No additional national discretionary grounds for exclusion are provided in the PPL.

Option to not exclude an economic operator in the case of bankruptcy or the equivalent: Article 57(4) of the Directive permits Member States to provide for the possibility to not exclude an economic operator on the grounds of bankruptcy or in equivalent situations where there are national rules and measures on the continuation of business.

This option is included in Article 9(8)1 $)^{2}$ of the PPL. However, it relates only to national procurement procedures with an estimated value between EUR 10000 and EUR 42000 for supply and service contracts and between EUR 20000 and EUR 170000 for works contracts. Such an option is not applicable to procurement with an estimated value equal to or above the EU thresholds.

Exclusion at any time in the procedure: Article 57(5) of the Directive permits a contracting authority to exclude an economic operator where it becomes aware at any time in the procedure that the grounds for mandatory or discretionary exclusion apply because of the acts committed or omitted by the economic operator either before or during the procedure. Member States have the option to make exclusion in these circumstances mandatory.

The above option is not included in the PPL.

Maximum periods of exclusion: The mandatory exclusion grounds and the maximum periods of exclusion, provided in Article 42(3) ${ }^{1}$ of the PPL, are as follows:

- conviction by final judgement for listed offenses: three years from the entry into force of the final judgement establishing the respective grounds;

- exclusion for the non-payment of taxes or social security contributions, established by a judicial or administrative decision: three years from the entry into force of the final judgement or the decision establishing the respective grounds;

- exclusion for the non-payment of taxes or social security contributions, established by other means of proof: exclusion only from the tender procedure in question;

- exclusion for the employment of a person without a work permit or of a person whose presence in the EU is unlawful, established by a judicial or administrative decision: three years from the entry into force of the final judgement or decision establishing the respective grounds;

- exclusion for the employment of a person without a written employment contract: 12 months from the entry into force of the final judgement or decision establishing the respective grounds; 
- exclusion for entry into a horizontal cartel agreement, in accordance with the Competition Law: 12 months from the entry into force of the final judgement or decision establishing the respective grounds;

- other mandatory exclusion grounds: exclusion only from the tender procedure in question.

For the discretionary exclusion grounds provided for in Article $42(2)^{2}$ of the PPL exclusion where the tenderer concerned has not executed the procurement contract or where the contracting authority in a framework agreement has unilaterally terminated the contract or framework agreement - the exclusion is for 12 months as from the date of the contract termination in the case of works, supply and service contracts.

\section{Self-cleaning}

Article 57(6) of the Directive permits an economic operator to provide evidence of measures it has taken to demonstrate its reliability despite the existence of relevant grounds for exclusion. If such evidence is considered to be sufficient, the economic operator concerned shall not be excluded from the procurement procedure.

Article $43(4)^{3}$ of the PPL stipulates the provisions for self-cleaning. According to Article 43, each contracting authority must itself verify its self-cleaning measures and decide on their adequacy. No central body operates for this purpose.

\section{Selection}

Article 58 of the Directive provides that selection criteria may relate to: (a) suitability to pursue the professional activity; (b) economic and financial standing; and (c) technical and professional ability. These requirements must be appropriate, relevant and proportionate to the subject matter of the contract.

The provisions on selection are set out in Articles 44-46 of the PPL:

- Article 44 refers to suitability to pursue the professional activity;

- Article 45 refers to economic and financial standing;

- Article 46 refers to technical and professional ability.

As the PPL itself stipulates only framework rules for the use of selection criteria, the details in practice are determined by the rulings of a review body as well as by guidelines and explanatory documents. Some of the most important considerations are the following:

- The period for the turnover requirement should be the three previous years. Tenderers established later are entitled to rely on the turnover accumulated during their period of activity. The level of turnover should not exceed twice the contracting value, unless such a level can be objectively justified.

- The period for the requirement of previous experience should be the previous three years. However, experience in years can never be used as a selection criterion. Instead, contracting authorities must refer to projects carried out by the tenderer during the previous three years. To ensure the principle of proportionality, contracting authorities are not allowed to demand projects with higher parameters (financial value, scope, etc.) than the subject matter of the contract and, as a general rule, they should not refer to more than three of such projects. 
- If the price/equity ratio is used as a qualification criterion, it should not, as a general rule, be higher than one.

Reduction in the number of otherwise qualified candidates to be invited to participate

Article 65 of the Directive lays down the rules on the reduction of the number of otherwise qualified candidates to be invited to participate in restricted procedures, competitive procedures with negotiation, competitive dialogue, and innovation partnerships.

The provision on the reduction of otherwise qualified candidates is set out in point 29 of the Regulations of the Cabinet of Ministers: "The process of procurement procedures and design contest" (28 February 2017; No. 107). This provision stipulates that contracting authorities should use only objective and non-discriminatory criteria, which need to be stated in advance in tender documentation.

In practice, the option of reducing the number of candidates is not used very often. When contracting authorities choose to use it, however, they usually refer to additional experience (i.e. experience of the tenderer in terms of projects carried out that exceed the minimum requirements provided in the tender documentation).

\section{European Single Procurement Document}

Article 59 of the Directive requires contracting authorities to accept the ESPD as preliminary evidence, in replacement of certificates issued by public authorities or third parties, confirming that the relevant economic operator fulfils the conditions relating to the grounds for exclusion, selection criteria and, where applicable, the objective rules and criteria for reduction in the number of otherwise qualified candidates to be invited to participate.

The provisions of the ESPD are set out in Article 49 of the PPL. The paper form of ESPD is no longer permitted for any contracts, both above and below the EU thresholds. For contracts above the EU threshold, a fully electronic procurement procedure and electronic system must be used, and so the ESPD is prepared and submitted using an electronic system. For contracts below the EU thresholds, a fully electronic procurement procedure and electronic system does not have to be used. Several options are available, including using the e-ESPD internet service offered by the Commission or manual completion of the ESPD, which is then scanned and included in the bid.

The PMB has published an explanatory note regarding the use of the ESPD on its website www.iub.gov.lv/lv/node/587.

Since the provisions on the ESPD were introduced into the PPL only recently, no broad conclusions have yet been reached regarding its effectiveness. However, some procurement actors, contracting authorities in particular, have expressed their concerns that the ESPD would prove to be more of an obstacle than an advantage, as it would delay the procurement procedure if the tenderer concerned failed to support with the relevant documents the statements expressed in the ESPD.

\section{Means of proof}

Article 60 of the Directive sets out the provisions on the means of proof as evidence for the grounds for exclusion and on the fulfilment of the selection criteria. 
The provisions on the means of proof are set out in Article 38 as well as in Articles 41-46 of the PPL.

In general, contracting authorities are not limited to requiring particular means of proof, as long as the required means are directly related to the requirements stated in the tender documentation and as long as tenderers are allowed to submit equivalent documentation (for instance, a copy of the contract instead of a reference from the client). The Higher Administrative Court of Latvia in its rulings supports the view that the aim of the contracting authorities is to verify that the tenderer fulfils the requirements, and that the documents required by the contracting authorities are simply instruments for achieving that aim.

The PPL does not mention any means of proof that contracting authorities are entitled to require in addition to the ESPD. However, in practice, contracting authorities are advised by the PMB that they are entitled to not require tenderers to submit the ESPD but to demand that they include all qualification-related documents in the tender, as it is objectively justifiable, due to the nature of a given procurement procedure or to the necessity to conduct the procedure as quickly as possible.

If, however, the ESPD has been required, the tenderer whose tender was evaluated as most economically advantageous may be asked to submit the documents that are indicated in the tender documentation and related to the requirements of the contract - for instance, the curriculum vitae of its personnel, statements of turnover and references from its clients.

Article 41(6) of the PPL essentially states that if the information that a tenderer has submitted in relation to its qualification is inaccurate or non-exhaustive, the contracting authority must request additional information from the tenderer. Minor deficiencies or omissions in qualification documents therefore cannot serve as a reason for the disqualification of a tenderer. This approach works in practice, without any significant drawbacks.

The PPL does not contain any provision regarding e-Certis, but tenderers and contracting authorities are aware of this database and use it in practice.

The provisions regarding quality assurance and environmental management standards are set out in Articles 47-48 of the PPL. As a general rule, contracting authorities, when referring to these standards, must accept other, equivalent means of proof that the tenderer actually follows the requirements and practices that these standards impose.

\section{Reliance on the capacity of other entities}

Article 63 of the Directive provides that, where appropriate and with regard to a specific contract, an economic operator may rely on the capacity of other entities to satisfy the criteria set by the contracting authority in relation to economic and financial standing. This provision is subject to the fulfilment of specified conditions.

Provisions on the reliance on the capacity of other entities are set out in Articles 45-46 of the PPL. In general, contracting authorities and tenderers are familiar with the concept, and tenderers often structure themselves as consortiums or seek subcontractors. In practice, different views are sometimes held as to which requirements can and cannot be met by relying on the resources of subcontractors. Practice by review bodies has established that a tenderer can meet the requirement of previous experience by relating to the resources of subcontractors, provided that it has actually planned to involve these 
subcontractors in the execution of works or the provision of services. The main factor here is that the contracting authority must verify that the subcontractors in question would carry out the specific works to which a particular requirement for experience is related. However, financial requirements, in particular requirements related to previous turnover, cannot be met by subcontractors but only by members of a consortium. This approach is based on the premise that the tenderer must actually be able to prove that the particular resources of third parties will be at its disposal during the stage of contract execution. However, unless a subcontractor assumes direct responsibility for contract execution, it may not be reasonably possible to claim that its turnover is at the disposal of the general contractor (tenderer), thereby reducing the risk of a shortage of cash flow during the contract execution stage. The contracting authority is entitled to require that particularly important tasks are carried out by the contractor and not by sub-contractors.

Lists

Official lists of approved economic operators

Article 64 of the Directive permits Member States to establish or maintain official lists of approved economic operators that have submitted acceptable evidence of their suitability to deliver public contracts.

The PPL does not provide for lists of approved economic operators, and such lists are not used in practice.

\section{Blacklists}

No specific provisions in the Directive permit or prohibit the use of blacklists of economic operators to whom the grounds for mandatory or discretionary exclusion apply.

Blacklists are not provided for in the PPL, and they are not used in practice. 


\subsection{MALTA}

\subsubsection{Overview}

\section{Public procurement legislation}

\section{Key legislation}

The key public procurement legislation covering the exclusion, selection and shortlisting stage of public procurement processes undertaken by contracting authorities is contained in the PPRs of 2016 (S.L. 174.04, introduced by Legal Notice 352 of 2016).

The key public procurement legislation is in the form of subsidiary legislation (Legal Notice) issued under the Financial Administration and Audit Act (Chapter 174 of the Laws of Malta).

Public procurement legislation can be downloaded from the Ministry of Justice website www.justiceservices.gov.mt/ or from the Resources Page on the website of the Department of Contracts, https://contracts.gov.mt/en/Resources/Pages/Resources.aspx.

Brief description of the key legislation

The main legislative documents governing public procurement in Malta are the following:

- PPRs (S.L. 174.04 introduced by Legal Notice 352 of 2016), which replaced the Public Contracts Regulations of 2010;

- Public Procurement of Entities operating in the Water, Energy, Transport and Postal Services Sectors Regulations (S.L. 174.06 and introduced by Legal Notice 351 of 2016), which replaced the similarly named regulations of 2005;

- Public Procurement of Contracting Authorities or Entities in the Fields of Defence and Security Regulations (S.L. 174.08);

- Public Concession Regulations (S.L. 174.10 introduced by Legal Notice 353 of 2016).

Legal Notices 351, 352 and 353 of 2016 entered into force on 28 October 2016 and were intended to fully transpose into Maltese law the provisions of the Directive on public procurement, Directive 2014/25/EU for entities operating in the utilities sector, and Directive 2014/23/EU on the award of concession contracts.

The Emergency Procurement Regulations (S.L. 174.09), issued at the same time as the new PPRs through Legal Notice 350 of 2016, do not have any specific parallel in the directives and envisage a relaxation of the rules that are generally applicable to public procurement, in the context of contracts with a value lower than EUR 135000 , provided that the necessity to award such "emergency contracts" arises due to unforeseen surges in the use of supplies or as a consequence of uncommon issues concerning national health, security or strategic importance.

The PPRs also contain provisions on remedies that are in line with the Remedies Directive 89/665/EC.

Rules relating to the exclusion, selection and shortlisting stage of public procurement are mainly found in the PPRs and the other Legal Notices referring to the PPR. 
The PPR applies to "contracting authorities", a term that also includes "central purchasing bodies" (currently the Department of Contracts and Malta Information Technology Agency).

The Public Procurement of Entities operating in the Water, Energy, Transport and Postal Services Sectors Regulations refer to both "contracting authorities" and "contracting entities", namely contracting authorities and public undertakings that pursue one of the activities covered by the same Regulations, as well as other entities that have activities in any of the above-mentioned sectors, or any combination thereof, and that operate on the basis of special or exclusive rights granted by the competent authority of Malta.

The Public Procurement of Contracting Authorities or Entities in the Fields of Defence and Security Regulations also refer to "contracting authorities".

Non-exhaustive lists of contracting authorities and entities are attached as Schedules to the PPRs and to the Public Procurement of Entities operating in the Water, Energy, Transport and Postal Services Sectors Regulations.

The Emergency Procurement Regulations apply only to the government entities specified in the Schedule attached to these Regulations, which are currently the Central Procurement Supplies Unit and the Civil Protection Department.

The Legal Notices mentioned above follow the English-language version of the Directive quite closely, while adapting the provisions to the Maltese legal system, particularly where matters of judicial and administrative procedure are concerned. The PPR in particular sets out quite detailed procedures related to the blacklisting of economic operators.

\section{National financial thresholds}

The PPR applies irrespective of the estimated value of the contract, but different procurement regimes apply depending on different thresholds. Where the estimated value is lower than EUR 144000 , the procedure is administered by the contracting authorities themselves, without the need to involve the Director of Contracts, with a simpler procurement process applicable to contracts with a value lower than EUR 10000 and an even more basic process where the value is lower than EUR 5000.

Where the estimated value exceeds EUR 144 000, the Director of Contracts, on behalf of the contracting authority, administers the process, and the applicable rules are generally more detailed and onerous. In those cases where, as prescribed by the regulations, the Ministerial Procurement Unit (rather than the contracting authority) administers the procedure, the Director of Contracts is involved only where the estimated value of the contract exceeds EUR 250000.

As far as the Regulations on the Public Procurement of Entities operating in the Water, Energy, Transport and Postal Services Sectors are concerned, the Director of Contracts on behalf of the contracting authority - determines, issues and administers the award of a contract of a value exceeding EUR 443000 , whereas the contracting authority concerned issues a contract of a lesser value directly.

The Regulations on the Public Procurement of Contracting Authorities or Entities in the Fields of Defence and Security concern the award of contracts that have estimated value no less than EUR 134000 in the case of a supply or service contract and no less than EUR 5186000 in the case of a works contract. 
The general rules set out in the Concession Contracts Regulations apply to all concession awards, irrespective of value, but the requirements are more onerous (particularly in relation to publicity and the publication of contract notices) in the case of works and service concessions with an estimated value exceeding EUR 5548000.

All of the values indicated above are exclusive of value-added tax (VAT).

\section{Regulation of contracts above the EU financial thresholds}

Contracts above the EU financial thresholds are regulated by the same Legal Notices applicable to the contracts above the national thresholds, and these contracts are subject to the same rules related to exclusion, selection and shortlisting.

\section{Regulation of contracts above the national thresholds and below the EU financial thresholds}

This type of contract follows the same rules related to exclusion, selection and shortlisting as contracts above the EU financial thresholds.

\section{Regulation of contracts below the national financial thresholds}

Contracts below the national thresholds are regulated by the PPR, although a "lighter" process is allowed, which can be based on a comparison of the quotes.

Procurement regulations for contracts below national thresholds are split as follows:

Regulation 100 (1) states that "Where the estimated value does not exceed five thousand euro (EUR 5 000), the supplies, works or services may be procured departmentally either after obtaining a minimum of three (3) quotations or after the publication in the government's e-procurement platform or through a direct contract at the discretion of the Head of the Contracting Authority taking into consideration the amount involved, the urgency attached to the procurement or restrictions of choice and availability."

Regulation 100 (2) states that "Where the estimated value meets or exceeds five thousand euro (EUR 5 000), but does not exceed ten thousand euro (EUR 10 000), the supplies, works or services may be procured departmentally either after obtaining quotations through government' $\mathrm{s}$ e-procurement platform or through a direct contract at the discretion of the Head of the Contracting Authority or any person delegated by him in writing, taking into consideration the amount involved, the urgency attached to the procurement or restrictions of choice and availability."

It should also be specified that the majority of the regulations of the PPR also apply for procurement where the estimated value meets or exceeds EUR 10000 but does not exceed the national threshold. In fact, Regulation 101 states that 'the supplies, works or services may be procured after a departmental call for tenders.' It is only in exceptional cases that procurement takes place through a direct contract for which the prior written approval of the Minister or his delegate is sought.

\section{Guidance, policy and other information}

The Department of Contracts regularly publishes Contracts Circulars, Procurement Policy Notes and Guidance Notes to assist contracting authorities in the conduct of their procurement procedures. In addition, the Standard Operating Procedures/Guidelines for Tender Evaluation Committees are updated as necessary. The latest version of these documents is available on the Department of Contracts website at www.contracts.gov.mt. 
Furthermore, from time to time, the Department updates the General Rules Governing Tenders and the General Conditions which are specific for the procurement of works, services and supplies. Moreover, additional procurement documentation is published, as and when necessary.

\section{Advertising}

Unless authorised otherwise by the Director of Contracts, all calls for quotations or calls for tenders for contracts with an estimated value exceeding EUR 5000 must be advertised through the Government of Malta's e-procurement platform. If the authority responsible for the tendering process does not make use of this platform, the tender must be advertised in the Government Gazette. In addition, contracts above the EU thresholds must be advertised in the OJEU.

\subsubsection{Choice of participants: Exclusion, selection and shortlisting -further information}

\section{General principles}

Article 18 of the Directive sets out the general principles of procurement, namely equal treatment, non-discrimination, transparency and proportionality. Article 18 also requires that procurement not be designed with the intention of excluding it from the scope of the Directive or artificially narrowing competition. Regulation 39 of the PPR sets out these general principles.

Article 56(1) of the Directive sets out general principles applying to the choice of participants and the award of contracts. Regulation 61 of the PPR sets out these general principles.

Article 56(2) of the Directive permits contracting authorities to examine tenders submitted in an open procedure prior to verifying the absence of grounds for exclusion and the fulfilment of the selection criteria. Member States have the option to exclude or restrict the use of this approach for specific types of procurement or in specified circumstances.

Regulation 117 of the PPR contains this provision. The provision applies to all types of procurement.

Article 56(3) of the Directive allows contracting authorities to ask economic operators to "submit, supplement, clarify or complete the relevant information or documentation" where information or documentation submitted by economic operators is, or appears to be, incomplete or erroneous or where specific documents are missing. This provision applies "unless otherwise provided by national law".

Regulation 62(2) contains this provision with reference to the procurement information or documentation.

\section{Mandatory grounds for exclusion}

Mandatory grounds for exclusion - conviction by final judgement: Article 57(1) of the Directive provides the mandatory grounds for exclusion for specified offences.

Regulation 192 of the PPR provides these mandatory grounds for exclusion and in each case makes a general reference to "an equivalent offence under Maltese law or as defined in the national law of the economic operator". 
Exclusion for the non-payment of taxes or social security contributions - judicial or administrative decision: Article 57(2) of the Directive refers to mandatory exclusion on the grounds of non-payment of taxes or social security contributions established by a judicial or administrative decision having final and binding effect.

Regulation 193(1) of the PPR refers to these mandatory grounds for exclusion.

Exclusion for the non-payment of taxes or social security contributions - other means of proof: Article 57(2) of the Directive permits contracting authorities to exclude an economic operator where they can demonstrate by any appropriate means that it is in breach of its obligations relating to the payment of taxes or social security contributions. Member States may make exclusion on these grounds mandatory.

Regulation 193(2) provides that exclusion on these grounds is not mandatory. "The authorities responsible for the tendering process are also entitled to exclude ..."

Derogations from mandatory exclusion

Article 57(3) of the Directive permits Member States to provide for a derogation from mandatory exclusion on the grounds of public interest.

This derogation is included in Regulation 197 of the PPR, which states: "On an exceptional basis only, the authority responsible for the tendering process may with the prior approval in writing of the Minister dispense from any exclusion mentioned under this Part for overriding reasons relating to the public interest".

Article 57(3) of the Directive permits Member States to provide for a derogation from mandatory exclusion for the non-payment of taxes or social security contributions where an exclusion would be clearly disproportionate. This derogation is not included in the PPR.

\section{Discretionary grounds for exclusion}

Articles 57(4)(a) to (i) of the Directive provide the discretionary grounds for exclusion. Member States have the option to make some or all of these grounds for exclusion mandatory.

In terms of the PPR, some of the discretionary grounds for exclusion are mandatory, whilst others are at the discretion of the Director of Contracts. In this regard, the PPR distinguishes between mandatory grounds for exclusion during the tendering process by the "authority responsible" for that tendering process and grounds on the basis of which the Director of Contracts is "empowered to blacklist an economic operator from participating in a procurement procedure" for a term of two years. Thus, Articles 57(4)(b), (e) and (f) of the Directive are provided in Regulation 194 as "other [mandatory] grounds for exclusion", whereas Articles 57(4)(c), (d), (g), (h) and (i) are provided in Regulation 199 as grounds for "blacklisting by the Director".

\section{Additional national discretionary grounds for exclusion}

Regulation 199(a) of the PPR empowers the Director to blacklist an economic operator from participating in a procurement procedure where that economic operator has been declared guilty by any court or tribunal of an offence relating to labour law, including offences listed in the Employment and Industrial Relations Act or in any subsidiary legislation under that Act. 
In addition, the terms of Regulation 206 of the PPR allows the Director of Employment and Industrial Relations to apply to the Commercial Sanctions Tribunal, established in accordance with the Regulation, and to request the blacklisting of a person from participating in procedures for the award of public contracts if that person imposed unfair employment conditions on employees. The instances of "unfair employment conditions" are listed in Regulation 206(1)(a) to (e). (See Section 3.4.2 below for additional information on blacklisting).

Option to not exclude an economic operator in the case of bankruptcy or the equivalent: Article 57(4) of the Directive permits Member States to provide for the possibility to not exclude an economic operator on the grounds of bankruptcy or in equivalent situations where there are national rules and measures on the continuation of business. This option is not included in the PPR.

Exclusion at any time in the procedure: Article 57(5) of the Directive permits a contracting authority to exclude an economic operator where it becomes aware at any time in the procedure that the grounds for mandatory or discretionary exclusion apply because of acts committed or omitted by the economic operator either before or during the procedure. Member States have the option to make exclusion in these circumstances mandatory. This option is included in Regulation 196 of the PPR, and the exclusion is mandatory.

Maximum periods of exclusion: The maximum periods of exclusion are as follows:

- Mandatory grounds for exclusion listed in Regulation 192 of the PPR: five years, as from the date of conviction by final judgement;

- Discretionary grounds for exclusion justifying blacklisting by the Director, as indicated in Regulation 201(2): two years, as from the date when the decision to blacklist becomes final;

- Discretionary grounds for exclusion justifying blacklisting by the Commercial Sanctions Tribunal at the request of the Director of Employment and Industrial Relations: between six months and one year, as decided by the Commercial Sanctions Tribunal, provided that where the defendant repeats the misconduct, the blacklisting period shall be between one and three years, as stipulated in Regulation 212 of the PPR.

\section{Self-cleaning}

Article 57(6) of the Directive permits an economic operator to provide evidence of measures that it has taken to demonstrate its reliability despite the existence of relevant grounds for exclusion. If such evidence is considered to be sufficient, the economic operator concerned shall not be excluded from the procurement procedure. Regulations 195 and 202 of the PPR set out the provisions related to self-cleaning.

Regulation 195 of the PPR states that an economic operator that is in one of the situations referred to in Regulations 192 and 194 (that is, the grounds for mandatory exclusion, except for the failure to abide by obligations concerning taxes or social contributions, which is covered by Regulation 193) may provide, in an offer or bid, evidence to the effect that it has taken sufficient measures to demonstrate its reliability. Any economic operator that feels aggrieved by a decision of exclusion can file an objection before the Public Contracts Review Board. A further appeal would be available before the Court of Appeal in its Superior Jurisdiction. 
Regulation 202 sets out the provisions for self-cleaning in relation to blacklisting by the Director of Contracts. The blacklisted operator may file an objection before the Commercial Sanctions Tribunal and present evidence of self-cleaning as a defence argument against the blacklisting. An appeal against an eventual decision of the Commercial Sanctions Tribunal would be available before the Court of Appeal in its Superior Jurisdiction.

The procedure related to blacklisting at the request of the Director of Employment and Industrial Relations does not include any specific provision for self-cleaning, although the economic operator concerned would have the right to contest the application of the Director's decision before the Commercial Sanctions Tribunal. A further appeal would also be available before the Court of Appeal in its Superior Jurisdiction.

\section{Selection}

Article 58 of the Directive provides that selection criteria may relate to: (a) suitability to pursue the professional activity; (b) economic and financial standing; and (c) technical and professional ability. These requirements must be appropriate, related and proportionate to the subject matter of the contract.

The provisions on selection are set out in Regulation 217 of the PPR and use substantially the same wording as in the Directive.

In practical terms, economic and financial standing are generally assessed in terms of yearly turnover, and yearly accounts of the preceding years are requested; it is pertinent to note that the PPRs regulate the extent and limitations that may be requested. In addition, in line with Regulation 218, contracting authorities may also require an appropriate level of professional risk indemnity insurance.

In terms of technical and professional ability, as specified in Regulation 222(2) contracting authorities may require, in particular, that economic operators have a sufficient level of experience demonstrated by suitable references from past contracts. To this effect, contracting authorities tend to request evidence of both a minimum number of contracts, including a brief description of each contract, and a minimum total value.

\section{Reduction in the number of otherwise qualified candidates to be invited to participate}

Article 65 of the Directive lays down the rules on the reduction of the number of otherwise qualified candidates to be invited to participate in restricted procedures, competitive procedures with negotiation, competitive dialogue, and innovation partnerships.

The provisions on the reduction of otherwise qualified candidates are set out in Regulation 237 of the PPR. This Regulation reflects the requirements of the Directive by setting a minimum number of five candidates in the restricted procedure and a minimum of three candidates in the competitive procedure with negotiation, the competitive dialogue procedure and the innovation partnership, as stipulated in Regulation 237(3).

\section{European Single Procurement Document}

Article 59 of the Directive requires contracting authorities to accept the ESPD as preliminary evidence, in replacement of certificates issued by public authorities or third parties, confirming that the relevant economic operator fulfils the conditions relating to 
the grounds for exclusion, the selection criteria and, where applicable, the objective rules and criteria for the reduction of the number of otherwise qualified candidates to be invited to participate.

The provisions on the ESPD are set out in Regulations 225 to 228 of the PPR. According to Regulation 228, the ESPD has to be drawn up on the basis of a standard form and is to be provided exclusively in electronic form.

\section{Means of proof}

Article 60 of the Directive sets out the provisions on the means of proof as evidence for the grounds for exclusion and the fulfilment of the selection criteria.

The provisions on the means of proof are set out in Regulations 229 to 234 of the PPR as follows:

- Regulation 229 sets out the general rules as to when, how and from where additional documents (apart from the ESPD) may be requested by a contracting authority.

- Regulation 230 specifies the proof that may be requested in relation to the exclusion and blacklisting of economic operators. It also states, inter alia, that contracting authorities shall not require means of proof other than those expressly referred to in the Regulations.

- Regulation 231 stipulates the general rules regarding the means of proof of financial standing that may be requested from economic operators.

- Regulation 232 sets out the acceptable evidence of the economic operator's technical abilities in accordance with the nature, quantity or importance, and use of the works, supplies or services.

- Regulation 233 obliges the Government of Malta to ensure that the information concerning certificates and other forms of documentary evidence introduced in e-Certis is constantly kept up to date. This Regulation follows closely the wording of Article 61 of the Directive.

- Regulation 234 regulates the production of certificates attesting to compliance with quality assurance standards and environmental management standards. The wording reproduces the text of Article 62 of the Directive.

\section{Reliance on the capacity of other entities}

Article 63 of the Directive provides that, where appropriate and with regard to a specific contract, an economic operator may rely on the capacity of other entities to satisfy the criteria set by the contracting authority in relation to economic and financial standing. This provision is subject to the fulfilment of specified conditions.

The provisions on the reliance on the capacity of other entities are set out in Regulation 235 of the PPR. 
Lists

\section{Official lists of approved economic operators}

Article 64 of the Directive permits Member States to establish or maintain official lists of approved economic operators that have submitted acceptable evidence of their suitability to deliver public contracts.

This provision is reflected in Regulation 236 of the PPR, which states that the Minister (responsible for Finance) shall have the authority to establish regulations for drawing up official lists of approved economic operators and for certification by bodies established under public or private law. No such regulations have been issued to date.

\section{Blacklists}

No specific provisions in the Directive permit or prohibit the use of blacklists of economic operators to whom the grounds for mandatory or discretionary exclusion apply.

As already mentioned, the PPR establishes detailed procedures for blacklisting. To recapitulate, the blacklisting process depends on the grounds involved. Where the grounds are those set out in Regulation 199 of the PPR, the Director of Contracts has the discretion to blacklist an economic operator. The operator concerned is informed of the decision and would then have the right of recourse to the Commercial Sanctions Tribunal and a subsequent right of appeal to the Court of Appeal (in its Superior Jurisdiction).

Where the grounds for blacklisting are "unfair employment conditions", as specified in Regulation 206 of the PPR, the Director of Employment and Industrial Relations may apply to the Commercial Sanctions Tribunal requesting the blacklisting of an operator, and the Tribunal will then decide whether the request is justified, after taking into account the economic operator's written reply. As per Regulation 210(1), the Secretary of the Commercial Sanctions Tribunal shall notify the Director of Employment and Industrial Relations and the defendant of the date on which the first hearing will be held. The notice of hearing shall be communicated to the defendant together with the application and documents. The operator would have a further right of appeal before the Court of Appeal in its Superior Jurisdiction (see the Information Note at the end of this Malta chapter for further information).

\section{Contracts below the EU financial thresholds}

The same grounds for exclusion apply to contracts below the EU financial thresholds. However, with regard to selection, it is to be noted that the ESPD is not applicable for procurement which is estimated below the national threshold. In addition, selection criteria pertaining to experience and economic/financial standing are not permitted for such procurement.

\section{Information note - blacklisting in Malta}

The PPRs in Malta, which transpose the 2014 Directive, include provisions on the operation of an official blacklist system ${ }^{141}$. Economic operators may be officially

${ }^{141}$ An official blacklist was also provided for in the previous PPL, but this provision was less far-reaching, and only a very limited number of economic operators were included on that list. 
blacklisted in two ways: (1) following a decision to blacklist by the Director of Contracts (the head of the national Department for Contracts) on the grounds listed in Regulation 199, subject to a right of appeal to the Commercial Sanctions Tribunal, which can be further appealed to the Court of Appeal; and (2) following a decision to blacklist by the Commercial Sanctions Tribunal in response to a request from the Director of Employment and Industrial Relations on the grounds listed in Regulation 206, subject to a right of appeal to the Court of Appeal. In both cases, blacklisting is only possible in relation to offences or situations specified in the PPR ${ }^{142}$.

An economic operator that has been blacklisted by final judgement from participation in procurement procedures (in accordance with one of the procedures outlined below) is not entitled to make use of the possibility of an appeal based on self-cleaning for the period of its blacklisting.

Once an economic operator has been blacklisted, it shall be excluded from the award of any public contract, quotation or direct contract for the period of its blacklisting.

Where the economic operator has been blacklisted in response to a request from the Director of Employment and Industrial Relations, all existing contracts signed by the central government authority, contracting authorities and bodies governed by public law with that economic operator are terminated ipso jure by operation of law. The termination of a contract in these circumstances takes effect, without any compensation for actual and future losses, as from the date on which the decision regarding the blacklisting becomes final. In addition, the economic operator is excluded from the award of any public contract, quotation or direct contract for the period of its blacklisting.

Blacklisting by the Director of Contracts: The Director of Contracts, who heads the national Department of Contracts, is empowered to blacklist an economic operator from participating in a procurement procedure in the situations listed in Regulation 199, where:

"(a) the economic operator has been declared guilty by any court or tribunal of an offence relating to labour law including those found in the Employment and Industrial Relations Act or any subsidiary legislation made under that Act; or

(b) the economic operator has been convicted of an offence concerning his professional conduct by a judgement which has the force of res judicata in accordance with the laws of Malta, which renders its integrity questionable; or

(c) the Director has sufficiently plausible indications to conclude that the economic operator has entered into agreements with other economic operators aimed at distorting competition; or

(d) the Director has been informed in writing by a contracting authority that an economic operator has shown significant or persistent deficiencies in the performance of a substantive requirement in a public contract, or a public

\footnotetext{
${ }^{142}$ Where grounds for mandatory or discretionary exclusion applying to an economic operator are not grounds listed in Regulation 199 or Regulation 206, the official blacklist provision does not apply. Exclusion in such cases must be considered on a case-by-case basis by the contracting authority, taking into account any self-cleaning measures taken by the economic operator. A decision to exclude made by the contracting authority is subject to a right of appeal to the Public Contracts Review Board. The procedure for appeal to the Public Contracts Review Board is covered elsewhere in the Regulations and does not result in official blacklisting.
} 
concession contract, which led to early termination of that contract, damages or other comparable sanctions; or

(e) the economic operator has been declared guilty by any court or tribunal of serious misrepresentation in supplying the information required for the verification of the absence of grounds for exclusion or the fulfilment of the selection criteria, has withheld such information or is not able to submit the supporting documents required pursuant to regulation $226^{143}$;

(f) the economic operator has undertaken to unduly influence the decision-making process of the contracting authority, to obtain confidential information that may confer upon it undue advantages in the procurement procedure or to negligently provide misleading information that may have a material influence on decisions concerning exclusion, selection or award."

The procedure for appealing against a blacklisting decision by the Director of Contracts, pursuant to Regulation 199, is summarised below:

- The Director of Contracts first informs the economic operator in writing (using a registered letter or a judicial letter, as provided for under the Code of Organization and Civil Procedure) of the blacklisting decision ("blacklisting decision"), detailing the grounds for blacklisting that apply.

- The economic operator is entitled to file an appeal against the blacklisting decision with the relevant appeal body, the Commercial Sanctions Tribunal ("the Tribunal"). It must do so within ten days from the date on which the registered letter shall be notified to the appellant.

- Where the economic operator does not file an appeal with the Tribunal, the blacklisting decision is final and the blacklisting period is two years, as from the date of the blacklisting decision. The economic operator files an appeal with the Tribunal - within the ten-day deadline - and in accordance with procedural requirements, including payment of a deposit of EUR 400 to the Tribunal (which may be refunded in whole or in part at the discretion of the Tribunal).

- The Tribunal immediately provides a copy of the appeal to the Director of Contracts.

- The Tribunal affixes a copy of the appeal to the public notice board of the Tribunal.

- The Director of Contracts may file a written reply to the appeal with the Tribunal, from the day on which the appeal is notified to them..

- The Tribunal affixes a copy of the written reply of the Director of Contracts to the public notice board of the Tribunal.

- The Director of Contracts sends all documents relating to the blacklisting of the appellant to the chairman of the Tribunal.

- The Tribunal sets a date for an oral hearing.

${ }^{143}$ Regulation 226 concerns the contents of the ESPD. 
- The oral hearing takes place, with the secretary of the board responsible for keeping a record of the proceedings.

- On conclusion of the oral hearing, the Tribunal:

$\circ$ delivers its decision on the same day; or

- reserves its decision for the earliest possible date, but not later than six weeks from the date on which written pleadings were deemed to be closed (subject to postponement by the Tribunal for serious and justified reasons, as notified by the Tribunal to the parties in writing).

- Where the Tribunal upholds the decision of the Director of Contracts, the blacklisting decision becomes final as from the date of the decision by the Tribunal and is effective for a two-year period as from the date of that decision.

- The decision of the Tribunal may be appealed to the Court of Appeal. Where the Court of Appeal upholds the decision of the Tribunal, the blacklisting decision becomes final as from the date of the decision by the Court of Appeal and is effective for a two-year period as from the date of that decision.

Self-cleaning: An economic operator may use the evidence of self-cleaning measures as a defence against the blacklisting decision by the Director of Contracts. The self-cleaning measures required are the same as the self-cleaning measures provided in the Directive. They require proof that the economic operator has a) paid or undertaken to pay compensation in respect of any damages caused by the criminal offence or misconduct; $b$ ) clarified the facts and circumstances in a comprehensive manner by actively collaborating with the investigating authorities; and c) taken concrete technical, organisational and personnel measures that are appropriate to prevent further criminal offences or misconduct.

The Tribunal considers the self-cleaning measures taken by the economic operator, taking into account the gravity and particular circumstances of the criminal offence or misconduct. If the Tribunal considers that the measures taken are sufficient, the economic operator concerned is not blacklisted from the procurement procedure. Where the Tribunal deems the measures to be insufficient, the economic operator will be blacklisted, and the Tribunal will include the reasons for such a decision in its judgement.

Blacklisting at the request of the Director of Employment and Industrial Relations: The PPR also allow the Director of Employment and Industrial Relations (DofEIR) to apply to the Tribunal and to request the blacklisting of a person (natural or legal or natural persons who represent a legal person) from participating in procedures for the award of public contracts if that person imposes "unfair employment conditions" on employees. Unfair employment conditions are defined in the PPR.

The procedure is summarised as follows:

- The DofEIR submits an application for blacklisting to the Commercial Sanctions Tribunal. The application contains:

- a statement of the facts and the grounds for the blacklisting;

$\circ$ a detailed report on the findings of the investigations by the DofEIR or a court decision (where relevant). 
- The application and supporting documents are served on the economic operator (defendant) by registered mail. The economic operator has 20 days to file a reply with the Tribunal.

- The economic operator files a reply and supporting documents with the Tribunal before the 20-day deadline and pays a deposit of EUR 400 to the Tribunal (which may be refunded in whole or in part, at the discretion of the Tribunal).

- The economic operator must also serve a copy of the reply and supporting documents on the DofEIR, on which date the written pleadings are deemed to be closed.

- The Tribunal notifies the DofEIR and the economic operator of the date of the first oral hearing, which shall be within 15 days of the date on which the written pleadings were closed.

- The Tribunal conducts an oral hearing, evaluates all of the evidence and considers all of the submissions presented by the parties. The Tribunal may also consider measures (if any) taken by the defendant to remedy the situation.

- On conclusion of the oral hearing, the Tribunal shall:

$\circ$ deliver its decision on the same day; or

- reserve its decision for the earliest possible date, but not later than four months from the date when the written pleadings were deemed to be closed (subject to postponement by the Tribunal for serious and justified reasons, of which the Tribunal must notify the parties in writing).

- The Tribunal shall decide whether to accede to or reject the the DofEIR's request for blacklisting.

- The Tribunal also has the option, where it has considered any measures taken by the defendant to remedy the situation and after taking into account the gravity and particular circumstances of the misconduct, to deliver a warning to the economic operator instead of proceeding with the blacklisting.

- Where the Tribunal decides that the economic operator shall be blacklisted, the blacklisting decision becomes final two months after the decision by the Tribunal. Thus, effects of blacklisting commence once the two-month period from the day of the final decision has lapsed.

- The blacklisting period is between six months and one year, as decided by the Tribunal.

- Where there is a further instance of the misconduct, the blacklisting period shall be between one and three years, as decided by the Tribunal.

- The decision of the Tribunal may be appealed to the Court of Appeal. Where the Court of Appeal upholds the decision of the Tribunal, the blacklisting decision becomes final as from the date of the decision by the Court of Appeal.

Self-cleaning: The procedure related to blacklisting at the request of the DofEIR does not have any specific provision related to self-cleaning. However, as mentioned above, the Tribunal may consider measures taken by the defendant to remedy the situation, presumably where the economic operator has indicated those measures to the Tribunal. As a consequence of its consideration, the Tribunal may decide to deliver a warning 
rather than blacklist the economic operator. The economic operator also has a further appeal available before the Court of Appeal (in its Superior Jurisdiction). 


\subsection{POLAND}

\subsection{Overview}

\section{Public procurement legislation}

\section{Key legislation}

The key public procurement legislation covering the exclusion, selection and shortlisting stage of public procurement processes undertaken by contracting authorities is contained in the Public Procurement Law of 29 January 2004 with further amendments (PPL).

The means of proof are regulated by the secondary legislation - the Regulation of the Minister of Economic Development of 26 July 2016 - on the type of documents that may be required by the contracting authority from the contractor in the procedure for the award of the contract.

Public procurement legislation can be downloaded from the official portal of the PPO www.uzp.gov.pl.

\section{Brief description of the key legislation}

The PPL was adjusted to the provisions of the Directive on public procurement and Directive 2014/25/EU on entities operating in the water, energy, transport and postal services sectors by the Law of 22 June 2016 amending the PPL and other Laws (in force as from 28 July 2016). All of the procedures launched after 28 July 2016 must be conducted according to the new rules, including the use of the ESPD.

The Polish Government has taken advantage of the permitted delay in the transposition of provisions applicable to electronic communication, which came into force on 18 April 2017 for central purchasing bodies and will come into force on 18 October 2018 for other contracting authorities. The requirements concerning the electronic format of the ESPD, supporting documents for the ESPD, and e-Certis will also come into force on 18 October 2018.

The PPL applies to procurement by contracting authorities of public contracts above and below the EU financial thresholds for works, supplies and services. Special chapters of the PPL regulate utilities procurement and procurement in the fields of defence and security.

The PPL also contains provisions on remedies, which have been adapted to align with the national legal system, in accordance with the Remedies Directive 89/665/EC.

The regulations on exclusions include mandatory and discretionary grounds for exclusion, including national grounds for exclusion.

\section{National financial thresholds}

The PPL applies to contracts above the national threshold of EUR 30 000. National law or regulations do not regulate contracts below the national thresholds, but the rules on public expenditures must be applied for contracts financed by public funds. The procedures have been simplified for contracts between EUR 30000 and the EU thresholds. 
The PPL applies to utilities contracts above the EU thresholds. For contracts in the fields of defence and security, the national threshold of EUR 30000 applies for works contracts, while for services and supplies the EU threshold of EUR 418000 applies.

\section{Regulation on contracts above the EU financial thresholds and of contracts above the national thresholds and below the EU financial thresholds}

The same provisions on exclusions are applied for contracts above EUR 30000 and for contracts above the EU thresholds. Differences are found in the means of proof. While for contracts above the EU thresholds the use of ESPD is mandatory, there is no such obligation for contracts above the national thresholds and below the EU thresholds. However, the statements of the economic operator must be submitted.

Similar provisions apply to documents and statements submitted as evidence in the non-existence of grounds for exclusion and for the fulfilment of the selection criteria. For low-value contracts, the contracting authority may rely on the statements of the economic operator. The request for documents specified in the Regulation of the Minister of Economic Development of 26 July 2016 on the type of documents that may be required by the contracting authority from the contractor in the procedure for the award of the contract is not obligatory.

\section{Regulation of contracts below the national financial thresholds}

Contracts below the national thresholds are not regulated by national legislation. The contracting authority adopts internal regulations on the procedures covering procurement below EUR 30 000. It is common practice to use a form of request for tenders announced on the website of the entity or to make a comparison of tenders submitted by the invited economic operators.

\section{Guidance, policy and other information}

The PPO issues the guidelines and opinions on various important topics of interest to the procurement community, publishing them on its website, www.uzp.gov.pl. These guidelines and opinions are not binding, but they do influence procurement practices.

For the regulations adopted by the Law of 22 June 2016 amending the PPL and other Laws, including new provisions on the grounds for exclusion, selection criteria and means of proof, the PPO has published special materials, e.g. guidelines on how to complete the ESPD.

\section{Advertising}

All contracts above the national thresholds but below the EU thresholds must be advertised in the Public Procurement Bulletin, the official publication of the PPO. The Bulletin, released in electronic form, allows contracting authorities to publish notices in real time seven days a week.

Contracts above the EU thresholds must be advertised in the OJEU.

In addition, all public procurement notices must be published electronically on the contracting authority's website and in paper form on its premises in a publicly available location. 


\subsubsection{Choice of participants: Exclusion, selection and shortlisting-further information}

\section{General principles}

Article 18 of the Directive sets out the general principles of procurement, namely equal treatment, non-discrimination, transparency and proportionality. Article 18 also requires that procurement not be designed with the intention of excluding it from the scope of the Directive or artificially narrowing competition.

Articles 7 to 10 of the PPL set out these general principles.

Article 56(1) of the Directive sets out the general principles applying to the choice of participants and the award of contracts.

The general principles set out in Articles 7 to 10 of the PPL apply to all stages of the procedure. In addition, Article 22.1a) of the PPL obliges the contracting authority to specify the selection criteria in a manner that is proportionate to the object of the contract and enables the contracting authority to assess the ability of the contractor to properly perform the contract.

The tenders that are not compliant with the requirements and conditions set out in the tender documentation are rejected, in accordance with Article 89 of the PPL.

Article 56(2) of the Directive permits contracting authorities to examine tenders submitted in an open procedure prior to verifying the absence of grounds for exclusion and the fulfilment of the selection criteria. Member States have the option to exclude or restrict the use of this approach for specific types of procurement or in specified circumstances.

Article 24aa of the PPL contains this provision. The provision applies to an open tender for all types of procurement and exclusively when the contracting authority has announced the intention to apply the examination procedure in a tender notice or in tender documentation.

Article 56(3) of the Directive allows contracting authorities to ask an economic operator to "submit, supplement, clarify or complete the relevant information or documentation" where the information or documentation submitted by the economic operator is, or appears to be, incomplete or erroneous or where specific documents are missing. This provision applies "unless otherwise provided by national law".

According to Article 26.3 of the PPL, the contracting authority evaluates the ESPD or the statements and documents submitted by the economic operator to certify the lack of grounds for exclusion or the fulfilment of the selection criteria. In the event that the documents or statements were not submitted or are incomplete, contain errors or raise doubts, the contracting authority is obliged to undertake specific actions. The contracting authority shall ask the economic operator to submit, supplement or correct the same or to provide the above-mentioned clarifications within the time limit specified by the contracting authority.

This provision does not apply in the case where, in spite of the submission, supplementation or correction of such documents or the provision of such clarifications by the economic operator, the tender submitted by the economic operator would be subject to rejection or the tender procedure would have to be cancelled. 


\section{Mandatory grounds for exclusion}

Mandatory grounds for exclusion - conviction by final judgement: Article 57(1) of the Directive lists the mandatory grounds for exclusion for specified offences.

Article 24.1.13-14 of the PPL lists those mandatory grounds for exclusion. Article 24.1.13 of the PPL refers to the equivalent national legislation:

- an offence referred to in Article 165a, Articles 181-188, Article 189a, Articles 218-221, Articles 228-230a, Article 250a, Article 258 or Articles 270-309 of the Law of 6 June 1997 - Penal Code as amended (Journal of Laws of the Republic of Poland, item 553) or Article 46 or Article 48 of the Law of 25 June 2010 on Sports (Journal of Laws of 2016, item 176);

- a crime of terrorism, as referred to in Article $115 \S 20$ of the Law of 6 June 1997 - Penal Code;

- $\quad$ an offence against the Treasury (fiscal offence);

- an offence referred to in Article 9 or Article 10 of the Law of 15 June 2012 Effects of Delegating Work to Foreigners unlawfully residing in the territory of the Republic of Poland (Journal of Laws, item 769).

Exclusion for the non-payment of taxes or social security contributions - judicial or administrative decision: Article 57(2) of the Directive refers to mandatory exclusion on the grounds of non-payment of taxes or social security contributions established by a judicial or administrative decision having final and binding effect.

Article 24.1.15 of the PPL refers to these mandatory grounds for exclusion.

Exclusion for the non-payment of taxes or social security contributions - other means of proof: Article 57(2) of the Directive permits contracting authorities to exclude an economic operator where they can demonstrate by any appropriate means that it is in breach of its obligations relating to the payment of taxes or social security contributions. Member States may make exclusion on these grounds mandatory.

Article 24.5.8 provides that exclusion on these grounds is not mandatory.

\section{Derogations from mandatory exclusion}

Article 57(3) of the Directive permits Member States to provide for derogation from mandatory exclusion on public interest grounds. This derogation is not included in the PPL.

Article 57(3) of the Directive permits Member States to provide for derogation from mandatory exclusion for the non-payment of taxes or social security contributions where exclusion would be clearly disproportionate. This derogation is not included in the PPL.

Additional national mandatory grounds for exclusion

Article 24.1.21-23 of the PPL includes additional national grounds for mandatory exclusion. The following shall also be excluded from the public procurement procedure:

- 21): A contractor that is a collective entity and against which a court has ruled the prohibition to apply for the award of a public contract on the basis of the Law of 28 October 2002 - Responsibility of Collective Entities for Acts Prohibited under 
Penalty (Journal of Laws of 2015, items 1212, 1844 and 1855; and Journal of Laws of 2016, items 437 and 544);

- 22): A contractor against which a preventive measure has been ruled, in the form of a public contract application ban;

- 23): Contractors that belong to the same group of companies, within the meaning of the Law of 16 February 2007 - Competition and Consumer Protection (Journal of Laws of 2015, items 184, 1618 and 1634) and that have submitted separate bids, partial offers or requests to participate in the proceedings, unless they demonstrate that the links existing between them do not lead to distortions of competition in the public procurement procedure.

\section{Discretionary grounds for exclusion}

Article 57(4)(a) to (i) of the Directive provides the discretionary grounds for exclusion. Member States have the option to make some or all of these grounds for exclusion mandatory.

Some of the discretionary grounds for exclusion in the PPL are mandatory: Article 24.1.16-20 states that the following grounds for exclusion are mandatory:

- "16) a contractor who, as a result of deliberate action or gross negligence, has misled the contracting authority with the information that it is not subject to exclusion, satisfies the conditions for participation in the proceedings or the objective and non-discriminatory criteria, hereinafter referred to as the 'selection criteria', or who has withheld such information, or is not able to provide the required documents;

- 17) a contractor who, as a result of deliberate action or gross negligence, has misled the contracting authority with the information which could significantly affect the decisions taken by the contracting authority in the public procurement proceedings;

- 18) a contractor who has unlawfully influenced, or attempted to unlawfully influence, the actions of the contracting authority, or to obtain confidential information that could give him an advantage in the public procurement procedure;

- 19) a contractor who has participated - or whose employee, or a person performing work on behalf of the contractor under a mandate contract, contract for specific work, agency or other service contract, has participated in the preparation of the procurement procedure, unless the resulting distortion in the competition can be eliminated in any way other than exclusion of the contractor from the proceedings;

- 20) a contractor who has entered into an agreement with other contractors with a view to distorting competition among the contractors participating in the procurement procedure, which can be demonstrated by the contracting authority by means of appropriate evidence."

Article 24.5 provides all of the national discretionary grounds for exclusion. The contracting authority has the option of applying the grounds only if they are announced in the notice, tender documentation or invitation to negotiations. 
According to Article 24.5, the contracting authority may exclude from the procedure:

- a contractor against which a liquidation procedure has been initiated, or for which the court has ordered the liquidation of its assets, or a contractor for which bankruptcy has been declared;

- a contractor that culpably and materially violated its professional duties, which undermines its integrity, and particularly, if the contractor, as a result of deliberate action or gross negligence, failed to perform or improperly performed any contract, provided that the contracting authority is able to demonstrate the same by means of appropriate evidence;

- a contractor, or persons referred to in paragraph 1 , point 14 , authorised to represent the contractor linked, in a manner specified in Article 17.1.2-4, to:

$\circ$ the contracting authority

$\bigcirc$ any person authorised to represent the contracting authority

$\bigcirc$ any member of the tender committee

- any person who has submitted the declaration referred to in Article 17.2a unless it is possible to ensure the impartiality of the contracting authority in any way other than exclusion of a contractor from the proceedings.

- a contractor that, for reasons attributable to it, has not performed or improperly performed, to a significant extent, any earlier public procurement agreement or concession contract, which resulted in the termination of the agreement or the award of compensation;

- a contractor that is a natural person and has been validly sentenced for an offence against employee rights or an offence against the environment, provided that the sentence involved detention, restriction of freedom or a fine of not less than PLN 3000 (EUR 695);

- a contractor that is an executive member of the management or supervisory body, partner of a general partnership or (professional) partnership, or general partner in a limited partnership or limited joint-stock partnership, or commercial proxy, has been validly sentenced for an offence referred to in the point above;

- a contractor against which a final administrative decision has been issued with regard to the breach of obligations under labour law, environmental law or social security legislation, provided that the sentence involved a fine of not less than PLN 3000 (EUR 695);

- a contractor that has breached the obligations relating to the payment of any taxes, fees or premiums for social or health insurance, provided that the contracting authority is able to demonstrate the same by means of appropriate evidence, except for the case referred to in paragraph 1, point 15, unless the contractor has already paid such overdue taxes, fees or premiums, together with any interest or fines, or has entered into a binding agreement on the repayment of such overdue amounts.

Additional national discretionary grounds for exclusion

No additional discretionary grounds for exclusion are provided in the PPL. 
Option to not exclude economic operators in case of bankruptcy or the equivalent: Article 57(4) of the Directive permits Member States to provide for the possibility to not exclude on the grounds of bankruptcy or in equivalent situations where there are national rules and measures on the continuation of business. This option is included in Article 24.5.1 of the PPL.

Exclusion at any time in the procedure: Article 57(5) of the Directive permits a contracting authority to exclude an economic operator where it becomes aware at any time in the procedure that the grounds for mandatory or discretionary exclusion apply because of acts committed or omitted by the economic operator either before or during the procedure. Member States have the option to make exclusion in these circumstances mandatory. This option is included in Article 24.12 of the PPL.

Maximum periods of exclusion: The mandatory exclusion grounds are provided in Article 24.7 of the PPL, as follows:

- mandatory grounds for the exclusion of a contractor in the case of final judgement for any of the listed crimes or offences: five years, as from the effective date of the judgement, subject to any other period of exclusion specified in the judgement;

- mandatory grounds for the exclusion of a contractor for any of the offences referred to in Article 9 or Article 10 of the Law of 15 June 2012 on the Effects of Delegating Work to Foreigners unlawfully residing in the territory of the Republic of Poland: three years, as from the effective date of the judgement, subject to any other period of exclusion specified in the judgement;

- mandatory grounds for the exclusion of a contractor against whom a final judicial or administrative decision has been issued with regard to arrears related to the payment of any taxes, fees or premiums for social or health insurance: three years, as from either the effective date of the judgement, subject to any other period of exclusion specified in the judgement, or the date on which the decision became final;

- discretionary grounds for the exclusion for offences and violation of environmental and labour laws: three years, as from either the effective date of the judgement, subject to any other period of exclusion specified in the judgement, or the date on which the decision became final;

- mandatory grounds for the exclusion of a contractor that has unlawfully influenced, or attempted to unlawfully influence, the actions of the contracting authority or that has entered into an agreement with other contractors with a view to distorting competition; and discretionary grounds for the exclusion of a contractor in the case of grave professional misconduct or poor prior performance: three years, as from the date of the event giving rise to the exclusion.

\section{Self-cleaning}

Article 57(6) of the Directive permits economic operators to provide evidence of measures that it has taken to demonstrate its reliability despite the existence of relevant grounds for exclusion. If such evidence is considered to be sufficient, the economic operator concerned shall not be excluded from the procurement procedure. 
Article 24.8 of the PPL sets out the provisions related to self-cleaning. The economic operator subject to exclusion according to Article 24.1.13-14 and 16-20 and to the discretionary grounds for exclusion provided in Article 24.5 can provide evidence that the measures it has undertaken are sufficient to demonstrate its reliability. The contracting authority is obliged to evaluate the explanations and documents provided as evidence by the economic operator, taking into account the significance and particular circumstances of the actions committed by that economic operator, and if the evidence is satisfactory, the contracting authority shall not proceed with the exclusion.

\section{Selection}

Article 58 of the Directive provides that selection criteria may relate to: (a) suitability to pursue the professional activity; (b) economic and financial standing; and (c) technical and professional ability. These requirements must be appropriate, related and proportionate to the subject matter of the contract.

The provisions on selection are set out in Article 22.1a and 1b of the PPL.

\section{Reduction in the number of otherwise qualified candidates to be invited to participate}

Article 65 of the Directive lays down the rules on the reduction of the number of otherwise qualified candidates to be invited to participate in restricted procedures, competitive procedures with negotiation, competitive dialogue, and innovation partnerships.

The provisions on the reduction of otherwise qualified candidates are set out in the PPL in Article 51.2 (restricted procedure), Article 57.3 (negotiated procedure with prior announcement), Article 60d.3 (competitive dialogue) and Article 73e (innovation partnership).

\section{European Single Procurement Document}

Article 59 of the Directive requires contracting authorities to accept the ESPD as preliminary evidence, in replacement of certificates issued by public authorities or third parties, confirming that the relevant economic operator fulfils the conditions relating to the grounds for exclusion, the selection criteria and, where applicable, the objective rules and criteria for the reduction in the number of otherwise qualified candidates to be invited to participate.

The provisions on the ESPD are set out in Article 25a of the PPL. Until 18 April 2018 (other than for central purchasing, where electronic submission applied from 18 April 2017), the ESPD had to be submitted in a written form, except in cases where the contracting authority allowed for submission in electronic form.

For contracts above the national thresholds but below the EU thresholds, an economic operator is not obliged to submit an ESPD. Instead, the economic operator must provide a self-statement to the effect that it is not subject to exclusion and meets the conditions for participation in the procurement procedure. In addition, in a procedure with pre-selection, it must also declare that the criteria for shortlisting have been fulfilled. 
Means of proof

Article 60 of the Directive sets out the provisions on the means of proof as evidence for the grounds for exclusion and for the fulfilment of the selection criteria.

The provisions on the means of proof are set out in Articles 25 and 26 of the PPL and in the Regulation of the Minister of Economic Development of 26 July 2016. The Regulation lists the types of documents that may be required by the contracting authority from the contractor in the procedure for the award of a contract, but these documents are not obligatory. The following paragraphs of the Regulation set out the types of documents that may be required:

- Paragraph 2 specifies the documents and statements that may be required in order to confirm that the economic operator fulfils the selection criteria.

- Paragraph 3 lists additional documents that may be used as means of proof for fulfilling the selection criteria for procurement in the field of defence and security.

- Paragraph 4 is related to contracts that involve the processing, request for access or use of documents containing classified information.

- Paragraph 5 lists the statements and documents required for proof that the economic operator is not subject to exclusion (mandatory and discretionary grounds for exclusion).

- Paragraph 6 provides for additional documents that may be required to prove the absence of grounds for exclusion for contracts in the field of defence and security.

- Paragraphs 7 and 8 specify documents that may be required from a foreign economic operator.

- Paragraph 9 refers to the proof that the economic operator, when relying on the capacity or situation of another entity or entities under the terms specified in Article 22a of the PPL, has the resources necessary for the proper performance of the public contract, and to the documents that will enable the assessment of whether the relationship between the contractor and the entity or entities ensures the effective access to their resources.

- Paragraph 13 provides for the documents requested in order to confirm that the construction works, supplies or services offered by the contractor meet the requirements specified by the contracting authority, including quality assurance standards and environmental management standards.

The Regulation also includes the provisions referring to the period of validity and the form in which the documents and statements may be submitted.

The general rule for requesting the documents and statements to be presented to prove the absence of grounds for exclusion and the fulfilment of the selection criteria states that the contracting authority may require the economic operator to provide only those statements or documents that are necessary for the conduct of the tendering procedure.

For procurement above the national threshold (EUR 30000 ) and below the EU thresholds, the contracting authority is permitted to choose the means of proof. It can accept a self-declaration or request the economic operator to submit the documents listed in the Regulation (if appropriate). 
For contracts of a value above the EU thresholds, the contracting authority is obliged to rely on the documents proving the absence of grounds for exclusion. Other documents may be requested if appropriate.

\section{Reliance on the capacity of other entities}

Article 63 of the Directive provides that an economic operator may, where appropriate and with regard to a specific contract, rely on the capacity of other entities to satisfy the criteria set by the contracting authority related to economic and financial standing. This provision is subject to the fulfilment of specified conditions.

The provisions on the reliance on the capacity of other entities are set out in Article 22a of the PPL.

\section{Lists}

\section{Official lists of approved economic operators}

Article 64 of the Directive permits Member States to establish or maintain official lists of approved economic operators that have submitted acceptable evidence of their suitability to deliver public contracts.

In the PPL, no list of approved economic operators is provided.

\section{Blacklists}

No specific provisions in the Directive permit or prohibit the use of blacklists of economic operators to whom the grounds for mandatory or discretionary exclusion apply.

No authorised or centralised blacklisting exists in Poland. 


\subsection{SCOTLAND}

\subsubsection{Overview}

\section{Public procurement legislation}

\section{Key legislation}

The key public procurement legislation covering the exclusion, selection and shortlisting stage of public procurement processes undertaken by contracting authorities is contained in:

- Public Contracts (Scotland) Regulations 2015 or PC(S)Rs (2015 No. 446) (as amended);

- Procurement Reform (Scotland) Act or PR(S)A (as amended);

○ 2016 Procurement Regulations (2016 No. 145) issued under the PR(S)A.

The Scottish Ministers issued the PC(S)Rs 2015 and the 2016 Procurement Regulations in the form of secondary/subsidiary legislation. The $\mathrm{PR}(\mathrm{S}) \mathrm{A}$ is primary legislation.

Separate regulations transpose Directive 2014/23/EU (award of concession contracts) and Directive 2014/25/EU (entities operating in the water, energy, transport and postal services sectors):

- The Utilities Contracts (Scotland) Regulations 2016 (2016 No. 49) (as amended), transposing Directive 2014/25/EU;

- The Concession Contracts (Scotland) Regulations 2016 (2016 No.65) (as amended), transposing Directive 2014/23/EU.

No purely national procurement legislation applies to the award of utilities contracts or concessions contracts under the EU financial thresholds.

All public procurement legislation can be downloaded from both the United Kingdom Government's legislation website, www.legislation.gov.uk and the Scottish Government's procurement website, www.gov.scot/Topics/Government/Procurement/ policy/ProcurementReform.

\section{Brief description of the key legislation}

The PC(S)Rs transpose the Directive on public procurement.

The PC(S)Rs apply to procurement by all contracting authorities of public contracts above the EU financial thresholds for works, supplies and services.

The PC(S)Rs came into force on 18 April 2016. The Scottish Government has taken advantage of the allowable delay in transposition of provisions applicable to electronic communication, which came into force on 18 April 2017 for central purchasing bodies and is due to come into force on 18 October 2018 for other contracting authorities. Requirements concerning the electronic format of the ESPD, supporting documents for the ESPD and e-Certis will also come into force on 18 October 2018.

The content and wording of the PC(S)Rs transposing the Directive have been closely aligned with the English-language version of the Directive, using a copy and paste approach, with limited adaptations and few additions to incorporate national provisions. 
The $\mathrm{PC}(\mathrm{S}) \mathrm{Rs}$ also contain provisions on remedies, which have been adapted to align with the national legal system, in line with Remedies Directive 89/665/EC.

The PR(S)A and national thresholds

The $\mathrm{PR}(\mathrm{S}) \mathrm{A}$ is national legislation that applies to all contracting authorities. Some of the provisions of the $\mathrm{PR}(\mathrm{S}) \mathrm{A}$ apply to all contracts above the national financial thresholds, including contracts above the EU financial thresholds. Some provisions only apply to contracts above the national financial thresholds and below the EU financial thresholds.

The PR(S)A came into force in stages, over the period between 17 June 2014 and 1 June 2016.

The PR(S)A assigns contracting authorities a number of general duties regarding their procurement activities, including a sustainable procurement duty ${ }^{144}$, as well as some specific measures aimed at promoting good, transparent and consistent practice in procurement. These measures include the requirement to advertise all contracts above the national financial thresholds and below the EU financial thresholds on the national Public Contracts Scotland website.

The $\mathrm{PR}(\mathrm{S}) \mathrm{A}$ also requires larger-spending contracting authorities to publish procurement strategies and annual reports, with the aim of increasing the visibility of the purchasing activities of these bodies and the fulfilment of their procurement obligations.

The PR(S)A contains some general provisions on exclusion and selection, which apply to contracts above the national financial thresholds and below the EU financial thresholds. More detailed provisions on exclusion and selection applying to these contracts are set out in Sections 8 and 9 of the 2016 Procurement Regulations.

Statutory guidance under the $\mathbf{P R}(\mathbf{S}) \mathbf{A}$ : The Scottish Ministers have published statutory guidance under the $\mathrm{PR}(\mathrm{S}) \mathrm{A}$. Contracting authorities must consult the statutory guidance, with the relevant sections of the $\mathrm{PR}(\mathrm{S}) \mathrm{A}$ and the $\mathrm{PC}(\mathrm{S}) \mathrm{Rs}$, where relevant. This statutory guidance is as follows:

- Guidance under the $P R(S) A$ - www.gov.scot/publications/2016/03/8410

- Guidance on selection of tenderers and award of contracts - Addressing Fair Work Practices, including the Living Wage, in Procurement, www.gov.scot/publications/2015/10/2086.

\section{National financial thresholds}

The national financial thresholds are the following:

- GBP 2000000 (EUR 2347 560) for public works contract

144 The Procurement Reform (Scotland) Act 2014 (PR(S)A) establishes a national legislative framework for sustainable public procurement. Contracting authorities must comply with the "sustainable procurement duty". This duty applies to all contracts above the national thresholds, including contracts above the EU financial thresholds. The sustainable procurement duty requires a contracting authority to consider how, in conducting the procurement process, it can 1) improve the economic, social and environmental well-being of the authority's area and in carrying out the Procurement Act with a view to securing such improvements; 2) facilitate the involvement of small and medium-sized enterprises, third-sector bodies and supported business in that process; and 3) promote innovation. 
- GBP 50000 (EUR 58 689) for other public contracts.

\section{Regulation of contracts above the EU financial thresholds}

Contracts above the EU financial thresholds are regulated by the $\mathrm{PC}(\mathrm{S}) \mathrm{Rs}$ and by some provisions of the $\mathrm{PR}(\mathrm{S}) \mathrm{A}$.

The grounds for mandatory and discretionary exclusion and the selection criteria applying to contracts above the EU financial thresholds are set out in the PC(S)Rs in Regulations 57 to 66 .

\section{Regulation of contracts between the national financial thresholds and the EU financial thresholds}

The PR(S)A regulates contracts between the national financial thresholds and the EU financial thresholds. This legislation includes the provisions on exclusion (Section 27) and selection (Section 28).

Sections 27 and 28 of the $\mathrm{PR}(\mathrm{S}) \mathrm{A}$ permit Scottish Ministers to make further provisions with regard to exclusion and selection by means of regulations. Scottish Ministers accordingly issued the 2016 Procurement Regulations. The 2016 Procurement Regulations 8 and 9 set out in detail the mandatory and discretionary grounds for exclusion and the selection criteria that apply to contracts between the national thresholds and the EU thresholds. These provisions are very similar to the grounds for exclusion and the selection criteria set out in the PC(S)Rs (see Section 3.6.2 below for an explanation of the key differences).

\section{Regulation of contracts below the national financial thresholds}

National law and regulations do not regulate contracts below the national thresholds.

Contracting authorities generally have their own internal rules covering the award of contracts under the national thresholds.

It is common practice for contracting authorities to use a form of competitive process for the award of contracts below the national thresholds, including the publication of the opportunity on the Public Contracts Scotland portal. The Scottish Government, through Public Contracts Scotland, operates an electronic system that contracting authorities may use to obtain competitive "Quick Quotes" for low-value procurement procedures. This system is used frequently, processing thousands of low-value purchases each month.

Guidance, policy and other information

The following guidance, policy and other information are also relevant:

The Scottish Government's procurement website, www.gov.scot/Topics/Government/Pro curement provides additional public procurement resources, including links to the public procurement legislation, guidance, procurement policy and action notes, the Scottish Procurement Policy Handbook and the Procurement Finance Manual. Most of the guidance is advisory in nature and is not legally binding.

The Scottish Government also maintains a "Procurement Journey" website www.procurementjourney.scot/procurement-journey. This website provides information, standard documents and other resources relating to key stages in the conduct of public procurement procedures. Three "routes" are located on the Procurement Journey. Route 1 provides guidance on unregulated, low-value and low-risk procurement. Route 2 offers guidance on regulated procurement between GBP 50000 (EUR 58 689) and the EU 
financial thresholds. Route 3 provides guidance on procurement above the EU thresholds, including information on exclusion, selection, shortlisting, and the use of the ESPD.

\section{Advertising}

All contracts above the national thresholds, including those above the EU thresholds, must be advertised on the Public Contracts Scotland portal, www.publiccontractsscotland.gov.uk/Default.aspx .

\subsubsection{Choice of participants: exclusion, selection and shortlisting-further information}

\section{General principles}

Article 18 of the Directive sets out the general principles of procurement, namely equal treatment, non-discrimination, transparency and proportionality. Article 18 also requires that procurement not be designed with the intention of excluding it from the scope of the Directive or artificially narrowing competition.

In the PC(S)Rs, Regulation 19 sets out these general principles.

Article 56(1) of the Directive sets out general principles applying to the choice of participants and the award of contracts.

In the PC(S)Rs, Regulation 57(1) sets out these general principles.

Article 56(2) of the Directive permits contracting authorities to examine tenders submitted in an open procedure prior to verifying the absence of grounds for exclusion and the fulfilment of the selection criteria.

In the PC(S)Rs, Regulation 57(3) contains this provision, which applies to all types of procurement and circumstances.

Contracts below the EU thresholds: Section 8 of the $\mathrm{PR}(\mathrm{S}) \mathrm{A}$ requires a contracting authority, in carrying out a regulated procurement, to treat economic operators from an EU Member State, Iceland, Liechtenstein and Norway "equally and without discrimination" and to "act in a transparent and proportionate manner".

\section{Mandatory grounds for exclusion}

Mandatory grounds for exclusion - conviction by final judgement: Article 57(1) of the Directive provides the mandatory grounds for exclusion in relation to convictions for specified offences.

In the $\mathrm{PC}(\mathrm{S}) \mathrm{Rs}$, Regulation 58(1) provides the mandatory grounds for exclusion. Regulation 58(1)(a) to (k) refers to the mandatory grounds for exclusion listed in Article 57(1) of the Directive, using references to the equivalent national legislation where appropriate.

Exclusion for the non-payment of taxes or social security contributions - judicial or administrative decision: Article 57(2) of the Directive refers to mandatory exclusion on the grounds of the non-payment of taxes or social security contributions established by a judicial or administrative decision having final and binding effect.

In the PC(S)Rs, Regulation 58(3) refers to these mandatory grounds for exclusion. 
Exclusion for the non-payment of taxes or social security contributions - other means of proof: Contracting authorities are permitted, but are not obliged, to exclude an economic operator where they can demonstrate by any appropriate means that it is in breach of its obligations relating to the payment of taxes or social security contributions.

In the $\mathrm{PC}(\mathrm{S}) \mathrm{Rs}$, Regulation 58(4) provides that exclusion on these grounds is not mandatory.

Derogations from mandatory exclusion: Article 57(3) of the Directive permits Member States to provide for a derogation from mandatory exclusion on the grounds of public interest.

This derogation is included in the PC(S)Rs, Regulation 58(6).

Article 57(3) of the Directive permits Member States to provide for a derogation from mandatory exclusion for the non-payment of taxes or social security contributions, where an exclusion would be clearly disproportionate.

This derogation is provided in the PC(S)Rs, Regulation 58(7).

Additional national grounds for mandatory exclusion - blacklist regulations: The PC(S)Rs, Regulation 58(3)(b) provides additional grounds for mandatory exclusion. Economic operators must be excluded where 1) the contracting authority is aware that the economic operator has committed an act prohibited under the Employment Relations Act 1999 (Blacklists) Regulations 2010 (2010 No. 493) (Blacklist Regulations); and 2) either the economic operator has admitted that it has committed such an act or it has been established by a judicial decision having final and binding effect that the economic operator has committed such an act.

The Blacklist Regulations prohibit the compilation, use, sale or supply of blacklists containing details of trade union members and activists, the purpose of which is to discriminate against workers on the grounds of trade union membership or trade union activities.

Contracts below the EU thresholds: In the 2016 Procurement Regulations, Regulation $8(1)$ (a) to (k) and Regulation 9(1) provide the mandatory grounds for exclusion applying to contracts between the national financial thresholds and the EU financial thresholds.

The mandatory grounds for exclusion in relation to a conviction for the offences listed in the 2016 Regulation 8(1) are essentially the same as the mandatory grounds provided in the PC(S)Rs, except for the fact that there is no reference in the PC(S)Rs to the use of the ESPD for verification of the grounds for exclusion.

No mandatory grounds for exclusion are provided for the failure to pay taxes or social security contributions. The additional national mandatory grounds for exclusion - the Blacklist Regulations - apply in the 2016 Procurement Regulations, Regulation 9(1).

A derogation is provided in the 2016 Procurement Regulations from the mandatory exclusion on public interest grounds, as stipulated in Regulation 8(3) and Regulation 9(4).

\section{Discretionary grounds for exclusion}

Articles 57(4)(a) to (i) of the Directive provide the discretionary grounds for exclusion. Member States have the option to make some or all of these grounds for exclusion mandatory. 
None of the discretionary grounds for exclusion listed in the Directive are mandatory in Scotland. All of these grounds are discretionary and are provided in the $\mathrm{PC}(\mathrm{S}) \mathrm{Rs}$, Regulation 58(8)(a) to (j). The grounds for exclusion in Article 57(4)(h) of the Directive is split in the $\mathrm{PC}(\mathrm{S}) \mathrm{Rs}$ into two grounds, Regulation 58(8)(h) and (i), which explains why the number of grounds in the $\mathrm{PC}(\mathrm{S}) \mathrm{Rs}$ is higher.

Option to not exclude economic operators in the case of bankruptcy or the equivalent: Article 57(4) of the Directive permits Member States to provide for the possibility to not exclude economic operators on the grounds of bankruptcy or in equivalent situations where there are national rules and measures on the continuation of business.

This option is not included in the PC(S)Rs.

Exclusion at any time in the procedure: Article 57(5) of the Directive permits a contracting authority to exclude an economic operator where it becomes aware at any time in the procedure that the grounds for mandatory or discretionary exclusion apply because of acts committed or omitted by the economic operator either before or during the procedure. Member States have the option to make exclusion in these circumstances mandatory.

In the PC(S)Rs, Regulation 58(10) includes this option, making exclusion mandatory in these circumstances.

Contracts below the EU thresholds: The 2016 Procurement Regulations 9(2) and 9(5)(a) to (j) provide the discretionary grounds for exclusion applying to contracts above the national financial thresholds and below the EU financial thresholds.

The discretionary grounds for exclusion listed in the 2016 Regulation 9(5) are essentially the same as those listed in the $\mathrm{PC}(\mathrm{S}) \mathrm{Rs}$, and in some cases, reference is made to the PC(S)Rs. The 2016 Procurement Regulations include discretionary grounds for exclusion where the contracting authority can demonstrate by any appropriate means that the economic operator is in breach of its obligations relating to the payment of taxes or social security contributions, as stipulated in Regulation 9(2).

A contracting authority must exclude (in the case of mandatory grounds) and may exclude (in the case of discretionary grounds) an economic operator if it becomes aware at any time in the procedure that relevant grounds apply, as stipulated in Regulations 8(4) and 9(7) of the 2016 Procurement Regulations.

No reference is made in the 2016 Procurement Regulations to the use of the ESPD for verification of discretionary grounds for exclusion, as the ESPD is not obligatory for contracts below the EU financial thresholds.

Periods of exclusion: The periods of exclusion are as follows:

- Mandatory grounds for exclusion for conviction for specified offences listed in the PC(S)Rs, Regulation 58(1): five years, as from the date of conviction by final judgement, as stipulated in PC(S)R 58(11);

- Mandatory grounds for exclusion listed in the PC(S)Rs, Regulation 58(3)(b) Blacklist Regulations: three years, as from the date of the relevant event, as stipulated in $\mathrm{PC}(\mathrm{S}) \mathrm{R} 58(12)$;

- Discretionary grounds for exclusion listed in the PC(S)Rs, Regulation 58(12): three years, as from the date of the relevant event, as stipulated in $\mathrm{PC}(\mathrm{S}) \mathrm{R} 58(8)$. 
Maximum periods of exclusion - contracts below the EU thresholds: The periods of exclusion in relation to contracts above the national financial thresholds and below the EU financial thresholds are set out in the 2016 Procurement Regulations and are as follows:

- Mandatory grounds for exclusion for the conviction for specified offences listed in Regulation 8(1): five years, as from the date of conviction by final judgement, as stipulated in 2016 Procurement Regulations 8(5);

- Mandatory grounds for exclusion listed in Regulation 9(1) - Blacklist Regulations: three years, as from the date of the relevant event, as stipulated in 2016 Procurement Regulations 9(8);

- Discretionary grounds for exclusion listed in Regulations 9(2), 9(3) and 9(5): three years, as from the date of the relevant event, as stipulated in 2016 Procurement Regulations 9(8).

\section{Self-cleaning}

Article 57(6) of the Directive permits an economic operator to provide evidence of measures it has taken to demonstrate its reliability despite the existence of relevant grounds for exclusion. If such evidence is considered to be sufficient, the economic operator concerned shall not be excluded from the procurement procedure.

In the $\mathrm{PC}(\mathrm{S}) \mathrm{Rs}$, Regulation 58(13-17) sets out the provisions related to self-cleaning.

Contracts below the EU thresholds: The same self-cleaning principles apply to contracts above the national thresholds and below the EU thresholds, as stipulated in 2016 Procurement Regulations, Regulation 8(6-10) and Regulation 9(9-13).

Guidance on self-cleaning ("self-cleansing") is available from the Procurement Journey website www.procurementjourney.scot/node/546/\#exclusion grounds

It is also covered by the statutory guidance issued under the $\mathrm{PR}(\mathrm{S}) \mathrm{A}$.

\section{Selection}

Article 58 of the Directive provides that selection criteria may relate to: (a) suitability to pursue the professional activity; (b) economic and financial standing; and (c) technical and professional ability. These requirements must be appropriate, related and proportionate to the subject matter of the contract.

In the PC(S)Rs, Regulation 59 sets out the provision on selection, and it uses substantially the same wording as in the Directive.

Contracts below the EU thresholds: Regulation 10 of the 2016 Procurement Regulations sets out the provision relating to the selection criteria for contracts above the national thresholds and below the EU thresholds.

The selection criteria are essentially the same as those listed in the $\mathrm{PC}(\mathrm{S}) \mathrm{Rs}$, although in the 2016 Procurement Regulations, there is no obligation for the contracting authority to state its reasons for requiring an economic operator to have a higher minimum yearly turnover than twice the estimated contract value. 


\section{Reduction in the number of otherwise qualified candidates to be invited to participate}

Article 65 of the Directive lays down the rules on the reduction of the number of otherwise qualified candidates to be invited to participate in restricted procedures, competitive procedures with negotiation, competitive dialogue, and innovation partnerships.

Regulation 66 in the $\mathrm{PC}(\mathrm{S}) \mathrm{Rs}$ sets out the provisions on the reduction of otherwise qualified candidates.

Contracts below the EU thresholds: No equivalent provisions apply to contracts above the national thresholds and below the EU thresholds.

It has been common practice in Scotland for contracting authorities to use a two-stage procedure, in particular for the restricted procedure.

\section{European Single Procurement Document}

Article 59 of the Directive requires contracting authorities to accept the ESPD as preliminary evidence, in replacement of certificates issued by public authorities or third parties, confirming that the relevant economic operator fulfils the conditions relating to the grounds for exclusion, the selection criteria and, where applicable, the objective rules and criteria for the reduction in the number of otherwise qualified candidates to be invited to participate.

In the PC(S)Rs, Regulation 60 sets out the provisions for the ESPD.

Scottish ESPD: The Scottish Government issued a Scottish ESPD for use by all contracting authorities for contracts above the EU financial thresholds as from 18 April 2016, updated subsequently, with minor changes.

The Scottish ESPD replaced the SPQQ, which Scottish contracting authorities had previously used. The sPQQ included self-declarations by economic operators in relation to the grounds for mandatory and discretionary exclusion, and this concept is thus not a new one for contracting authorities in Scotland. The sPQQ also included standard selection-stage questions, which permitted contracting authorities to request a considerable amount of information relating to technical and professional capacity and to also ask a number of additional, optional questions.

A template version in Microsoft Word of the Scottish ESPD can be downloaded from the Procurement Journey website. For contracting authorities using the Public Contracts Scotland tender portal, an online version of the ESPD is available. Contracting authorities are not permitted to amend the Scottish ESPD or to add new questions.

The Scottish ESPD differs slightly from the ESPD published in accordance with Commission Regulation 2015/1986. The Scottish Government explains the differences in its Procurement Policy Note 06/2016 as follows:

"Why is ESPD (Scotland) different to the standard form produced by the EC?

ESPD (Scotland) is only superficially different to the standard version produced by the EC.

We have made two types of changes. First, to reflect language and terms which are more commonly used in Scotland. For example, ESPD (Scotland) refers to supported businesses, rather than sheltered workshops. 
Second, to insert some sub-questions to reflect developments in Scotland. For example, we have added a sub-question which asks specifically whether the bidder has breached the Employment Relations Act 1999 (Blacklists) Regulations 2010, because this is a mandatory ground for exclusion in Scotland."

The Scottish Government emphasises the importance of information provided in the contract notice advertising the opportunity. The Scottish Government has published standardised statements (explanatory statements) aligned with the exclusion and selection questions, which can be inserted into the contract notice to assist in developing a standard approach to defining minimum requirements in contract notices. The standardised statements are available online at www.procurementjourney.scot/route-3/route-3-developdocuments-espd-scotland.

Contracts below the EU thresholds: According to the Scottish ESPD, it is best practice to use the Scottish ESPD for all nationally regulated procurement below the EU thresholds, but contracting authorities are not obliged to do so.

\section{Means of proof}

Article 60 of the Directive sets out the provisions on the means of proof that are meant to serve as evidence for the grounds for exclusion and the fulfilment of the selection criteria.

Regulation 61 of the $\mathrm{PC}(\mathrm{S}) \mathrm{Rs}$ sets out the provisions on the means of proof.

$\mathrm{PC}(\mathrm{S}) \mathrm{R}$ 61(1-8) uses substantially the same wording as in Article 60 of the Directive. PC(S)R 61(9) lists the means of proof, using substantially the same wording as in Annex XII, Part I, of the Directive.

Contracts below the EU thresholds: The means of proof for contracts above the national thresholds and below the EU thresholds are regulated to a limited extent only. Regulation 10(19) of the 2016 Procurement Regulations obliges contracting authorities to set out the requirements for participation, which may be expressed as minimum levels of ability, together with the means of proof to be provided. Regulation 10 refers specifically to the proof of enrolment in professional or trade registers and to the authorisation of or membership in particular organisations. It also refers to the use of "suitable references from contracts performed in the past" in relation to the requirement for economic operators to have sufficient levels of experience. It is not obligatory to require this evidence, and the list of the means of proof is not exhaustive.

\section{Reliance on the capacity of third parties}

Article 63 of the Directive provides that an economic operator may, where appropriate and with regard to a specific contract, rely on the capacity of other entities to satisfy the criteria set by the contracting authority in relation to economic and financial standing. This reliance on other entities is subject to the fulfilment of specified conditions.

Regulation 64 of the $\mathrm{PC}(\mathrm{S}) \mathrm{Rs}$ sets out the provisions on the reliance on the capacity of other entities.

Contracts below the EU thresholds: No equivalent provisions apply to contracts above the national thresholds and below the EU thresholds.

\footnotetext{
${ }^{145}$ www.gov.scot/Topics/Government/Procurement/policy/SPPNSSPANS/policynotes/SPPN2016/SPPN06-2016ESPD
} 
Official lists

Official lists of approved economic operators

Article 64 of the Directive permits Member States to establish or maintain official lists of approved economic operators that have submitted acceptable evidence of their suitability to deliver public contracts.

In the PC(S)Rs, Regulation 64 transposes Article 64 of the Directive. There are no official lists of approved economic operators in Scotland, however.

\section{Blacklists}

No specific provisions in the Directive permit or prohibit the use of blacklists of economic operators to whom the grounds for mandatory or discretionary exclusion apply.

No authorised or centralised blacklisting exists in Scotland. 


\section{Case law of the Court of Justice of the European Union}

\subsection{Introduction}

The purpose of this chapter is to highlight some of the cases of the CJEU related to the choice of participants in public procurement procedures. It also provides a commentary on the relevant CJEU judgements included in Part 2.

Part 5 starts with an overview of selected cases related to key issues on the choice of participants. Further details on some of the cases are provided in the Case Notes at the end of the chapter.

The role of the CJEU: The CJEU ensures observance of the law in the interpretation and application of the Treaty and its implementing rules. To this end, a number of powers have been expressly conferred on the CJEU. These powers are mainly intended to enable the CJEU to judge the acts and omissions of institutions and Member States, in accordance with EU law, and to ensure uniformity in the interpretation of EU law and in the application of this law by national courts. The CJEU's rulings on matters of law are binding on national courts. Thus, a national court must follow a legal ruling of the CJEU - a national court cannot decline to follow the CJEU.

CJEU case law and the 2014 Directive: The case law of the CJEU affects both the drafting and interpretation of EU legislation, as will be shown below. It is important to note that in the cases listed here the CJEU was considering the legal framework for public procurement under the 2004 Directive $^{146}$ or earlier directives. At the time of writing, no CJEU judgements are based on the provisions of the 2014 Directive with regard to the choice of participants in public procurement procedures. In some cases, therefore, the wording of the legal provisions considered by the CJEU will not be precisely the same as in the 2014 Directive on public procurement - and the judgements need to be understood in that light. Some CJEU judgements have also been codified in the Directive - the text of some provisions has been adjusted to better reflect the conclusions reached by the CJEU. Where this is the case, we have aimed to highlight this codification in our comments on the cases in Parts 5 and/or 2.

1462004 Directive of 31 March 2004 on the co-ordination of procedures for the award of public works contracts, public supply contracts and public service contracts, predecessor of the 2014 Directive. 


\subsection{Case law on the grounds for exclusion}

\subsubsection{Grounds for exclusion: Groups of economic operators - eligibility to participate}

The CJEU has been asked to consider the issue of the extent to which it is possible to limit the types of economic operators that are eligible to participate in a public procurement procedure. The CJEU has held that national legislation requiring economic operators to assume a particular legal form in order to submit a tender or excluding economic operators that do not have a prescribed legal form cannot be considered. In C-357/06 Frigerio Luigi \& $C$., the CJEU decided that Italian legislation limiting participation in procurement procedures to specific types of companies with share capital was in breach of the EU procurement rules. In C-305/08 CoNISMa, the CJEU decided that Italian legislation excluding a group of non-profit bodies from tendering for a contract was also in breach of EU rules. In C-203/14 Maresme, the CJEU concluded that the Spanish rules, which had the effect of barring public authorities that had been authorised to act as economic operators, whilst reserving the right to participate to other economic operators that were either registered on the list or certified, were incompatible with EU law. These types of provisions could potentially restrict competition and have an adverse impact on the internal market. See the case notes, Section 4.6, for further information on the three cases.

This approach is reflected in the Directive, which makes it clear that the concept of an economic operator is wide and at the stage of the choice of participants the specific legal form is irrelevant (see Recital 14).

\subsubsection{Exhaustive list of grounds for exclusion related to professional qualities and additional grounds for exclusion subject to the proportionality principle and to the requirement to be clearly defined and announced in advance}

Member States have the possibility of establishing additional grounds for exclusion, although the Directive does not explicitly regulate this possibility.

In C-213/07 Michaniki, the CJEU confirmed that the grounds for exclusion listed in the Directives were not totally exhaustive. It also confirmed that, whilst the list of grounds for exclusion relating to professional qualities was exhaustive, contracting authorities might also exclude for additional reasons. The CJEU set out the principle that "further exclusionary measures designed to ensure observance of the principles of equal treatment of tenderers and of transparency" were permitted "provided that such measures [did] not go beyond what [was] necessary to achieve that objective". Thus, both the purpose of the additional measures and the proportionality of those measures were important in this context. See the case notes, Section 5.6, for further information on this case.

In all cases, the discretion to exclude on the additional grounds must be exercised in accordance with the general principles of the Directives and of EU law in general.

The principle of proportionality requires that a measure restricting access to the market should be proportionate to its objectives. This principle will, for example, place limits on the amount of time during which an economic operator can be excluded. It also limits the possibility of excluding an economic operator for very minor offences, especially those that do not involve any kind of intentional or negligent misconduct. The proportionality principle also requires contracting authorities to take account of "self-cleaning" measures undertaken by economic operators. The cases highlighted below show how the CJEU has 
applied the principle of proportionality to cases concerning additional grounds for exclusion.

C-21/03 Fabricom concerned a conflict of interest arising from the fact that a firm had participated in the preparation of specifications. In this case, the CJEU ruled that a Belgian law that prohibited from tendering all persons who had themselves been involved in the preparatory work, even if they could demonstrate that competition was not at risk, was contrary to the directives because it was not proportionate to the aimed objective the law went beyond what was necessary to achieve the objective of the national rule. This ruling held that the objective of ensuring the equal treatment of those participating in the competition could be safeguarded by a less restrictive method, namely by prohibiting participation only to those who were unable to prove that no risk to competition was involved.

In C-213/07 Michaniki, the CJEU considered a Greek law that prohibited the award of public contracts to media undertakings or to certain companies or individuals linked to or working for media undertakings. The effect of the national law was to automatically exclude specific types of economic operators from participating in tenders for public contracts. The CJEU ruled that the list of grounds for exclusion for reasons relating to an economic operator's professional qualities was an exhaustive list. The CJEU confirmed that a Member State was entitled to provide for additional exclusionary measures designed to ensure observance of the principles of equal treatment and transparency and that Member States were allowed a certain amount of discretion when adopting those measures. However, in accordance with the principle of proportionality, such measures must not exceed what is necessary to achieve the objective.

The CJEU took the view that there was a risk that media undertakings would unlawfully influence the contract award decision concerning a public contract, for example by using mass information campaigns. The CJEU confirmed that EU law did not preclude the application of national law that was designed to avoid the risk of practices that might jeopardise transparency and distort competition. However, the Greek law in question had the consequence of automatically excluding economic operators because of their media links. These economic operators had no way of demonstrating that there was no real risk of being faced with the danger that the measure was designed to avoid. The CJEU ruled that the automatic and absolute nature of the prohibition was disproportionate and was not permitted under EU law. See the case notes, Section 5.6, for further information on this case.

In C-537/08 Assitur, the CJEU considered a law that excluded tenderers from participating in the same tender procedure where particular relationships of control and affiliation existed between them. The effect of this law was to automatically exclude certain linked or affiliated economic operators from participating in tenders for public contracts. According to the CJEU, it was clear that the national law at issue was intended to i) prevent any collusion between participants in the procedure for the award of contracts, and ii) safeguard equal treatment and transparency. The national legislation must nevertheless be examined with regard to the principle of proportionality. When considering the principle of proportionality, the CJEU also referred to the need to ensure the widest possible participation of tenderers. The CJEU ruled that the national legislation in question went beyond what was necessary to achieve the objective of ensuring equal treatment and transparency, as it systematically excluded affiliated tenderers. This exclusion occurred without allowing tenderers the opportunity to demonstrate that their participation presented no real risk of jeopardising transparency and distorting 
competition. The national legislation was incompatible with EU law. See the case notes, Section 5.6, for further information on this case.

In C-376/08 Serrantoni, the law in question prohibited members of a permanent consortium and individual consortium members from participating in the same tendering procedure. The effect of the national law was to automatically exclude permanent consortia and their members from participating in certain award procedures. The permanent consortia were treated differently under the law than other joint working arrangements between economic operators. The CJEU ruled that automatic exclusion applying to a single type of consortium did not constitute equal treatment and that even if the exclusion were applied without distinction, a provision that required automatic exclusion would be incompatible with the principle of proportionality. The CJEU was also of the view that a provision of this kind was likely to have a dissuasive effect on economic operators from other Member States and impede the freedom of establishment and the freedom to provide services. The national legislation was incompatible with EU law. See the case notes, Section 5.6, for further information on this case.

The CJEU also commented on the principle of equal treatment and the obligation of transparency in the context of grounds for exclusion.

In C-27/15 Pippo Pizzo, the CJEU confirmed that the grounds for exclusion must be clearly defined in advance and made public, in particular the obligations of tenderers. This clear definition ensures that tenderers know exactly the procedural requirements and that the same requirements apply to all candidates. The principle of equal treatment and the obligation of transparency must be interpreted as precluding the exclusion of an economic operator from a procedure for the award of a public contract as a result of the economic operator's non-compliance with an obligation that does not expressly arise from the documents relating to that procedure or from the national law in force, but from an interpretation of that law and those documents and from the incorporation of provisions into those documents by the national authorities or administrative courts.

\subsection{Case law on evidence of compliance}

In C-74/09 Bâtiments et Ponts and WISAG Produktionsservice ("BPC-WIG"), the CJEU considered whether the evidence required by a contracting authority from tenderers to demonstrate the payment of taxes and social security contributions was permitted under EU law. This case arose from a long dispute over a contract awarded in 1995 for the renovation of the EC's main office building (Berlaymont) in Brussels. The amended advertisement in the $O J E U$ for the renovation works required evidence that tax and social security payments had been made. Belgian firms had to be listed on the professional register in Belgium. Foreign firms were required to provide a copy of a certificate of application to the competent Belgian authority responsible for assessing compliance. For these firms, the final confirmation certificate was required prior to the decision for the award of the contract.

The BPC-WIG consortium was unsuccessful in the tendering process. It appealed against that decision and claimed damages. The Belgian court held that the BPC-WIG consortium was ineligible to tender due to its failure to submit a certificate of application to the competent Belgian authority. The CJEU upheld the ruling of the Belgian court. The CJEU confirmed that it was lawful to require a tenderer to register in the Member State where the contracting authority was based, provided that the registration requirements did not i) complicate or delay the participation of the tenderer concerned, or ii) give rise to 
excessive administrative charges. The CJEU confirmed that it was also permitted to verify that tax and social security payments had been made in the Member State where the tenderer was based and that the authorities of that Member State was obliged to accept certificates of compliance from competent authorities in other Member States as conclusive evidence.

This case relates to the grounds for exclusion for the non-payment of taxes and social security contributions. The CJEU was clear that its decision had a wider application and that it applied to each of the grounds for exclusion listed in the Works Directive ${ }^{147}$. See the case notes, Section 5.6, for further information on this case.

In C-425/14 Impresa Edilux, the CJEU considered the legality of the imposition by a contracting authority of an obligation for an economic operator to submit a legality protocol concerning the standards of behaviour that it would apply in the event that it were chosen as the successful tenderer. Without this legality protocol, an economic operator would be excluded from the procedure. The declarations required in the legality protocol were regarded by the CJEU as proportionate, in other words they did not exceed what was necessary in order to prevent the infiltration by organised crime of the public contract awards sector. The CJEU considered, however, that the requirement of a declaration by a participant that it was not in a relationship of control or association (legal and/or factual) with other competitors and that it would not subcontract any type of tasks to other companies participating in the tender was disproportionate. See the case notes, Section 5.6, for further information on this case.

\subsection{Case law on selection criteria}

\subsubsection{Evidence of economic and financial standing}

In the case presented below, the CJEU confirmed the non-exhaustive nature of the list of information or evidence to demonstrate economic and financial standing. It also confirmed that Member States had discretion in setting additional requirements in that context.

In C-218/11 Édukövízig and Hochtief Construction (HH), a ruling decided in 2012, the CJEU considered the lawfulness of national requirements relating to the evidence of economic and financial standing. This case concerned a major transport infrastructure project in Hungary. As part of the qualification requirements, Édukövizig obliged economic operators to submit a uniform financial document, which had been drawn up in accordance with Hungarian accounting rules. Edukövízig fixed a minimum requirement related to economic and financial standing. According to accounting rules in Germany, where $\mathrm{HH}$ was incorporated, it was possible for a company to transfer profits to another group company and thus to obtain positive profit and loss (P\&L) after taxes, even though negative P\&L was shown on the balance sheet. This possibility was not permitted under Hungarian accounting rules. HH had a zero or negative P\&L on its balance sheet and was unable to satisfy Edukövizig's requirements relating to P\&L. HH questioned the lawfulness of Édukövízig's requirement in the Hungarian courts, which then referred a number of questions to the CJEU for a preliminary ruling.

${ }^{147}$ Directive 93/37/EEC of 14 June 1993 concerning the co-ordination of procedures for the award of public works contracts, which was a predecessor of the 2014 Directive. 
The CJEU confirmed that the Directive permitted a contracting authority to require a minimum level of economic and financial standing. In this context, the CJEU confirmed that the Directive left "a fair degree of freedom to the contracting authorities". According to the CJEU, the Directive "expressly authorises contracting authorities to choose the probative references which must be produced by [economic operators] to furnish proof of their economic and financial standing." The CJEU emphasised that the freedom available to contracting authorities was not unlimited. The minimum capacity level set by the contracting authority had to be related and proportionate to the subject matter of the contract. The CJEU stated that, in relation to the proof of economic and financial standing, contracting authorities could legitimately require a reference "... even if, objectively, not every candidate or tenderer [was] able to produce it ... because of a difference in legislation". The CJEU held that "such a requirement [could] not in itself be considered to constitute discrimination".

The CJEU held, based on the facts of this case, that there was only one option available to $\mathrm{HH}$ in order to satisfy the balance sheet requirement. That option was to rely on the capacity of another entity, in this case HH's parent company. When the economic operator relies on the capacity of another entity, the Directive requires proof in the form of a legal undertaking. See the case notes, Section 5.6, for further information on this case.

\subsubsection{Technical and/or professional ability}

Under Article 58 of the Directive, a contracting authority is permitted (but not obliged) to consider the economic and financial standing of economic operators. This provision was the same under the 2004 Directive.

The Directive contains an exhaustive list of evidence that a contracting authority may request from economic operators to prove that the set of technical and professional ability criteria are satisfied in accordance with the nature, quantity or importance, and use of the works, supplies or services (Annex XII, Part II). Since this list of evidence is exhaustive, a contracting authority may only apply the criteria that are derived from the list. However, within these limits, it is left to the discretion of the contracting authority to determine the specific criteria to apply.

The principle that the list of evidence is exhaustive was confirmed by the CJEU in C-218/11 Édukövízig and Hochtief Construction (see Section 2.6.3). The CJEU stated that, in relation to technical and professional capacity, the Directive established "a closed system which limits the methods of assessment and verification available to [contracting authorities] and, therefore, limits their opportunities to lay down requirements".

The principle that the list of evidence of technical and professional ability is exhaustive was again confirmed by the CJEU in the case C-368/10 Commission v Netherlands. This case concerned the award of a contract by the province of North Holland for the supply and management of automatic tea and coffee machines. The procedure was carried out under the 2004 Directive. The contracting authority stated in the contract documents that economic operators should fulfil "criteria concerning sustainable purchases and socially responsible business". This requirement was included under the general heading, "suitability conditions/minimum conditions", and the sub-heading, "quality conditions". The contracting authority asked economic operators to explain the way in which they fulfilled those criteria. The contracting authority also asked them to indicate how they contributed "to improving the sustainability of the coffee market and to environmentally, socially and economically responsible coffee production". The CJEU was of the view that 
these requirements set the minimum levels of professional capacity and should therefore be considered in the light of Article 48 of the 2004 Directive. The CJEU confirmed that Article 48 provided an exhaustive list of technical and professional ability criteria. As the requirements set by the contracting authority in relation to sustainable purchases and socially responsible business were not included in the exhaustive list provided in Article 48, they were therefore not permitted as selection criteria.

The CJEU also confirmed earlier case law (C-496/99 Commission v CAS Succhi di Frutta) that had established that the principle of transparency implied that all of the rules of the award procedure had to be clear, precise and unequivocal.

The requirement of clear rules in the context of selection had also been emphasised by the CJEU in C-324/14 Partner Apelski Dariusz. Here the CJEU underlined that all of the conditions and detailed rules for the evaluation of technical and professional ability had to be drawn up in a clear, precise and unequivocal manner in the notice or contract documents. First, all reasonably informed tenderers exercising ordinary care could understand the exact significance of these conditions and rules and interpret the rules in the same way; second, the contracting authority was able to ascertain whether the tenders submitted satisfied the criteria applying to the relevant contract. See the case notes, Section 5.6, for further information on this case.

\subsection{Case law on procedural issues}

The Directive, when compared to the 2004 Directive, has extended the powers of contracting authorities to seek clarifications or additional information from candidates and tenderers. Article 56(3) of the Directive provides that "where information or documentation to be submitted by economic operators is or appears to be incomplete or erroneous or where specific documents are missing, contracting authorities may, unless otherwise provided by the national law implementing this Directive, request the economic operators concerned to submit, supplement, clarify or complete the relevant information or documentation within an appropriate time limit, provided that such requests are made in full compliance with the principles of equal treatment and transparency".

The case the most closely related to the provisions of Article 56(3) of the Directive was case C-599/10 SAG ELV Slovensko and Others, even though that case concerned the evaluation of the tender phase and not the selection of participants. In that case, the CJEU indicated that the Directive did not preclude a provision of national law allowing the contracting authority to ask tenderers in writing to clarify their tenders, while at the same time neither requesting nor accepting any amendments to those tenders. In the exercise of discretion thus enjoyed by the contracting authority, it was nevertheless obliged to treat the various tenderers equally and fairly.

In a later ruling in the case C-336/12 Manova (see the case notes, Section 5.6, for further information on this case), the CJEU clarified that the Slovensko case provided guidance in relation to tenders that could also be useful for applications submitted at the selection stage by candidates in a restricted procedure.

The limitations for clarification and submission of additional statements were also considered in the case C-324/14 Partner Apelski Dariusz. The declaration made by an economic operator regarding the priority of the evaluation of experience for lots was regarded as extending beyond the permitted clarification. See the case notes, Section 5.6, for further information on this case. 


\subsection{Case notes - Court of Justice of the European Union's cases in more detail}

\subsubsection{Grounds for exclusion}

\section{Groups of economic operators - eligibility to participate}

\section{C-357/06 Frigerio Luigi \& C}

This case, decided by the CJEU in 2007, concerned the Italian national rules limiting the types of economic operators that were eligible to participate in tendering for specific types of contracts. The effect of the national rules was to automatically exclude specific types of economic operators from participating in some tenders.

The Comune di Triuggio (the contracting authority) proposed the award of a five-year contract for environmental hygiene services to a company in which the authority intended to take a controlling interest. The proposed award was made without a competitive tendering procedure. Another company, Frigerio Luigi (FL), had previously provided these services for six months through a temporary joint venture partnership arrangement.

FL challenged the proposed contract award. The contracting authority argued that FL's claim was inadmissible, because under the relevant Italian law, a contracting authority could only award the contract concerned to specific types of companies with share capital. FL did not meet those eligibility requirements.

The lawfulness of the Italian national rules was considered in the light of Article 26(1) and (2) of the Services Directive ${ }^{148}$. In its judgement, the CJEU referred to the underlying intentions of the Services Directive, which were to promote the internal market and, in that context, to ensure the free movement of goods, persons, services and capital, and to eliminate practices that restricted competition.

Article 26(1) of the Services Directive permits tenders to be submitted by groups of service providers. That Article stipulates that "these groups may not be required to assume a specific legal form in order to submit the tender...". Article 26(2) further specifies that candidates or tenderers that are entitled to carry out the relevant service activity in the Member State in which they are established "shall not be rejected solely on the grounds that, under the law of the Member State in which the contract is awarded, they would have been required to be either natural or legal persons" 149 .

The CJEU ruled that Article 26(2) precluded national legislation of the type that was under consideration in this case. Such legislation excluded economic operators from a tender process on the grounds that they did not have a particular legal form. The CJEU also confirmed that Article 26(1) of the Services Directive meant that groups of service providers could not be required to assume a specific legal form in order to submit a tender.

\footnotetext{
${ }^{148}$ Directive 2006/123/EC of 12 December 2006 on services in the internal market, which was a predecessor of the 2014 Directive.

${ }^{149}$ Article 19 of the 2014 Directive contains provisions that are similar to those in Article 26 of the Services Directive: "Economic operators that, under the law of the Member State in which they are established, are entitled to provide the relevant service, shall not be restricted solely on the [grounds] that, under the law of the Member State in which the contract is awarded, they would be required to be either legal or natural persons."
} 


\section{C-305/08 CoNISMa}

The case C-305/08 CoNISMa, decided in 2009, arose from the decision of an Italian contracting authority to exclude a group of non-profit bodies from tendering for a contract.

The case concerned a call for tenders by the Regione Marche for a contract to provide marine and seismic data services and related activities. CoNISMa was a group of 14 universities and Government ministries that wished to submit a tender. Regione Marche was of the view that Italian legislation excluded this type of body from the economic operators eligible to tender. It therefore excluded CoNISMa from the tender process, and CoNISMa appealed against this decision.

The CJEU held that Article 1(2)(a) and (8) of the 2004 Directive did not prevent a group (consortium) of this type from participating in a procurement process. It stated that eligibility to participate was valid even when the group (consortium) was predominantly non-profit-making and did not have an organised business structure or a regular presence on the market. The CJEU concluded that any person or entity that believed it was capable of carrying out the contract was eligible to submit a tender (paragraph 42). The CJEU commented that "the Community legislature did not intend to restrict the concept of 'economic operator which offers its service on the market' solely to operators which are structured as a business or to impose specific conditions which can restrict access to tendering procedures, from the outset, on the basis of the legal form and internal organisation of the economic operator" (paragraph 35).

The CJEU also held that the 2004 Directive precluded the interpretation of national legislation such as the one under consideration in this case. The national legislation had been interpreted as prohibiting entities such as universities and research institutes, which were primarily non-profit-making, from tendering.

\section{C-203/14 Maresme}

In the case C-203/14 Maresme, the CJEU confirmed that the provisions of the 2004 Directive did not prevent public authorities from participating in tendering procedures. The term "economic operator" must be interpreted as including public authorities, which may therefore participate in public tendering procedures. The CJEU stated that if and to the extent that certain entities were authorised to offer services in return for remuneration on the market, even occasionally, Member States could not prevent those entities from participating in tendering procedures for the award of public contracts related to the provision of those services.

The second important observation in this case concerned the instrument of the official list of economic operators. According to Spanish law, an economic operator taking part in a procedure of a certain value for services or works must be duly classified. Consorci Sanitari del Maresme was not classified on the official list because of its status as a public entity. The CJEU stated that Article 52 of the 2004 Directive did not establish whether public entities could be registered on official lists or certified, nor did it specify whether or not registration or certification was compulsory. The CJEU concluded that national rules that had the effect of barring public authorities that were authorised to act as economic operators, whilst reserving the right to participate to other economic operators that were either registered on the list or certified, were incompatible with EU law. 
Exhaustive list of grounds for exclusion related to professional qualities and additional grounds for exclusion subject to the proportionality principle

\section{C-213/07 Michaniki}

This 2008 case C-213/07 Michaniki concerned a Greek law that prohibited the award of public contracts to media undertakings or to certain companies or individuals linked to or working for media undertakings. The effect of the national law was to automatically exclude certain types of economic operators from participating in tenders for public contracts.

Michaniki was an unsuccessful tenderer in a competitive procurement process to award a works contract for the construction of the embankment and technical infrastructure for a new high-speed railway line. The Works Directive applied to the award procedure. The contracting authority made the decision to award the contract to the company Sarantopoulos. In order to enter into the contract with the company, the contracting authority required a formal certificate issued by an official body. The certificate confirmed that Sarantopoulos complied with the law related to media undertakings. Michaniki, an unsuccessful tenderer, demanded the annulment of the certificate related to the company Sarantopoulos.

Article 24(1) of the Works Directive ${ }^{150}$ lists seven optional grounds for the exclusion of economic operators from participation related to "professional qualities". These qualities concern, for example, professional honesty, solvency, and economic and financial capacity.

In accordance with Article 24 of the Works Directive, the CJEU pointed out that the approach of the legislator was "to adopt only grounds of exclusion based on the objective finding of facts or conduct specific to the contractor concerned, such as to cast discredit on his professional reputation or call into question his economic or financial ability to complete the works covered by the public contract for which he is tendering" (paragraph 42).

The CJEU ruled that the list of grounds for exclusion relating to an economic operator's professional qualities was an exhaustive list. Member States or contracting authorities were not permitted to add any other grounds to the list of grounds for exclusion based on professional qualities.

According to the CJEU, the exhaustive nature of the list of grounds "does not preclude the option for Member States to maintain or adopt substantive rules designed, in particular, to ensure ... observance of the principle of equal treatment ... and transparency ... in any procedure for the award of a public contract" (paragraph 43).

The CJEU proceeded to explain that these principles meant that economic operators had to be in a position of equality, both when preparing their tenders and when those tenders were assessed. These principles constitute the basis of the procurement directive, which contracting authorities have the duty to observe. Contracting authorities must also ensure that there is no discrimination between economic operators (paragraphs 45 and 46).

Additional grounds for exclusion subject to the proportionality principle: The CJEU concluded that a Member State was entitled to provide for additional exclusionary

${ }^{150}$ In the 2014 Directive, the grounds for exclusion are set out in Article 57. 
measures designed to ensure the observance of the principles of equal treatment and transparency. Such additional measures are permitted when they do not relate to professional qualities. The CJEU confirmed that Member States were allowed a certain degree of discretion when adopting those measures. However, in accordance with the principle of proportionality, such measures must not go beyond what is necessary to achieve the objective (paragraphs 47-48 and 55-57).

As can be seen in Part 2 of this Paper, it is common practice in Member States to include additional exclusionary measures. Additional measures must be proportionate and must not go beyond what is necessary to achieve the objective. For example, Scotland has included additional grounds for mandatory exclusion of an economic operator that has committed an act prohibited under the Employment Relations Act 1999 (Blacklist) Regulations $2010^{151}$.

In the case C-213/07 Michaniki, Greece took the view that there was a risk that media undertakings would unlawfully influence the contract award decision for a public contract, for example by using mass information campaigns. The CJEU confirmed that Community law did not preclude the application of national law that was designed to avoid the risk of practices that might jeopardise transparency and distort competition. However, the Greek law in question had the consequence of automatically excluding economic operators because of their media links. These economic operators had no way of demonstrating that their media links did not entail any real risk of the danger that the measure was designed to avoid. The CJEU ruled that the automatic and absolute nature of the prohibition was disproportionate and was not permitted under EU law (paragraphs $58-68)$.

\section{C-538/07 Assitur}

In 2009, the CJEU considered again this issue of additional grounds for exclusion, in relation to an Italian law that excluded tenderers from participating in the same tender procedure where there were particular relationships of control and affiliation. The effect of the national law was to automatically exclude certain linked or affiliated economic operators from participating in tenders for public contracts.

The case C-538/07 Assitur concerned the award of a contract for courier services. The Services Directive applied at the time that the procedure was conducted. The contracting authority invited three tenderers to participate in the tender process: SDA, Poste Italiane and Assitur. Assitur asked the contracting authority to exclude SDA and Poste Italiane from the tendering process because of the links between the two companies. The contracting authority investigated the alleged links. It rejected Assitur's request and decided to award the contract to SDA, which had submitted the lowest bid. Assitur brought an action to annul the contract award decision.

The CJEU took the approach that it had taken in the C-213/07 Michaniki case. It confirmed that the list of seven grounds for exclusion related to professional qualities was an exhaustive list. However, this list did not prevent Member States from setting substantive rules designed to ensure transparency and the equal treatment of tenderers. According to the CJEU, it was clear that the national law at issue was intended to i)

${ }^{151}$ The Blacklist Regulations prohibit the compilation, use, sale or supply of blacklists containing information on trade union members and activists, the purpose of which is to discriminate against workers on the grounds of trade union membership or trade union activities. 
prevent any collusion between participants in the procedure for the award of contracts, and ii) safeguard equal treatment and transparency. The national legislation must nevertheless be examined with regard to the principle of proportionality (paragraphs 19-24).

In considering the principle of proportionality, the CJEU also referred to the need to ensure the widest possible participation of tenderers. The CJEU ruled that the national legislation in question went beyond what was necessary to achieve the objective of ensuring equal treatment and transparency (paragraph 30). The national law systematically excluded affiliated tenderers. This exclusion occurred without allowing tenderers the opportunity to demonstrate that there was no real risk of jeopardising transparency and distorting competition. The national legislation was incompatible with EU law.

\section{C-376/08 Serrantoni}

The CJEU considered this issue further in 2009, in relation to another Italian law. The law in question prohibited members of a permanent consortium ${ }^{152}$ and individual consortium members from participating in the same tendering procedure. The effect of the national law was to automatically exclude permanent consortia and their members from participating in certain award procedures.

This case arose from a call for tenders for a works contract related to district registry offices. The value of the contract was below the EU financial threshold for works contracts, which meant that the detailed provisions of the Directive did not apply. The CJEU therefore limited its consideration of the national law to the application of basic principles.

The Italian law at issue treated permanent consortia differently from other joint working arrangements between economic operators. The CJEU ruled that automatic exclusion applying to a single type of consortium did not constitute equal treatment. It considered that even if the exclusion were applied without distinction, a provision that required automatic exclusion would be incompatible with the principle of proportionality. The CJEU was also of the view that a provision of this kind was likely to have a dissuasive effect on economic operators from other Member States. The provision could dissuade economic operators from establishing themselves in a particular Member State by setting up permanent consortia with national economic operators. This provision could therefore impede the freedom of establishment and the freedom to provide services. The national legislation was incompatible with EU law.

\section{Evidence of compliance}

\section{C-74/09 Bâtiments et Ponts and WISAG Produktionsservice}

In this case, decided in 2010, the CJEU considered whether the evidence required by a contracting authority from tenderers to demonstrate the payment of taxes and social security contributions was permitted under EU law.

${ }^{152}$ According to Italian law, a permanent consortium is created when economic operators agree to jointly participate in public contracts. The agreement, valid for a period of not less than five years, establishes a joint undertaking. 
This case arose from a long dispute over a contract awarded in 1995 for the renovation of the EC's main office building (Berlaymont) in Brussels. The amended advertisement in the OJEU for the renovation works required evidence that tax and social security payments had been made. Belgian firms were obliged to be listed on the professional register in Belgium. Foreign firms were required to provide a copy of a certificate of application to the competent Belgian authority (a registration committee). The registration committee would then assess compliance, based on the evidence submitted by the foreign firm. The $O J E U$ advertisement stated:

"As regards the validity of the tender (at the time it is submitted), it will be sufficient for a copy of the application for registration to be attached to the tender. No decision to award the contract will be taken before the competent authority has ruled on the application."

$B P C$, a Belgian company, and WIG, a German company, formed a consortium, $B P C-W I G$, for the purposes of submitting a tender. BPC was listed on the appropriate Belgian professional register. WIG submitted documents from the German authorities to demonstrate that it had paid taxes and social security contributions. Neither WIG nor $B P C$-WIG submitted copies of the application for registration with the competent Belgian authority. In fact, they only made those applications after the closing date for the submission of tenders. Their registrations were not confirmed until after the date of the award of the contract.

The $B P C$-WIG consortium was unsuccessful in the tendering process. It appealed against that decision and claimed damages. The Belgian court held that the BPC-WIG consortium was ineligible to tender due to its failure to submit the required documents.

The CJEU confirmed that the wording of Article 24 of the Works Directive was clear: a contracting authority can exclude a tenderer that has not met its obligations in the Member State where the contracting authority is based. A separate verification is also permitted (paragraph 48). It is lawful to require a tenderer to register in the Member State where the contracting authority is based, provided that the registration requirements do not i) complicate or delay the participation of the tenderer concerned, or ii) give rise to excessive administrative charges (paragraphs 42 and 49). In this case, the evidence required was limited to a copy of the certificate of application. The award decision was not going to be made until after the completion of registration. The CJEU concluded that the ruling of the Belgian court was lawful.

The CJEU confirmed that it was also permitted to check that tax and social security payments had been made in the Member State where the tenderer was based. The Works Directive expressly states that contracting authorities must accept certificates of compliance from competent authorities in other Member States as conclusive evidence. Verification is therefore to be limited to formal issues, which include ensuring that the submitted certificates from the tenderer's Member State are authentic or sufficiently recent (paragraphs 63-64).

This case relates to the grounds for exclusion for the non-payment of taxes and social security contributions. The CJEU was clear that its decision had a wider application and that it applied to each of the grounds for exclusion listed in the Works Directive ${ }^{153}$. This

153 The 2014 Directive contains expanded and revised provisions covering the grounds for exclusion. These provisions are set out in Article 57 as follows: 
decision is to be applied "provided that such an obligation does not hinder or delay the contractor's participation in the public contract or give rise to excessive administrative charges and provided that its sole objective is to check the professional qualities of the contractor concerned for the purposes of that provision" (paragraph 53).

\section{C-425/14 Impresa Edilux}

In the case C-425/14 Impresa Edilux, the contracting authority imposed in the tender documentation an obligation on each economic operator to submit a legality protocol concerning the standards of behaviour that it would apply in the event that it were chosen as the successful tenderer. The standards of behaviour included requirements related to integrity, fairness, transparency and reporting of potentially corrupt or criminal behaviour for the purpose of preventing organised crime from infiltrating the public procurement sector. If an economic operator did not submit such a legality protocol, it would be excluded from the procurement procedure.

The $C J E U$ held that, with regard to the principles of equal treatment and transparency, Member States should be granted a certain degree of discretion for the purpose of adopting measures that were intended to ensure the observance of those principles, which are binding on contracting authorities in any procedure for the award of a public contract. It considered that each Member State was best placed to identify, in the light of its own historical, legal, economic or social considerations, the situations that were liable to favour conduct resulting in breaches of those principles.

The CJEU considered the legality of statements, taking into account the principles of competitiveness and transparency. The declarations included in the legality protocol which were submitted (i) to indicate the progress of the works, the purpose, amount and recipients of subcontracts and derived contracts, and the procedures for selecting contractors; (ii) to report any attempted interference, irregularity or distortion in the conduct of the tendering procedure; and (iii) during the performance of the contract, to co-operate with the police, by reporting any attempt at extortion, intimidation or influence of a criminal nature, and to include the same clauses in subcontracts - were regarded by the $C J E U$ as proportionate, in other words they did not go beyond what was necessary in order to prevent organised crime from infiltrating the public contract awards sector. The CJEU considered as disproportionate, however, the declarations required of a tenderer that it was not in a relationship of control or association (legal and/or factual) with other competitors and that it would not subcontract any type of task to other companies participating in the tender procedure.

- Article 57(1) includes new additional mandatory grounds for exclusion, including child labour and human-trafficking offences and the non-payment of taxes and social security contributions.

- Article 57(4) includes new additional optional grounds for exclusion, including collusive behaviour, conflicts of interest, and "significant or persistent deficiencies" in the performance of public contracts.

- Article 57(6) provides that in some cases, a contracting authority will not be permitted to exclude an economic operator from a procurement process, even though grounds for exclusion are recognised. This provision is applied when the economic operator can demonstrate that it is sufficiently reliable, despite the existence of relevant grounds for exclusion, and when it satisfies certain stringent conditions. 


\subsubsection{Selection criteria}

\section{Evidence of economic and financial standing}

\section{C-218/11 Édukövízig and Hochtief Construction}

In this case, decided in 2012, the CJEU considered the lawfulness of national requirements relating to the demonstration of economic and financial standing.

In July 2006 the contracting authority, Édukövízig, launched a restricted procedure for the award of transport infrastructure works in Hungary. The estimated value of the works was between EUR 23.30 million and EUR 24.87 million. The 2004 Directive applied to the conduct of the procedure.

As part of the qualification requirements, Édukövízig obliged economic operators to submit a uniform financial document, which had been drawn up in accordance with Hungarian accounting rules. Edukövízig fixed a minimum requirement related to economic and financial standing. This minimum requirement was that the profit and loss ("P\&L") item on the balance sheet must not have been negative for more than one year in the previous three financial years. That information was to be shown in the uniform financial document.

Hochtief Hungary $(\mathrm{HH})$ wished to participate in the tender process. $\mathrm{HH}$ was the Hungarian subsidiary of Hochtief Construction (HC), which was a wholly owned subsidiary of Hochtief AG. Both of these companies were incorporated in Germany.

German accounting rules, applying to group companies incorporated in Germany, permitted a company to transfer profits to another group company. This rule meant that it was possible for a company to have positive $P \& L$ after taxes, even though negative $P \& L$ was shown on the balance sheet. This was not permitted under Hungarian accounting rules.

$H C$ had a profit transfer agreement under which it transferred profits to Hochtief AG. It therefore had a zero or negative P\&L on its balance sheet. HH wished to rely on the financial standing of $\mathrm{HC}$ to satisfy the minimum requirements set by Édukövízig. Due to the treatment of HC's accounts, HH was unable to satisfy Édukövízig's requirements relating to $\mathrm{P} \& \mathrm{~L}$.

HH questioned the lawfulness of Édukövízig's requirement in the Hungarian courts, which in turn referred a number of questions to the CJEU for a preliminary ruling.

Minimum level of economic and financial standing: Does the Directive permit a contracting authority to fix a minimum level of economic and financial standing with reference to a given item on the balance sheet? Is this permitted even if the legislation on annual accounts varies between Member States and if as a result balance sheets also vary? (paragraph 25).

The CJEU confirmed in the above case that the Directive permitted a contracting authority to require a minimum level of economic and financial standing (paragraph 26).

The $C J E U$ also noted that the Directive permitted a contracting authority to require economic operators to provide proof of that standing through the presentation of its balance sheet. The CJEU proceeded to observe that a minimum level of economic and financial standing could generally not be established by reference to a balance sheet. The 
contracting authority could therefore refer to one or more specific aspects of the balance sheet (paragraphs 26-27).

The CJEU confirmed that, in this context, the Directive left "a fair degree of freedom to the contracting authorities". According to the CJEU, the Directive "expressly authorises contracting authorities to choose the probative references which must be produced by (economic operators) to furnish proof of their economic and financial standing".

The CJEU emphasised that the freedom available to contracting authorities was not unlimited. The minimum capacity level set by the contracting authority had to be related and proportionate to the subject matter of the contract (paragraph 29). The specific aspects of a balance sheet chosen by a contracting authority to demonstrate a minimum level of economic and financial standing must:

- provide objective information on such standing

- adapt to the size of the contract concerned

- not go beyond what is reasonable for the purpose (paragraph 29)

The CJEU contrasted the assessment of economic and financial standing with the assessment of technical and professional capacity. The CJEU stated that, in relation to technical and professional capacity, the Directive established "a closed system which limits the method of assessment and verification available and therefore limits [the contracting authorities'] opportunities to lay down requirements" (paragraph 28).

The CJEU noted that the legislation of Member States regarding the annual accounts of companies was not the subject of full harmonisation. One could therefore not rule out the possibility of differences with regard to a specific aspect of a balance sheet. There might be differences in the aspects of a balance sheet according to which a contracting authority established a minimum capacity level. The CJEU stated that, in relation to the proof of economic and financial standing, contracting authorities could legitimately require a reference "... even if, objectively, not every candidate or tenderer [would be] able to produce it ... because of a difference in legislation". The CJEU held that "such a requirement [could] not in itself be considered to constitute discrimination" (paragraphs 30-31).

Evidence that an economic operator meets the minimum level of economic and financial standing: What are the provisions of the Directive when an economic operator cannot meet the minimum level of economic and financial standing required by the contracting authority?

In relation to the balance sheet requirement in this particular case, is the economic operator permitted to rely on the capacity of a third party? Under the provisions of the Directive, must the economic operator prove its economic standing by submitting an appropriate document?

Based on the facts of this case, the CJEU held that only one option was available to the economic operator $(\mathrm{HH})$ in order to satisfy the balance sheet requirement. That option was to rely on the capacity of another entity, in this case HH's parent company. When the economic operator relies on the capacity of another entity, the Directive, as stipulated in 
Article 47(2) of the 2004 Directive ${ }^{154}$, then requires proof in the form of a legal undertaking (paragraph 39).

Differences in legislation between two Member States with regard to annual accounts and the transfer of profits are irrelevant (paragraph 39).

\section{Technical and/or professional ability}

\section{C-368/10 Commission v Netherlands}

This case, decided in 2012, related to the award of a contract by the province of North Holland for the supply and management of automatic tea and coffee machines. The procedure was carried out under the 2004 Directive.

The contracting authority stated in the contract documents that economic operators should fulfil "criteria concerning sustainable purchases and socially responsible business". This requirement was included under the general heading, "suitability conditions/minimum conditions", and the sub-heading, "quality conditions". The contracting authority asked economic operators to explain the way in which they fulfilled those criteria. The contracting authority also asked them to indicate how they contributed to "improving the sustainability of the coffee market and to environmentally, socially and economically responsible coffee production" (paragraphs 24 to 26).

The CJEU was of the view that these requirements set the minimum levels of professional capacity and should therefore be considered in the light of Article 48 of the Directive (paragraphs 102 to 104). The CJEU confirmed that Article 48 provided an exhaustive list of the information or evidence that a contracting authority could use to assess the technical and professional abilities of tenderers (paragraph 105). The requirements set by the contracting authority in relation to sustainable purchases and socially responsible business were not included in the exhaustive list, and these requirements were therefore not permitted as selection criteria.

The CJEU also confirmed earlier case law (C-496/99 Commission v CAS Succhi di Frutta) that the principle of transparency implied that all the rules of the award procedure had to be clear, precise and unequivocal. This requirement was meant to ensure that (i) all reasonably informed tenderers understood the exact significance of the rules and interpreted them in the same way, and (ii) the contracting authority was able to ascertain whether the tenders submitted satisfied the selection criteria. The CJEU agreed with the Advocate General's view that in this case, the selection criteria did not meet the requirement of transparency (paragraphs 109-111).

\subsubsection{Procedural issues}

\section{C-336/12 Manova}

The CJEU clarified that C-599/10 SAG ELV Slovensko and Others provided guidance in relation to tenders that could also be applied to applications submitted at the selection stage for candidates in a restricted procedure. The case C-336/12 Manova concerned a call for tenders for the award of a framework agreement in which two candidates were allowed to submit the missing documents after the deadline for submission of their

\footnotetext{
${ }^{154}$ Article 63 of the 2014 Directive.
} 
applications. One of the unsuccessful economic operators participating in the process challenged the award decision.

The CJEU considered the question referred to it by the national court in the light of the principles of equal treatment and transparency. These principles included a general rule that a tender could not be amended after it had been submitted (paragraph 31). The Directive does not, however, preclude corrections or "amplifications" (i.e. provision of further information) to a tender, on a limited and specific basis. This possibility is particularly the case when it is clear that the amendment is merely a "clarification" or the correction of an obvious material error (paragraph 32).

\section{C-324/14 Partner Apelski Dariusz}

The procurement procedure in this case was divided into eight lots. According to the tender documentation, in order to demonstrate its technical abilities, each tenderer was required to submit a list of winter maintenance services for roadways, providing pre-wetting technology in the three years prior to the expiry of the deadline for submitting the tender. The total value of those services had to be at least PLN 1 million for each of the eight lots of the contract at issue. Therefore, in order to submit a tender for the whole contract, a tenderer had to prove that it had provided services of a value of at least PLN 8 million (approximately EUR 1.8 million).

A company called "Partner" submitted its candidature for the whole contract, stating that in the previous three years it had supplied 14 services, 12 of which were based on its own experience and two services based on the experience of another entity. The contracting authority did not take into account the two service contracts executed by the other entity, and the 12 contracts realised by Partner did not attain the value required for the whole contract. During the clarification procedure, Partner requested that its tender be taken into consideration when each of the eight lots of that contract was awarded in a particular order of priority.

In these circumstances, a question was raised as to whether the principles of equal treatment and non-discrimination of economic operators, laid down in Article 2 of the 2004 Directive, were to be interpreted as meaning that a contracting authority would be prohibited, after the opening of the tenders submitted in a public procurement procedure, from allowing the request of an economic operator that had submitted a tender for the entire contract concerned, to consider its tender solely for the award of particular lots that were part of that contract.

The CJEU stated that the principles of equal treatment and non-discrimination and the obligation of transparency precluded any negotiation between the contracting authority and a tenderer during a public procurement procedure. The situation where an economic operator indicates to the contracting authority, after the opening of the tenders, the order of priority of the lots of the contract concerned, according to which its tender should be assessed, is far from constituting a mere clarification made on a limited or specific basis or a simple correction of obvious material errors. Such a situation constitutes, in fact, a substantive amendment that is more closely related to the submission of a new tender. 


\section{The SIGMA Programme}

SIGMA (Support for Improvement in Governance and Management) is a joint initiative of the OECD and the European Union (EU), principally financed by the EU. SIGMA has been working with partner countries on strengthening public governance systems and public administration capacities for 25 years.

In partnership with the European Commission (EC) Directorate-General for Neighbourhood and Enlargement Negotiations (DG NEAR), we currently work with:

Albania, Bosnia and Herzegovina, the former Yugoslav Republic of Macedonia, Kosovo, Montenegro, Serbia, and Turkey as EU candidate countries and potential candidates; and

Algeria, Armenia, Azerbaijan, Egypt, Georgia, Jordan, Lebanon, Moldova, Morocco, Tunisia and Ukraine as EU Neighbourhood countries.

SIGMA provides assistance in six key areas:

1. Strategic framework of public administration reform

2. Policy development and co-ordination

3. Public service and human resource management

4. Accountability

5. Service delivery

6. Public financial management, public procurement and external audit.

SIGMA reviews and gives feedback on:

- Governance systems and institutions

- Legal frameworks

- Reform strategies and action plans

- Progress in reform implementation.

SIGMA provides:

- Advice on the design and prioritisation of reforms

- Methodologies and tools to support implementation

- Recommendations for improving laws and administrative arrangements

- Opportunities to share good practice from a wide range of countries, including regional events

- Policy papers and multi-country comparative studies.

For further information on SIGMA, consult our website: www.sigmaweb.org

\section{(C) OECD 2018}

As SIGMA is part of the Organisation for Economic Co-operation and Development (OECD) the same conditions of use apply to its publications: http://www.oecd.org/termsandconditions. 